SANDIA REPORT

SAND2010-6684

Unlimited Release

Printed October 2010

\title{
High Fidelity Nuclear Energy System Optimization Towards an Environmentally Benign, Sustainable, and Secure Energy Source
}

David E. Ames II, Pavel V. Tsvetkov, Gary E. Rochau, Salvador Rodriguez

Prepared by

Sandia National Laboratories

Albuquerque, New Mexico 87185 and Livermore, California 94550

Sandia National Laboratoires is a multiprogram laboratory managed and operated by Sandia Corporation, a wholly owned subsidiary of Lockheed Martin Corporation, for the United States Department of Energy's National Nuclear Security Administration under the Contract DE-AC04-94AL85000.

Approved for public release; further dissemination unlimited. 
Issued by S andia National Laboratories, operated for the United States Department of Energy by Sandia Corporation.

NOTICE: This report was prepared as an account of work sponsored by an agency of the United States Government. N either the U nited S tates Government, $n$ or an y a gency thereof, $n$ or an y of their e mployees, nor a ny of $t$ heir c ontractors, $s$ ubcontractors, or their e mployees, $\mathrm{m}$ ake an $\mathrm{y}$ warranty, e xpress or i mplied, or a ssume a ny 1 egal 1 iability or responsibility for the a ccuracy, completeness, or us efulness of a ny i nformation, a pparatus, pr oduct, or process di sclosed, or represent that its use would not infringe privately owned rights. Reference herein to any specific commercial p roduct, p rocess, o $\mathrm{s}$ ervice b y t rade $\mathrm{n}$ ame, $\mathrm{t}$ rademark, $\mathrm{m}$ anufacturer, o $\mathrm{r}$ o therwise, does not ne cessarily c onstitute or i mply $i$ ts e ndorsement, $r$ ecommendation, or favoring $b$ y $t$ he United States Government, any agency thereof, or any of their contractors or subcontractors. The views and opinions expressed herein do not necessarily state or reflect those of the United States Government, any agency thereof, or any of their contractors.

Printed in the United S tates of America. This r eport has been reproduced directly from the best available copy.

Available to DOE and DOE contractors from

U.S. Department of Energy

Office of Scientific and Technical Information

P.O. Box 62

Oak Ridge, TN 37831

Telephone: $\quad$ (865) 576-8401

Facsimile: (865) 576-5728

E-Mail: $\quad$ reports@adonis.osti.gov

Online ordering: http://www.osti.gov/bridge

Available to the public from

U.S. Department of Commerce

National Technical Information Service

5285 Port Royal Rd.

Springfield, VA 22161

Telephone: $\quad$ (800) 553-6847

Facsimile: (703) 605-6900

E-Mail: $\quad$ orders@ntis.fedworld.gov

Online order: $\quad$ http://www.ntis.gov/help/ordermethods.asp?loc=7-4-0\#online

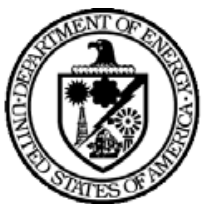




\title{
High Fidelity Nuclear Energy System Optimization Towards an Environmentally Benign, Sustainable, and Secure Energy Source
}

\author{
D. E. Ames ${ }^{1}$, P. V. Tsvetkov ${ }^{1}$, G.E. Rochau ${ }^{2}$, S. Rodriguez ${ }^{2}$ \\ ${ }^{1}$ Texas A\&M University, 129 Zachry Engineering Center, College Station, TX 77843-3133 \\ ${ }^{2}$ Sandia National Laboratories, P.O. Box 5800, Albuquerque, NM 87185-0748
}

\begin{abstract}
A new hi gh-fidelity i ntegrated $\mathrm{s}$ ystem $\mathrm{m}$ ethod a nd a nalysis approach $\mathrm{w}$ as de veloped a nd implemented for consistent and comprehensive evaluations of a dvanced fuel cycles leading to minimized Transuranic (TRU) inventories. The method has been implemented in a developed code system integrating capabilities of Monte Carlo N - Particle Extended (MCNPX) for highfidelity fuel cycle component simulations.

In this report, a Nuclear Energy System (NES) configuration was developed to take advantage of used fuel $r$ ecycling and $t$ ransmutation capabilities in waste $m$ anagement $s$ cenarios 1 eading $t o$ minimized TRU waste inventories, long-term activities, and radiotoxicities. The reactor systems and fuel cycle components that make up the NES were s elected for their abi lity to perform in tandem to produce clean, safe, and dependable energy in an environmentally conscious manner. The di versity i n performance and spectral ch aracteristics w ere us ed to enhance T RU w aste elimination while e fficiently ut ilizing ur anium resources a nd p roviding a $\mathrm{n}$ a bundant energy source.
\end{abstract}

A computational modeling approach was developed for integrating the individual models of the NES. A general approach was utilized allowing for the Integrated System Model (ISM) to be modified in order to provide simulation for other s ystems with similar attributes. By utilizing this approach, the ISM is capable of performing system evaluations under many different design parameter opt ions. A dditionally, the predictive capabilities of the ISM and its computational time e fficiency a llow f or s ystem s ensitivity/uncertainty a nalysis a nd the impl ementation of optimization techniques. 


\section{ACKNOWLEDGEMENTS}

This paper is based upon work supported through the Excellence in Engineering Research

Program by the Sandia Research Graduate Program at Texas A\&M University and the College of Engineering, Texas A\&M University. 


\section{CONTENTS}

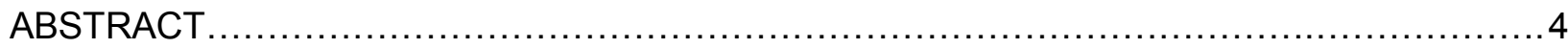

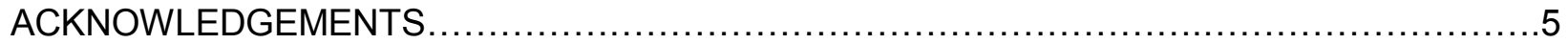

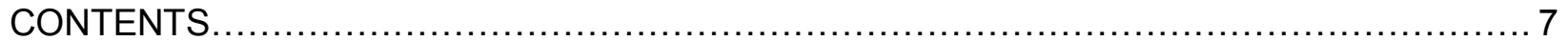

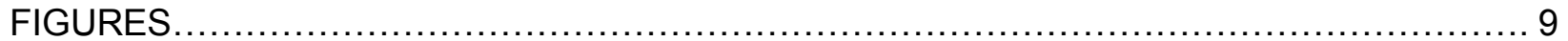

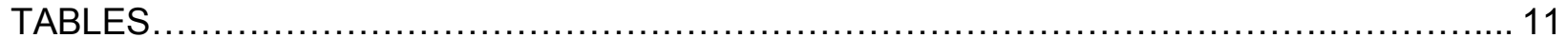

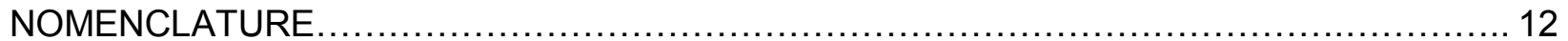

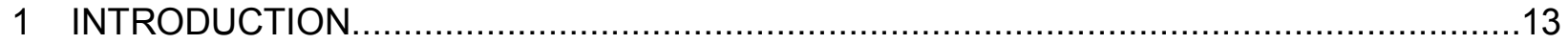

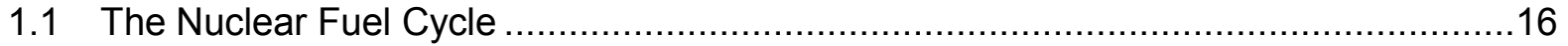

1.1.1 Advanced Fuel Cycle Initiative …………...........................................17

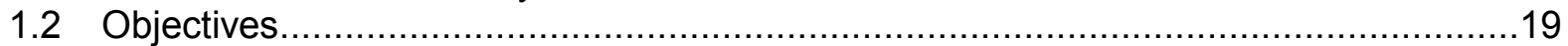

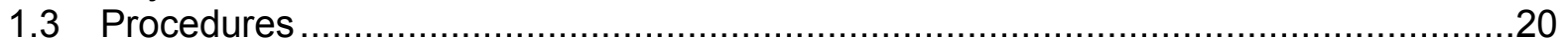

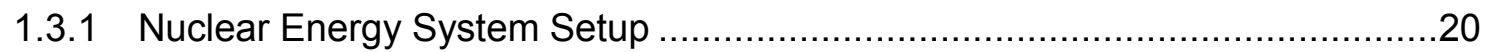

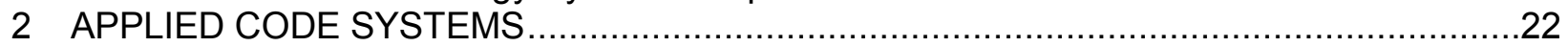

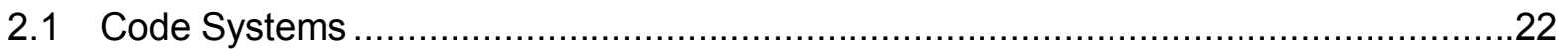

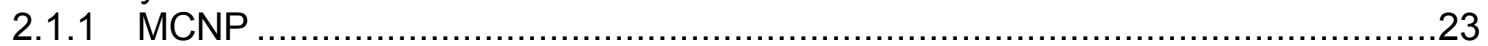

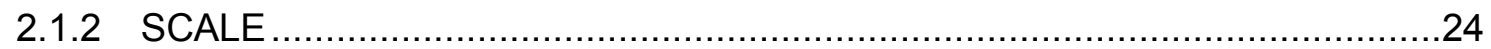

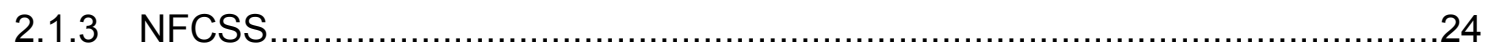

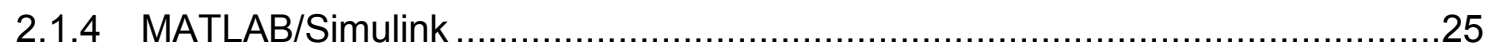

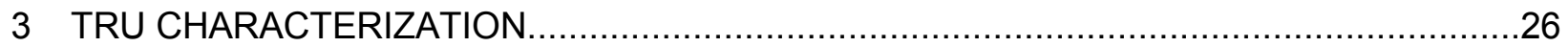

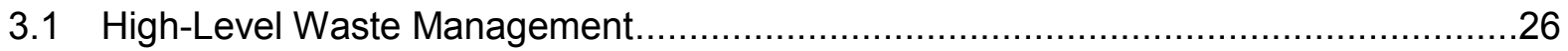

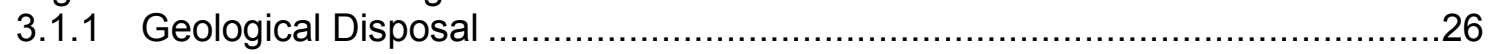

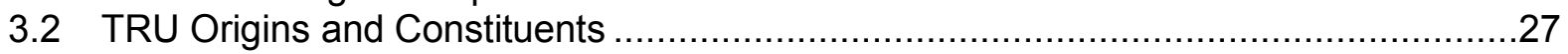

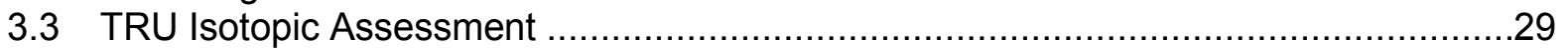

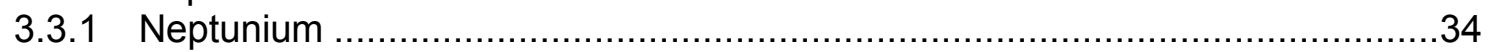

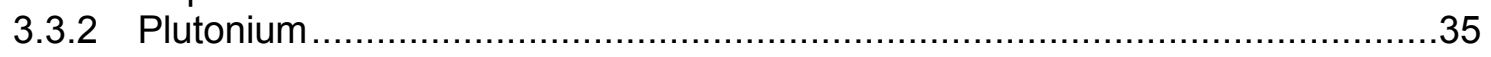

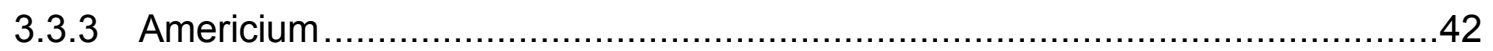

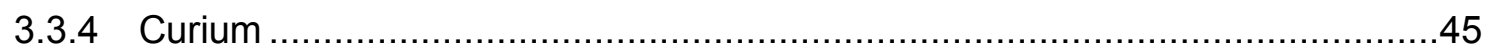

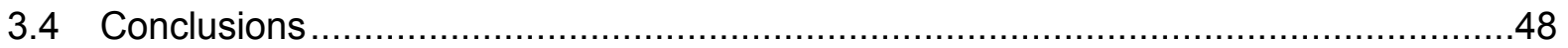

4 SYSTEM PARAMETERIZATION AND REPRESENTATIVE MODELS ….......................50

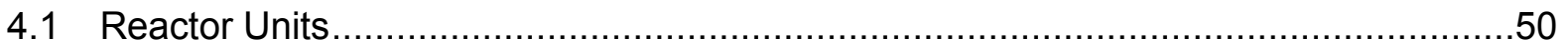

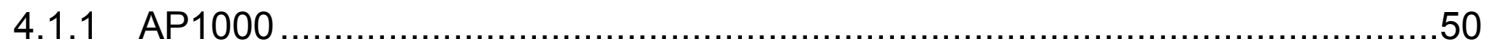

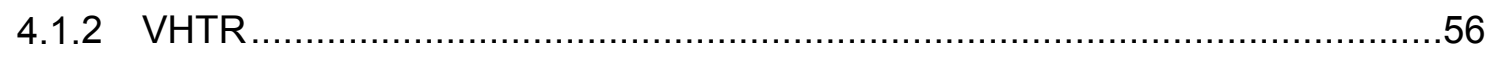

4.1.3 High-energy External Source Transmuter (HEST) ………........................68

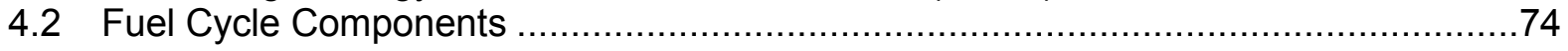

4.2.1 Front-end Components ........................................................................74

4.2.2 Reprocessing - Partitioning/Separation ....................................................

4.2.3 High Level Waste Storage Facility ..............................................................

4.3 Integrated System Model .........................................................................

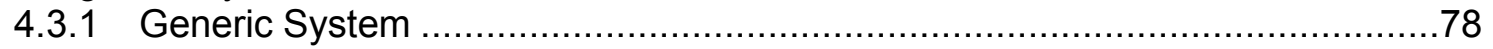

4.3.2 Integrated System Model for the Nuclear Energy System ..............................83

5 ENERGY SYSTEM NEUTRONIC AND FUEL COMPOSTION ANALYSIS .........................88

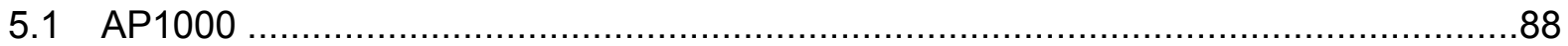

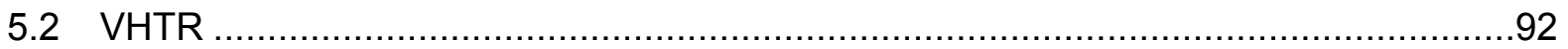

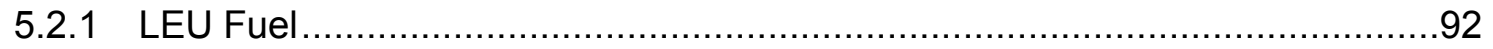

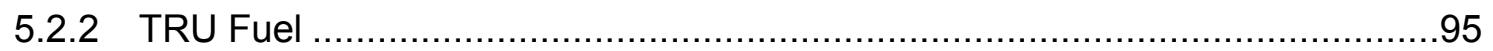

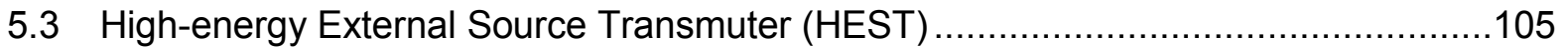

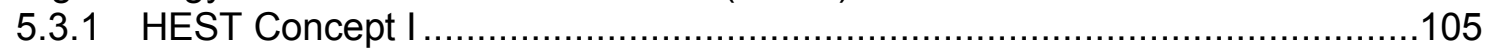

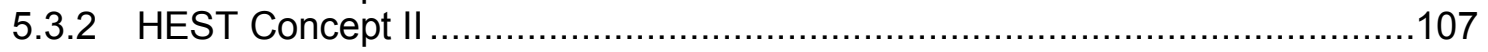




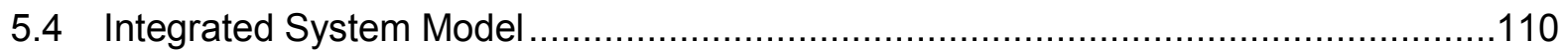

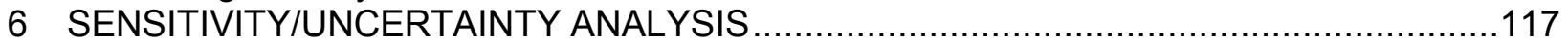

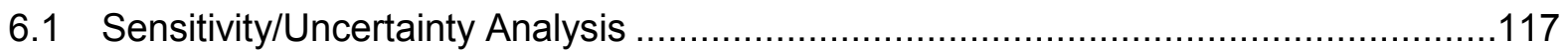

7 DOMAIN IDENTIFICATION VIA MIN/MAX SEARCH FOR OPTIMIZATION STUDIES .....123

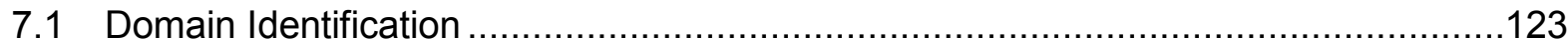

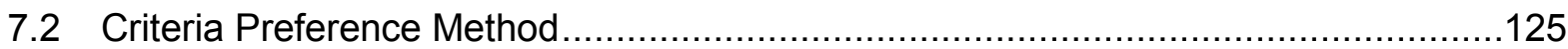

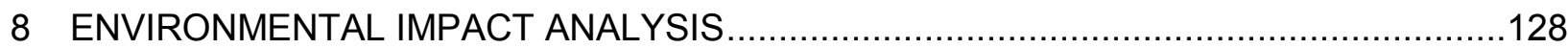

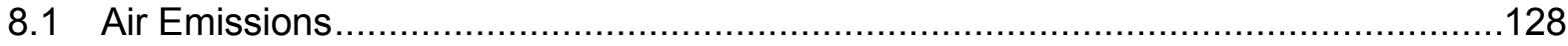

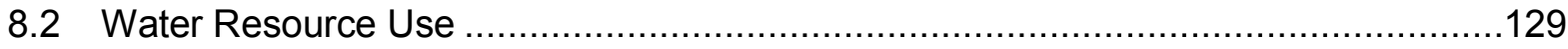

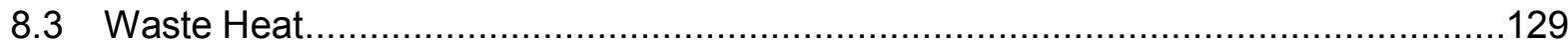

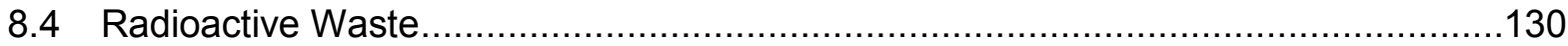

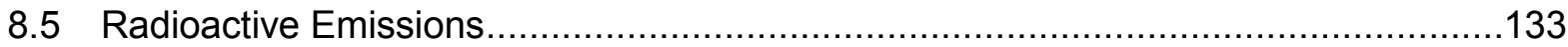

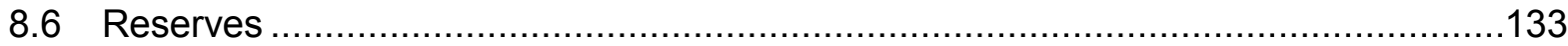

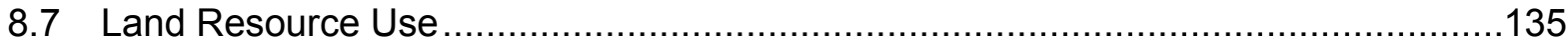

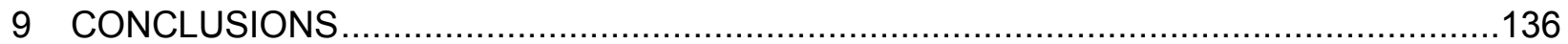

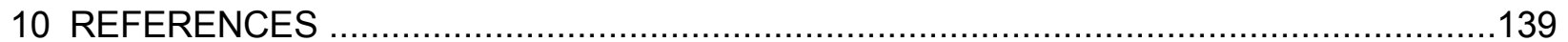

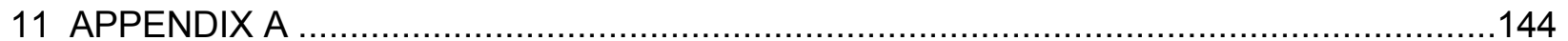

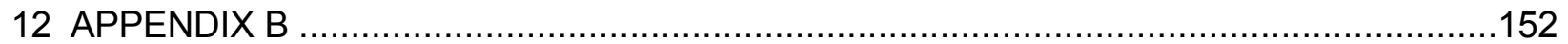

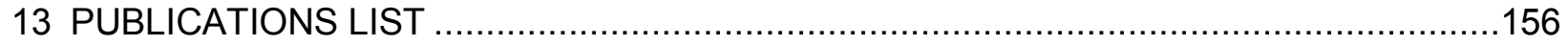

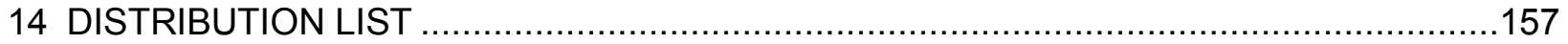




\section{FIGURES}

Figure 1.1. Relationship of HDI and Electricity Consumption per Capita. ...............................14

Figure 1.2. $\mathrm{HDI}$ vs. $\mathrm{CO}_{2}$ Emissions per Capita for 180 Countries. .....................................15

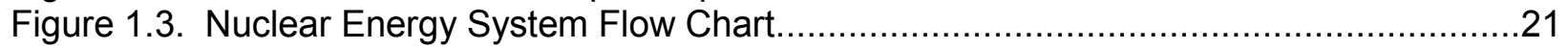

Figure 3.1. Transmutation and Decay Schemes for Important Nuclides. ............................28

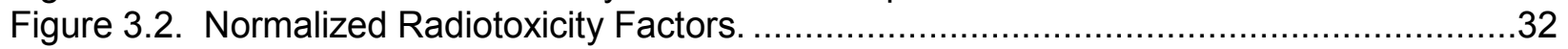

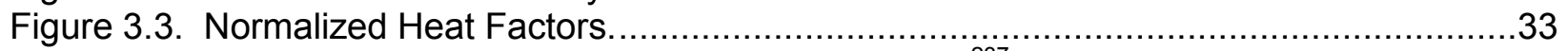

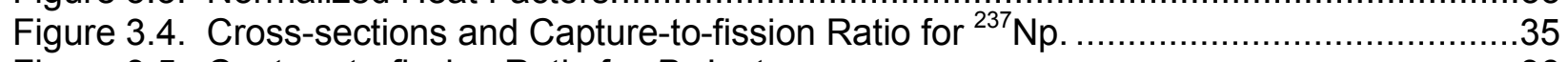

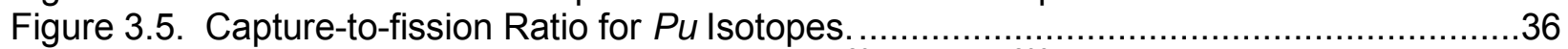

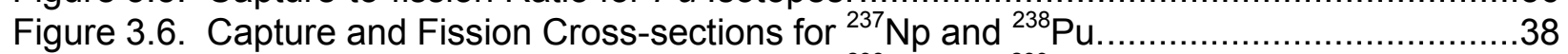

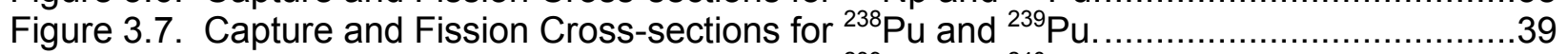

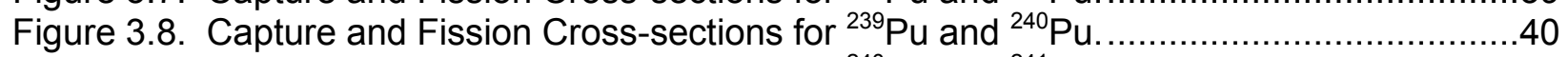

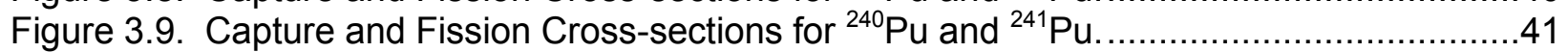

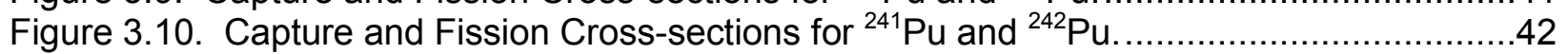

Figure 3.11. Capture-to-fission Ratio for Am Isotopes................................................43

Figure 3.12. Capture and Fission Cross-sections for Am Isotopes. .................................44

Figure 3.13. Capture and Fission Cross-sections for ${ }^{242} \mathrm{Cm}$ and ${ }^{243} \mathrm{Cm}$. ...........................46

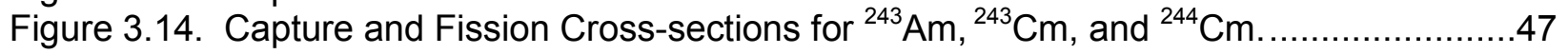

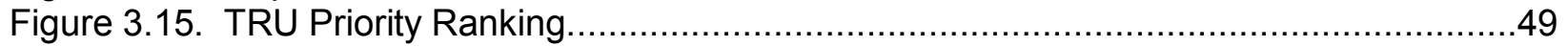

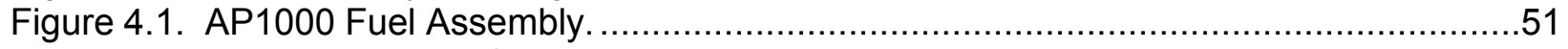

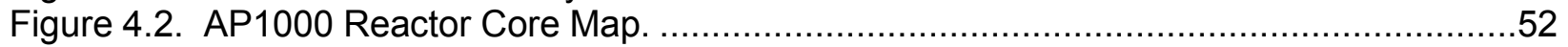

Figure 4.3. PYREX Rod Arrangement within the AP1000 Fuel Assembly. ...........................53

Figure 4.4. IFBA Rod Arrangement within the AP1000 Fuel Assembly. .............................53

Figure 4.5. Neutron Flux Profiles in the AP1000 Fuel Rods (MCNP vs. SCALE)..................55

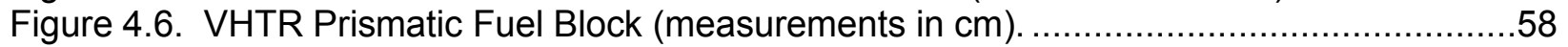

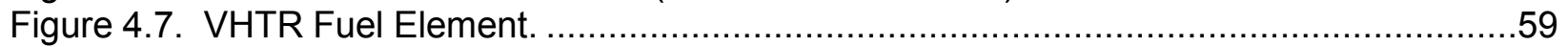

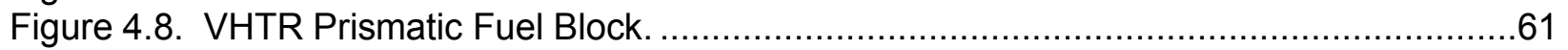

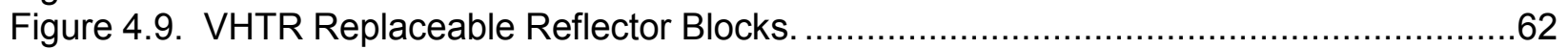

Figure 4.10. VHTR Control Rod Guide Block (measurements in $\mathrm{cm}$ ). ............................6

Figure 4.11. VHTR Whole-core 3D Model Geometry Details..............................................64

Figure 4.12. Neutron Flux Profiles in the VHTR Fuel Compacts (MCNP vs. SCALE). ............68

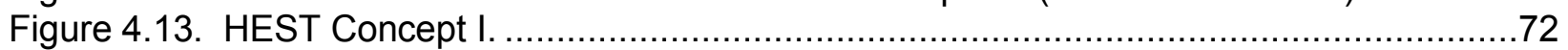

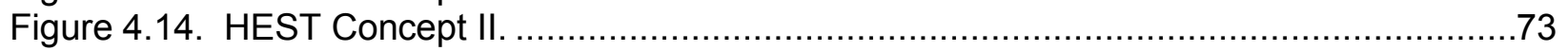

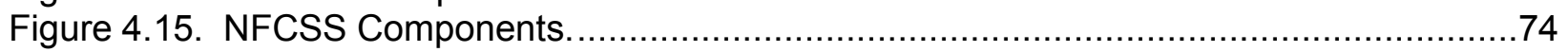

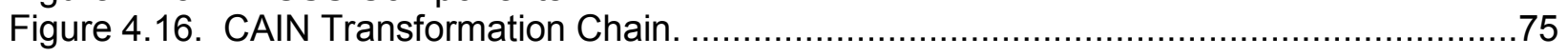

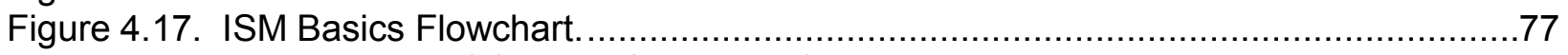

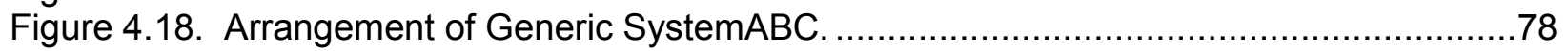

Figure 4.19. NES Interdependence Flowchart for ISM Simulation. ....................................84

Figure 4.20. Detailed Mapping of the ISM Dataflow as Related to the NES .........................87

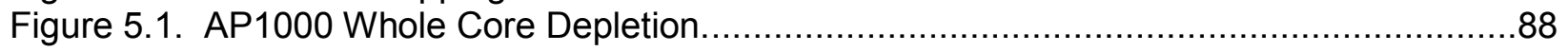

Figure 5.2. AP1000 Spectra at Different Burnup Levels. ............................................. 89

Figure 5.3. AP1000 Production and Consumption of Higher Isotopes. .................................90

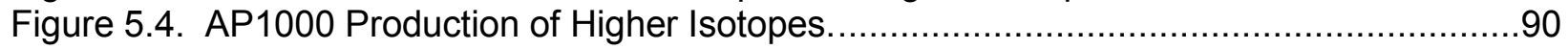

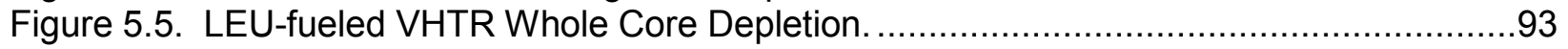

Figure 5.6. LEU-fueled VHTR Spectra for Core Regions..........................................93

Figure 5.7. Production and Consumption of Higher Isotopes in LEU-fueled VHTR.................94

Figure 5.8. Average Neutron Flux in the Fuel Components for the AP1000 \& VHTR...............95

Figure 5.9. TRU-fueled VHTR Whole Core Depletion.................................................97

Figure 5.10. TRU-fueled VHTR Spectra for Core Regions. .............................................. 
Figure 5.11. TRU-fueled VHTR Actinide Consumption...............................................98

Figure 5.12. TRU-fueled VHTR Actinide Production.......................................................99

Figure 5.13. Procedure for Calculating Reactivity Temperature Coefficients. .......................100

Figure 5.14. Fuel Doppler Coefficient at Specified Temperatures as Function of Burnup.......101

Figure 5.15. Moderator Coefficient at Specified Temperatures as Function of Burnup. ..........102

Figure 5.16. Neutron Flux and Capture-to-cross Section Ratios.....................................103

Figure 5.17. Isothermal Coefficient at Specified Temperatures as Function of Burnup...........104

Figure 5.18. Neutron Flux Spectrum in the Fuel Particle for HEST Concept I and VHTR. ......105

Figure 5.19. $\mathrm{D}_{\mathrm{eq}}^{\mathrm{TRU}}$ (neutron consumption/fission) for VHTR and HEST Concept I................106

Figure 5.20. Neutron Flux Spectrum in the Fuel Particle for HEST Concept I and II..............108

Figure 5.21. $\mathrm{D}_{\text {eq }}{ }^{\mathrm{TRU}}$ (neutron consumption/fission) for HEST Concept II. .............................108

Figure 5.22. VHTR EOC Mass as a Function of AP1000 Fuel Enrichment........................115

Figure 5.23. Electricity Generation as a Function of AP1000 Fuel Enrichment.....................115

Figure 5.24. TRU Destruction in VHTR as a Function of AP1000 Fuel Enrichment..............116

Figure 6.1. Example of Sensitivity Calculations Performed within the ISM Structure. ............118

Figure 6.2. Pu Production /Destruction Rates in the VHTR vs. TRISO Packing Fraction........121

Figure 6.3. Am and ${ }^{237} \mathrm{~Np}$ Production/Destruction Rates in the VHTR vs. TRISO PF.............122

Figure 6.4. ${ }^{240} \mathrm{Pu}$ and ${ }^{242} \mathrm{Cm}$ Production Rates in the VHTR vs. AP1000 Enrichment. ...........122

Figure 8.1. TRU Radiotoxicity Measure as a Function of Time.....................................131

Figure 8.2. Isotopic Radiotoxicity Measure as a Function of Time ..................................132 


\section{TABLES}

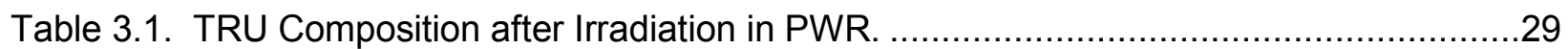

Table 3.2. TRU Isotopic Parameters Related to Waste Management...................................30

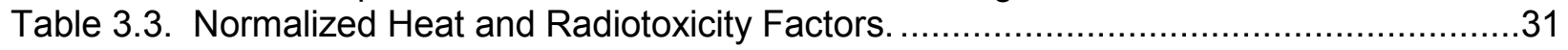

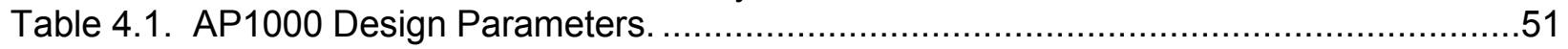

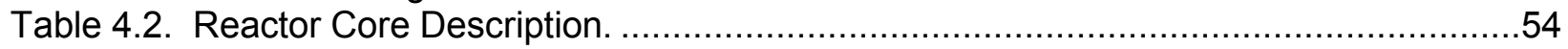

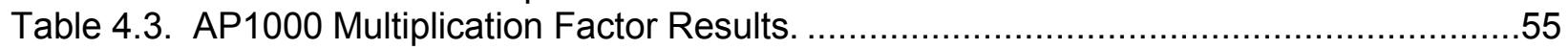

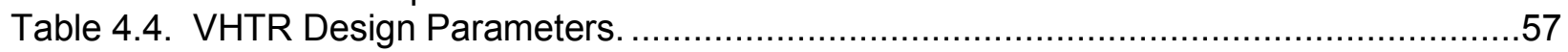

Table 4.5. VHTR Prismatic Fuel Block Properties. ...................................................59

Table 4.6. VHTR Fuel Element Properties. .............................................................60

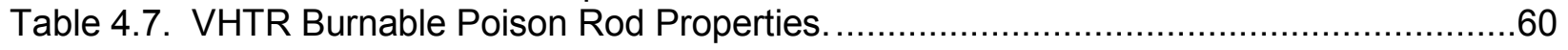

Table 4.8. VHTR Replaceable Reflector Block Properties.............................................61

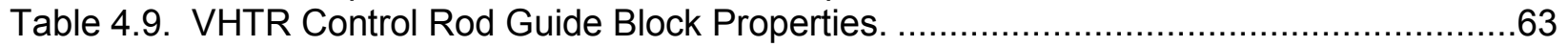

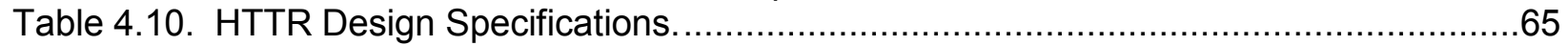

Table 4.11. Results for Different Heterogeneity Treatments. .........................................66

Table 4.12. HTTR Experiment-to-code Benchmark Results. ..........................................66

Table 4.13. Basic Reactor Physics Results (Withdrawn Control Rods)............................67

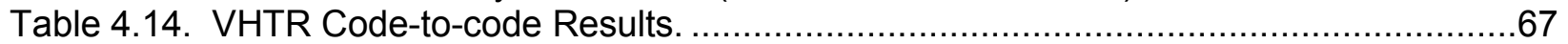

Table 4.15. Neutron Consumption Factor for Different Reaction Types..............................70

Table 4.16. $R_{r}^{(i)}$ and $P_{r}^{(i)}$ for Reaction Type............................................................. 71

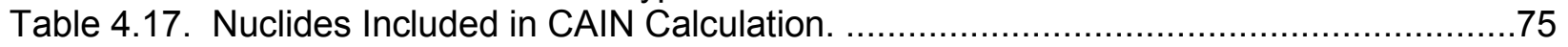

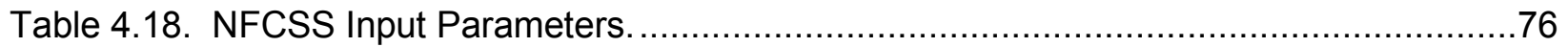

Table 5.1. Nuclide Masses in the AP100 at Different Burnup Levels. ................................91

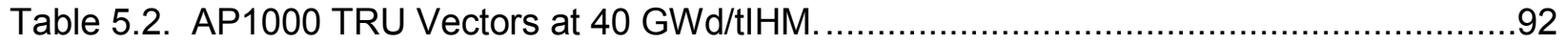

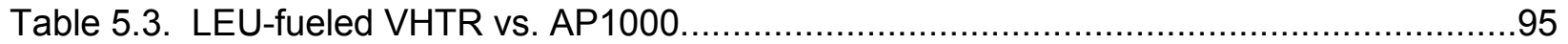

Table 5.4. Fuel Composition for the TRU-fueled VHTR..................................................96

Table 5.5. BOC and EOC Fuel Composition for the TRU-fueled VHTR .............................99

Table 5.6. Temperature Coefficients Averaged Over Entire Temperature Range..................104

Table 5.7. $D_{\text {eq }}^{\prime}$ Values for VHTR and HEST Concept I. ..............................................107

Table 5.8. $D_{\text {eq }}$ (neutron consumption/fission) for VHTR, HEST Concept I and II..................109

Table 5.9. ISM Reference Case Results. .............................................................. 111

Table 5.10. Percent Difference MCNPX to ISM........................................................114

Table 6.1. Non-dimensional Sensitivity Coefficients for Overall System. ..........................119

Table 7.1. NES Minimum and Maximum Output Data................................................... 124

Table 7.2. NES Optimum Input Values by Criteria Preference Method..............................126

Table 7.3. Criteria Preference Method Results...........................................................126

Table 8.1. $\mathrm{CO}_{2}$ Emissions Reductions per Year. ........................................................129

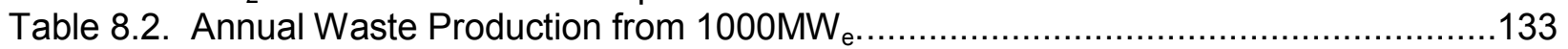

Table 8.3. Uranium Resources........................................................................ 134 


\section{NOMENCLATURE}

$\begin{array}{ll}\text { ADS } & \text { Accelerator Driven System } \\ \text { AFCI } & \text { Advanced Fuel Cycle Initiative } \\ \text { AP1000 } & \text { Westinghouse Electric Company Reactor } \\ \text { BOC } & \text { Beginning of Cycle } \\ \text { CAIN } & \text { CAlculation of INventory of Spent Fuel } \\ \text { CPU } & \text { Central Processing Unit } \\ \text { D } & \text { Deuterium } \\ \text { DOE } & \text { U.S. Department of Energy } \\ \text { DU } & \text { Depleted Uranium } \\ \text { EFPD } & \text { Effective Full Power Days } \\ \text { ENDF/B } & \text { Evaluated Nuclear Data Files - Basic } \\ \text { EOC } & \text { End of Cycle } \\ \text { FP } & \text { Fission Products } \\ \text { GCC } & \text { Gulf Cooperation Council } \\ \text { GDP } & \text { Gross Domestic Product } \\ \text { Gen-IV } & \text { Generation IV Nuclear Fuel Systems } \\ \text { GIF } & \text { Generation IV International Forum } \\ \text { HDI } & \text { Human Development Index } \\ \text { HEST } & \text { High-energy External Source Transmuter } \\ \text { HLW } & \text { High Level Waste } \\ \text { HTGR } & \text { High Temperature Gas Reactor } \\ \text { HTR } & \text { High Temperature Reactor } \\ \text { HTTR } & \text { High Temperature Test Reactor } \\ \text { IAEA } & \text { International Atomic Energy Agency } \\ \text { IEC } & \text { Inertial Electrostatic Confinement } \\ \text { IFBA } & \text { Integral Fuel Burnable Absorber } \\ \text { ISM } & \text { Integrated System Model } \\ \text { JAERI } & \text { Japan Atomic Energy Research Institute } \\ \text { LEU } & \text { Low Enriched Uranium } \\ \text { LLW } & \text { Low Level Waste } \\ \text { LWR } & \text { Light Water Reactor } \\ \text { MCNP } & \text { Monte Carlo N - Particle } \\ \text { MCNPX } & \text { Monte Carlo N - Particle Extended } \\ \text { MT } & \text { Metric Tons } \\ \text { MTU } & \text { Metric Tons of Uranium } \\ \text { NES } & \text { Nuclear Energy System } \\ \text { NFCSS } & \text { Nuclear Fuel Cycle Simulation System } \\ \text { NGNP } & \text { Next Generation Nuclear Plant } \\ \text { NRC } & \text { Nuclear Regulatory Commission } \\ \text { ORNL } & \text { Oak Ridge National Laboratory } \\ \text { OTTO } & \text { Once-Through-Then-Out } \\ \text { PWR } & \text { Pressurized Water Reactor } \\ \text { PYREX } & \text { Discrete Burnable Absorber Rods } \\ \text { SCALE } & \text { Standardized Computer Analysis for Licensing Evaluation } \\ & \end{array}$




$\begin{array}{ll}\text { SWU } & \text { Separative Work Unit } \\ \text { T } & \text { Tritium } \\ \text { tIHM } & \text { Ton Initial Heavy Metal } \\ \text { TRISO } & \text { Tri-structural Isotropic } \\ \text { TRU } & \text { Transuranic Isotopes (Np, Pu, Am, Cm) } \\ \text { UNDP } & \text { United Nations Development Program } \\ \text { UQ } & \text { Uncertainty Quantification } \\ \text { UREX } & \text { URanium EXtraction } \\ \text { VHTR } & \text { Very High Temperature Reactor }\end{array}$




\section{INTRODUCTION}

It is di fficult to de scribe how important e nergy has be come in the world today. Industrialized nations are totally dependent on an abundantly reliable supply of energy for living and working. Energy is a key ingredient in all s ectors of modern e conomies. Even so, it is often taken for granted because it plays such a large role in our everyday existence. Meanwhile, in developing countries there is a lmost a n unque nchable thirst for substantial increases in energy generation and usage. In any case, energy is one of the single most important factors in regards to living standards of individuals throughout the world. S tudies have continually shown an indisputable link between energy consumption and individuals overall wellbeing [1-3].

Extensive da ta ha ve $b$ een collected comparing average energy consumption per capi ta to measurements $t$ hat $r$ epresent $t$ he $s$ tandard of living, or qua lity of 1 ife, a chieved i $n$ a ny community. O ne such measure is the Human Development Index (HDI), which incorporates factors s uch a s 1 ife expectancy, education, i ncome i nequality, pov erty $r$ ates, $G$ ross D omestic Product (GDP) per capita, and the environment [2].

The HDI is widely considered the best and most comprehensive measure for quality of life. The index is nor malized to give a $\mathrm{v}$ alue be tween $\mathrm{z}$ ero and on $\mathrm{e}, \mathrm{w}$ ith one representing the hi ghest possible standard of living or most developed country, and zero being the least. Countries that score an HDI greater than 0.90 are considered to have a "very high quality of life," while those with values be tween 0.60 and 0.90 a re rated as having an "average quality of life," and those below 0.60 are classified as having a "very low quality of life."

A ve ry compelling $\mathrm{r}$ elationship e xists be tween $\mathrm{H} \mathrm{DI}$ and e nergy us age. T he $\mathrm{U}$ nited $\mathrm{N}$ ations Development Program (UNDP) released the data presented in Figure 1.1 on December 20, 2008. It includes the HDI and electricity generation per capita (as determined in 2006) for 180 different countries, with some of count ries 1 abeled for $g$ eneral $r$ eference. A $s$ indicated, the $r$ esults overwhelmingly show that the greater the energy consumption per capita for a community, the greater the standard of living (HDI) for those individuals. C onsequently, energy consumption can be used as a litmus test for the overall wellbeing of a society and for a comparison between different societies around the globe. 


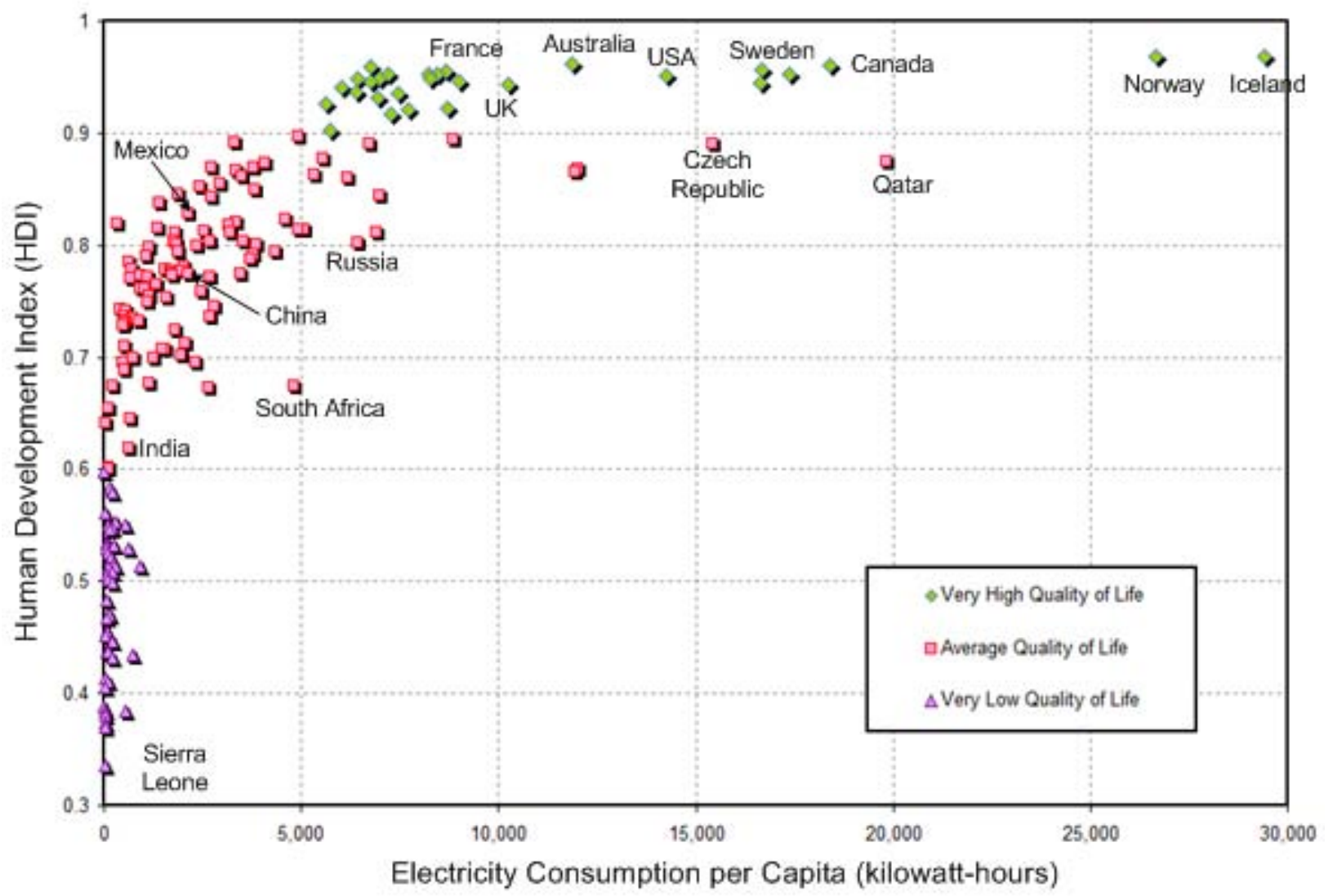

Figure 1.1. Relationship of HDI and Electricity Consumption per Capita.

Iceland and Norway have the highest HDI at 0.968 , while Sierra Leone ranks lowest at 0.329 , which is shown in the upper right and lower left of Figure 1.1, respectively. The USA has an HDI of 0.950 and is ranked number 15 overall. As expected, all nations strive to increase their HDI s tanding. The most ef fective and straightforward w ay to a ccomplish this i s by adding energy generation c apacity. $\mathrm{O} f$ pa rticular not ice is $\mathrm{C}$ hina and India, the $\mathrm{t}$ wo $\mathrm{m}$ ost popul ated countries in world, which have HDI values that place them in the lower portion of the "average quality of life" group of nations. India and C hina a re striving to $r$ apidly increase their H DI. Their i mproved H DI w ill g reatly a ffect t he r est of the w orld. W ith over $35 \%$ of w orld's population between these two countries, just a slight increase in either's electricity consumption per capita will have a huge impact on overall energy needs worldwide.

The coupled effect of energy use and living standards leads to an interesting dilemma. Just like energy's link to quality of life, energy is also intricately entwined with the environment. Much of the global-scale environmental de gradation seen today is attributed to the adverse effects of energy pr oduction a nd us e. T hus, na tions a re f aced $\mathrm{w}$ ith $\mathrm{t}$ he $\mathrm{s}$ truggle $\mathrm{t} \mathrm{o}$ i ncrease energy generation in order to provide a higher standard of living for their citizens, but must also do so in an environmentally responsible way.

Figure 1.2 di splays HDI data and $\mathrm{C}$ arbon Dioxide $\left(\mathrm{CO}_{2}\right)$ emissions for 180 countries. The six countries (Bahrain, Kuwait, Oman, Qatar, S audi A rabia, and the U nited A rab Emirates) that make up the Gulf Cooperation Council (GCC) are at the top or near the top of the list for $\mathrm{CO}_{2}$ 
emitters. Their $\mathrm{r}$ anking is ma inly du e to their hi gh emitting ga s production sector, small populations, a nd e xportation of e nergy. Q atar is t he $\mathrm{n}$ umber one e mitter, g enerating 79.3 tones/capita - such a high value that it is off the scale of the provided plot. M ost of the GCC countries ha ve $t$ aken a ggressive $m$ easures $t o$ reduce $t$ heir $\mathrm{C} \mathrm{O}_{2}$ emissions. M easures $t$ aken including tightening controls on gas flaring, researching carbon capture and sequestration, and investigating the use of non- $\mathrm{CO}_{2}$ emitting energy forms such as nuclear energy and wind power.

It is interesting to note that counties such as France and Iceland have extremely high HDI values while a the $\mathrm{s}$ ame time $\mathrm{g}$ enerating ve ry low le vels of $\mathrm{C} \mathrm{O}_{2}$ emission pe $\mathrm{r} \mathrm{c}$ apita. $\mathrm{F}$ urther investigation reveals that France gets about $80 \%$ of its electricity generation from nuclear power. Much of Iceland's energy needs are met by renewable sources (particularly geothermal power). Both c ountries a re fulfilling a large por tion of their e nergy ne eds by us ing non $-\mathrm{CO}_{2}$ emitting sources. F rance and Iceland have something else in common - they both have very few fossil fuel energy resources within their borders. Even so, they have a dopted energy plans that have made them much more energy-independent compared to other industrialized nations.

The United States is ninth on the list for $\mathrm{CO}_{2}$ emissions per capita and second, just behind China, for overall $\mathrm{CO}_{2}$ emissions. The rest of the world shares the belief that the USA needs to take a more proactive role in $\mathrm{CO}_{2}$ reduction and set an example for the others around world to follow. Again, a s m entioned previously, India a nd $\mathrm{C}$ hina a re of $\mathrm{m}$ ajor concern due to their increased energy demands and the impact they will have in the near future.

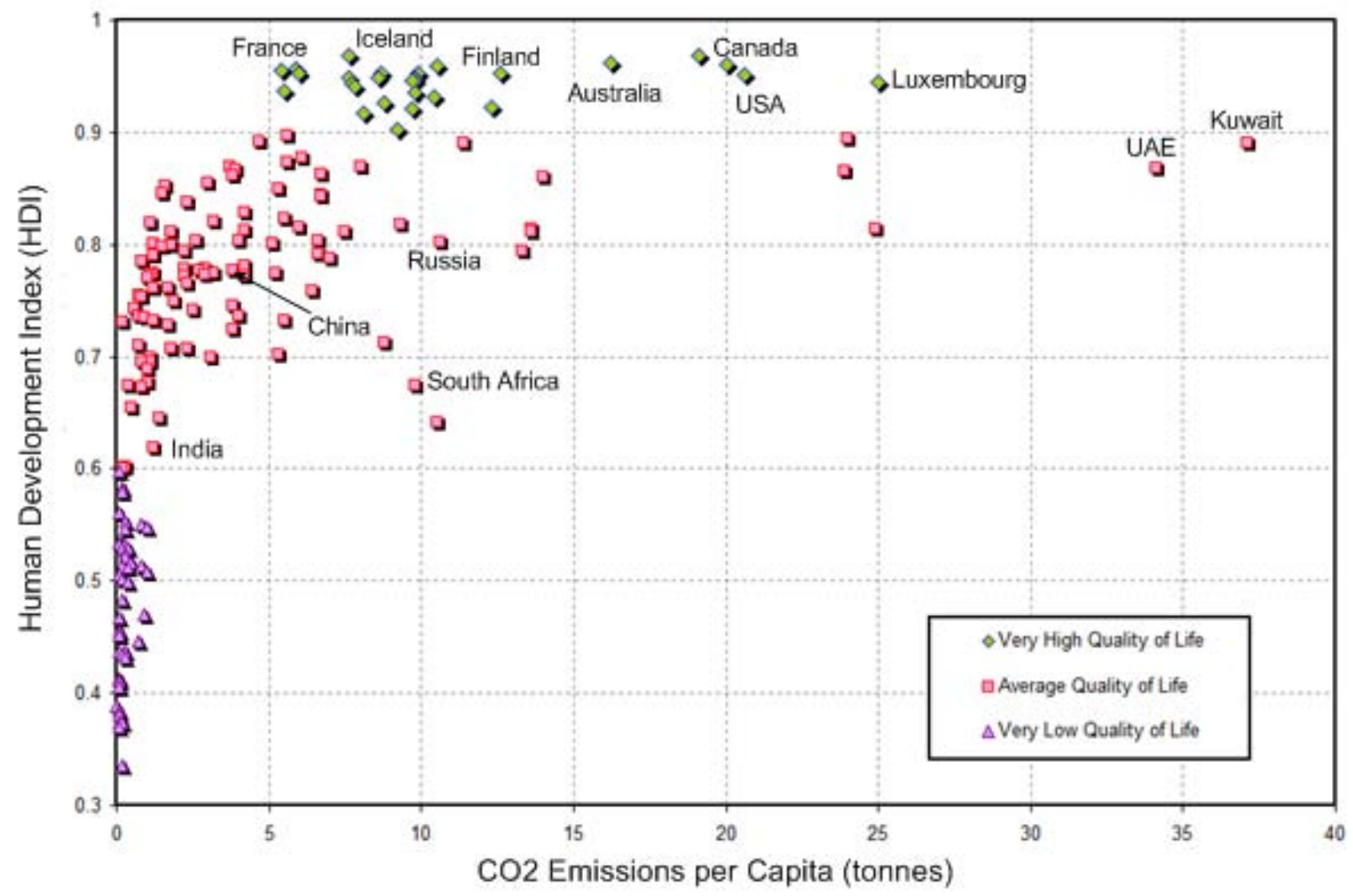

Figure 1.2. $\mathrm{HDI}$ vs. $\mathrm{CO}_{2}$ Emissions per Capita for 180 Countries. 
In recent years the w orld has be come much more sensitive to the relationship be tween energy and the environment, to the point that it has become nearly impossible to discuss one without the other. In response, nations and groups of nations have proposed and/or implemented policies to mitigate the ha rmful e nvironmental e ffects a ssociated $w$ ith e nergy generation $[4,5]$. $T$ hese energy policies are de veloped to a id the environment through tactics s uch a s arbon e mission caps, e missions $\mathrm{t}$ rade $\mathrm{pl}$ ans, $\mathrm{c}$ arbon $\mathrm{t}$ axes, efficiency and conservation incentives, clean renewable e nergy incentives, e tc. In a ddition to the ve ry i mportant e nvironmental i ssues that have $\mathrm{c}$ ome $\mathrm{t}$ o t he f orefront, $t$ here a re s ome ot her i mportant $r$ equirements $f$ or $f$ uture energy systems. Important goals and basic principles of future energy sources include:

1) Reducing greenhouse gas emissions,

2) Minimizing the overall environmental footprint,

3) Safety and reliability,

4) Sustainability,

5) Economically viable,

6) Efficiency, and

7) Energy independence.

From the onset nuclear power has shown great promise in meeting all of the above principles. As the technology has matured s o has its effectiveness in a ccomplishing these goals. T oday nuclear en ergy is arguably one of the best sources for electricity generation that can meet future needs and requirements. Even so, advances and improvements must be made for nuclear energy to be $\mathrm{c}$ ompetitive i $\mathrm{n} t$ he f uture. The $\mathrm{r}$ esearch $\mathrm{w}$ ork pr esented $\mathrm{w}$ ithin a ddresses $\mathrm{t}$ he a bove principals with emphasis on environmental aspects by means of developing a modeling approach for a dvanced nuclear e nergy s ystems that mini mize hi gh level waste inve ntories while at the same time maximizing fuel utilization.

\subsection{The Nuclear Fuel Cycle}

The nuclear fuel cycle can be described as the comprehensive collection of components that are linked t ogether for the main pur pose of g enerating e lectricity b y m eans of nuc lear pow er. It includes everything from the exploration for uranium deposits, to harnessing the energy released during fission, to the disposal of radioactive waste. The nuclear fuel cycle can be thought of as the progression of nuclear fuel through a series of differing stages which involve the production of el ectricity in nuclear reactors. There a re three major parts to the cycle: 1) Front-end, 2) Incore, and 3) Back-end.

The front-end of the fuel cycle be gins with the exploration of uranium deposits. Estimates for uranium $r$ eserves a $t$ di fferent $s$ tated c osts a re d eveloped and reported [6]. O nce the ur anium deposits ha ve be en i dentified, $\mathrm{t}$ he ur anium or e i $\mathrm{s}$ e xtracted b y v arious $\mathrm{m}$ ining $\mathrm{m}$ ethods. Conventional t echniques s uch a s ope $\mathrm{n}$ pit and underground $\mathrm{m}$ ining a re $\mathrm{m}$ ost $\mathrm{c}$ ommonly us ed. Next the mined uranium ore is processed and treated to extract the uranium through the milling process. The mille $\mathrm{d}$ uranium is then converted t o a form that $\mathrm{c}$ an be us ed b y commercial facilities to enrich the fissile component by either gaseous diffusion or gas centrifuge enrichment technologies. The last step for the front-end is fuel fabrication, where enriched fuel is converted to a final usable fuel form and incased in a protective cladding for service in nuclear reactors. 
The in-core or service period of the fuel cycle makes up the second major category of the fuel cycle. As the name implies, this part of the fuel cycle is concerned with fuel performance while in the reactor core. Much emphasis is placed on fuel management strategies, irradiation effects on the fuel, fuel cladding interactions, and radioactivity release during normal use and accidents. The $\mathrm{r}$ eactor $\mathrm{t}$ ype, $\mathrm{n}$ eutron s pectrum, and fuel $\mathrm{t}$ ype a re $\mathrm{i}$ mportant pa rameters $\mathrm{f}$ or $\mathrm{t}$ he $\mathrm{s}$ ervice period.

The ba ck-end of the fuel c ycle be gins when the fuel is di scharged from the reactor. U pon removal, the fuel is stored onsite temporarily and then prepared for either permanent storage or for reprocessing. The decision of whether to recycle the used reactor fuel or to place it directly into storage greatly affects the makeup of the back-end of the fuel cycle. Waste management is the key issue with this part of the fuel cycle.

The United States employs what is referred to as the once-through fuel cycle. The fuel makes one pass through a thermal neutron s pectrum reactor core and after removal it is prepared for permanent di sposal. $T$ he $\mathrm{c}$ ycle is qui te wasteful of nuclear energy resources, being that the valuable remaining energy in the us ed fuel is not reclaimed. F or this reason, the once-through cycle is sometimes called a "throw-away" fuel cycle [7]. Due to its wide use the once-through cycle is often used as the standard reference when comparing differing fuel cycles.

\subsubsection{Advanced Fuel Cycle Initiative}

Making i mprovements to and/or replacing the onc e-through fuel cycle with a superior method that $\mathrm{r}$ ecycles us ed nuclear $\mathrm{f}$ uel is a goal that many $\mathrm{d}$ eveloped countries are s erious a bout achieving. $\mathrm{F}$ or i nstance, $\mathrm{t}$ he $\mathrm{U}$ nited $\mathrm{S}$ tates $\mathrm{D}$ epartment of $\mathrm{E}$ nergy ( DOE) e stablished $\mathrm{t}$ he Advanced $\mathrm{F}$ uel $\mathrm{C}$ ycle Initiative ( $\mathrm{AFCI}$ ) pr ogram $\mathrm{t}$ o f ocus on $\mathrm{t}$ he $\mathrm{r}$ esearch and de velopment needed to support a transition from the current once-through fuel cycle to an advanced nuclear fuel cycle. The AFCI program is envisioned to support the growth of nuclear power and enable energy independence in the U.S. by developing and demonstrating technologies that facilitate the transition t o a s table, l ong-term, e nvironmentally, e conomically, a nd politically a cceptable advanced fuel cycle. The main goals of the AFCI are to reduce high-level waste volume, greatly reduce long-lived and highly radiotoxic elements, and reclaim valuable energy content of spent nuclear fuel. In part, the AFCI program seeks to:

- Reduce the long-term environmental bur den of nuclear energy through more e fficient disposal of waste materials.

- Enhance overall nuclear fuel cycle proliferation resistance via improved technologies for spent fuel management.

- Reduce the inventories of civilian plutonium

- Enhance en ergy s ecurity by extracting ene rgy recoverable in spent fuel and depleted uranium, ensuring that uranium resources do not become a limiting resource for nuclear power.

- Improve fuel cycle management, while continuing competitive fuel cycle economics and excellent safety performance of the entire nuclear fuel cycle system. 
- Develop fuels and fuel c ycles for cu rrent reactor s ystems and future Generation IV nuclear fuel systems

The Generation IV International Forum (GIF) focuses on future nuclear energy system concepts to meet the growing energy needs of the world. It is an international program consisting of 13 member na tions ( United S tates of A merica, Argentina, Brazil, Canada, France, Japan, S outh Korea, S outh A frica, S witzerland, U nited K ingdom, the E uropean U nion, C hina, a nd R ussia) coordinating research and w orking together to de velop promising new nu clear energy systems. Attention is given to improving safety features, addressing nuclear nonproliferation and physical protection issues, optimizing na tural resource ut ilization, minimizing waste, a nd be ing economically com petitive $\mathrm{w}$ ith other ene rgy generating s ystems. The G IF ha s s elected six systems for further development. The systems are:

1) Gas-Cooled Fast Reactor,

2) Very High Temperature Reactor,

3) Supercritical Water Cooled Reactor,

4) Sodium Cooled Fast Reactor,

5) Lead Cooled Fast Reactor, and

6) Molten Salt Reactor.

As part of the Generation IV program the U.S. DOE has focused efforts on the Next Generation Nuclear Plant (NGNP). The NGNP program promotes research and development specific to the Very High Temperature Reactor (VHTR).

The VHTR is designed to be a high-efficiency energy system, which can supply electricity and process heat to a wide-range of high temperature and energy intensive applications. The VHTR is a pa ssively s afe de sign. The refractory core, low pow er de nsity, and low ex cess reactivity enable this design feature. It is a graphite moderated gas-cooled reactor that supplies heat with core outlet temperatures equal to or greater than $850^{\circ}$ Celsius, which enables applications such as hydrogen production, process heat for the petrochemical industry, or seawater desalination.

To r ealize the full pot ential of a dvanced fuel $\mathrm{c} y c l e s$, fast ne utron $\mathrm{s}$ pectrum $\mathrm{s}$ ystems $\mathrm{m}$ ust be implemented. $\mathrm{F}$ ast $\mathrm{s}$ ystems of fer a hi gher de gree of $\mathrm{f}$ lexibility $\mathrm{w}$ hen it $\mathrm{c}$ omes to the transmutation process. They not only provide the ability to better control the isotopic makeup of the waste stream through nuclide destruction, but also the capability to fully utilize the available fuel resources with hi gh conversion/breeding ratios. The GIF recognizes this and has included fast neutron spectrum systems for further development.

In addition to the $\mathrm{f}$ ast $\mathrm{r}$ eactors $\mathrm{w}$ ithin the G IF f ramework, subcritical s ystems $\mathrm{w}$ ith external sources, a lso c alled h ybrid s ystems, de monstrate significant promise for e nergy generation as well as a $\mathrm{n}$ eutron excess which could be us ed for nuc lear waste transmutation [8-12]. H ybrid systems are generally separated into two general concepts that are relevant to the approach used to generate the ex ternal s ource of ne utrons. These conc epts ar e: 1) T he acc elerator dr iven systems, which combines a pa rticle a ccelerator with a sub-critical cor e, and 2) F usion-fission systems, which take advantage of an intense high-energy fusion neutron source. 
Subcritical systems driven by an external ne utron source have the ability to achieve ex tremely high transmutation efficiencies in a single core loa ding $\mathrm{w}$ ithout mul tiple $\mathrm{r}$ ecycles [13], thus minimizing the handling and storage of nuclear waste, making hybrids highly efficient relative to other waste reduction schemes. In addition, recent de velopments and advances in the arena of combining neutron-rich fusion with energy-rich fission has made fusion-fission hybrid systems a waste destruction strategy that is considerably less costly than known alternatives [14].

\subsection{Objectives}

The overall objective of the proposed research is the development of high fidelity nuclear energy system optimization towards an environmentally benign design that is sustainable and provides a secure energy source. System needs and performance requirements that lead to an actinide-free high-level $\mathrm{w}$ aste a ssuming $\mathrm{p}$ artitioning and transmutation will be ta rgeted. The research objectives can be cataloged as follows:

\section{1) Development of Realistic Reactor Core Models:}

An i ntegral pa rt of $t$ he $r$ esearch i s the de velopment of high fidelity whole-core 3D ex act geometry models accounting for core physics in the fuel cycle analysis. The modeling approach will be limited to technologically feasible configurations and use hybrid Monte Carlo methods. A major constraint on the computational models will be the computational run time.

\section{2) Code System Integration:}

Develop an approach to seamlessly couple the various models that compose the environmentally benign system. The goal being to devise a computational shell that effectively controls the entire set of reactor and component models with control over key user input parameters and the ability to e ffectively c onsolidating vi tal out put $r$ esults $i$ nto $r$ eadily usable $f$ orm for uncertainty/sensitivity analysis and optimization procedures.

\section{3) Uncertainty Quantification (UQ):}

Quantify the unc ertainties for specific core characteristics that greatly af fect pe rformance with respect to nuclear $\mathrm{w}$ aste mini mization and determine $\mathrm{w}$ hich data $\mathrm{c}$ ontribute the mos $\mathrm{t} t \mathrm{o}$ uncertainty.

\section{4) Optimization Analysis:}

High fidelity nuclear energy system multi-objective optimization for minimizing the problematic actinide isotopes as related to long-term repository storage, minimizing used fuel handling issues throughout the process, and at the same time maximizing the efficient use of the fuel component for prolonged usage and sustainability of fuel resources. 


\section{5) Environmental Impact Analysis:}

Demonstrate $t$ he e ffectiveness of $t$ he opt imized nuclear en ergy $s$ ystem as $r$ elated to environmental impact by drawing comparisons to other proposed a dvanced fuel cycle schemes and the current once-through fuel cycle.

\subsection{Procedures}

\subsubsection{Nuclear Energy System Setup}

In the context of this pa per a Nuclear Energy S ystem (NES) is de fined as a c onfiguration of nuclear reactors and corresponding fuel cycle components. There are numerous possibilities for nuclear energy systems, many of which have been studied in great detail. The proposed NES has some unique characteristics that set it apart from other systems. It is arranged for minimization or e limination of $\mathrm{h}$ igh-level $\mathrm{w}$ aste i nventories, which i s a $\mathrm{n}$ e ssential $\mathrm{c}$ omponent of publ icly acceptable sustainable nuclear energy strategies [15].

The a rrangement of the N ES i s de picted i n Figure 1.3. T he front-end (mining, milling, enrichment, and fuel fabrication) of the fuel cycle is shown in the top center and follows current practices i ncorporated a nd us ed in the onc e-through $f$ uel $\mathrm{c}$ ycle. $\mathrm{T}$ he only difference is the availability of D epleted $\mathrm{U}$ ranium ( DU) a rising from the $r$ eprocessing $s$ tep, allowing $f$ or the recycling of the uranium.

Following the front-end procedures the fuel elements enter the Pressurized Water Reactor (PWR) for reactor operation and power production. When the fuel is exhausted it is removed from the reactor and temporarily stored to allow the used fuel to cool down to the specified limits required before $\mathrm{r}$ eprocessing $\mathrm{c}$ an be performed. $\mathrm{D}$ uring $\mathrm{r}$ eprocessing the $\mathrm{fuel}$ is partitioned into three separate s treams: 1. F ission P roducts (FP), 2. D epleted U ranium (DU) a nd 3. T ransuranics (TRU). The FP are conditioned and prepared for long-term High Level Waste (HLW) storage. The DU is stored as Low-Level W aste (LLW) and is al so available for recycle. The TRU are fabricated into fuel elements to be recycled in the VHTR, which operates in the Once-ThroughThen-Out (OTTO) mode. T he fuel is removed from the VHTR onc e it no longer can sustain criticality. A fter a d ecay/cool-down period, the used VHTR fuel is sent to the external source driven s ubcritical $r$ eactor, or $\mathrm{H}$ igh-Energy $\mathrm{E}$ xternal $\mathrm{S}$ ource $\mathrm{T}$ ransmuter ( HEST), where it is transmuted via single pass. A fter removal, the used HEST fuel is considered HLW and sent to the designated facility for permanent HLW storage.

The material is tracked throughout the NES with emphasis on c omposition changes within the reactor s ystems, material s treams dur ing reprocessing, and the $\mathrm{f}$ inal affect on HLW w aste management $s$ trategies. The $\mathrm{r}$ epresentative $\mathrm{m}$ odels $\mathrm{f}$ or $\mathrm{t}$ he reactor $\mathrm{s}$ ystems and fuel cycle components are stand-alone units that also offer the ability to link each for the purpose of NES uncertainty quantification and optimization procedures. 
The proposed advanced NES is anticipated to have a hi gh na tional and international impact, potentially changing nu clear w aste management and reactor de ployment paradigms by offering an environmentally benign, sustainable, and secure energy source.

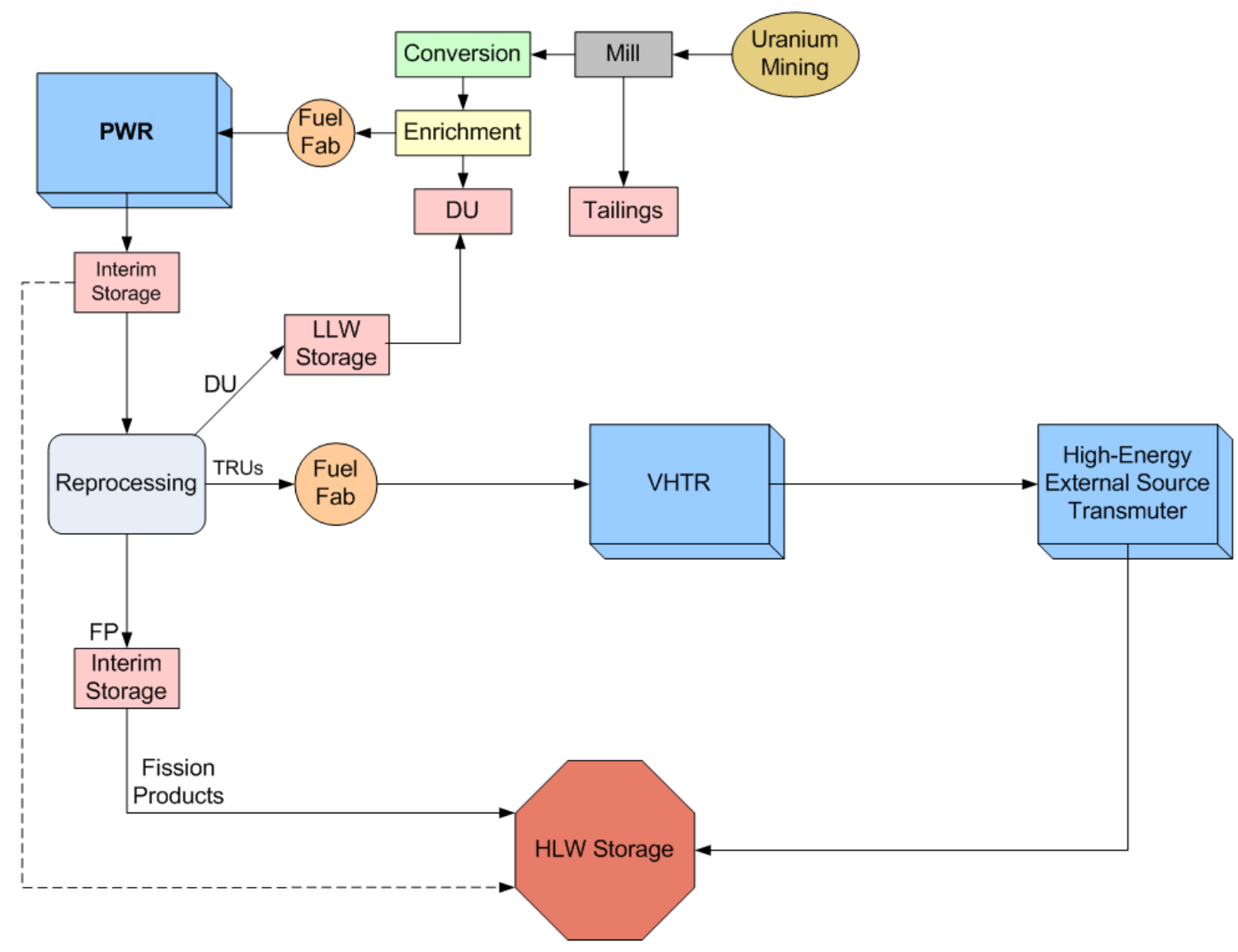

Figure 1.3. Nuclear Energy System Flow Chart. 


\section{APPLIED CODE SYSTEMS}

Modeling and simulation play a critical role in modern scientific and technical endeavors. To the extent $\mathrm{t}$ hat $\mathrm{s}$ cientific adva nces are de pendent o $\mathrm{n} t$ heir e ffective us e. Modeling, $\mathrm{t}$ heory, a nd simulation $\mathrm{c}$ an $\mathrm{e}$ nhance our und erstanding o f know $\mathrm{n} \mathrm{s}$ ystems, pr ovide qua litative a nd quantitative ins ights int o experimental $\mathrm{w}$ ork, guide the choice of the experimental s ystem to study, enable the design of new systems, provide quantitative results to replace experiments, and extend 1 imited e xperimental da ta i nto ne $\mathrm{w}$ dom ains of pa rameter s pace [16]. D ue to the difficulties of dealing with radioactive materials, modeling and simulation will play a critical role in advancing nuclear research programs.

Most of the ava ilable, well-established, and validated computer cod e s ystems are or iented for evaluating 1 ight $\mathrm{w}$ ater reactor s ystems. T o apply t hem $\mathrm{f}$ or advanced reactor s ystems a specialized approach of application i s r equired. F or i nstance, pr evious w ork ha s i dentified insufficiencies in the ability of code systems to accurately a ccount for the multi-heterogeneity effects associated with VHTR systems [17]. Additionally, the modeling of subcritical systems with e xternal s ources $\mathrm{p}$ resent $\mathrm{c}$ hallenges i nvolved $\mathrm{w}$ ith a ccounting $\mathrm{f}$ or the introduction of a neutron source ins ide a multiplying me dia. T he ne utron kinetic characteristics of subcritical, source-driven cores, as well as the mathematical methods to treat their temporal be havior, are markedly different from those of critical cores [18]. Also, a reliable and consistent procedure for coupling the $\mathrm{r}$ eactors a nd ot her $\mathrm{f}$ uel $\mathrm{c}$ ycle $\mathrm{c}$ omponents, w hile pr eserving a nd pr oducing ke $\mathrm{y}$ component parameters, must be approached with great care.

Uncertainty qua ntification ( UQ) i s a ke y c omponent $f$ or $s$ uccessfully m eeting the ove rall objectives of the proposed research work. UQ is the science of combining imperfect information from multiple sources to reach conclusions and to evaluate the validity of the conclusions. UQ is thus concerned with the transformation from data to knowledge to decisions. It defines the link between science and the decision process. UQ starts with the identification and characterization of e rror or unc ertainties f rom a $11 \mathrm{~s}$ teps i $\mathrm{n} t$ he s equence o f a pproximation $\mathrm{t}$ hat 1 eads $\mathrm{t} \mathrm{o}$ a computational $\mathrm{m}$ odel pr ediction. $\mathrm{U} \mathrm{Q}$ us es $\mathrm{t}$ echniques $\mathrm{f}$ rom $\mathrm{f}$ ields $\mathrm{s}$ uch a $\mathrm{s} s$ tatistics a nd optimization to determine the sensitivity of models to inputs with errors, and to design models in order to minimize the effect of the errors. Integrating uncertainty quantification approaches into simulation allows potentially more efficient interrogation of parameter dependencies and model certainties [19].

\subsection{Code Systems}

State-of-the-art computer code systems were utilized to create realistic high fidelity 3D wholecore m odels $r$ epresenting the $r$ eactors and fuel $\mathrm{c}$ ycle $\mathrm{c}$ omponents that $\mathrm{c}$ ompose the NES. A collection of di verse c ode $\mathrm{s}$ ystems $\mathrm{w}$ ere $\mathrm{s}$ elected ba sed on $\mathrm{t}$ heir a bility $\mathrm{t} \mathrm{o} \mathrm{m}$ eet $\mathrm{t}$ he out lined research objectives and the capabilities and limitations accompanying each.

The $\mathrm{M}$ onte $\mathrm{C}$ arlo ba sed c ode ( $\mathrm{MCNP}$ ) $\mathrm{w}$ as he avily ut ilized $\mathrm{f}$ or $\mathrm{c}$ reating the $3 \mathrm{D}$ w hole-core models representing the reactor units in the NES. F unctional modules within the Standardized 
Computer A nalysis for Licensing Evaluation ( SCALE) code s ystem w ere us ed to model the HLW facility and for 3D whole-core modeling. The front-end components were modeled using the $\mathrm{N}$ uclear Fuel C ycle $\mathrm{S}$ imulation System ( NFCSS). $\mathrm{T}$ he MATrix LABoratory MATLAB/Simulink computational environment was utilized to model the reprocessing facility and provided the means for developing an integrated system model representing the NES.

\subsubsection{MCNP}

Monte Carlo N-Particle (MCNP) is a general purpose code that can be used for neutron, photon, electron, or coupled neutron/photon/electron transport. MCNP is the internationally recognized code for analyzing the transport of neutrons and gamma rays, and is developed and maintained by Los Alamos National Laboratory.

\section{MCNP5}

MCNP i s a c ode t hat i s c ontinuously und ergoing de velopment a $t$ Los A lamos $n$ ational Laboratory a nd $\mathrm{h}$ as pe riodic $\mathrm{r}$ eleases. T he di stinction of the num ber $5 \mathrm{i} \mathrm{n} \mathrm{M} \mathrm{CNP5}$ i s f or identifying the version of MCNP. The current release (2010) is version MCNP5 (1.51). MCNP5 is very versatile due to important standard features such as: multiple source description options, flexible tally structure, an extensive collection of cross section data, large collection of variance reduction techniques, and geometry and output tally plotters. Neutron energy ranges in MCNP5 are limited to that of $10^{-11}$ to $20 \mathrm{MeV}[20,21]$.

\section{MCNPX}

The code s ystem M CNPX ( Monte C arlo N-Particle eX tended) ex tends the capa bilities of MCNP4C3 to nearly all particles, nearly all energies, and to nearly all applications without an additional computational time penalty. It is fully 3D and time dependent, and us es up to date nuclear cross section libraries and physics models for particle types and energies where tabular data are not available. MCNPX version 2.6.0 includes depletion/burnup/transmutation capability that is limited to criticality calculations [22].

\section{MAKXSF}

The MAKXSF code is part of the MCNP5/MCNPX distribution, but is run external to MCNP. MAKXSF is a ut ility program for manipulating cross s ection library files for us e in MNCP5. The ba sic $f$ unctions pe rformed $b$ y M AKXSF i nclude: cha nging t he f ormat of cr oss s ection libraries, copying e ntire libr aries to new files or to copy s elected nuclide da ta s ets to new libraries, and to create nuclide datasets at new temperatures, resulting in a temperature dependent library for specific application [23].

Capabilities of M AKXSF f or cr eating nuc lide datasets at a ne w $t$ emperature i nvolves $t$ hree operations: 1) Doppler broadening of resolved data to any higher temperature, 2) Interpolation of unresolved resonance data between datasets at two different temperatures, and 3) Interpolation of thermal scattering kernels $(\mathrm{S}(\alpha, \beta)$ data) between datasets at two different temperatures. 


\subsubsection{SCALE}

The Standardized Computer Analysis for Licensing Evaluation (SCALE) code system serves in conjunction $\mathrm{w}$ ith M CNP $\mathrm{t}$ o pr ovide $\mathrm{c}$ ode-to-code be nchmarking $\mathrm{w}$ hen a pplicable and $\mathrm{f}$ or additional analysis beyond that of MNCP. SCALE is developed and maintained by Oak Ridge National Laboratory (ORNL) a nd is widely a ccepted around the w orld f or criticality safety analysis, radiation s ource t erm a nd s hielding, pr oblem de pendent $r$ esonance s elf-shielding of cross section data, sensitivity and uncertainty, and reactor physics analysis [24].

\section{KENO-VI}

KENO-VI is a functional module in the SCALE system. It is a mutigroup Monte Carlo code applied to determine the effective multiplication factor $\left(\mathrm{k}_{\mathrm{eff}}\right)$ for three-dimensional systems. The geometry package in KENO-VI is capable of modeling any volume that can be constructed using quadratic equations [25].

\section{ORIGEN-S}

ORIGEN-S is a depletion and de cay module in the SCALE code system, and it can be called from a control module or run as a stand-alone program. O RIGEN-S computes time-dependent concentrations and radiation source $t$ erms w hich are s imultaneously generated or d epleted through n eutronic transmutation, fission, and radioactive decay [26]. In relation to this report, ORIGEN-S w as us ed in s tand-alone m ode for c alculating s pent fuel radiotoxicities and de cay heat terms as a function of time for the TRU nuclides and fission products.

\subsubsection{NFCSS}

The International A tomic E nergy A gency's ( IAEA) s imulation s ystem, $\mathrm{N}$ uclear Fuel C ycle Simulation System (NFCSS) was used to model fuel cycle components of the NES. NFCSS is a scenario ba sed c omputer m odel for the e stimation of nuc lear fuel cycle $\mathrm{m}$ aterial and service requirements. It has be en de signed to qui ckly estimate long-term fuel cycle r equirements and actinide production. Natural uranium, conversion, enrichment, and fuel fabrication quantities are predicted. Additionally, the quantities and qualities (isotopic composition) of unloaded fuels are evaluated.

The IAEA developed CAIN (CAlculation of Inventory of spent fuel) specifically for the needs of NFCSS. C AIN solves the Bateman's Equations for a point assembly using one group neutron cross s ections. In o rder $t \mathrm{o} m$ eet $\mathrm{t}$ he a ccuracy, $\mathrm{s}$ implicity, and $\mathrm{s}$ peed requirements a $\mathrm{s}$ et of assumptions were built into the code. C AIN currently has 28 reaction and decay chains during irradiation and 14 decay chains during cooling [27]. 


\subsubsection{MATLAB/Simulink}

MATrix LABoratory (MATLAB) first appeared in the late 1970s and was originally designed to simplify the impl ementation of num erical line ar a lgebra $r$ outines [28]. M ATLAB ha s s ince grown $\mathrm{i}$ nto s omething $\mathrm{m}$ uch bi gger, a nd i t i s c ontinually de veloped b y t he $\mathrm{M}$ athWorks Corporation. It is both a powerful computational environment and a programming language that easily ha ndles ma trix and complex a rithmetic. T ypical us es inc lude ma th/computation, algorithm de velopment, $\mathrm{m}$ odeling, $\mathrm{s}$ imulation/prototyping, da ta analysis, e xploration, visualization, scientific graphics, and application development.

Simulink w orks w ith M ATLAB t o of fer m odeling, s imulation, a nd a nalysis of $\mathrm{m}$ ultidomain dynamic s ystems und er a graphical us er i nterface environment. Simulinki ncludes a comprehensive s et of customizable bl ock libraries for bot h 1 inear and nonl inear a nalyses. A $s$ Simulink is a n integral part of MATLAB, it is easy to s witch back and forth du ring a nalysis making it possible to take advantage of the features offered in each environment. The available options a nd f lexibility of M ATLAB/Simulink $\mathrm{m}$ ake i t a $\mathrm{n}$ i deal $\mathrm{c}$ andidate $\mathrm{f}$ or de veloping an integrated system model representing the NES.

The num erical computing environment and pr ogramming 1 anguage M ATLAB s erves as the shell, or driver, for the s imulated nuclear energy s ystem b y int erfacing th e c onfiguration of nuclear $\mathrm{r}$ eactors a nd c orresponding $\mathrm{f}$ uel $\mathrm{c}$ ycle $\mathrm{c}$ omponents. $\mathrm{S}$ imulink, a $\mathrm{n}$ e xtension of MATLAB, is utilized for storing system output results and parameters, tracking material streams, data pr ocessing, a nd pr edicting s ystem performance t hroughout t he $N$ ES. $T$ he sensitivity/uncertainty analysis a nd opt imization $t$ echniques a re de veloped a nd i mplemented within the MALAP/Simulink environment. 


\section{TRU CHARACTERIZATION}

The tracking and analysis of the transuranic elements (TRU: $N p, P u, A m, C m$ ) are a key aspect of $t$ he pr oject. T he T RU i nventory i s $r$ esponsible $f$ or $t$ he 1 ong-term he at $g$ eneration and radiotoxicity $t$ hat a ccompanies us ed nuc lear $\mathrm{f}$ uel. $\mathrm{H}$ igh-level nu clear $\mathrm{w}$ aste $\mathrm{r}$ epository performance parameters are dependent on the TRU composition, which presents challenges for effectively i solating nuclear waste in order to ensure the safety of the public and to protect the surrounding environment. Therefore, focus is placed on the destruction of the TRU stream as a means to alleviate pr oblematic as pects of $\mathrm{w}$ aste $\mathrm{m}$ anagement and to strengthen support $\mathrm{f}$ or nuclear $\mathrm{f}$ ission a s a future s ource for $\mathrm{clean}, \mathrm{s}$ ustainable, a nd e nvironmentally f riendly e nergy production.

Through $r$ eprocessing and partitioning techniques the TRU s tream can be separated from the other elements present in used nuclear fuel [29]. As a group, the TRU elements exhibit neutronic properties that $\mathrm{make}$ them an ideal fuel component that $\mathrm{c}$ an be taken advantage of by thermal neutron a nd $f$ ast ne utron s pectrum $r$ eactor s ystems $b$ y w ay o $f$ hi gh bur nup $\mathrm{c}$ ores [ 30,31]. Consequently, the TRU inventory can be considered a valuable fuel resource and if utilized to its potential, nuclear en ergy can greatly strengthen its pos ition as a s ustainable and secure ene rgy source.

\subsection{High-Level Waste Management}

The top priority in managing radioactive waste is to protect human health and the environment, now and in the future, $w$ ithout i mposing undue bur dens on $f$ uture generations. There ar e a number of different strategies to achieve this end goal, but no matter what the approach, they all have one thing in common, and that is the need to contain and isolate the waste from interacting with the bi osphere unt il it ha s de cayed to ha rmless levels. C urrently the $\mathrm{m}$ ost s tudied a nd accepted long-term isolation technique is deep geological disposal.

\subsubsection{Geological Disposal}

Repositories are normally sited in stable geological environments that offer favorable conditions in which the w aste and engineered ba rriers a re protected ove $\mathrm{r}$ a long time pe riod [32]. $\mathrm{K}$ ey characteristics such as mechanical stability, low groundwater flux, and favorable geochemical conditions $t$ hat ar e unl ikely $t \mathrm{o}$ ch ange $\mathrm{s}$ ignificantly over $\mathrm{r}$ elevant $\mathrm{t}$ imescales at $\mathrm{t}$ argeted. Currently four types of geological formations a re c onsidered a s pos sible $\mathrm{c}$ andidates for de ep disposal of long-lived radioactive waste:

- Hard rock formations, mainly granite;

- Argillaceous formations, clays and mudstones;

- Salt formations, salt domes and salt layers;

- Volcanic formations, tuff and basalt (Yucca Mountain). 
Generally, the HLW isotopic compositions resulting from the typical LWR operating on the once through fuel cycle are used to assess repository performance. The compositions along with the type of geological formation and the design details of the repository will set the limits on the amount of HLW that $\mathrm{c}$ an be stored at any on e site. A lthough there a re countless de sign and locational possibilities, in each case, the maximum HLW allowance will be constrained by just a few common limiting factors. The two major constraints are temperature limits and peak dose rate for repository releases to satisfy regulatory limits.

Results from pr evious studies ha ve $\mathrm{s}$ hown $\mathrm{t}$ hat $\mathrm{m}$ aximum a llowable di sposal de nsity for a repository is determined mainly by thermal limitations [33]. The removal of TRU elements from the $\mathrm{w}$ aste $\mathrm{s}$ tream has a large i mpact on the 1 ong-term ( $>300$ years) he at g eneration and can significantly increase the amount of allowable waste within a geological repository [33]. As for the $m$ aximum dos e $r$ ate, $r$ emoval of the T RU i nventory does not ha ve $m$ uch i mpact on $t$ he allowable disposal density, but it doe s d rastically affect the timescale for which the repository must $f$ unction. E limination of the 1 ong-lived radioactive $T$ RU nuc lides $r$ educes the s torage timescale from the 100,000 year timeframe to hundreds of years.

By targeting the transmutation of the TRU nuclides that are intense long-lived sources of decay heat and dose rates accomplishes two main goals: 1) more efficient us e of the available space within $\mathrm{t}$ he $\mathrm{r}$ epository allowing f or greater qua ntities of $\mathrm{H} \mathrm{LW} \mathrm{t} \mathrm{o} \mathrm{be} \mathrm{s} \mathrm{afely} \mathrm{s} \mathrm{tored,} \mathrm{a} \mathrm{nd} \mathrm{2)}$ decreasing the amount of time the HLW must be isolated from the biosphere.

\subsection{TRU Origins and Constituents}

During the operation of a nuclear reactor the composition of the fuel is constantly changing as various fuel nuc lei are transmuted by neutron capture and subsequent decay. It is this process through which the TRU inventory is created and subsequently utilized as a fuel component and ultimately de stroyed by fission. Within the front-end procedures of the NES ur anium ore is mined, milled, converted, enriched, and then fabricated into fresh $\mathrm{UO}_{2}$ fuel elements for use in the PWR. Once the PWR begins operation, the creation of the TRU nuclides begins. The fresh $\mathrm{UO}_{2}$ contains ur anium that is s lightly enriched in ${ }^{235} \mathrm{U}(3-6 \%)$ a nd the remaining ur anium is made up of ${ }^{238} \mathrm{U}(94-97 \%)$. It is ${ }^{238} \mathrm{U}$ that is almost entirely responsible for TRU production, which starts with the neutron capture of ${ }^{238} \mathrm{U}$ producing ${ }^{239} \mathrm{U}$, which is very unstable and quickly beta-decays to ${ }^{239} \mathrm{~Np}$ w hich likewise qui ckly b eta-decays to the m ore s table ${ }^{239} \mathrm{PU}$ i sotope, as shown below.

$$
{ }^{238} U+n \rightarrow{ }^{239} U \stackrel{\beta^{-}}{\longrightarrow}{ }^{239} \mathrm{~Np} \stackrel{\beta^{-}}{\longrightarrow}{ }^{239} \mathrm{Pu}
$$

The remaining TRU vector is populated by subsequent neutron captures and isotopic decay. The composition of the TRU inventory is changing constantly and at any particular time is dependent on many factors, such as: i nitial enrichment, ne utron flux, fuel burnup, and LWR operational parameters. U pon removal from a typical LWR the fuel contains roughly $95 \%$ ur anium, 4\% fission products, and 1\% TRU. The TRU elements have the approximate composition of $90 \%$ $\mathrm{Pu}, 5 \% \mathrm{~Np}, 4 \% \mathrm{Am}$, and 1\% Cm. F igure $3.1 \mathrm{~s}$ hows the important actinide nuc lides a nd their relations as related to neutron absorption events, beta-decay, and alpha-decay. The nuclide half- 
life values and thermal ene rgy n eutron cross-sections for radiative capt ure $\left(\sigma_{c}\right)$ and fission $\left(\sigma_{f}\right)$ are displayed. The figure is al so color coded to emphasize important nuc lide characteristics as related to thermal neutron spectrum reactor systems.

Initially ${ }^{235} \mathrm{U}$ is the fissile component of the fuel that allows the reactor to achieve and maintain criticality. As time progresses the ${ }^{235} \mathrm{U}$ is depleted, but simultaneously the fissile isotopes ${ }^{239} \mathrm{Pu}$ and ${ }^{241} \mathrm{Pu}$ are created in the core. In some reactors, although not today's LWR, the core will eventually reach a point $\mathrm{w}$ here c riticality be comes $\mathrm{m}$ ore he avily de pendent on $\mathrm{t}$ he fissile $\mathrm{Pu}$ isotopes than ${ }^{235} \mathrm{U}$, and eventually the a ccumulation of ne utron absorbers and the depletion of fissile inventory will cause the reactor to no longer be able to maintain criticality. At this point reactor fuel will have to be replaced with fresh fuel to continue operating.

By referring to Figure 3.1 a few general conclusion c an be made about the TRU composition resulting from the irradiation of fresh $\mathrm{UO}_{2}$ in PWR reactors. To begin with, $\mathrm{Pu}$ will always have the highest composition percentage, as it is a direct product from neutron capture in ${ }^{238} \mathrm{U}$, which makes up well over $90 \%$ of the fuel. Similarly, $\mathrm{Cm}$ having the greatest number of protons (Z) in the nucleus will take the most interactions to be formed, thus $\mathrm{Cm}$ will always have the lowest composition percentage. Also, for thermal neutron fluxes, most of the TRU nuclides have much greater probability to undergo the radiative capture reaction $(n, \gamma)$ than the fission reaction $(n, f)$. This indicates that, for thermal flux reactors, the longer the fuel is under irradiation, more higher actinides (esp., $\mathrm{Am}$ and $\mathrm{Cm}$ ) will accumulate in the core.

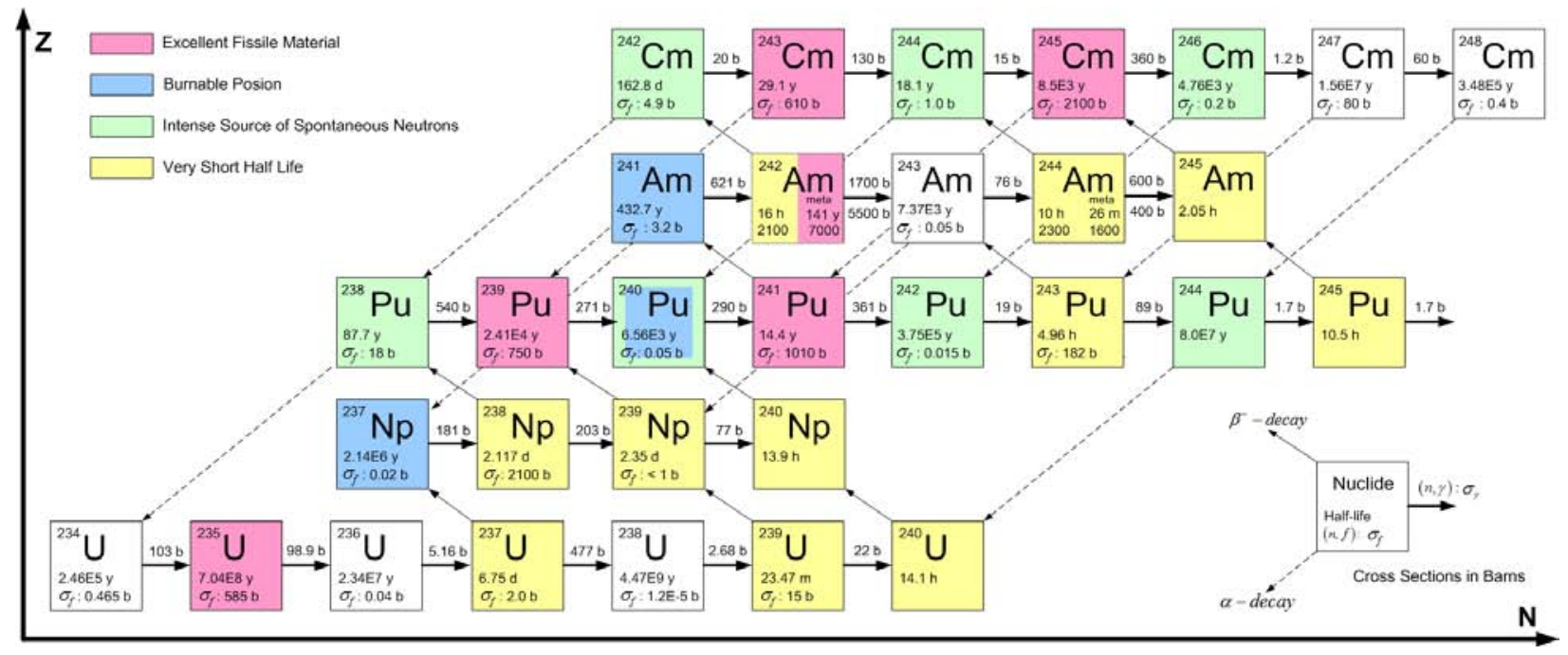

Figure 3.1. Transmutation and Decay Schemes for Important Nuclides.

Table 3.1 is provided as an example of the TRU compositions upon removal from the core. The compositions are representative of a single pass fuel scheme for the AP1000, operating on $4 \%$ Low Enriched Uranium (LEU) fuel and irradiated to a burnup level of $40 \mathrm{GWd} / \mathrm{tIHM}$. 
Table 3.1. TRU Composition after Irradiation in PWR.

\begin{tabular}{|l|l|}
\hline Nuclide & TRU (\%) \\
\hline${ }^{237} \mathrm{~Np}$ & 4.68 \\
\hline${ }^{238} \mathrm{~Np}$ & 0.014 \\
\hline${ }^{239} \mathrm{~Np}$ & 0.93 \\
\hline${ }^{238} \mathrm{Pu}$ & 1.37 \\
\hline${ }^{239} \mathrm{Pu}$ & 49.69 \\
\hline${ }^{240} \mathrm{Pu}$ & 24.37 \\
\hline${ }^{241} \mathrm{Pu}$ & 12.10 \\
\hline${ }^{242} \mathrm{Pu}$ & 5.23 \\
\hline${ }^{243} \mathrm{Pu}$ & $1.29 \times 10^{-3}$ \\
\hline${ }^{244} \mathrm{Pu}$ & $1.56 \times 10^{-4}$ \\
\hline
\end{tabular}

\begin{tabular}{|l|l|}
\hline Nuclide & TRU (\%) \\
\hline${ }^{241} \mathrm{Am}$ & 0.32 \\
\hline${ }^{242 m} \mathrm{Am}$ & $1.29 \times 10^{-3}$ \\
\hline${ }^{243} \mathrm{Am}$ & 0.83 \\
\hline${ }^{244} \mathrm{Am}$ & $7.43 \times 10^{-4}$ \\
\hline${ }^{242} \mathrm{Cm}$ & 0.14 \\
\hline${ }^{243} \mathrm{Cm}$ & $2.57 \times 10^{-3}$ \\
\hline${ }^{244} \mathrm{Cm}$ & 0.31 \\
\hline${ }^{245} \mathrm{Cm}$ & 0.015 \\
\hline${ }^{246} \mathrm{Cm}$ & $1.53 \times 10^{-3}$ \\
\hline${ }^{247} \mathrm{Cm}$ & $1.27 \times 10^{-5}$ \\
\hline
\end{tabular}

\subsection{TRU Isotopic Assessment}

The TRU nuclides a re evaluated considering the objective of utilizing the TRU inventory as a fuel resource while at the same time seeking to eliminate TRU i sotopes that present dangers to the environment a nd $\mathrm{c}$ hallenges for long-term HLW s torage. T o a ccomplish this, i ndividual nuclides ar e as sessed accordingly. Important pa rameters $\mathrm{s}$ uch as $\mathrm{d}$ ecay $\mathrm{h}$ eat generation, radioactivity, dos e me asurements, nuclide lif etimes, and TRU composition are all taken into consideration.

Table 3.2 list parameters, with respect to waste management, that are essential for identifying and ranking the TRU nuclides. One important parameter is radiotoxicity, which is the measure of how nocuous a radionuclide is to human health. The type and energy of rays, absorption in the or ganism, residence $t$ ime i $\mathrm{t} t$ he bod $y$, e tc. i nfluence $t$ he de gree of $r$ adiotoxicity o f a radionuclide. The measure of radiotoxicity is very useful for comparing the radiological hazard of different nuclides. R adiotoxicity of the TRU nuc lides are de termined by us ing the effective dose coe fficients, $e(T)$, provided by the International $\mathrm{C}$ ommission on $\mathrm{R}$ adiological $\mathrm{P}$ rotection (ICRP) [34] and the activity of the isotope of interest. The dose coefficients are applicable for intake by ingestion for adult humans, $e_{\text {ing }}(50)$.

Each of the parameters in Table 3.2 are us eful in determining $w$ hat af fect ea ch of the TRU nuclides $m$ ight $h$ ave $o n l$ ong-term $\mathrm{H} \mathrm{LW} m$ anagement $i$ ssues and $d$ angers pos ed $t$ ot he environment. T he half-life gives a m easure of the stability of the i sotope and an idea of the timeframe involved with isolating it from the biosphere. The isotopic power relates the amount of de cay $h$ eat that $\mathrm{w}$ ill be ge nerated and which nuclides pr esent the greatest ch allenge $\mathrm{f}$ or meeting repository thermal limits. The radiotoxicity measures how dangerous each radionuclide potentially is to the environment. Related to radiotoxicity, but not included in the calculation, is 
the ne utron e mission originating from $(\alpha, n)$ reactions and s pontaneous $\mathrm{f}$ ission, which i s particularly high for a few of the nuclides and can present additional challenges for dealing with HLW. T he provided TRU fraction is representative of the us ed fuel for a PWR, 4\% enriched LEU fuel, and 5 years decay time.

Table 3.2. TRU Isotopic Parameters Related to Waste Management.

\begin{tabular}{|c|c|c|c|c|c|c|}
\hline Nuclide & $\begin{array}{c}\text { Half-life } \\
\text { (yr) }\end{array}$ & $\begin{array}{c}\text { Iso. Power } \\
\text { (w/gm) }\end{array}$ & $\begin{array}{c}\text { Sp. Act. } \\
\text { (Ci/gm) }\end{array}$ & $\begin{array}{c}\text { Radiotoxicity } \\
\text { (Sv/gm) }\end{array}$ & $\begin{array}{c}\text { Neutron yield } \\
\text { (n/g s) }\end{array}$ & $\begin{array}{c}\text { TRU Fraction } \\
\text { (\%) }\end{array}$ \\
\hline${ }^{237} \mathrm{~Np}$ & $2.14 \times 10^{6}$ & $2.20 \times 10^{-5}$ & $7.05 \times 10^{-4}$ & 2.87 & $5.11 \times 10^{-5}$ & 4.28 \\
\hline${ }^{238} \mathrm{Pu}$ & 87.7 & 0.568 & 17.1 & $1.46 \times 10^{5}$ & $2.60 \times 10^{3}$ & 1.21 \\
${ }^{239} \mathrm{Pu}$ & $2.41 \times 10^{4}$ & $1.91 \times 10^{-3}$ & 0.062 & 574 & 0.017 & 52.26 \\
${ }^{240} \mathrm{Pu}$ & $6.54 \times 10^{3}$ & $7.10 \times 10^{-3}$ & 0.227 & $2.10 \times 10^{3}$ & $1.03 \times 10^{3}$ & 24.47 \\
${ }^{241} \mathrm{Pu}$ & 14.4 & $4.06 \times 10^{-3}$ & 103 & $1.80 \times 10^{4}$ & $9.19 \times 10^{-4}$ & 9.27 \\
${ }^{242} \mathrm{Pu}$ & $3.76 \times 10^{5}$ & $1.13 \times 10^{-4}$ & $3.95 \times 10^{-3}$ & 35.1 & $1.72 \times 10^{3}$ & 4.79 \\
${ }^{244} \mathrm{Pu}$ & $8.26 \times 10^{7}$ & $5.30 \times 10^{-7}$ & $1.83 \times 10^{-5}$ & 0.163 & $1.94 \times 10^{3}$ & $1.30 \times 10^{-4}$ \\
\hline${ }^{241} \mathrm{Am}$ & 432 & 0.115 & 3.43 & $2.54 \times 10^{4}$ & 1.36 & 2.80 \\
${ }^{242 \mathrm{~m}} \mathrm{Am}$ & 152 & $4.65 \times 10^{-3}$ & 10.5 & $7.37 \times 10^{4}$ & 159 & $1.46 \times 10^{-3}$ \\
${ }^{243} \mathrm{Am}$ & $7.38 \times 10^{3}$ & $6.42 \times 10^{-3}$ & 0.20 & $1.48 \times 10^{3}$ & 0.714 & 0.71 \\
\hline${ }^{242} \mathrm{Cm}$ & 0.446 & 122 & $3.31 \times 10^{3}$ & $1.47 \times 10^{6}$ & $1.89 \times 10^{7}$ & $5.44 \times 10^{-5}$ \\
${ }^{243} \mathrm{Cm}$ & 28.5 & 1.90 & 51.6 & $2.87 \times 10^{5}$ & 0.017 & $1.79 \times 10^{-3}$ \\
${ }^{244} \mathrm{Cm}$ & 18.1 & 2.83 & 80.9 & $3.60 \times 10^{5}$ & $1.12 \times 10^{7}$ & 0.19 \\
${ }^{245} \mathrm{Cm}$ & $8.50 \times 10^{3}$ & $5.89 \times 10^{-3}$ & 0.17 & $1.33 \times 10^{3}$ & 38.7 & 0.01 \\
${ }^{246} \mathrm{Cm}$ & $4.73 \times 10^{3}$ & 0.010 & 0.31 & $2.39 \times 10^{3}$ & $8.80 \times 10^{6}$ & $9.53 \times 10^{-4}$ \\
\hline
\end{tabular}

Although the above-mentioned parameters assist in assessing the TRU nuclides, it is difficult to perform a fair comparison because many of the parameters are interrelated. As example, ${ }^{242} \mathrm{Cm}$ has extremely high radiotoxicity and thermal heat output; therefore, one would assume it would dominate 1 ong-term H LW s torage is sues. B ut ${ }^{242} \mathrm{Cm}$ al so has a relatively s hort ha lf-life and makes up only a small fraction of the TRU inventory, and when this is taken into consideration, other radionuclides will be much more important.

In or der $\mathrm{t}$ o be tter c ompare $\mathrm{t}$ he $\mathrm{T}$ RU nuc lides a $\mathrm{m}$ ethod $\mathrm{w}$ as de veloped $\mathrm{t}$ o $\mathrm{c}$ ombine $\mathrm{c}$ ertain parameters by weighting factors and then normalize the final result. A s established previously, the two major conc erns are thermal heat sources and dose rates so a factor was determined for each case. F or the dos e rate a $\mathrm{N}$ ormalized Radiotoxicity Factor (NRF) for ea ch nuclide is calculated by:

$$
\begin{aligned}
& R F_{i}=\left[e_{\text {ing }}(50)\right]_{i} \cdot S A_{i} \cdot w_{\text {Comp }, i} \cdot w_{T_{1 / 2}, i} \\
& N R F_{i}=\frac{R F_{i}}{R F_{\max }}
\end{aligned}
$$

where $R F_{i}$ is the radiotoxicity factor for nuclide $i,\left[e_{\text {ing }}(50)\right]_{\mathrm{i}}$ is the effective dose coefficient, $S A_{i}$ is the s pecific activity, $\omega_{c o m p, i}$ is the weighting factor for composition, $\omega_{T 1 / 2, i}$ is the w eighting 
factor indicating nuc leus stability, a nd $R F_{\max }$ is the maximum radiotoxicity factor a mong the TRU isotopes. Similarly, for the thermal heat source a Normalized Heat Factor (NHF) for each nuclide is calculated by:

$$
\begin{aligned}
& H F_{i}=P_{i} \cdot w_{\text {Comp }, i} \cdot w_{T_{1 / 2}, i} \\
& N H F_{i}=\frac{H F_{i}}{H F_{\max }}
\end{aligned}
$$

where $H F_{i}$ is the heat factor for nuclide $i, P_{i}$ is the isotopic power, and $H F_{\text {max }}$ is the maximum heat factor for the evaluated TRU nuclides.

Table $3.3 \mathrm{i} \mathrm{s}$ a c ollection of the nor malized he at a nd $\mathrm{r}$ adiotoxicity factors a s de termined first without $\mathrm{w}$ eighting, $\mathrm{t}$ hen $\mathrm{w}$ ith $\mathrm{c}$ omposition $\mathrm{w}$ eighting onl $\mathrm{y}$, a nd finally with $\mathrm{c}$ ombined composition a nd half-life w eighting. A factor of 1 indicates the nu clide that most strongly affects that particular measure. As the factor approaches zero it becomes more and more benign as related to the determining parameters. The factor for isotopic pow er and radiotoxicity only takes $\mathrm{i}$ nto a ccount $\mathrm{t}$ he $\mathrm{i}$ ndividual $\mathrm{i}$ sotope $\mathrm{w}$ ithout regard $\mathrm{t}$ ot imescale. $\mathrm{T}$ he $\mathrm{c}$ omposition weighting factor takes it a step further by incorporating the quantity of the nuclide relative to the rest of T RU s tream. The $\mathrm{r}$ emaining $\mathrm{f}$ actor i s $\mathrm{w}$ eighted by ha lf-life and $\mathrm{t}$ he c omposition; therefore, taking into account not only the makeup of the TRU inventory but also how long the radionuclide needs to be isolated from the biosphere.

Table 3.3. Normalized Heat and Radiotoxicity Factors.

\begin{tabular}{|c|c|c|c|c|c|c|}
\hline \multirow{2}{*}{ Nuclide } & \multicolumn{2}{|c|}{ Normalized Heat Factor } & \multicolumn{2}{c|}{ Normalized Radiotoxicity Factor } \\
\cline { 2 - 7 } & $\begin{array}{c}\text { Isotopic } \\
\text { Power }\end{array}$ & $\begin{array}{c}\text { Comp. } \\
\text { Weighted }\end{array}$ & $\begin{array}{c}\text { Comp./ } \\
\text { Weighted }\end{array}$ & $\begin{array}{c}\text { Isotopic } \\
\text { Radiotoxicity }\end{array}$ & $\begin{array}{c}\text { Comp. } \\
\text { Weighted }\end{array}$ & $\begin{array}{c}\text { Comp./ } \mathrm{T}_{1 / 2} \\
\text { Weighted }\end{array}$ \\
\hline${ }^{237} \mathrm{~Np}$ & $1.80 \times 10^{-7}$ & $1.38 \times 10^{-4}$ & 0.084 & $1.95 \times 10^{-6}$ & $7.00 \times 10^{-5}$ & 0.036 \\
\hline${ }^{238} \mathrm{Pu}$ & $4.66 \times 10^{-3}$ & 1.00 & 0.025 & 0.099 & 1.00 & 0.021 \\
${ }^{239} \mathrm{Pu}$ & $1.57 \times 10^{-5}$ & 0.15 & 1.00 & $3.90 \times 10^{-4}$ & 0.17 & 1.00 \\
${ }^{240} \mathrm{Pu}$ & $5.82 \times 10^{-5}$ & 0.25 & 0.47 & $1.43 \times 10^{-3}$ & 0.29 & 0.46 \\
${ }^{241} \mathrm{Pu}$ & $3.33 \times 10^{-5}$ & 0.055 & $2.25 \times 10^{-4}$ & 0.012 & 0.95 & $3.32 \times 10^{-3}$ \\
${ }^{242} \mathrm{Pu}$ & $9.26 \times 10^{-7}$ & $7.91 \times 10^{-4}$ & 0.084 & $2.34 \times 10^{-5}$ & $9.58 \times 10^{-4}$ & 0.087 \\
${ }^{244} \mathrm{Pu}$ & $4.34 \times 10^{-9}$ & $1.01 \times 10^{-10}$ & $2.37 \times 10^{-6}$ & $1.11 \times 10^{-7}$ & $1.21 \times 10^{-10}$ & $2.42 \times 10^{-6}$ \\
\hline${ }^{241} \mathrm{Am}$ & $9.39 \times 10^{-4}$ & 0.47 & 0.057 & 0.017 & 0.40 & 0.042 \\
${ }^{242 \mathrm{~m}} \mathrm{Am}$ & $3.81 \times 10^{-5}$ & $9.93 \times 10^{-6}$ & $4.29 \times 10^{-7}$ & 0.050 & $6.13 \times 10^{-4}$ & $2.26 \times 10^{-5}$ \\
${ }^{243} \mathrm{Am}$ & $5.26 \times 10^{-5}$ & $6.67 \times 10^{-3}$ & 0.014 & $1.00 \times 10^{-3}$ & $5.98 \times 10^{-3}$ & 0.011 \\
\hline${ }^{242} \mathrm{Cm}$ & 1.00 & $9.70 \times 10^{-3}$ & $1.23 \times 10^{-6}$ & 1.00 & $4.56 \times 10^{-4}$ & $4.94 \times 10^{-8}$ \\
${ }^{243} \mathrm{Cm}$ & 0.016 & $4.98 \times 10^{-3}$ & $4.03 \times 10^{-5}$ & 0.19 & $2.92 \times 10^{-3}$ & $2.02 \times 10^{-5}$ \\
${ }^{244} \mathrm{Cm}$ & 0.023 & 0.80 & $4.10 \times 10^{-3}$ & 0.24 & 0.39 & $1.73 \times 10^{-3}$ \\
${ }^{245} \mathrm{Cm}$ & $4.83 \times 10^{-5}$ & $8.61 \times 10^{-5}$ & $2.08 \times 10^{-4}$ & $9.07 \times 10^{-4}$ & $7.60 \times 10^{-5}$ & $1.57 \times 10^{-4}$ \\
${ }^{246} \mathrm{Cm}$ & $8.20 \times 10^{-5}$ & $1.39 \times 10^{-5}$ & $1.87 \times 10^{-5}$ & $1.62 \times 10^{-3}$ & $1.30 \times 10^{-5}$ & $1.49 \times 10^{-5}$ \\
\hline
\end{tabular}


The normalized radiotoxicity factors are represented graphically in Figure 3.2, giving a side-byside comparison of each of the TRU nuc lides. The radiotoxicity s cale on the ve rtical axis is logarithmic, indicating that di fferences $\mathrm{c}$ an be $\mathrm{v}$ ery 1 arge and even extent to many or ders of magnitude in some cases. The radiotoxicity measure (yellow bar) shows that ${ }^{242} \mathrm{Cm},{ }^{243} \mathrm{Cm}$, and ${ }^{244} \mathrm{Cm}$ a re $\mathrm{r}$ anked the $\mathrm{m}$ ost $\mathrm{t}$ oxic, $w$ ith ${ }^{238} \mathrm{Pu}$ a nd ${ }^{242 \mathrm{~m}} \mathrm{Am}$ the hi ghest a mong the ot her T RU nuclides. A lso of note are the very small radiotoxicity factors for ${ }^{237} \mathrm{~Np}$ and ${ }^{244} \mathrm{Pu}$, which are each over 6 orders of magnitude lower than the most toxic isotope.

When $\mathrm{t}$ he $\mathrm{r}$ elative qua ntity of each nuc lide i s taken i nto $\mathrm{c}$ onsideration, i $\mathrm{m}$ ost $\mathrm{c}$ ases, $\mathrm{t}$ he radiotoxicity $\mathrm{f}$ actor ( blue ba $\mathrm{r}$ ) $\mathrm{c}$ hanges qui te $\mathrm{dr}$ astically. D ue to their s mall qua ntities, the radiotoxic factors for the $\mathrm{Cm}$ isotopes drop considerably with the exception of ${ }^{244} \mathrm{Cm}$, which is still one of the highest radiotoxicity contributors. The $\mathrm{Pu}$ isotopes, with exception of ${ }^{242} \mathrm{Pu}$ and ${ }^{244} \mathrm{Pu}$, now reach the highest levels. ${ }^{244} \mathrm{Cm}$ and ${ }^{241} \mathrm{Am}$ are also marked as major contributors with high radiotoxicity factors.

Considering the length of time that which the nuclides will remain highly radiotoxic (red bar), the factors again change, and is most noticeable by the decrease in the $\mathrm{Cm}$ factors due to their relatively short half-lives. The dominant nuclides are now ${ }^{239} \mathrm{Pu},{ }^{240} \mathrm{Pu},{ }^{242} \mathrm{Pu}$, and ${ }^{241} \mathrm{Am}$, as they will remain at high radiotoxicity levels for many years into the future.

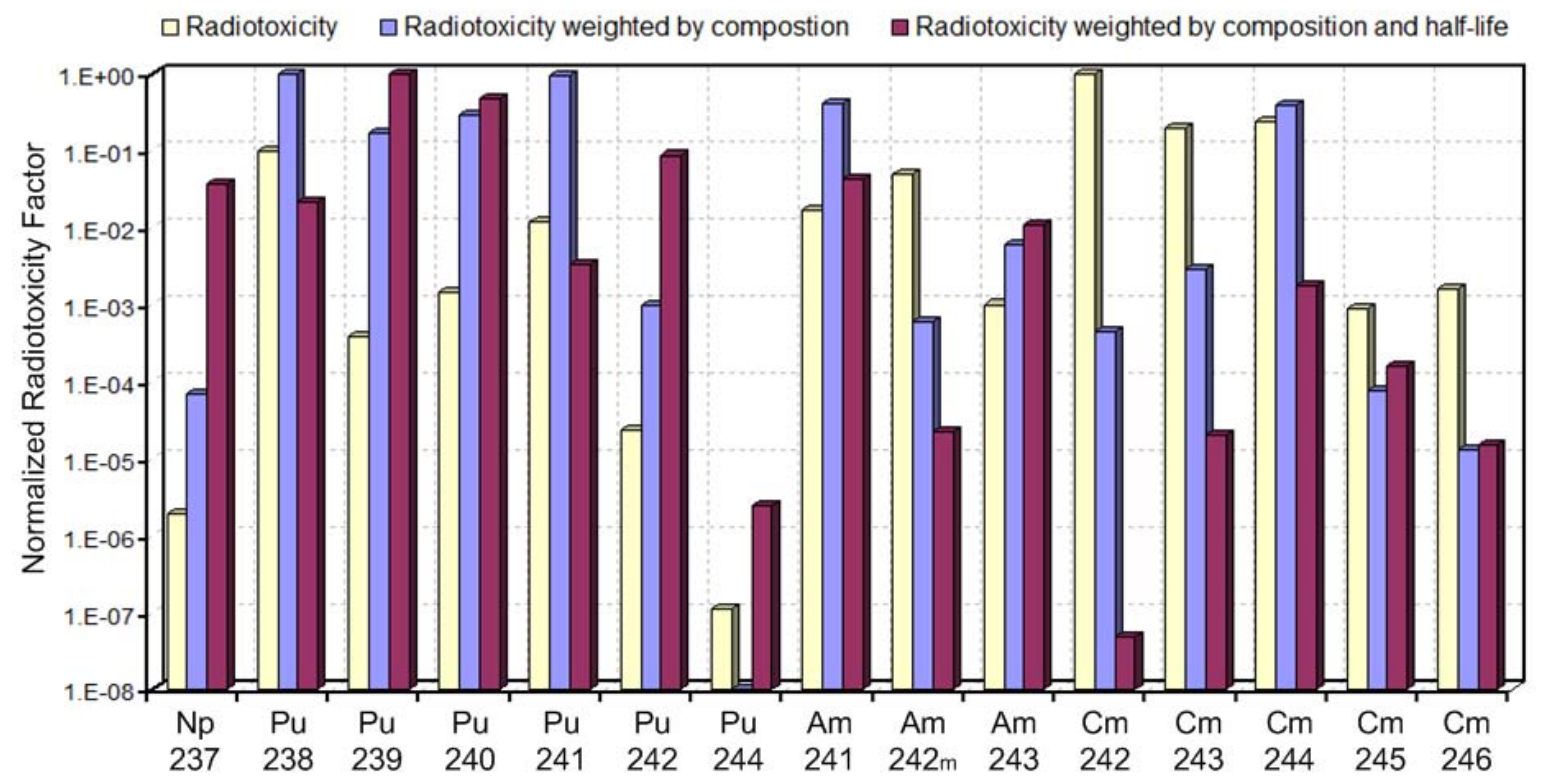

Figure 3.2. Normalized Radiotoxicity Factors.

The nor malized h eat factors a re represented graphically in Figure 3.3, g iving a side-by-side comparison of e ach o $\mathrm{f} t$ he $\mathrm{T}$ RU nuc lides. Many of $\mathrm{t}$ he $\mathrm{s}$ ame $\mathrm{t}$ rends $\mathrm{i}$ dentified $\mathrm{w}$ ith $\mathrm{t}$ he radiotoxicity factors are seen with the heat factors. The thermal heat scale on the vertical axis is logarithmic, indicating that di fferences $\mathrm{c}$ an be $\mathrm{v}$ ery 1 arge and even extent to many or ders of magnitude in s ome cases. T he he at load measure (yellow bar) shows that ${ }^{242} \mathrm{Cm},{ }^{243} \mathrm{Cm}$, and 
${ }^{244} \mathrm{Cm}$ produce the most decay heat, with ${ }^{238} \mathrm{Pu}$ and ${ }^{242 \mathrm{~m}} \mathrm{Am}$ close behind. Comparatively, ${ }^{237} \mathrm{~Np}$ and ${ }^{244} \mathrm{Pu}$ produce minimal amounts of decay heat.

Once the composition of the TRU stream is taken into account the heat factors (blue bar) for the $\mathrm{Pu}$ isotopes increase drastically. Now the largest decay heat contributors in descending order are ${ }^{238} \mathrm{Pu},{ }^{244} \mathrm{Cm},{ }^{241} \mathrm{Am},{ }^{240} \mathrm{Pu},{ }^{239} \mathrm{Pu}$, and ${ }^{241} \mathrm{Pu}$. W ith respect to decay heat, the major concern is repository the rmal limits, which deals with maximum he at levels. Therefore, the timescale on which $t$ he $\mathrm{T}$ RU i nventory produces he at is $\mathrm{n}$ ot a s impor tant a s the $\mathrm{y} \mathrm{w}$ ere in the $\mathrm{c}$ ase of radiotoxicity factors. Still the half-life weighted heat factors (red bar) are included because they offer additional insight that could prove to be useful once more details concerning the design of the repository are available. Such would be the case for natural or forced ventilation designs that would be ope rated for a specified number of years, or for pe rmanent closure da tes that w ould affect heat removal capabilities within the repository.

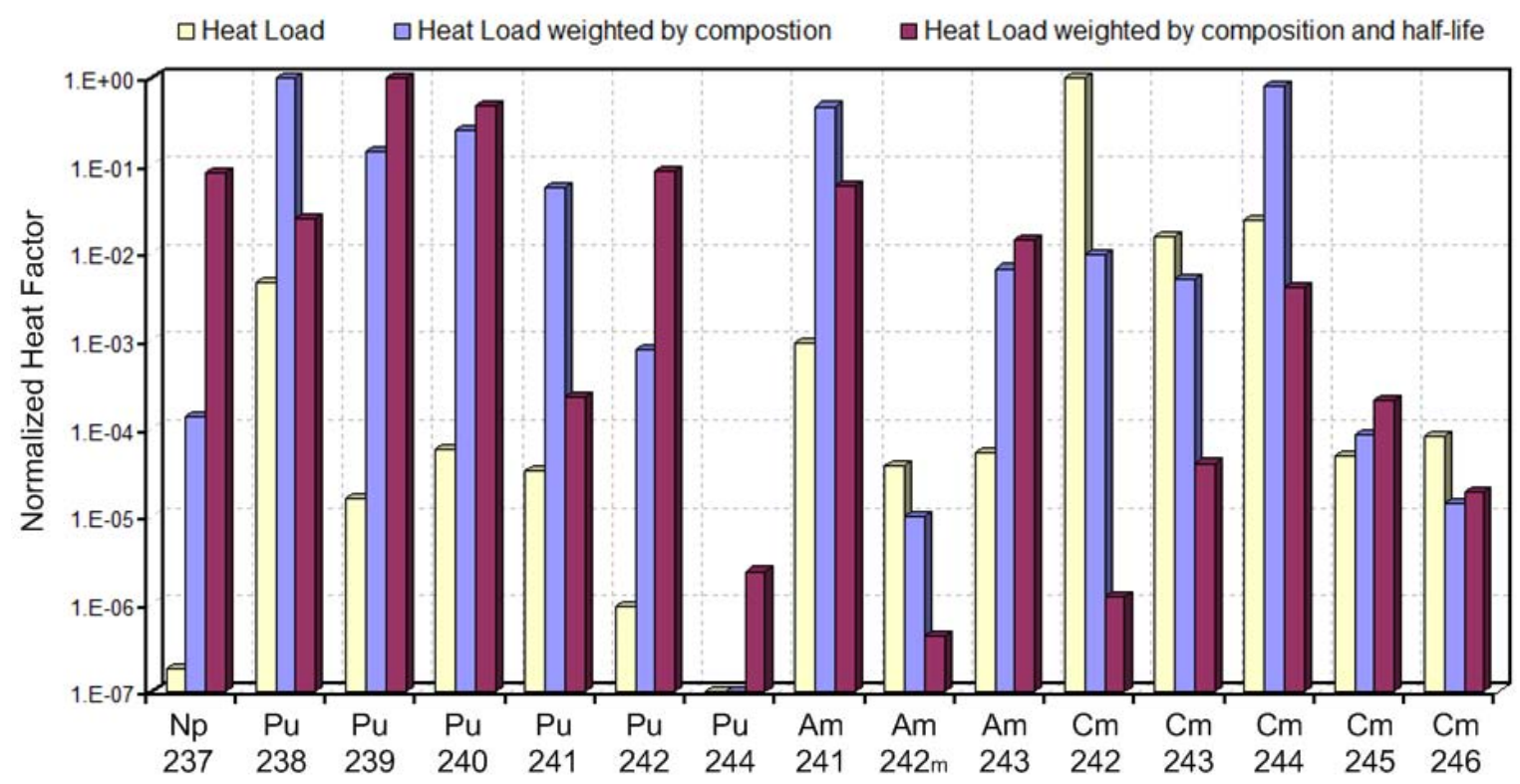

Figure 3.3. Normalized Heat Factors.

A few primary conclusions can be made from Figures 3.1, 3.2, and 3.3. First, the Pu isotopes as a $\mathrm{w}$ hole a re $\mathrm{t}$ he $\mathrm{m}$ ost significant $\mathrm{r}$ adiotoxicity a nd de cay $\mathrm{h}$ eat $\mathrm{c}$ ontributors, $\mathrm{w}$ hich $\mathrm{c}$ an be explained by the high composition percentage of $\mathrm{Pu}$ in the TRU stream. In any case the $\mathrm{Pu}$ isotopes s hould be $\mathrm{t}$ argeted $\mathrm{f}$ or de struction b y fission. $\mathrm{T}$ he $\mathrm{Cm}$ group ar e v ery s trong h eat sources and extremely radiotoxic, but their small fraction of the TRU inventory and shorter halflives rank them behind a number of the $\mathrm{Pu}$ and $\mathrm{Am}$ nuclides. Even so, $\mathrm{Cm}$ and, in particular, the longer-lived isotopes and ${ }^{244} \mathrm{Cm}$, need to be monitored closely because irradiating TRU fuels in a thermal neutron spectrum (as is the case with the VHTR component of the NES) will result in a buildup of the $\mathrm{Cm}$ inventory. In a ddition, ${ }^{242} \mathrm{Cm},{ }^{244} \mathrm{Cm}$, a nd ${ }^{246} \mathrm{Cm}$ ha ve ve ry hi gh ne utron emission rates that cause additional burdensome radiation issues separate from those included in the radiotoxicity calculation. 
A phe nomenon $t$ hat do es not $m$ anifest $i$ tself $i \mathrm{n} t$ he he at $\mathrm{f}$ actor or $\mathrm{t}$ he $\mathrm{r}$ adiotoxicity $\mathrm{f}$ actor calculations is the production of ${ }^{241} \mathrm{Am}\left(\mathrm{T}_{1 / 2}=432.7\right.$ years $)$ from the beta-decay of ${ }^{241} \mathrm{Pu}\left(\mathrm{T}_{1 / 2}=\right.$ 14.4 years). For a $\mathrm{s}$ ubstantial $\mathrm{t}$ ime $\mathrm{i}$ nto $\mathrm{t}$ he f uture $\mathrm{t}$ he radiotoxicity 1 evels a nd de cay he at generated by ${ }^{241} \mathrm{Am}$ will increase and needs to be considered when evaluating ${ }^{241} \mathrm{Am}$. Similarly, but not as crucial, ${ }^{237} \mathrm{~Np}\left(\mathrm{~T}_{1 / 2}=2.14+10^{6}\right.$ years $)$ is produced by the alpha-decay of ${ }^{241} \mathrm{Am}\left(\mathrm{T}_{1 / 2}=\right.$ 432.7 years).

\subsubsection{Neptunium}

Neptunium, na med for the planet $\mathrm{N}$ eptune, was the first s ynthetic t ransuranic e lement of the actinide series discovered (1940) [35]. $N p$ metal has a silvery appearance, is chemically reactive, and very dense at $20.25 \mathrm{~g} / \mathrm{cm}^{3}$. Nineteen $N p$ radioisotopes have been characterized ranging from ${ }^{226} \mathrm{~Np}$ to ${ }^{244} \mathrm{~Np}$. T he most stable of the isotopes is ${ }^{237} \mathrm{~Np}$ with a half-life of $2.14 \mathrm{~m}$ illion years, followed by ${ }^{236} \mathrm{~Np}$ with a half-life of 154,000 years, and then ${ }^{235} \mathrm{~Np}$ with a half-life of 396.1 days. The remaining isotopes are very short-lived with half-lives less than 4.5 days with a majority of them being less than 50 minutes.

As indi cated by the tr ansmutation-decay s cheme in F igure $3.1,{ }^{237} \mathrm{~Np}$ a nd ${ }^{239} \mathrm{~Np}$ are m ainly produced by the beta-decay of ${ }^{237} \mathrm{U}$ and ${ }^{239} \mathrm{U}$, and subsequently ${ }^{238} \mathrm{~Np}$ and ${ }^{240} \mathrm{~Np}$ are produced by neutron capture in ${ }^{237} \mathrm{~Np}$ and ${ }^{239} \mathrm{~Np}$. Even so, ${ }^{237} \mathrm{~Np}$ is the only neptunium isotope stable enough to a ccumulate $t o$ a ny m eaningful a mount $w$ ithin $t$ he $c$ ore or s hortly a fter $r$ emoval. A lso of interest is the a lpha-decay of ${ }^{241} \mathrm{Am}$ to ${ }^{237} \mathrm{~Np}$, which c an a ffect long-term w aste ma nagement issues as it builds on the ${ }^{237} \mathrm{~Np}$ inventory. Compared to the other TRU isotopes, ${ }^{237} \mathrm{~Np}$ has one of the longest half-lives, indicating it will be around after many of the other isotopes have decayed away. Both the radiotoxicity and decay heat of ${ }^{237} \mathrm{~Np}$ is much less than that of the other TRU nuclides.

\section{Neptunium-237}

The incore transmutation of ${ }^{237} \mathrm{~Np}$ will g reatly depend on $\mathrm{t}$ he ne utron e nergy s pectrum. In a thermal ne utron s pectrum s ystem, like the V HTR, the pr edominant $r$ eaction will be ne utron capture and ${ }^{237} \mathrm{~Np}$ will mainly contribute to the buildup of higher actinides. In the HEST, or fast neutron spectrum system, there is a much higher probability for fission and the contribution to production of higher actinides will be reduced.

Figure $3.5 \mathrm{~s}$ hows the $\mathrm{r}$ adiative $\mathrm{c}$ apture a nd fission $\mathrm{c}$ ross-sections a long $\mathrm{w}$ ith the capt ure-tofission ratio $(\alpha)$ f or ${ }^{237} \mathrm{~Np}$. In T RU-fueled $\mathrm{r}$ eactors the re is mini mal pr oduction of ${ }^{237} \mathrm{~Np}$. Therefore, in any neutron spectrum ${ }^{237} \mathrm{~Np}$ will be depleted under irradiation conditions, and can be represented by the following relation:

$$
\frac{d N_{N p 237}}{d t}=-\left[N \cdot \sigma_{a}\right]_{N p 237} \phi
$$

where $N$ is the nuclide concentration, $\sigma_{a}$ is the absorption cross section $\left(\sigma_{c}+\sigma_{f}\right)$ and $\Phi$ is the neutron flux. 
The difference between thermal neutron and fast neutron spectrums is the mode of transmutation, whether it is by n eutron c apture or by fission. As indicated by Figure 3.4, a thermal n eutron spectrum system will transmute predominately by capture, while a fast neutron spectrum will increase the amount of fissions in relation to capture. The capture-to-fission ratio does not drop below uni ty unt il a bout $5.5 \times 10^{5} \mathrm{eV}$, w hich m eans in or der to p referentially d estroy ${ }^{237} \mathrm{~Np}$ by fission, a very high neutron energy spectrum would be needed.

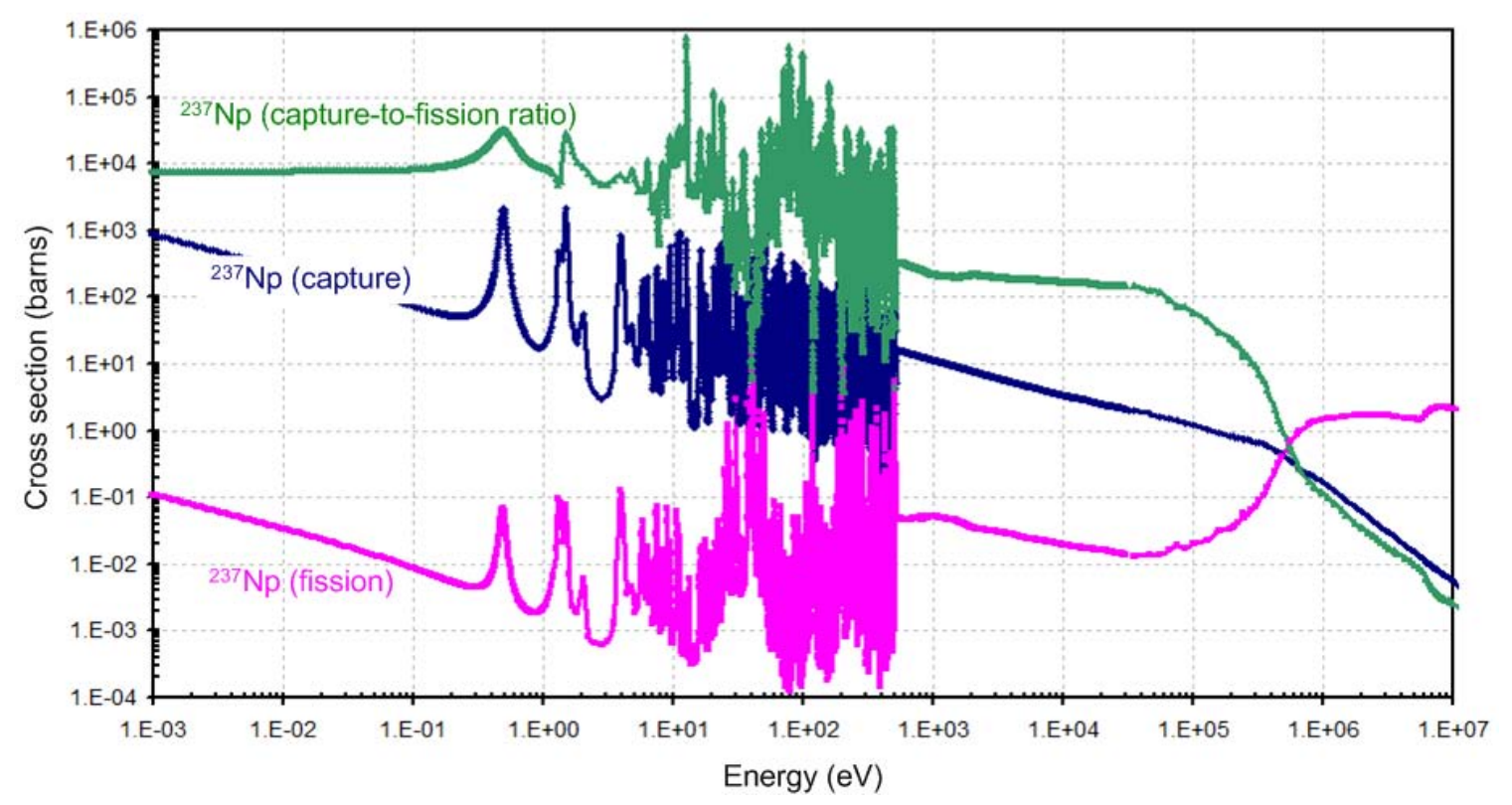

Figure 3.4. Cross-sections and Capture-to-fission Ratio for ${ }^{237} \mathrm{~Np}$.

\subsubsection{Plutonium}

Plutonium, na med $\mathrm{f}$ or $\mathrm{t}$ he $\mathrm{pl}$ anet $\mathrm{P}$ luto, $\mathrm{w}$ as the s econd $\mathrm{s}$ ynthetic $\mathrm{t}$ ransuranic element of the actinide series di scovered (1940) [35]. Pu metal has a s ilvery-white appearance that tarnishes when exposed to air, forming a dull coating when oxidized. It has a density of $19.816 \mathrm{~g} / \mathrm{cm}^{3}$. Twenty $\mathrm{Pu}$ radioisotopes have been characterized ranging from ${ }^{228} \mathrm{Pu}$ to ${ }^{247} \mathrm{Pu}$. The most stable of the i sotopes is ${ }^{244} \mathrm{Pu}$ with a half-life of $80 \mathrm{~m}$ illion years; long enough to be found in trace quantities in na ture. $\mathrm{M}$ ost i mportant of the i sotopes is ${ }^{239} \mathrm{Pu}$ be cause today it e xists in much higher qua ntities $\mathrm{t}$ han the ot her i sotopes a nd i $\mathrm{t}$ i s a $\mathrm{k}$ ey c omponent i $\mathrm{n}$ nuc lear weapon development a nd nuc lear e nergy. $\quad P u$ is the $m$ ost pr ominent of the T RU e lements, $m$ ainly because of its link to atomic bombs, but also because it has a number of other applications, such as radioisotope thermoelectric generators, radioisotope he ater units, and as a pow er source for artificial heart pacemakers.

There ar e five $\mathrm{Pu}$ isotopes $\left({ }^{238} \mathrm{Pu}-{ }^{242} \mathrm{Pu}\right)$ t hat pos e environmental $\mathrm{d}$ angers a nd a re o $\mathrm{m}$ ain concern for 1 ong-term HLW w aste $\mathrm{m}$ anagement a nd i ncore be havior. $\mathrm{W}$ hen $\mathrm{U} \mathrm{O}_{2}$ fuel is irradiated in PWRs the resulting TRU composition at the end of irradiation is mostly composed of $\mathrm{Pu}(\sim 90 \%)$. D ue to the large qua ntities of $\mathrm{Pu}$ relative to the ot her TRU nuc lides, the $\mathrm{Pu}$ isotopes a re e xceedingly i mportant for $\mathrm{r}$ eactor $\mathrm{c}$ ore pe rformance a nd a fterward for 1 ong-term 
waste $m$ anagement. The N ES i ncorporates the V HTR f or the first $r$ ecycle of the T RU f uel produced by the LWR. Being a thermal neutron spectrum reactor the VHTR relies on the fissile components of the fuel to a chieve a nd $\mathrm{m}$ aintain $\mathrm{c}$ riticality, ${ }^{239} \mathrm{Pu}$ a nd ${ }^{241} \mathrm{Pu}$ fill that $\mathrm{r}$ ole. In particular, ${ }^{239} \mathrm{Pu}$, alone accounts for about $40-50 \%$ of the total composition of the TRU nuclides. A good indicator for the achievable burnup level of the VHTR core is the combined ${ }^{239} \mathrm{Pu}$ and ${ }^{241} \mathrm{Pu}$ composition. With this in mind, the relatively short half-life of ${ }^{241} \mathrm{Pu}$ (14.4 years) will have a not iceable affect on the $\mathrm{Pu}$ composition during the stage when the TRU is out of core. The transit t ime c an be four or more years a s cooling is required be fore entering the reprocessing stage and time needed to fabricate the fuel. During this time period significant amounts of ${ }^{241} \mathrm{Pu}$ will de cay b y beta pa rticle e mission to ${ }^{241} \mathrm{Am}$, w hich translates t o a decrease in the fissile inventory and a $\mathrm{n}$ i ncrease i $\mathrm{n}$ the f ertile i nventory; ha ving a considerable e ffect on reactor performance.

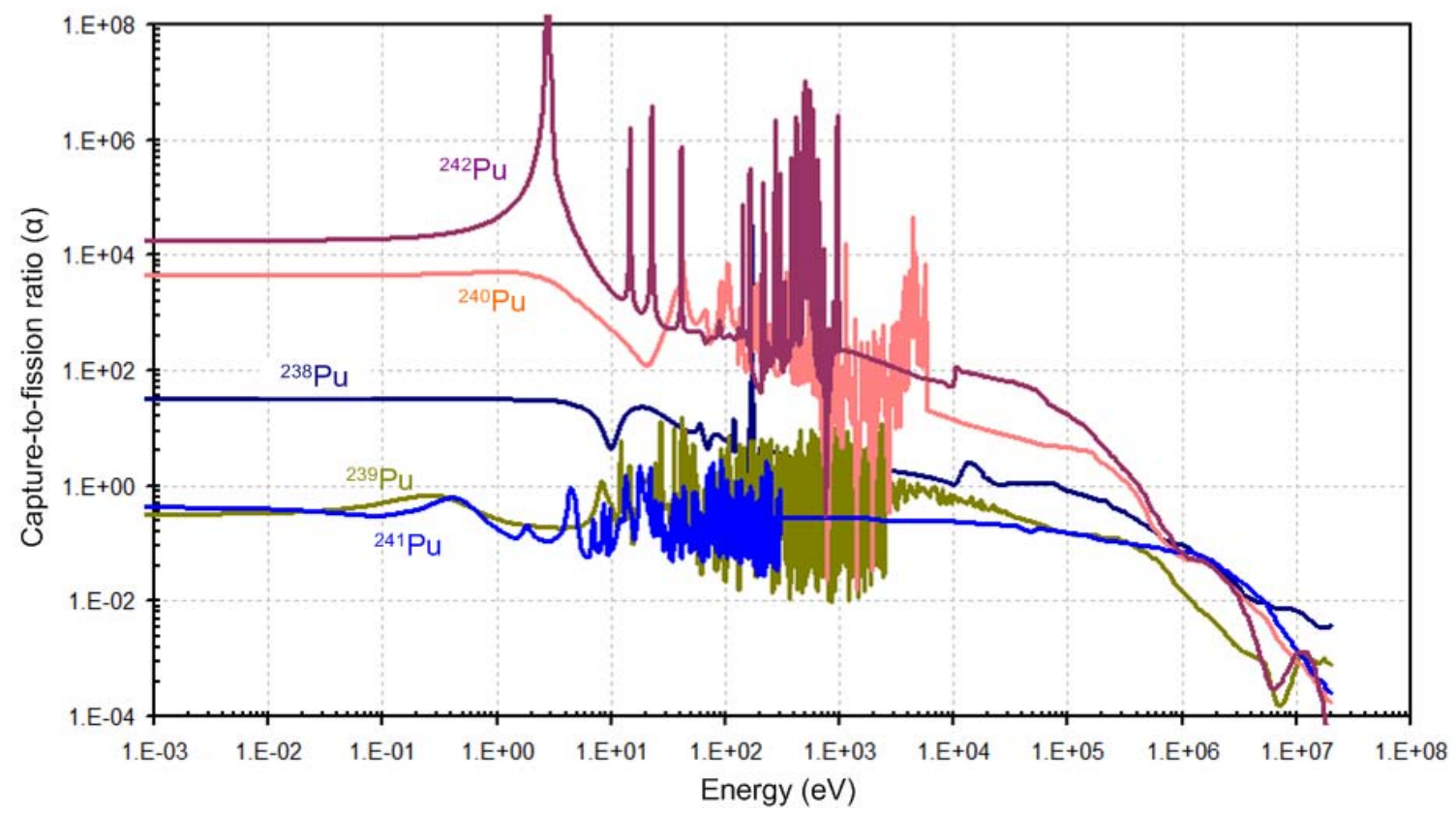

Figure 3.5. Capture-to-fission Ratio for Pu Isotopes.

Figure 3.5 s hows the capture-to-fission ratio for the $P u$ isotopes. As indicated the two isotopes with hi gher fission than c apture cross-sections throughout the entire s pectrum a re ${ }^{239} \mathrm{Pu}$ a nd ${ }^{241} \mathrm{Pu}$. Whereas, ${ }^{238} \mathrm{Pu},{ }^{240} \mathrm{Pu}$, and ${ }^{242} \mathrm{Pu}$ all have much greater probability of radiative capture in the thermal and resonance energy regions. C apture-to-fission $r$ atios greater than uni ty a re of high i mportance $b$ ecause of the bui ldup of hi gher a ctinides that a ccompany them. $T$ his is especially true for $\mathrm{Pu}$ as it dominates the TRU vector and can lead to the buildup of problematic $\mathrm{Am}$ and $\mathrm{Cm}$ isotopes.

Estimations for the isotopic production and destruction/transmutation rates for the $P u$ nuclides under i rradiation in thermal ne utron and fast ne utron s pectrums $\mathrm{c}$ an be made b y referring to isotopic concentrations, the transmutation and decay scheme in Figure 3.2, the capture-to-fission 
ratios in Figure 3.5, and the fission and radiative capture cross sections provided in the next five figures.

\section{Plutonium-238}

In the TRU-fueled VHTR, at beginning of cycle, ${ }^{237} \mathrm{~Np}$ exist at about five times the amount of ${ }^{238} \mathrm{Pu}$. As evident by the very high capture-to-fission ratio for ${ }^{237} \mathrm{~Np}$ in the thermal energy range, it is expected that ne arly all of the n eutron interactions that ta ke place in ${ }^{237} \mathrm{~Np} \mathrm{w}$ ill produce ${ }^{238} \mathrm{~Np}$, which quickly de cays to ${ }^{238} \mathrm{Pu}$. S ince the half-life of ${ }^{238} \mathrm{~Np}$ is so short the assumption is made that all neutron captures in ${ }^{237} \mathrm{~Np}$ immediately produce ${ }^{238} \mathrm{Pu}$. The destruction of ${ }^{238} \mathrm{Pu}$ is dependent on $\mathrm{i}$ ts a bsorption c ross-section $\left(\sigma_{c}+\sigma_{f}\right)$, its concentration, i rradiation time, a nd the neutron flux. Thus, the overall composition change of ${ }^{238} \mathrm{Pu}$ can be represented by:

$$
\frac{d N_{P u 238}}{d t}=[N \cdot \lambda]_{N p 238}-\left[N \cdot \sigma_{a}\right]_{P u 238} \phi
$$

where $N$ is t he nuc lide c oncentration, $\sigma_{y}$ is t he $\mathrm{r}$ adiative c apture cross s ection, $\sigma_{a}$ is the absorption c ross s ection $\left(\sigma_{c}+\sigma_{f}\right), \lambda$ is the de cay constant, and $\Phi$ is the ne utron flux. A s indicated, the de cay of ${ }^{238} \mathrm{~Np}$ can be replaced with the reaction rate for radiative capt ure in ${ }^{237} \mathrm{~Np}$ to give:

$$
\frac{d N_{P u 238}}{d t}=\left(\left[N \cdot \sigma_{\gamma}\right]_{N p 237}-\left[N \cdot \sigma_{t}\right]_{P u 238}\right) \phi .
$$

Shown in Figure 3.6, the capture cross-sections for ${ }^{238} \mathrm{Pu}$ below $0.3 \mathrm{eV}$ are higher, but then the capture cross-sections for ${ }^{237} \mathrm{~Np}$ dom inate for the remainder of the thermal energy region and throughout the resonance e nergy r egion. T he a bove obs ervations lead to the a ssumption that ${ }^{238} \mathrm{Pu}$ w ill bui ldup as the V HTR op erates. U nder c ontinual i rradiation a time will e ventually come where the production of ${ }^{238} \mathrm{Pu}$ will level off and begin to decrease as result of ${ }^{237} \mathrm{~Np}$ being completely depleted, but this is not expected to happen within the lifetime of the core. The same trend is expected for a fast neutron spectrum system such as the HEST, but being that the ratio of ${ }^{237} \mathrm{~Np}$ to ${ }^{238} \mathrm{Pu}$ ha s de creased and the abs orption cross-sections for ${ }^{238} \mathrm{Pu}$ are greater than the capture cross-sections for ${ }^{237} \mathrm{~Np}$ for neutron energies greater than $1.0 \times 10^{5} \mathrm{eV}$, the concentration of ${ }^{238} \mathrm{Pu}$ will increase at a slower rate and reach a turnover point quicker. 


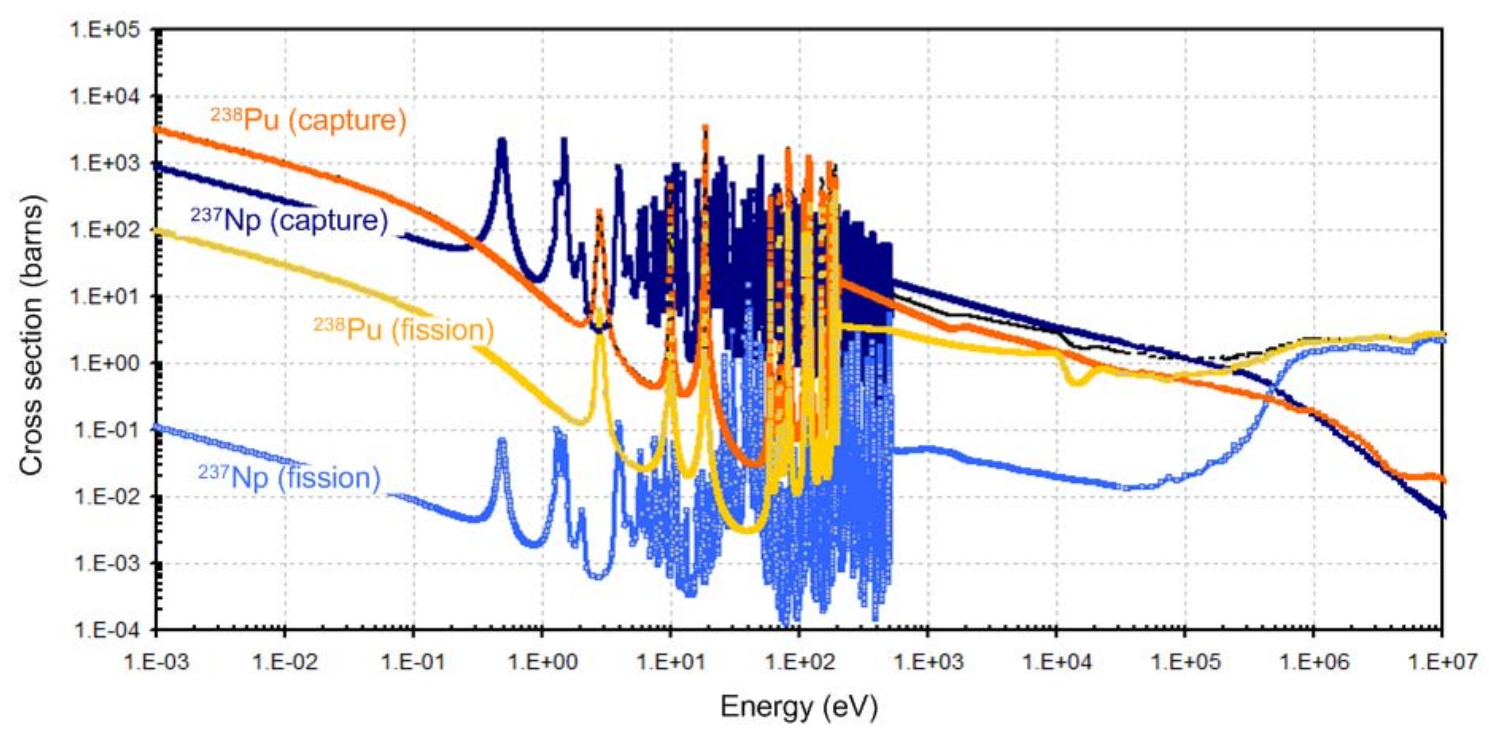

Figure 3.6. Capture and Fission Cross-sections for ${ }^{237} \mathrm{~Np}$ and ${ }^{238} \mathrm{Pu}$.

As shown in Figure 3.5, ${ }^{238} \mathrm{Pu}$ has a relatively low capture-to-fission ratio throughout the energy spectrum. Therefore, neutron capture will dominate below the threshold energy of $3.0 \times 10^{5} \mathrm{eV}$, but the probability for fission to oc cur is much greater for ${ }^{238} \mathrm{Pu}$ than for ${ }^{240} \mathrm{Pu}$ and ${ }^{242} \mathrm{Pu}$. T o effectively destroy ${ }^{238} \mathrm{Pu}$ by fission a fast spectrum system would be necessary.

\section{Plutonium-239}

As discussed earlier, ${ }^{239} \mathrm{Pu}$ is a fissile isotope and comprises the largest percentage of the TRU inventory. Considering the TRU under irradiation, the production of ${ }^{239} \mathrm{Pu}$ comes almost entirely from neutron capture in ${ }^{238} \mathrm{Pu}$, which is minimal considering ${ }^{238} \mathrm{Pu}$ exist in such a small amount compared to ${ }^{239} \mathrm{Pu}$. The destruction of ${ }^{239} \mathrm{Pu}$ is from the combination of capture and fission. The time evolution of ${ }^{239} \mathrm{Pu}$ under irradiation is represented by:

$$
\frac{d N_{P u 239}}{d t}=\left(\left[N \cdot \sigma_{\gamma}\right]_{P u 238}-\left[N \cdot \sigma_{a}\right]_{P u 239}\right) \phi .
$$

As s hown in F igure 3.7, the c apture-cross se ctions for ${ }^{238} \mathrm{Pu}$ in the thermal e nergy region a re much 1 ower $t$ han $t$ he combined $f$ ission a nd capture cross-sections $f$ or ${ }^{239} \mathrm{Pu}$, especially considering the large resonance pe ak in ${ }^{239} \mathrm{Pu}$ at $0.32 \mathrm{eV}$. A dditionally, the c ross-sections for ${ }^{239} \mathrm{Pu}$ in the resonance region are larger. This indicates that ${ }^{239} \mathrm{Pu}$ will be depleted at a rapid rate in the VHTR core. Likewise, in a fast neutron spectrum system ${ }^{239} \mathrm{Pu}$ would be fissioned and can reach very high fission efficiencies above $4.5 \times 10^{5} \mathrm{eV}$, as indicated by Figure 3.5. 


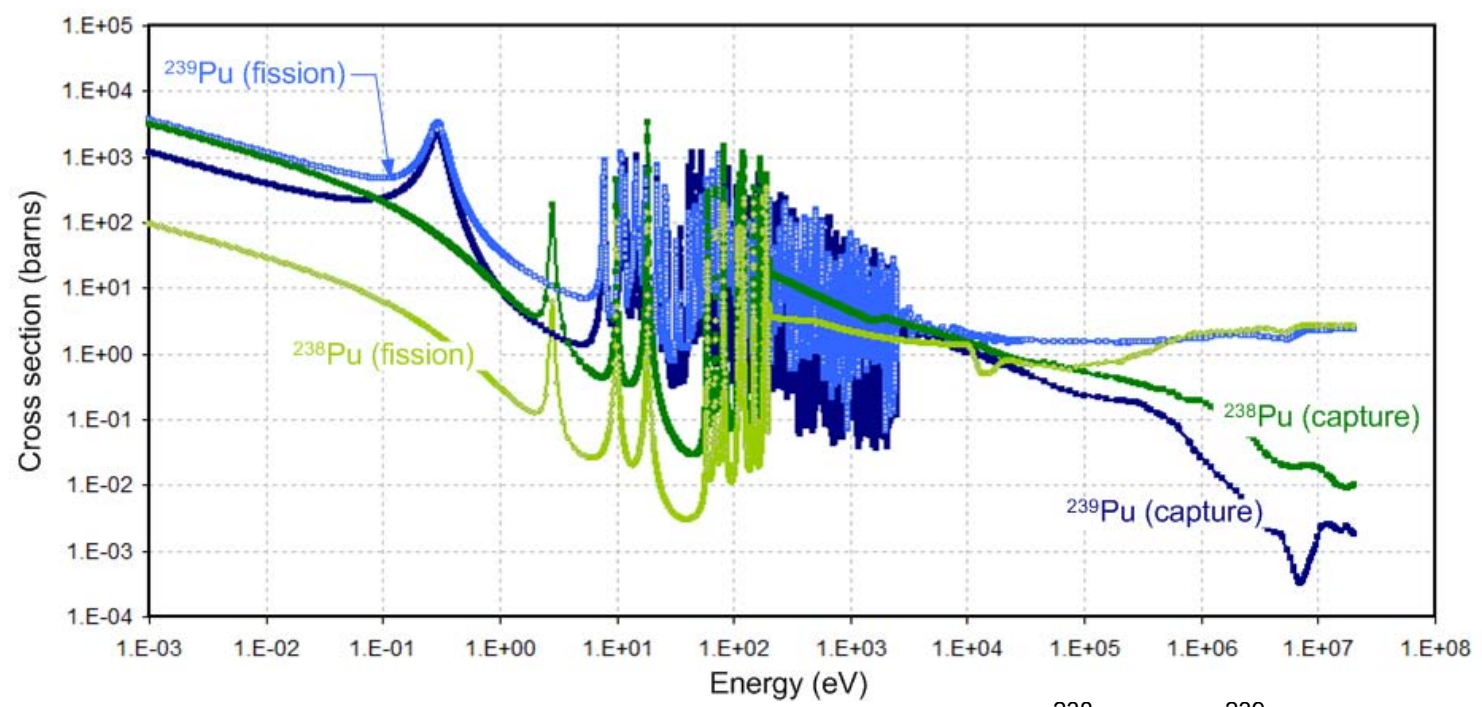

Figure 3.7. Capture and Fission Cross-sections for ${ }^{238} \mathrm{Pu}$ and ${ }^{239} \mathrm{Pu}$.

\section{Plutonium-240}

Upon removal from a typical PWR the isotopic composition of ${ }^{240} \mathrm{Pu}$ will be the second greatest at about $25 \%$ of the TRU inventory. The production of ${ }^{240} \mathrm{Pu}$ comes from neutron capture by ${ }^{239} \mathrm{Pu}$. T he absorption of a neutron by ${ }^{240} \mathrm{Pu}$ is the mechanism by which it is destroyed by the transmutation process. The concentration of ${ }^{240} \mathrm{Pu}$ at a nytime in the core is signified by the following relation:

$$
\frac{d N_{P u 240}}{d t}=\left(\left[N \cdot \sigma_{\gamma}\right]_{P u 239}-\left[N \cdot \sigma_{a}\right]_{P u 240}\right) \phi .
$$

As the T RU fuel is ir radiated in the V HTR, the ${ }^{240} \mathrm{Pu}$ qua ntity w ill s lightly inc rease a the beginning of the cycle, eventually level off, and then start to decrease, and finally end the cycle slightly depleted from its original state. Of course this is just an identified trend and variations are possible. The reasoning behind the described behavior of ${ }^{240} \mathrm{Pu}$ under irradiation in a thermal neutron spectrum system can be explained by the equation above and Figure 3.8, which plots the capture a nd fission c ross-sections for ${ }^{239} \mathrm{Pu}$ and ${ }^{240} \mathrm{Pu}$ across a b road energy s pectrum. T he capture cross-sections for ${ }^{239} \mathrm{Pu}$ are close to the same as the capture cross-section for ${ }^{240} \mathrm{Pu}$ in the thermal energy region, with the exception being the very large resonance in ${ }^{240} \mathrm{Pu}$ at $1.0 \mathrm{eV}$. The cross-sections in the $\mathrm{r}$ esonance r egion are comparable for both i sotopes. T aking all this into consideration and also accounting for the greater amount of ${ }^{239} \mathrm{Pu}$ present, the production rate of ${ }^{240} \mathrm{Pu}$ will outpace its transmutation rate, thus a slow increase in ${ }^{240} \mathrm{Pu}$. Not forgetting though, that fission is the predominant event in ${ }^{239} \mathrm{Pu}$ and when fission and capture are accounted for, ${ }^{239} \mathrm{Pu}$ is be ing de pleted at a $\mathrm{m}$ uch faster $\mathrm{r}$ ate than ${ }^{240} \mathrm{Pu}$ is be ing produced and e ventually the production/ destruction $r$ ate will e ven out and then turnover. D epending of the bu rnup of the VHTR core, at the end of cycle ${ }^{240} \mathrm{Pu}$ will likely be depleted from its original composition, but its destruction will contribute to the buildup of higher actinides, through radiative capture. 


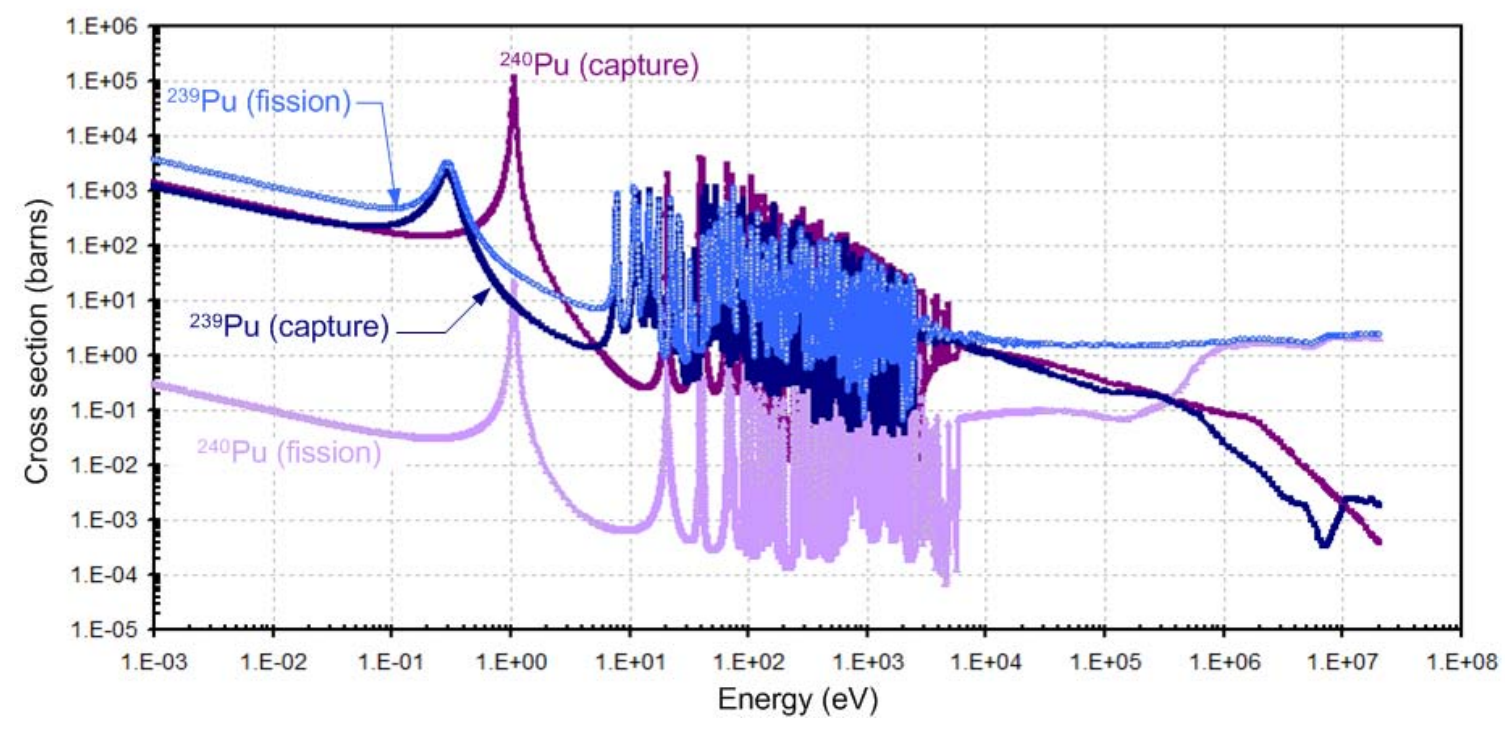

Figure 3.8. Capture and Fission Cross-sections for ${ }^{239} \mathrm{Pu}$ and ${ }^{240} \mathrm{Pu}$.

In the HEST the ${ }^{239} \mathrm{Pu}$ to ${ }^{240} \mathrm{Pu}$ ratio will be reduced significantly and the capture cross-sections for ${ }^{239} \mathrm{Pu}$ w ill be 1 ower $\mathrm{t}$ han $\mathrm{t}$ he a bsorption c ross-section values $\mathrm{f}$ or ${ }^{240} \mathrm{Pu}, \mathrm{s}$ o ${ }^{240} \mathrm{Pu} \mathrm{w}$ ill be depleted throughout the irradiation time in the HEST.

As s hown i n F igure 3. 5, ${ }^{240} \mathrm{Pu}$ has a ve ry 1 arge capt ure-to-fission ratio calculated to be approximately $4,500 \mathrm{i} \mathrm{n}$ the $\mathrm{t}$ hermal e nergy region. $\mathrm{F}$ or a thermal ne utron s pectrum s ystem operating on T RU fuel, such a s the V HTR, this m eans ${ }^{240} \mathrm{Pu}$ is $\mathrm{r}$ emoving ne utrons from the system and a cting as a neutron poi son. A s this happens the ${ }^{240} \mathrm{Pu}$ is transmuted to ${ }^{241} \mathrm{Pu}$, and ${ }^{241} \mathrm{Pu}$ is fissile. The end affect is that ${ }^{240} \mathrm{Pu}$ serves as a burnable poison in the VHTR and allows for longer life cores while minimizing reactivity swings. O ther TRU i sotopes a ct a s burnable poisons $\left({ }^{237} \mathrm{~Np}\right.$ and $\left.{ }^{241} \mathrm{Am}\right)$, but the higher concentration of ${ }^{240} \mathrm{Pu}$ makes it more effective in this sense.

In or der $\mathrm{t} \mathrm{o}$ efficiently $\mathrm{d}$ estroy ${ }^{240} \mathrm{Pu} \mathrm{b}$ y fission, a fast ne utron $\mathrm{s}$ pectrum s ystem i $\mathrm{s}$ equired. Neutron energies of $4.5 \times 10^{5} \mathrm{eV}$ and greater are needed for fission reactions to outweigh capture. In a high-energy system, such as the HEST, elevated ${ }^{240} \mathrm{Pu}$ incineration rates are achievable.

\section{Plutonium-241}

The ${ }^{241} \mathrm{Pu}$ composition can be expected to increase with VHTR core lifetime as it is produced at a $g$ reater $r$ ate than it is destroyed, which is $m$ ainly attributed $t o$ ne utron $c$ apture in the $m$ ore abundant ${ }^{240} \mathrm{Pu}$. The rate of change in ${ }^{241} \mathrm{Pu}$ is described by:

$$
\frac{d N_{P u 241}}{d t}=\left[N \cdot \sigma_{\gamma}\right]_{P u 240}-\left([N \cdot \lambda]_{P u 241}+\left[N \cdot \sigma_{a}\right]_{P u 241}\right) \phi .
$$

As displayed in Figure 3.9 the neutron capture in ${ }^{240} \mathrm{Pu}$ at thermal energies is comparable to the transmutation of ${ }^{241} \mathrm{Pu}\left(\sigma_{c}+\sigma_{f}\right)$, but that does not include the very large resonance peak at $1.0 \mathrm{eV}$ 
for ${ }^{240} \mathrm{Pu}$. O nce the r esonance $\mathrm{p}$ eak i s i ncluded, it pus hes the production $\mathrm{rate}$ of ${ }^{241} \mathrm{Pu}$ to be greater tha $\mathrm{n}$ its tr ansmutation rate. $\mathrm{T}$ his a long $\mathrm{w}$ ith the ${ }^{240} \mathrm{Pu} \mathrm{c}$ oncentration $\mathrm{c}$ ontinually increasing under irradiation translates into a buildup in the ${ }^{241} \mathrm{Pu}$ inventory.

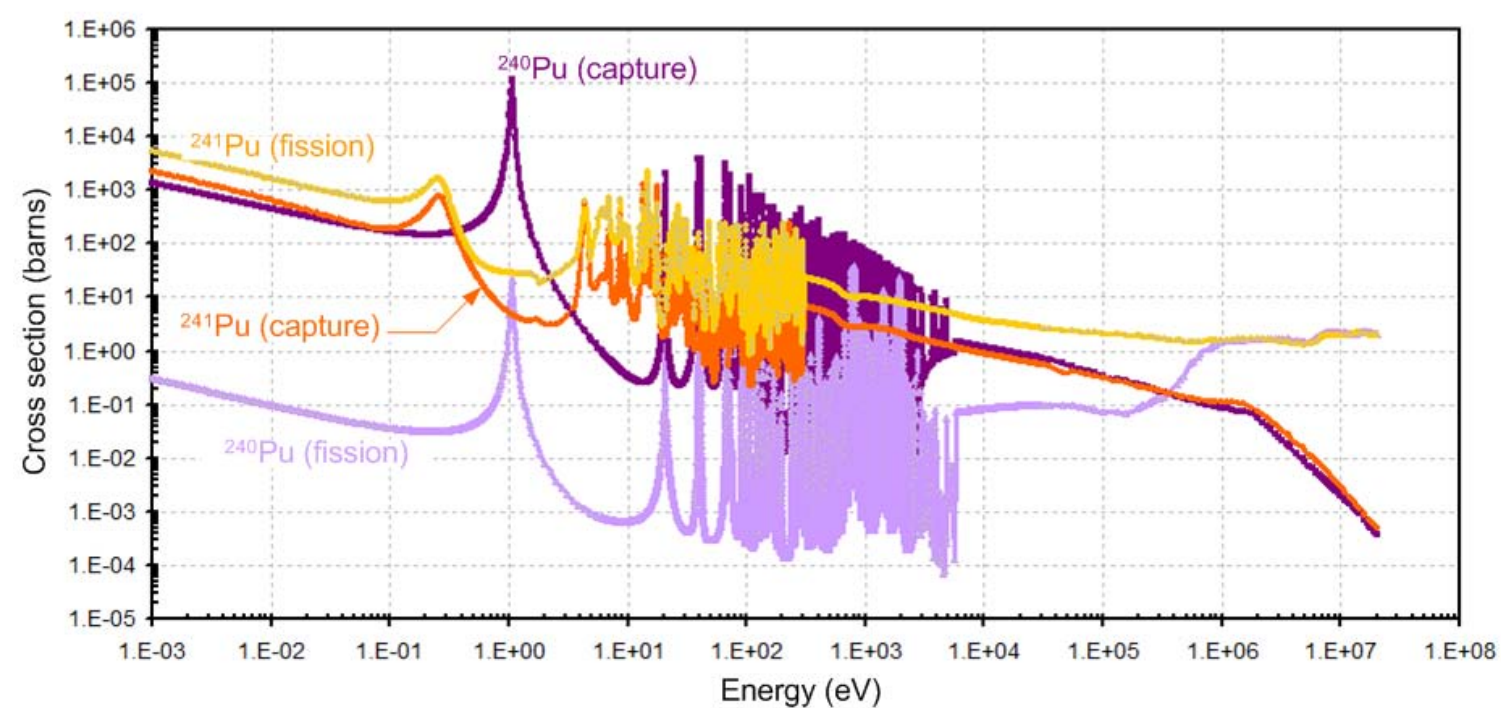

Figure 3.9. Capture and Fission Cross-sections for ${ }^{240} \mathrm{Pu}$ and ${ }^{241} \mathrm{Pu}$.

As de tailed in F igure 3.2, ${ }^{241} \mathrm{Pu}$ has a r elatively s hort ha lf-life of $14.4 \mathrm{y}$ ears a nd de cays b y emitting a be ta particle to generate ${ }^{241} \mathrm{Am}$, thus providing a pathway to the production of the higher actinides $\mathrm{Am}$ and $\mathrm{Cm}$. The destruction rate of ${ }^{241} \mathrm{Pu}$ by decay is minimal in comparison to neutron absorption.

In a fast ne utron s pectrum ${ }^{241} \mathrm{Pu}$ will e xperience an even greater di vide in the cr oss-section values f or $\mathrm{c}$ apture a nd fission t hat c ontinues $\mathrm{t}$ o gr ow w ith i ncreased neutron e nergy. $\mathrm{T}$ he production $\mathrm{r}$ ate from ${ }^{240} \mathrm{Pu}$ w ill de crease, but as 1 ong as ${ }^{240} \mathrm{Pu} \mathrm{m}$ akes up $\mathrm{m}$ ore of $\mathrm{t}$ he $\mathrm{f}$ uel composition than ${ }^{241} \mathrm{Pu}$, the inventory of ${ }^{241} \mathrm{Pu}$ can be expected to also increase.

\section{Plutonium-242}

Under irradiation, ${ }^{242} \mathrm{Pu}$ will be produced by neutron capture in ${ }^{241} \mathrm{Pu}$ and transmuted via capture and fission events, represented by:

$$
\frac{d N_{P u 242}}{d t}=\left(\left[N \cdot \sigma_{\gamma}\right]_{P u 241}-\left[N \cdot \sigma_{a}\right]_{P u 242}\right) \phi .
$$

Taking a look at Figure 3.10 and the capture cross-sections for ${ }^{241} \mathrm{Pu}$ c ompared to the capture cross-sections $\mathrm{f}$ or ${ }^{242} \mathrm{Pu}$, it is $\mathrm{e}$ asy to conclude tha $\mathrm{t}$ the ${ }^{241} \mathrm{Pu}$ pr oduction out paces $\mathrm{i}$ ts transmutation rate. As determined previously, ${ }^{241} \mathrm{Pu}$ is also generated throughout the lifetime of the core. Following the same trend ${ }^{242} \mathrm{Pu}$ is also continually generated. This is true for thermal neutron and fast ne utron s pectrum s ystems, c onsidering that ${ }^{241} \mathrm{Pu}$ is at comparable or greater quantities than ${ }^{242} \mathrm{Pu}$, but the fast system's rate of production will be considerably lower, and the 
transmutation process will favor fission and limit higher actinide production. Prolonged periods of irradiation in the HEST will eventually deplete the ${ }^{242} \mathrm{Pu}$ inventory.

The $t$ ransmutation of ${ }^{242} \mathrm{Pu} b$ y ne utron $\mathrm{c}$ apture $\mathrm{w}$ ill g enerate ${ }^{243} \mathrm{Pu}$. The $\mathrm{i}$ sotope ${ }^{243} \mathrm{Pu}$ is extremely uns table with a half-life of 4.96 hours, and it promptly beta-decays to ${ }^{243} \mathrm{Am}$. In this sense ${ }^{242} \mathrm{Pu}$ is very similar to ${ }^{241} \mathrm{Pu}$, because it provides a pathway for higher actinide production.

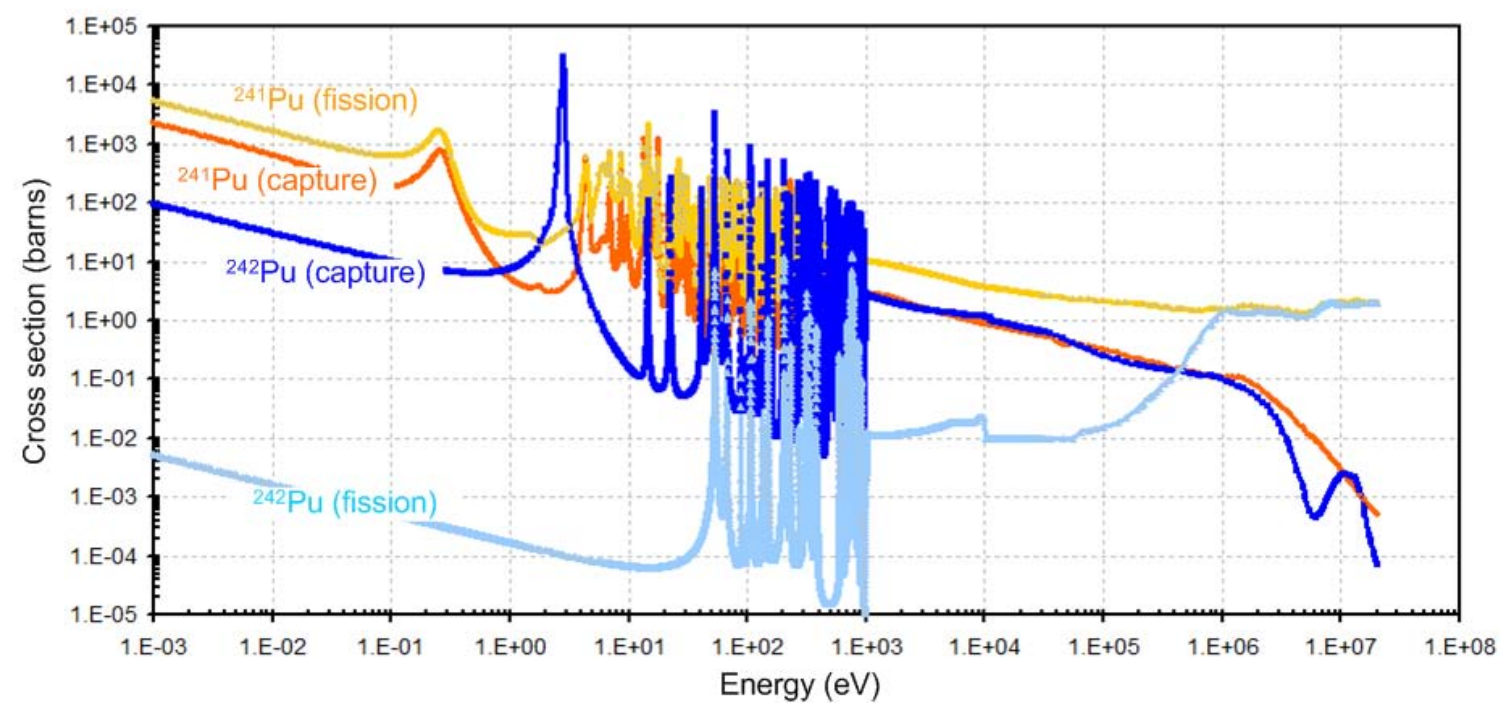

Figure 3.10. Capture and Fission Cross-sections for ${ }^{241} \mathrm{Pu}$ and ${ }^{242} \mathrm{Pu}$.

\subsubsection{Americium}

Americium, named after $t$ he A mericas, $w$ as $t$ he $f$ ourth $s$ ynthetic $t$ ransuranic e lement of the actinide series discovered (1944) [35]. Am metal has a silvery-white luster that tarnishes slowly in dry air at room temperature. It has a density of $12 \mathrm{~g} / \mathrm{cm}^{3}$. Sixteen $A m$ radioisotopes have been characterized ranging from ${ }^{232} \mathrm{Am}$ to ${ }^{247} \mathrm{Am}$. T he most $\mathrm{s}$ table of the i sotopes is ${ }^{243} \mathrm{Am}$ with a half-life of 7,370 years, followed by ${ }^{241} \mathrm{Am}$ with a half-life of 432.7 years, and ${ }^{242 \mathrm{~m}} \mathrm{Am}$ with a half-life of 141 years. The remaining isotopes all have half-lives that are less the 51 hours, and a majority have half-lives that are less than 100 m inutes. The most famous $\mathrm{Am}$ isotope is ${ }^{241} \mathrm{Am}$ because it is the only TRU i sotope to find its w ay into the hous ehold, by w ay of americiumbased smoke detectors. Am is used as a source for gamma rays and alpha particles for a number of medical and industrial us es. Am can also be combined with lighter elements to become a neutron emitter with many possible medical and industrial applications.

There a re three $A m$ isotopes that are of main concern for HLW waste management and incore behavior; they are: ${ }^{241} \mathrm{Am},{ }^{242 \mathrm{~m}} \mathrm{Am}$, a nd ${ }^{243} \mathrm{Am}$. When $\mathrm{UO}_{2}$ fuel is ir radiated in PWRs the resulting TRU composition at the end of irradiation has a small fraction of Am present, typically a few percent by weight. Of the $\mathrm{Am}$ isotopes ${ }^{243} \mathrm{Am}$ is present in the highest quantities, followed by ${ }^{241} \mathrm{Am}$, and then by ${ }^{242 \mathrm{~m}} \mathrm{Am}$. The decay time after removal from the core is important for $\mathrm{Am}$ because the amount of ${ }^{241} \mathrm{Am}$ will increase considerably with time due to the beta-decay of ${ }^{241} \mathrm{Pu}$, 
which has a half-life of 14.4 years. It will only take a few years of decay for ${ }^{241} \mathrm{Am}$ to become the dominant $A m$ nuclide in terms of composition.

Figure 3.11 shows the capture-to-fission ratio for the $A m$ isotopes. A s indicated ${ }^{242 \mathrm{~m}} \mathrm{Am}$ has a ratio that is 1 ess than 1 for the e ntire e nergy s pectrum and, therefore, is c onsidered a fissile isotope. B oth ${ }^{241} \mathrm{Am}$ and ${ }^{243} \mathrm{Am}$ have ratios much greater than on e with the threshold energy being at about $7.8 \times 10^{5} \mathrm{eV}$.

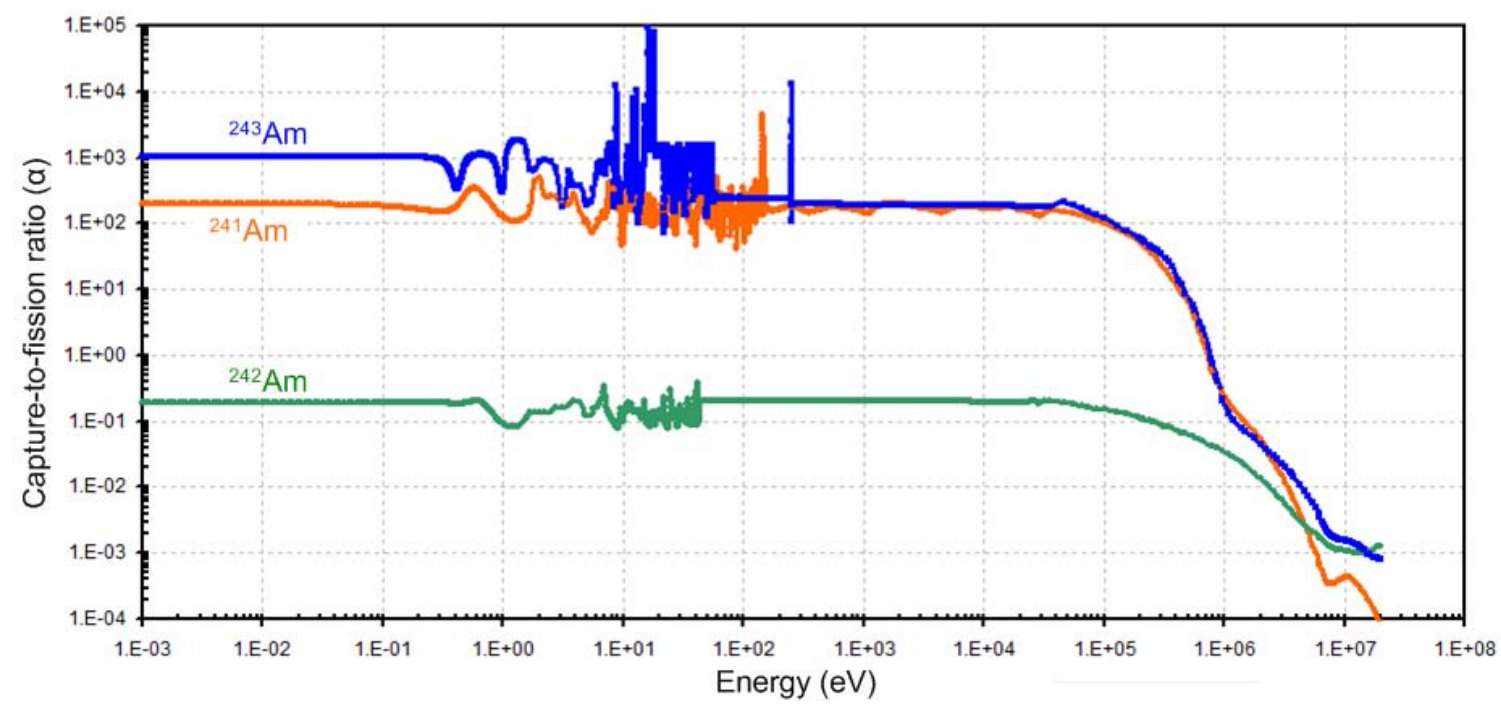

Figure 3.11. Capture-to-fission Ratio for Am Isotopes.

\section{Americium-241}

Under $\mathrm{i}$ rradiation $\mathrm{t}$ he $\mathrm{p}$ roduction $\mathrm{m}$ echanism $\mathrm{f}$ or ${ }^{241} \mathrm{Am}$ is the be ta-decay of ${ }^{241} \mathrm{Pu}$ a nd $\mathrm{i}$ ts competing destruction mechanism is radiative capture. Whether the ${ }^{241}$ Am inventory is depleted or increased has to do with the amount of ${ }^{241} \mathrm{Pu}$ in relation to ${ }^{241} \mathrm{Am}$ and the capture reaction rates throughout the irradiation time, such that:

$$
\frac{d N_{A m 241}}{d t}=[N \cdot \lambda]_{P u 241}-\left[N \cdot \sigma_{a}\right]_{A m 241} \phi
$$

Considering the typical TRU composition recycled from a PWR, irradiation in a thermal neutron spectrum s ystem, such as the VHTR, will result in the depletion of ${ }^{241}$ Am throughout the core lifetime. As for a fast neutron spectrum system, such as the HEST, the ${ }^{241} \mathrm{Pu}$ to ${ }^{241} \mathrm{Am}$ ratio will be greater i nitially and the a bsorption c ross-section for ${ }^{241} \mathrm{Am} w$ ill b e c onsiderably low er. Therefore, the ${ }^{241} \mathrm{Am}$ concentration will buildup initially, but as time progresses it becomes more difficult to predict e xactly $\mathrm{w}$ hat the tr end will be $\mathrm{w}$ ithout pe rforming de tailed depletion calculations.

\section{Americium-242m}

Americium has eight meta states, with ${ }^{242 \mathrm{~m}}$ Am being the most stable. In fact ${ }^{242 \mathrm{~m}} \mathrm{Am}$ is one of the few isotopes that has a much more stable meta state, with a half-life of 142 years compared 
to ${ }^{242} \mathrm{Am}$ which has a half 1 ife of 16 hour s. T he production of ${ }^{242 \mathrm{~m}} \mathrm{Am}$ comes from radiative capture in ${ }^{241} \mathrm{Am}$ and is transmuted by neutron absorption, and can be described by the following relationship:

$$
\frac{d N_{A m 242 m}}{d t}=\left(\omega_{e}[N \cdot \sigma]_{A m 241}-\left[N \cdot \sigma_{a}\right]_{A m 242 m}\right) \phi
$$

where $\omega_{e}$ represents the fraction of capture events that lead to ${ }^{242 \mathrm{~m}} \mathrm{Am}$ as opposed to ${ }^{242} \mathrm{Am}$, and is an energy dependent value that increases with the increase in incident neutron energy.

As s hown in F igure 3.12 the a bsorption c ross-sections for ${ }^{242 \mathrm{~m}} \mathrm{Am}$ is much greater tha $\mathrm{n}$ the radiative capture cross-sections for ${ }^{241} \mathrm{Am}$ in the thermal and resonance energy regions, but very similar in the fast region. Even so, the quantity of ${ }^{241} \mathrm{Am}$ present at the start of irradiation in the VHTR greatly outweighs that of ${ }^{242 \mathrm{~m}} \mathrm{Am}$, and due to this, there will be an increase in the ${ }^{242 \mathrm{~m}} \mathrm{Am}$ inventory upon removal from the VHTR. Likewise, the relative composition at the beginning of cycle for the HEST heavily favors ${ }^{241} \mathrm{Am}$, but to a lesser amount. Still it is such that a buildup of ${ }^{242 \mathrm{~m}} \mathrm{Am}$ is expected, but at a reduced rate as compared to the VHTR. Protracted irradiation in the HEST will effectively reduce the ${ }^{242 \mathrm{~m}} \mathrm{Am}$ inventory. ${ }^{242 \mathrm{~m}} \mathrm{Am}$ is a fissile isotope so the preferred transmutation mechanism is fission for all neutron energy regions.

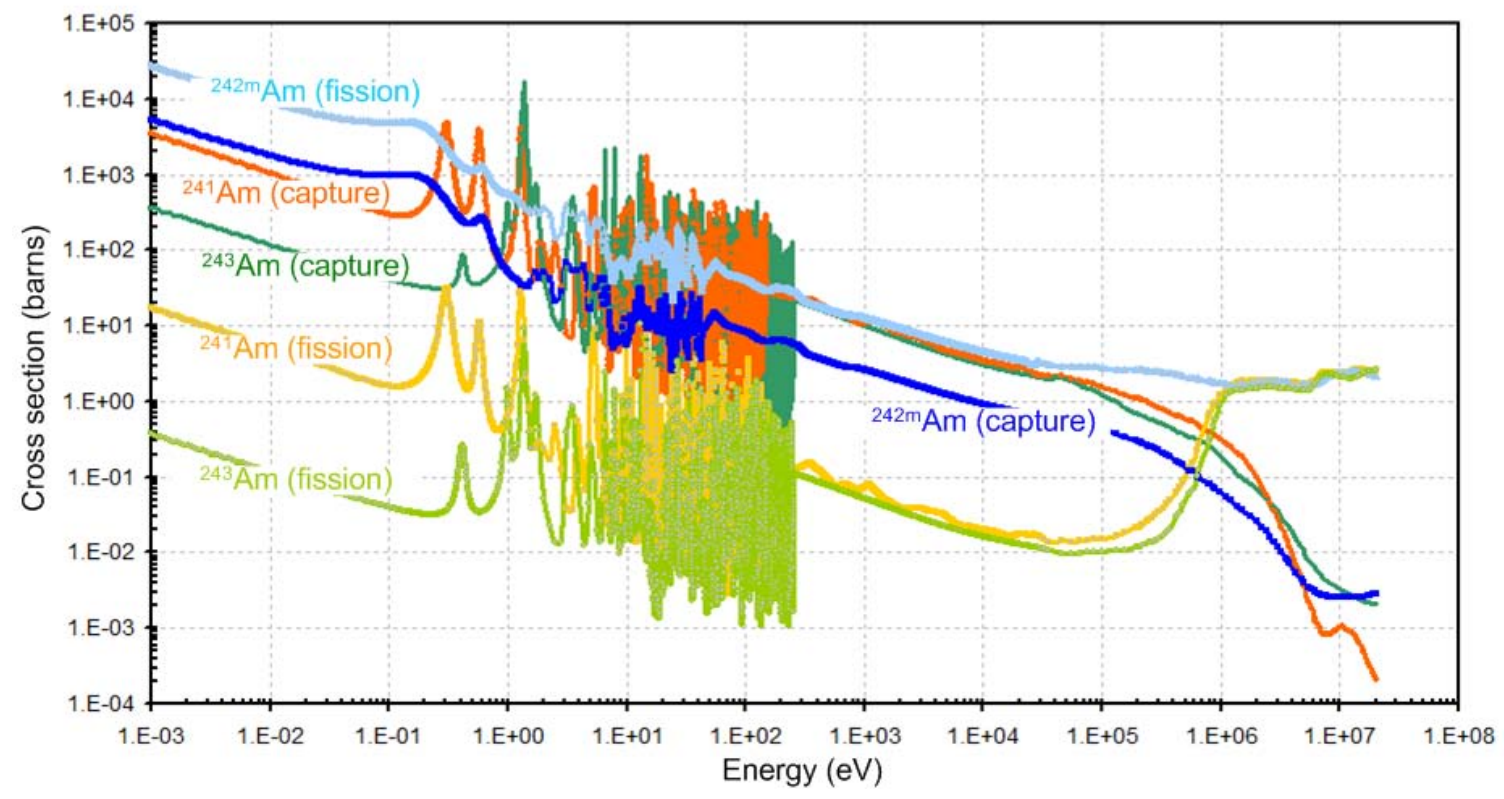

Figure 3.12. Capture and Fission Cross-sections for Am Isotopes.

\section{Americium-243}

The production of ${ }^{243} \mathrm{Am}$ can be attributed to two sources, one being radiative capture in ${ }^{242 \mathrm{~m}} \mathrm{Am}$ and the other being the beta-decay of ${ }^{243} \mathrm{Pu}$. The destruction of ${ }^{243} \mathrm{Am}$ is by neutron absorption resulting i $\mathrm{n}$ e ither $\mathrm{r}$ adiative $\mathrm{c}$ apture o $\mathrm{r}$ f ission. $\mathrm{T}$ he $\mathrm{t}$ ime de pendent $\mathrm{r}$ epresentation $\mathrm{f}$ or $\mathrm{t}$ he concentration change of ${ }^{243} \mathrm{Am}$ follows: 


$$
\frac{d N_{A m 243}}{d t}=[N \cdot \lambda]_{P u 243}+\left(\left[N \cdot \sigma_{\gamma}\right]_{A m 242 m}-\left[N \cdot \sigma_{a}\right]_{A m 243}\right) \phi .
$$

Since the ha lf-life of ${ }^{243} \mathrm{Pu}$ is s o s hort ( 4.96 ho urs) the a ssumption is made that all $\mathrm{r}$ adiative neutron captures in ${ }^{242} \mathrm{Pu}$ immediately produce ${ }^{243} \mathrm{Am}$. The relation above is adjusted to reflect this observation and is now presented as:

$$
\frac{d N_{A m 243}}{d t}=\left(\left[N \cdot \sigma_{\gamma}\right]_{P u 242}+\left[N \cdot \sigma_{\gamma}\right]_{A m 242 m}-\left[N \cdot \sigma_{a}\right]_{A m 243}\right) \phi .
$$

The amount of ${ }^{242 \mathrm{~m}} \mathrm{Am}$ present at any time is very small compared to that of ${ }^{242} \mathrm{Pu}$ and due to this, the production term is dominated by ${ }^{242} \mathrm{Pu}$. The absorption cross-section values for ${ }^{243} \mathrm{Am}$ are noticeably greater than the radiative capture cross-sections for ${ }^{242} \mathrm{Pu}$ in all energy regions, but ${ }^{242} \mathrm{Pu}$ concentrations heavily outweigh ${ }^{243} \mathrm{Am}$ concentrations. In addition, the concentration rate change for ${ }^{242} \mathrm{Pu}$ increases with time. $\mathrm{U}$ sing the above information, the inventory of ${ }^{243} \mathrm{Am}$ is expected to increase un der i rradiation in the VHTR. In the HEST it is ex pected to initially increase but at a slower rate and then eventually begin to decrease as the ${ }^{242} \mathrm{Pu}$ is depleted.

\subsubsection{Curium}

Curium, named a fter $\mathrm{M}$ arie $\mathrm{C}$ urie and he $\mathrm{r}$ hus band $\mathrm{P}$ ierre, $\mathrm{w}$ as the third s ynthetic transuranic element of the actinide series discovered (1944) [35], even though it follows a mericium in the periodic table. $\mathrm{Cm}$ metal has a silvery color that is chemically reactive and tarnishes slowly in dry air at room temperature. It has a density of $13.51 \mathrm{~g} / \mathrm{cm}^{3}$. Seventeen $\mathrm{Cm}$ radioisotopes have been characterized ranging from ${ }^{235} \mathrm{Cm}$ to ${ }^{251} \mathrm{Cm}$. The most stable of the isotopes is ${ }^{247} \mathrm{Cm}$ with a half-life of $1.56 \times 10^{7}$ years. $\mathrm{Cm}$ has been studied significantly as a potential fuel for radioisotope thermoelectric generators, but $\mathrm{r}$ adiation issues and cost ha ve pr evented extensive us e. Applications have included using a ${ }^{244} \mathrm{Cm}$ s ource for the Alpha particle X-ray spectrometer on board several American and European space missions, and as an alpha particle source.

The $\mathrm{Cm}$ nuclides a re a mong the most $\mathrm{r}$ adiotoxic a nd $\mathrm{l}$ argest de cay $\mathrm{h}$ eat producers a mong the TRU. T his i s pa rticularly the case $f$ or ${ }^{242} \mathrm{Cm},{ }^{243} \mathrm{Cm}$, a nd ${ }^{244} \mathrm{Cm}$. H owever, their 1 ow concentrations a nd short ha lf-lives greatly $r$ educe the $c$ oncern they pos e for 1 ong-term H LW management. ${ }^{242} \mathrm{Cm}$ is the most radiotoxic and biggest contributor of decay he at out of all the TRU i sotopes s urveyed, but it's ve ry s hort half-life makes it a non-issue for long-term w aste management, but it doe s pos e other p roblems di scussed later. Even though ${ }^{243} \mathrm{Cm}$ and ${ }^{244} \mathrm{Cm}$ have relatively short half-lives and are a small fraction of the TRU inventory, they still need to be closely tracked and assessed. In any case, the $\mathrm{Cm}$ isotopes $\mathrm{n}$ eed monitored for inventory increases as the TRU fuel is irradiated, particularly in thermal neutron spectrum systems, as their heat load and radiotoxicity levels can be very sensitive to composition changes.

\section{Curium-242}

The beta-decay of ${ }^{242} \mathrm{Am}$ generates ${ }^{242} \mathrm{Cm}$, but considering that ${ }^{242} \mathrm{Am}$ has a very short half-life it can be assumed that the production of ${ }^{242} \mathrm{Cm}$ is a product of ne utron capture in ${ }^{241} \mathrm{Am}$. T he 
competing factor for the production of ${ }^{242 \mathrm{~m}} \mathrm{Am}$ also has to be accounted for in ${ }^{241} \mathrm{Am}$ capture. The de struction term includes c apture and fission e vents and the alpha-decay of ${ }^{242} \mathrm{Cm}$. T he process can be described by:

$$
\frac{d N_{C m 242}}{d t}=\left(\left(1-\omega_{e}\right)\left[N \cdot \sigma_{\gamma}\right]_{A m 242}-\left[N \cdot \sigma_{a}\right]_{C m 242}\right) \phi-[N \cdot \lambda]_{C m 242}
$$

Considering that ${ }^{242} \mathrm{Cm}$ composition before irradiation in the VHTR is essentially zero, it is only produced during its residency time under irradiation. T he goal is to limit its production rate as much as possible and to transmute it by fission in the HEST.

Due to its short half-life ${ }^{242} \mathrm{Cm}$ does not present long-term problems, but it is important because it $\mathrm{g}$ enerates the 1 onger-lived ${ }^{243} \mathrm{Cm}$. I $\mathrm{n}$ a ddition, i $\mathrm{c}$ auses di fficulties i $\mathrm{n}$ the $\mathrm{s}$ hort-term for radiological protection from neutron emissions and other high-energy radiation fields, along with high heat generation that can make reprocessing procedures complicated.

\section{Curium-243}

The production of ${ }^{243} \mathrm{Cm}$ can be at tributed to radiative capt ure in ${ }^{242} \mathrm{Cm}$. In contrast it $\mathrm{i} \mathrm{s}$ transmuted $\mathrm{t} \mathrm{o}$ a nother nuclide $\mathrm{b}$ y radiative $\mathrm{c}$ apture or $\mathrm{b} \mathrm{y} f$ ission. The $\mathrm{t}$ ime de pendent representation for the concentration change of ${ }^{243} \mathrm{Cm}$ follows:

$$
\frac{d N_{C m 243}}{d t}=\left(\left[N \cdot \sigma_{\gamma}\right]_{C m 242}-\left[N \cdot \sigma_{a}\right]_{C m 243}\right) \phi .
$$

The rate of increase in ${ }^{243} \mathrm{Cm}$ is linked to production of ${ }^{242} \mathrm{Cm}$ and since ${ }^{242} \mathrm{Cm}$ will continually increase in the VHTR, the same can be expected for ${ }^{243} \mathrm{Cm}$. H owever, as indicated in Figure 3.13 , the c apture c ross-sections for ${ }^{242} \mathrm{Cm}$ ar e cons iderably s maller than the cross-sections for ${ }^{243} \mathrm{Cm}$ throughout the entire spectrum, so the concentration of ${ }^{243} \mathrm{Cm}$ will be much lower than that of ${ }^{242} \mathrm{Cm}$. As shown in the plot, ${ }^{243} \mathrm{Cm}$ is a fissile isotope and very high fission efficiencies are achieved in the HEST.

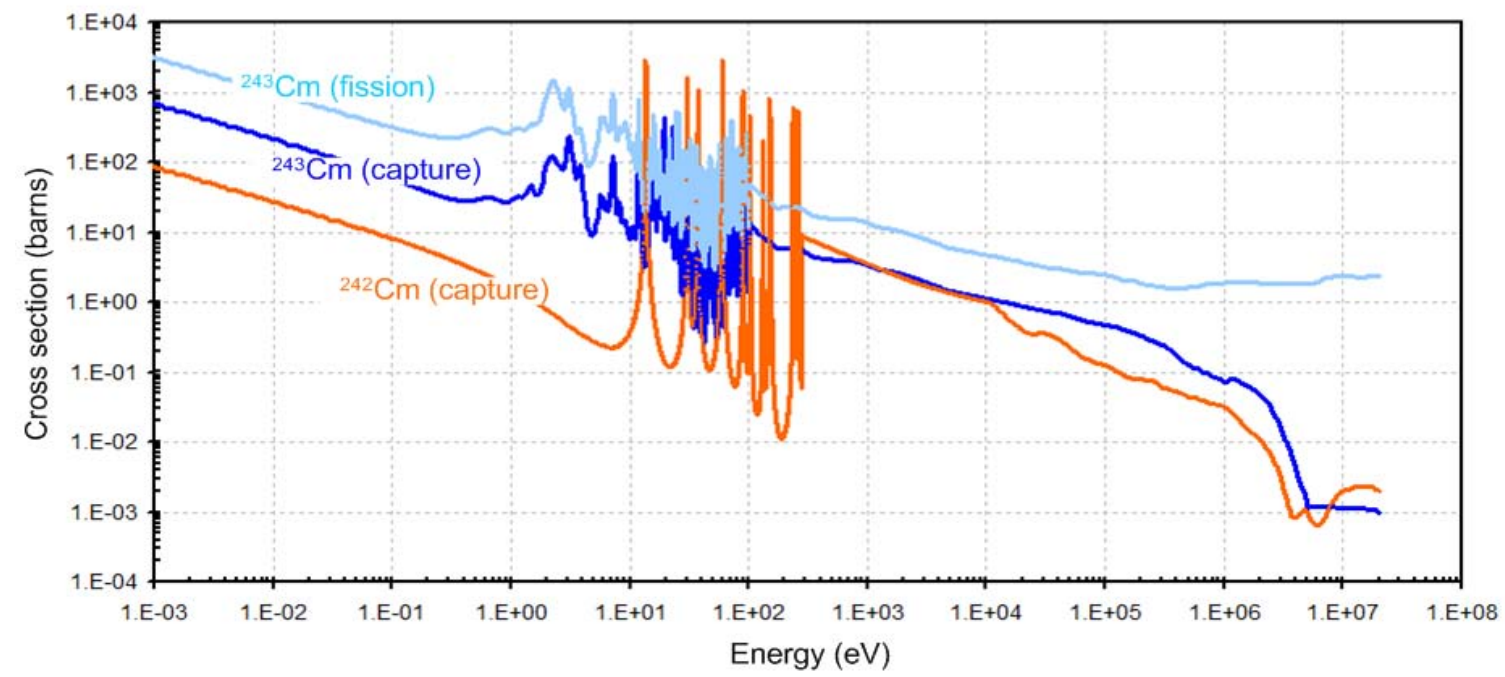

Figure 3.13. Capture and Fission Cross-sections for ${ }^{242} \mathrm{Cm}$ and ${ }^{243} \mathrm{Cm}$. 


\section{Curium-244}

The production of ${ }^{244} \mathrm{Cm}$ can be attributed to three sources, one being radiative capture in ${ }^{243} \mathrm{Cm}$, another being the beta-decay of ${ }^{244} \mathrm{Am}$, and the last being beta-decay of ${ }^{244 \mathrm{~m}} \mathrm{Am}$. The destruction of ${ }^{244} \mathrm{Cm}$ i s b y ne utron a bsorption $\mathrm{r}$ esulting i $\mathrm{n}$ e ither $\mathrm{r}$ adiative $\mathrm{c}$ apture or fission. $\mathrm{T}$ he $\mathrm{t}$ ime dependent representation for the concentration change of ${ }^{244} \mathrm{Cm}$ follows:

$$
\frac{d N_{C m 244}}{d t}=[N \cdot \lambda]_{A m 244}+[N \cdot \lambda]_{A m 244 m}+\left(\left[N \cdot \sigma_{\gamma}\right]_{C m 243}-\left[N \cdot \sigma_{a}\right]_{C m 244}\right) \phi .
$$

Since the half-life of ${ }^{244} \mathrm{Am}$ is very short ( 10 hours) the a ssumption is made that the radiative capture event in ${ }^{243} \mathrm{Am}$ immediately produces ${ }^{244} \mathrm{Am}$. The meta state ${ }^{244 \mathrm{~m}} \mathrm{Am}$ has even a shorter half-life and it also beta-decays to ${ }^{244} \mathrm{Cm}$. Therefore, it can be included in the radiative capture term with ${ }^{244} \mathrm{Am}$. The relation above is adjusted to reflect these observations and presented as:

$$
\frac{d N_{C m 244}}{d t}=\left(\left[N \cdot \sigma_{\gamma}\right]_{A m 243}+\left[N \cdot \sigma_{\gamma}\right]_{C m 243}-\left[N \cdot \sigma_{a}\right]_{C m 244}\right) \phi
$$

At the beginning of cycle for the VHTR, the TRU fuel contains essentially no ${ }^{243} \mathrm{Cm}$, therefore, production will c ome from ${ }^{243} \mathrm{Am}$ a lone. A s time proceeds, ${ }^{243} \mathrm{Cm}$ w ill a lso contribute. B y referring to Figure 3.14 it can be seen that the capture cross-sections for ${ }^{243} \mathrm{Am}$ are greater than the cr oss-sections f or ${ }^{244} \mathrm{Cm}$. I $\mathrm{n}$ a ddition, the i nitial c oncentration of ${ }^{243} \mathrm{Am}$ is la rger a nd it increases with irradiation time. All indicate a significant production rate of ${ }^{244} \mathrm{Cm}$ during its time in the VHTR. In the HEST, the production rates will definitely be slowed considerably, and with high burnup, can be reduced and eventually eliminated.

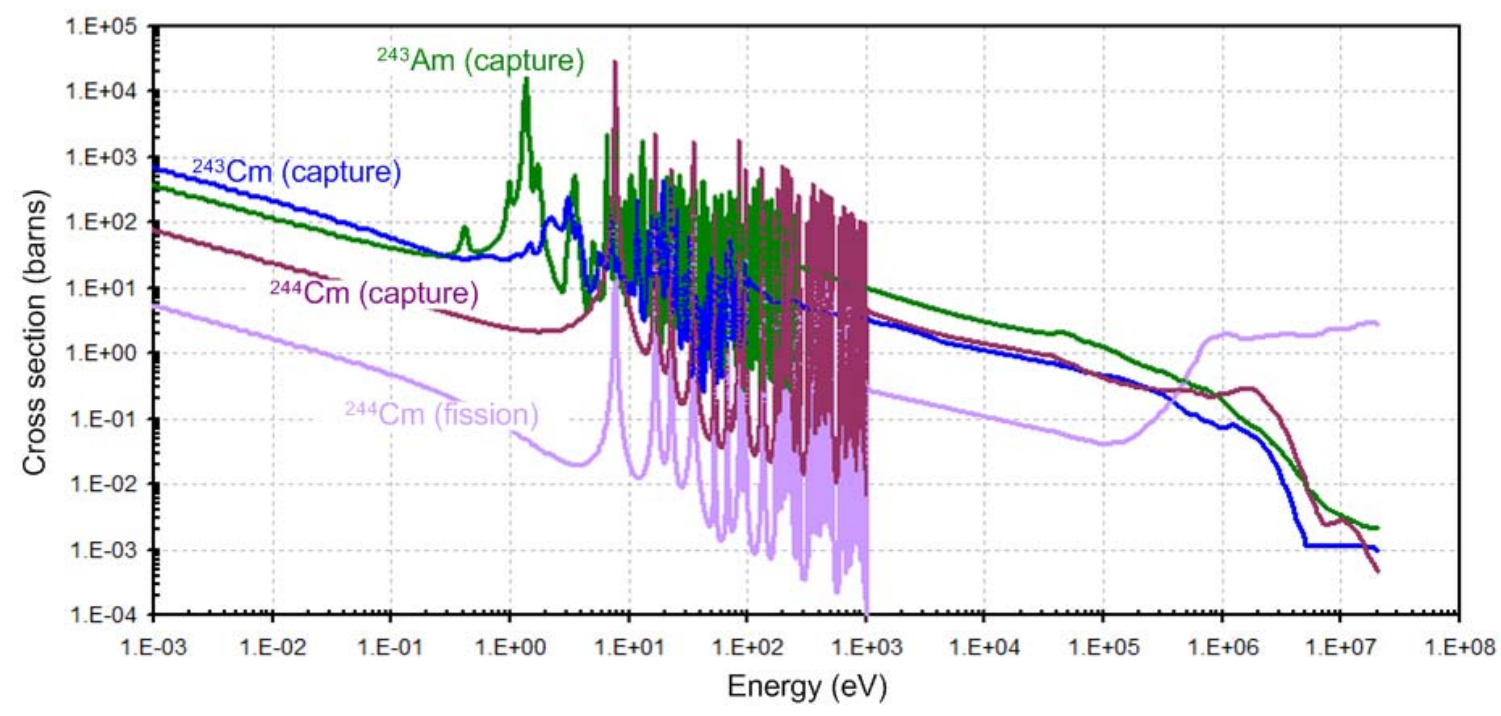

Figure 3.14. Capture and Fission Cross-sections for ${ }^{243} \mathrm{Am},{ }^{243} \mathrm{Cm}$, and ${ }^{244} \mathrm{Cm}$. 


\subsection{Conclusions}

The fuel in an operating nuclear reactor is constantly changing as fuel nuclei are transmuted by neutron $\mathrm{c}$ apture a nd s ubsequent de cay. $\mathrm{T}$ he fresh LEU fuel that e nters the $\mathrm{r}$ eactor a nd 1 ater removed after an irradiation cycle now contains TRU elements that will be highly radioactive for 100 's of thousands of years. C urrently, the favored plan is to contain and isolate the us ed fuel from interacting with the biosphere until it has decayed to safe levels, assuring the protection of human he alth a nd $t$ he environment. C ountless cha llenges ex ist be cause of $t$ he $t$ imeframe involved with such an endeavor, plus it is predicted that it will take a large number of storage facilities to house all of the current and future HLW. Presently, different sites around the world have be en characterized to serve as pos sible de ep geological $r$ epositories for $s$ afe 1 ong-term waste storage facilities.

The T RU i nventory is responsible f or the 1 ong-term he at generation and radiotoxicity th at accompanies used nuclear fuel. High-level nuclear waste repository performance parameters are dependent on the TRU composition. Therefore, focus is on the destruction of the TRU stream by transmutation as a means to alleviate problematic aspects of waste management.

Highest importance is placed on the TRU nuclides that are intense sources of decay heat and that are highly radiotoxic for many years into the future. Focusing on the elimination of these TRU nuclides accomplishes two main goals: 1) more efficient use of the available space within the repository al lowing for greater qua ntities of $\mathrm{HLW}$ to be s tored safely, and 2) d ecreasing the amount of time the HLW must be isolated from the biosphere.

A systematic method was developed and utilized to assess and rank the TRU nuclides according to $r$ adiotoxicity, $t$ hermal he at ge neration, $r$ elative $c$ oncentration, $t$ imescale, a nd ne utron emissions. F igure 3.15 presents the r elevant T RU nuc lides $w$ ith dom inant transmutation and decay s chemes. $\mathrm{T}$ he $\mathrm{i}$ sotopes a re c olor c oded t o $\mathrm{s}$ how their $\mathrm{r}$ anking, from hi ghest to lowest priority. A s indicated, the hi ghest pr iority i sotopes a re: ${ }^{239} \mathrm{Pu},{ }^{240} \mathrm{Pu},{ }^{241} \mathrm{Pu}$, and ${ }^{241} \mathrm{Am}$. T he medium hi gh pr iority i sotopes i nclude: ${ }^{238} \mathrm{Pu},{ }^{242} \mathrm{Pu},{ }^{243} \mathrm{Am}$, a nd ${ }^{244} \mathrm{Cm}$. T he m edium 1 ow priority isotopes are: ${ }^{242 \mathrm{~m}} \mathrm{Am},{ }^{242} \mathrm{Cm},{ }^{243} \mathrm{Cm}$, and ${ }^{245} \mathrm{Cm}$. The low priority isotopes are: ${ }^{237} \mathrm{~Np}$, ${ }^{244} \mathrm{Pu}$, and ${ }^{246} \mathrm{Cm}$. 


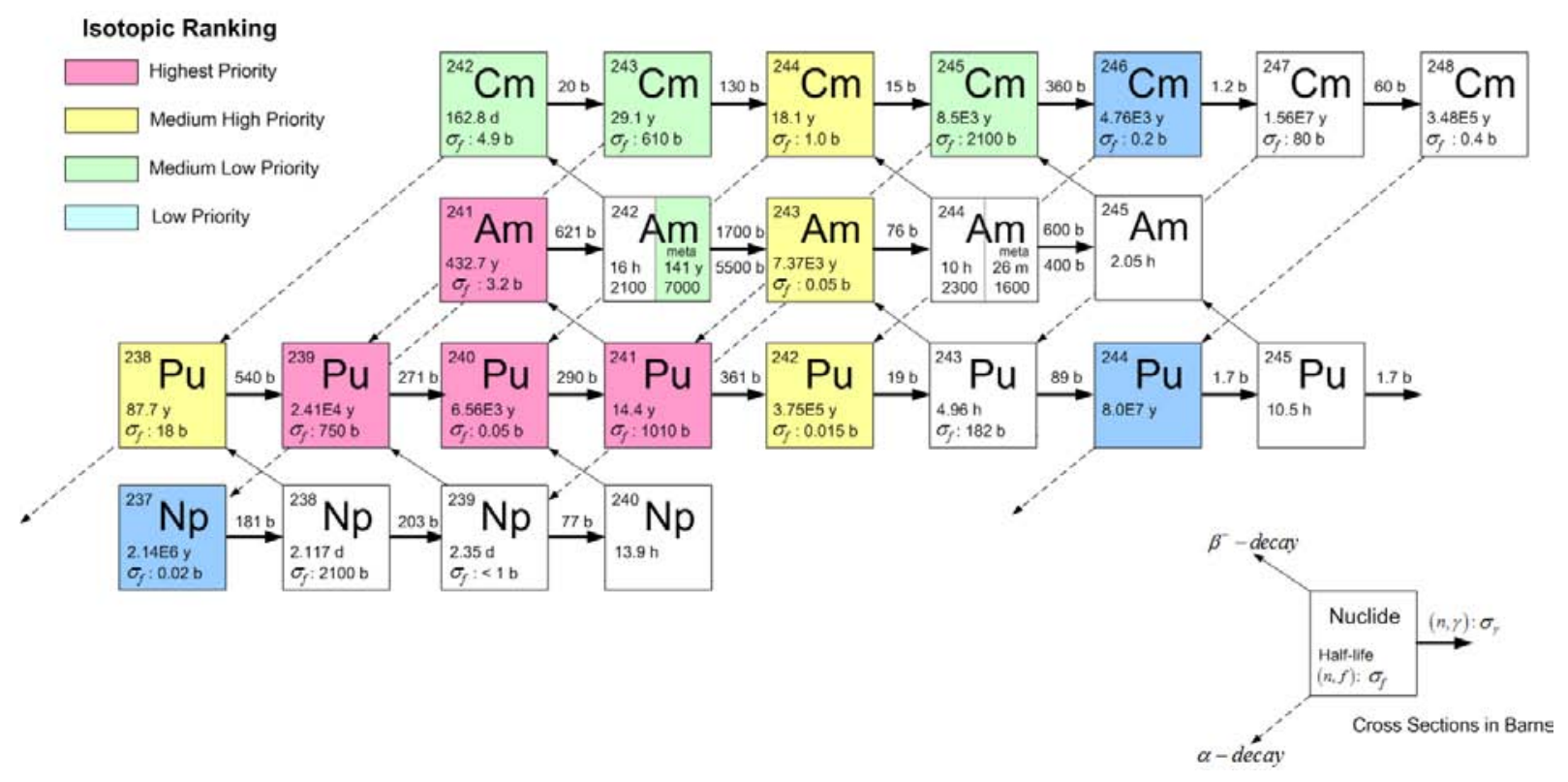

Figure 3.15. TRU Priority Ranking.

The ranking s ystem is ba sed on t he T RU c omposition g enerated by a typical P WR w ith five years of decay time. The highest priority ranking identifies isotopes that have the greatest effect on HLW storage and need to be targeted foremost for inventory reduction.

According to the characteristics associated with the TRU nuclides, irradiation in thermal neutron spectrum systems, such as the VHTR, can significantly reduce TRU inventories. Attention to the buildup of hi gher actinides is a c oncern f or the V HTR, but b y linki ng it to a f ast ne utron spectrum s ystem, such as the HEST, the inventory i ncrease can b e e fficiently di minished or eventually eliminated. The beneficial results are twofold, on the one hand reducing the burden on the management of HLW, and while on the other hand, utilizing the valuable fuel resource remaining in PWR used fuel. 


\section{SYSTEM PARAMETERIZATION AND REPRESENTATIVE MODELS}

The NES is composed of different reactors and components that work in coordination with each other to produce the de sired out put. $E$ ach $h$ as its ow $n$ function and e ach is considered in a standalone fashion. T he first s ection of the chapter (4.1) de scribes e ach of the reactor units, followed by chapter section (4.2) which details the fuel cycle components along with the models created to represent each, with the final section (4.3) de dicated to de scribing the integration of the individual models into a single system model. When possible experiment-to-code and codeto-code benchmarking procedures were applied with results presented within.

\subsection{Reactor Units}

The performance of the NES is heavily based on the reactor units. The three reactors selected for the s ystem are the AP1000, V HTR, and HEST. T he AP1000 is a Gen-III+ P WR de sign by Westinghouse. The V HTR i s a $G$ en-IV de sign and $\mathrm{c}$ urrently $\mathrm{t}$ he $\mathrm{c}$ andidate $\mathrm{f}$ or $\mathrm{t}$ he Next Generation Nuclear Plant (NGNP). It is the prismatic core design and utilizes the Tri-structural isotropic (TRISO) fuel type. The HEST is a subcritical system that takes advantage of the highenergy $14.1 \mathrm{M} \mathrm{eV}$ neutrons produced $\mathrm{b} y \mathrm{t}$ he $\mathrm{D} \mathrm{T}$ f usion $\mathrm{r}$ eaction $\mathrm{t} o \mathrm{dr}$ ive $\mathrm{t}$ he $\mathrm{s}$ ystem a nd $\mathrm{t} o$ eliminate waste.

\subsubsection{AP1000}

The AP1000 is a Westinghouse Electric Company reactor design and is the first Generation III+ reactor to receive final design approval from the NRC. The AP1000 is a two-loop PWR planned to produce $1154 \mathrm{M} \mathrm{W}_{\mathrm{e}}$. T he de sign is built on p roven technology from over 35 years of PWR operating e xperience. $\mathrm{M}$ ajor i mprovements ove $\mathrm{r} \mathrm{G}$ en-III reactors i nclude the ut ilization of passive $\mathrm{s}$ afety $\mathrm{t}$ echnology, overall s ystem simplification, a nd m odular c onstruction. $\mathrm{T}$ hese improvements make the AP1000 safer, easier and less expensive to build, operate, and maintain.

In the $n$ ear future the AP1000 is expected to play a large r ole in nu clear energy generation worldwide. A $\mathrm{s}$ i ndication, $\mathrm{t}$ he $\mathrm{S}$ anmen $\mathrm{N}$ uclear $\mathrm{P}$ ower $\mathrm{P}$ lant $\mathrm{i} \mathrm{n} \mathrm{Z}$ hejiang $\mathrm{C}$ hina be gan construction of two AP1000s in F ebruary 2008, which are s cheduled to go op erational during 2013-15. C onstruction began in July 2008 o f t wo ot her units at the Haiyang N uclear P ower Plant in Shandong. China has o fficially adopted the AP1000 as a standard for inland nuclear projects. Additionally, in the USA, twelve Combined Construction and Operating Licenses have been s ubmitted a s o f 2009 . T he A P1000 i s s een a s the ne w s tandard f or nuc lear e nergy generation and will bridge the gap from yesterday's Gen-III technology to tomorrow's advanced Gen-IV reactor systems.

The major design parameters for the AP1000 a re s imilar to that of other PWRs. T he thermal power is rated at $3400 \mathrm{MW}_{\text {th }}$ and with a thermodynamic efficiency of $32.7 \%$, it c an produce a 
usable electrical power of $1115 \mathrm{MW}_{\mathrm{e}}$. The fuel type is enriched $\mathrm{UO}_{2}$ and the coolant/moderator is light water. A listing of the AP1000 design parameters are provided in Table 4.1.

Table 4.1. AP1000 Design Parameters.

\begin{tabular}{|l|c|}
\hline \multicolumn{1}{|c|}{ Parameter } & Value \\
\hline \hline Thermal power (MWth) & 3400 \\
\hline Electrical power (MWe) & 1115 \\
\hline Thermodynamic efficiency $(\%)$ & 32.8 \\
\hline Fuel & $\mathrm{UO} 2$ \\
\hline Average fuel enrichment (wt \%) & 3.8 \\
\hline Type of fuel assembly & $17 \times 17$ \\
\hline Number of fuel assemblies & 157 \\
\hline Active fuel length $(\mathrm{m})$ & 4.3 \\
\hline Equivalent core diameter $(\mathrm{m})$ & 3.04 \\
\hline Operating cycle length $(\mathrm{months})$ & 18 \\
\hline Linear heat rating (kW/m) & 18.7 \\
\hline Operating pressure $(\mathrm{Mpa})$ & 15.5 \\
\hline Coolant & light water \\
\hline Coolant inlet temperature $\left({ }^{\circ} \mathrm{C}\right)$ & 280.7 \\
\hline Coolant outlet temperature $\left({ }^{\circ} \mathrm{C}\right)$ & 321.1 \\
\hline
\end{tabular}

\section{Model Description}

The model is ba sed on t he A P1000 D esign C ontrol D ocumentation [36] provided by the US Nuclear Regulatory Commission (NRC). The reactor core consists of 157 fuel assemblies that are a rranged in a pattern, w hich a pproximates a right circular c ylinder. E ach fuel assembly contains 264 fuel rods, 24 guide tubes for control rod clusters, and one centrally located guide tube for in-core i nstrumentation, a ll of w hich a re a rranged in a 17 x 17 s quare lattice array. Figure 4.1 shows a cross-sectional view of the fuel assembly and related fuel rod and guide tube placements.

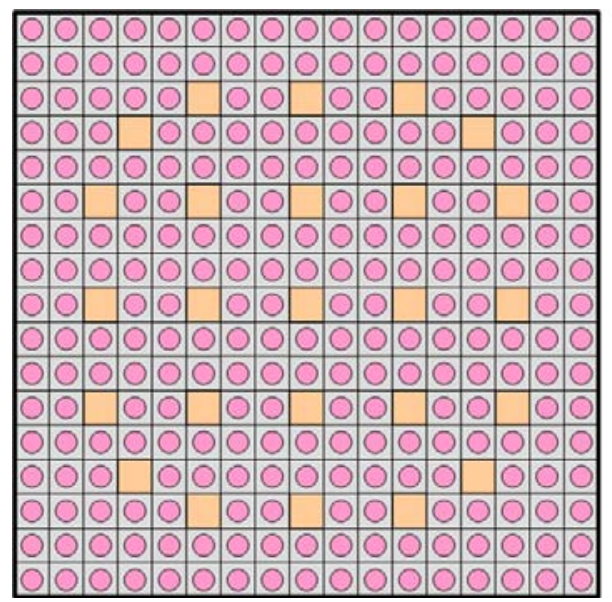

Fuel Rod (264)

Guide Tube (25)

Figure 4.1. AP1000 Fuel Assembly. 
The model de sign is based on the initial core loading, in which the fuel rods within any given assembly have the same uranium enrichment in both the radial and axial planes. Fuel assemblies of three different enrichments are used to establish a favorable radial power distribution.

Figure $4.2 \mathrm{~s}$ hows the fuel assembly loading pattern used for the AP1000 model. It also shows the placement of the assemblies containing the Discrete Burnable Absorber (PYREX) rods and Integral Fuel Burnable Absorber (IFBA) rods within the core.

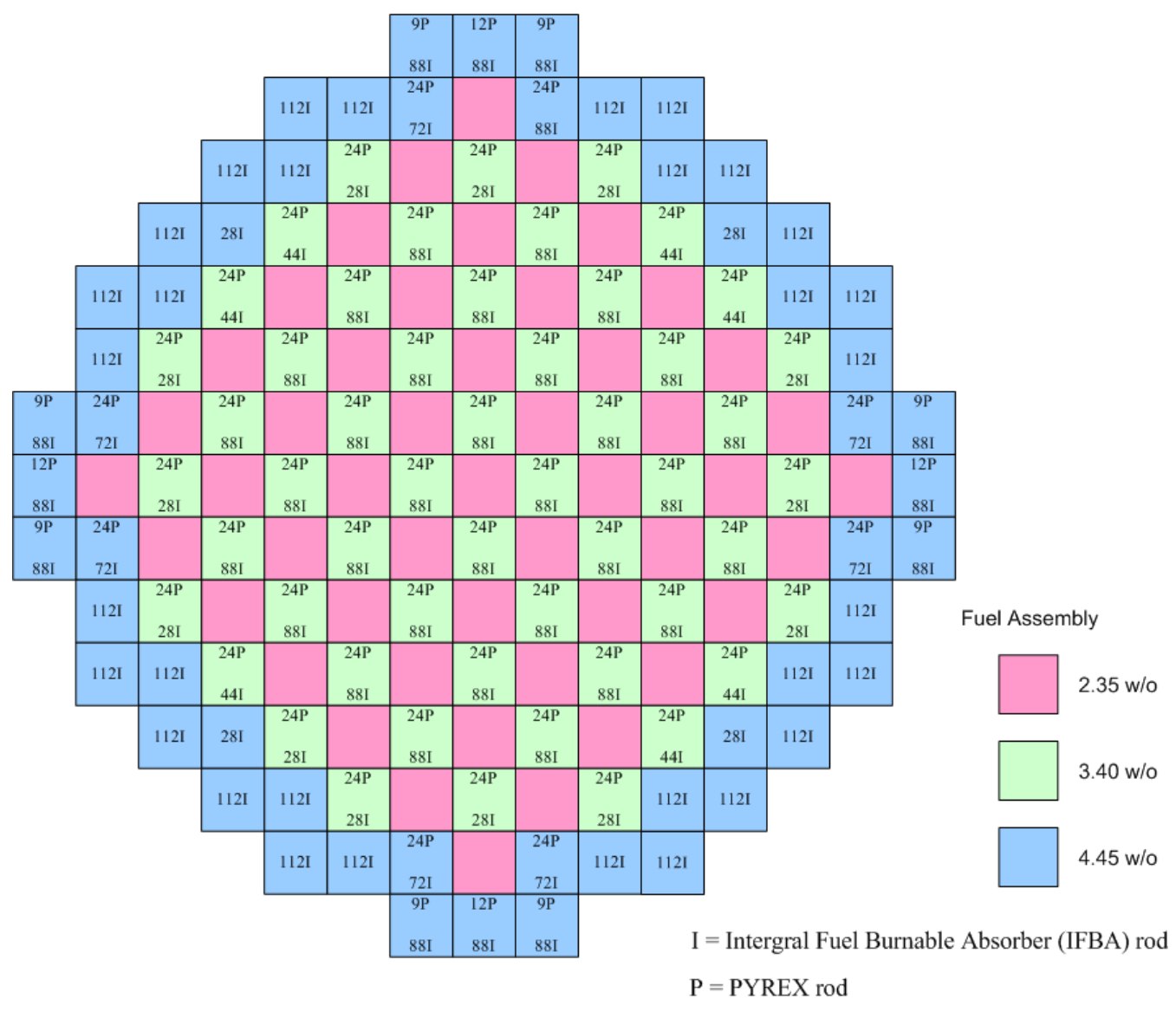

Figure 4.2. AP1000 Reactor Core Map.

Burnable absorbers in the form of PYREX and IFBA rods are used to provide partial control of the excess reactivity present during the fuel cycle. Their main function is to limit peaking factors and pr event $t$ he $m$ oderator $t$ emperature $c$ oefficient $f$ rom be ing pos itive a $t$ nor mal ope rating conditions. W ithin a chosen fuel assembly, the PYREX rods can be arranged in one of three different configurations, as shown in Figure 4.3. S imilarly, the IFBA rods $\mathrm{c}$ an be arranged in five different configurations as shown in Figure 4.4. The placement of the assemblies containing the burnable absorber within the core is di splayed in Figure 4.2. A de scription of the reactor core, including dimensions and core materials, is provided in Table 4.2. 


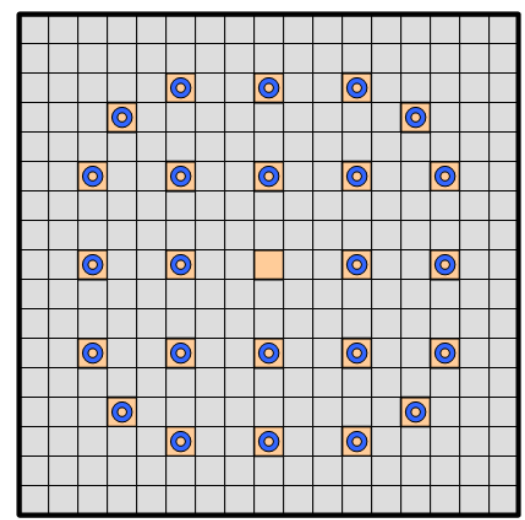

24 PYREX Rods

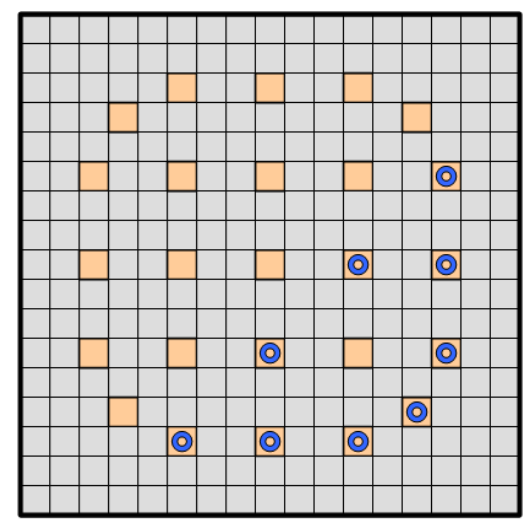

9 PYREX Rods

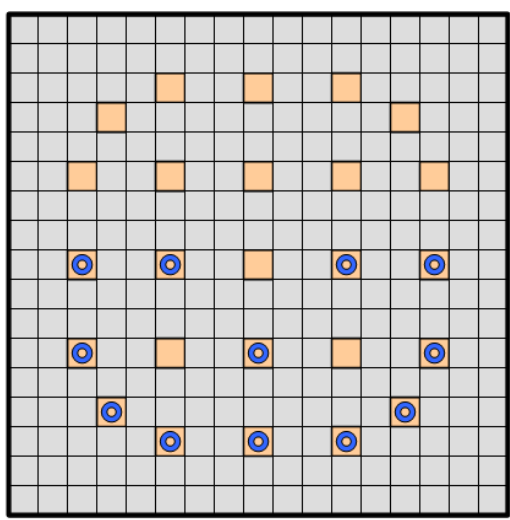

12 PYREX Rods

$$
\begin{array}{l|l|l}
\square \text { Fuel rod region } \quad \square \text { Guide tube } \quad \text { ○ PYREX rod } \\
\hline
\end{array}
$$

Figure 4.3. PYREX Rod Arrangement within the AP1000 Fuel Assembly.

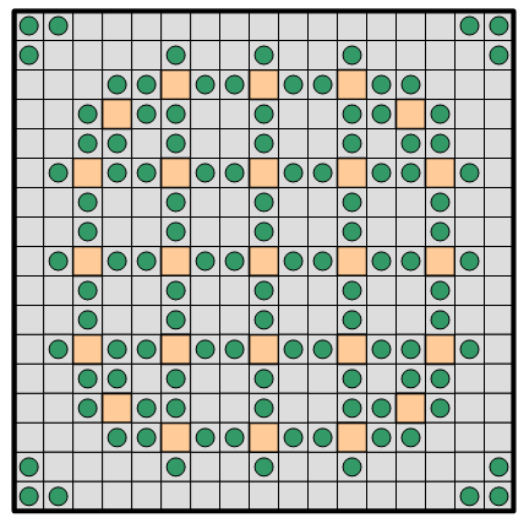

112 IFBA Rods

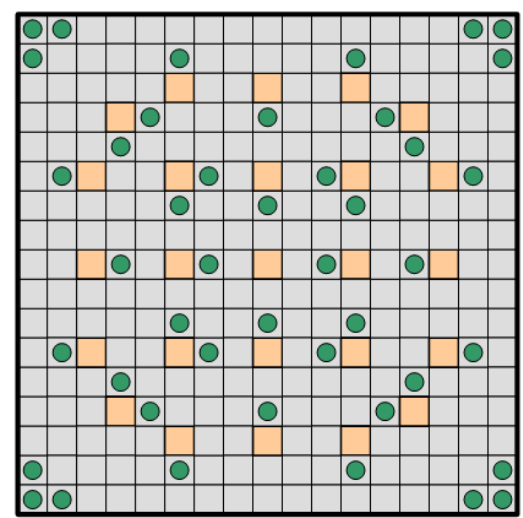

44 IFBA Rods

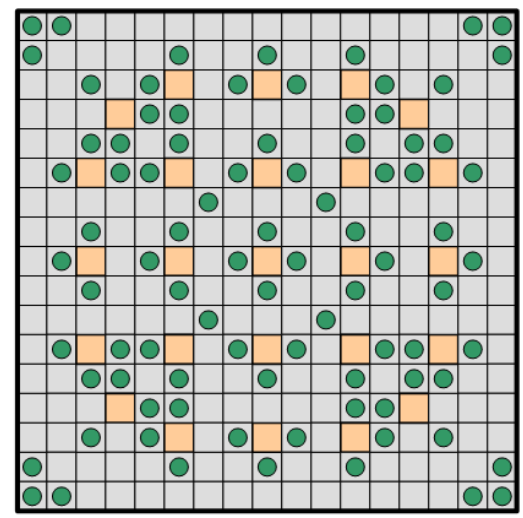

88 IFBA Rods

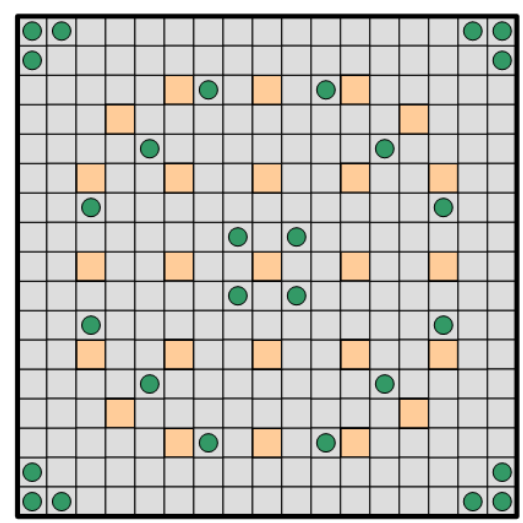

28 IFBA Rods

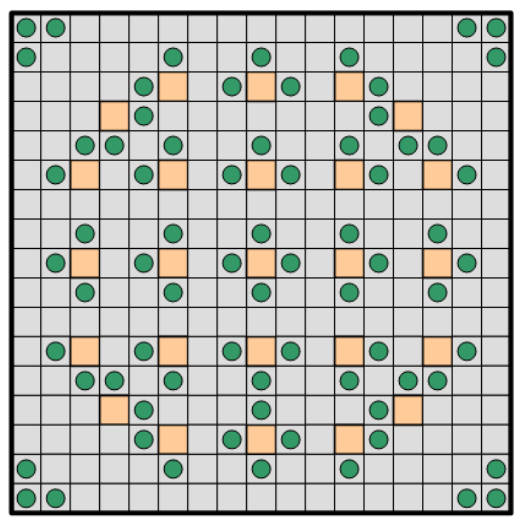

72 IFBA Rods

Fuel rod region

Guide tube

IFBA rod

Figure 4.4. IFBA Rod Arrangement within the AP1000 Fuel Assembly. 
Table 4.2. Reactor Core Description.

\begin{tabular}{|c|c|}
\hline \multicolumn{2}{|c|}{ Active Core } \\
\hline Equivalent diameter $(\mathrm{cm})$ & 304.04 \\
\hline Active fuel height $(\mathrm{cm})$ & 426.72 \\
\hline Height-to-diameter ration & 78.14 \\
\hline Total cross section area $\left(\mathrm{m}^{2}\right)$ & 7.26 \\
\hline Fuel weight, as $\mathrm{UO}_{2}(\mathrm{~g})$ & $9.76 \times 10^{7}$ \\
\hline \multicolumn{2}{|c|}{ Fuel Assembly } \\
\hline Number & 157 \\
\hline Rod array & $17 \times 17$ \\
\hline Rods per assembly & 264 \\
\hline Rod pitch $(\mathrm{cm})$ & 1.26 \\
\hline Overall transverse dimensions $(\mathrm{cm})$ & 21.40 \\
\hline \multicolumn{2}{|c|}{$\begin{array}{ll}\text { Fuel Rods } \\
\end{array}$} \\
\hline Number & 41448 \\
\hline Outside diameter $(\mathrm{cm})$ & 0.9500 \\
\hline Gap diameter $(\mathrm{cm})$ & 0.0165 \\
\hline Clad thickness $(\mathrm{cm})$ & 0.0572 \\
\hline Clad material & ZIRLO \\
\hline \multicolumn{2}{|c|}{ Fuel Pellets } \\
\hline Material & UO2 sintered \\
\hline Density (\% theoretical) & 95.5 \\
\hline \multicolumn{2}{|l|}{ Fuel Enrichments (weight percent) } \\
\hline Region 1 & 2.35 \\
\hline Region 2 & 3.40 \\
\hline Region 3 & 4.45 \\
\hline Diameter $(\mathrm{cm})$ & 0.819 \\
\hline Length $(\mathrm{cm})$ & 0.983 \\
\hline \multicolumn{2}{|c|}{ Discrete Burnable Absorber Rods (PYREX) } \\
\hline Number & 1558 \\
\hline Material & Borosilicate Glass \\
\hline Outside diameter $(\mathrm{cm})$ & 0.968 \\
\hline Inner diameter $(\mathrm{cm})$ & 0.461 \\
\hline Clad material & Stainless Steel \\
\hline $\mathrm{B}_{10}$ content $(\mathrm{Mg} / \mathrm{cm})$ & 6.24 \\
\hline Absorber length $(\mathrm{cm})$ & 368.30 \\
\hline \multicolumn{2}{|c|}{$\begin{array}{c}\text { Integral Fuel Burnable Absorbers (IFBA) } \\
\end{array}$} \\
\hline Number & 8832 \\
\hline Type & IFBA \\
\hline Material & Boride Coating \\
\hline $\mathrm{B}_{10}$ content $(\mathrm{Mg} / \mathrm{cm})$ & 0.772 \\
\hline Absorber length $(\mathrm{cm})$ & 386.08 \\
\hline Absorber coating thickness $(\mathrm{cm})$ & 0.00256 \\
\hline
\end{tabular}




\section{Benchmark Analysis}

To test the validity of the AP1000 whole-core 3D model, a benchmark test was developed. The AP1000 Design Control Documentation [36] provided by the US NRC for the licensing process was us ed for the procedure. T he report provided the multiplication factor $\left(\mathrm{k}_{\mathrm{eff}}\right)$ for cold, zero power, beginning of cycle, and zero soluble boron core conditions. The code systems, MCNP5 and SCALE (KENO-VI), were used to model the reactor at the specified core conditions in order to be nchmark $\mathrm{t}$ he $\mathrm{k}$ eff value a gainst publ ished $\mathrm{r}$ esults a nd $\mathrm{f}$ or a $\mathrm{c}$ ode-to-code be nchmark procedure.

For bot $\mathrm{h} t$ he M CNP a nd S CALE $\mathrm{c}$ alculations, $\mathrm{t}$ he $\mathrm{s}$ olution $\mathrm{w}$ as obt ained us ing one $\mathrm{m}$ illion neutron histories, 5,000 histories per cycle for 260 cycles with the first 60 cycles ignored. The results are 1 isted in Table 4.3. A s i ndicated, the MCNP cal culation was ve ry ac curate when compared to the published results, giving a difference of only $0.0498 \%$ between $\mathrm{k}_{\text {eff }}$ values. The result cal culated by S CALE had a s lightly hi gher di fference at $0.1942 \%$. C omparing the two codes systems (MCNP vs. SCALE) the difference was measured at $0.1445 \%$.

Table 4.3. AP1000 Multiplication Factor Results.

\begin{tabular}{|c|c|c|c|}
\hline Multiplication Factor Origin & $\mathbf{k}_{\text {eff }}$ & $\begin{array}{c}\text { \% difference } \\
\text { (published-to-code) }\end{array}$ & $\begin{array}{c}\text { \% difference } \\
\text { (code-to-code) }\end{array}$ \\
\hline \hline AP1000 Design Control Documentation & 1.205 & na & na \\
\hline MCNP Code System (version 5 1.51) & 1.2044 & 0.0498 & 0.1445 \\
\hline SCALE Code System (KENO-VI) & 1.2026 & 0.1942 & \\
\hline
\end{tabular}

The ave rage energy-dependent ne utron flux in the fuel el ements, as p roduced by M CNP and SCALE, are provided in Figure 4.5. As shown, the profile is as expected for a PWR, but what is of more interest is the direct comparison of the two code systems. It is easily determined that the spectrum produced by MCNP and SCALE are nearly identical, as they appear to be directly on top of each other.

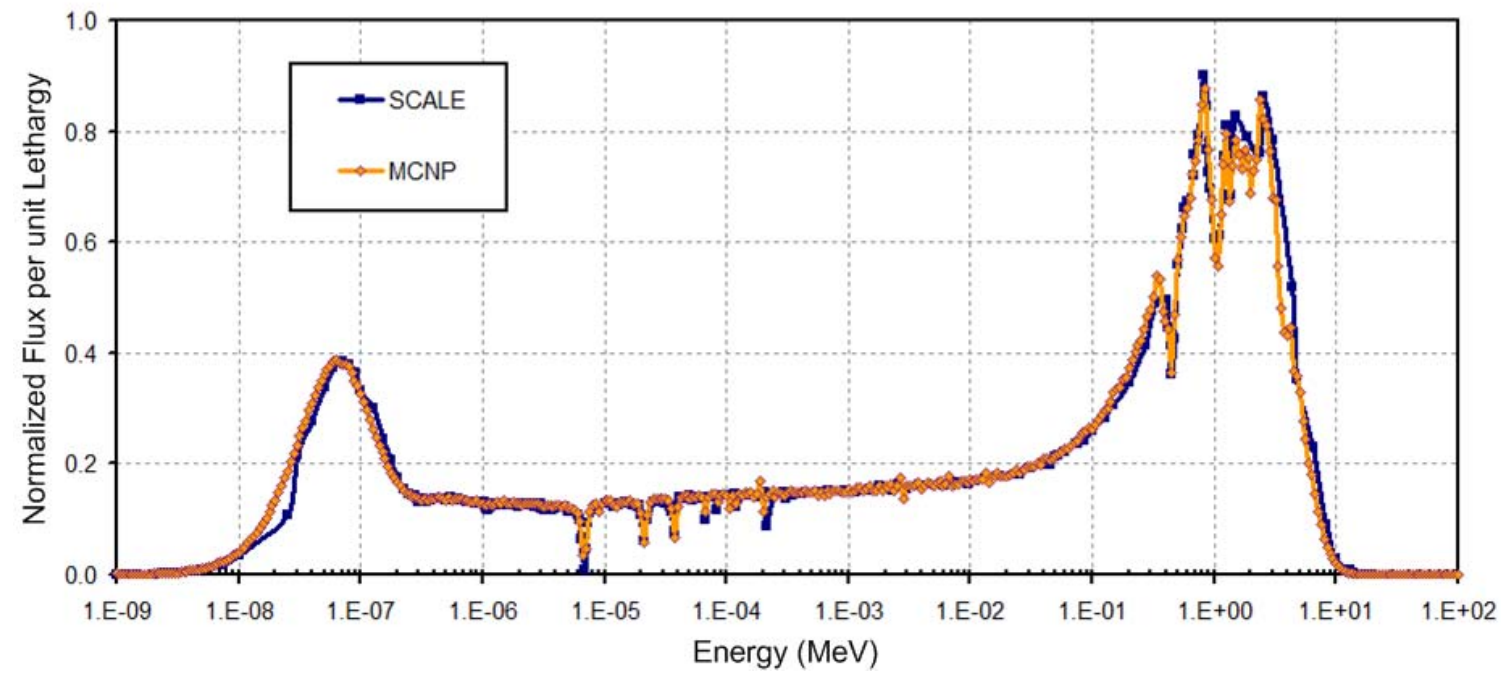

Figure 4.5. Neutron Flux Profiles in the AP1000 Fuel Rods (MCNP vs. SCALE). 


\subsubsection{VHTR}

The United States Department of Energy has given priority to the VHTR concept making it the focus of intensive research programs. The VHTR is designed to be a high-efficiency system, which can supply electricity and process he at to a wide-range of high temperature and energy intensive applications. The VHTR is a passively safe design. The refractory core, low power density, and low excess reactivity enable this design feature.

The V HTR i s a graphite $\mathrm{m}$ oderated gas-cooled $\mathrm{r}$ eactor $\mathrm{t}$ hat $\mathrm{s}$ upplies heat $\mathrm{w}$ ith core out let temperatures in $\mathrm{t}$ he $\mathrm{r}$ ange of $850-1000^{\circ} \mathrm{C}$. T his e nables a pplications $\mathrm{s}$ uch a $\mathrm{s}$ ydrogen production, process he at for the pe trochemical i ndustry, or s eawater de salination. I ts ba sic technology has been well established in former High Temperature Gas Reactors (HTGR), such as the G erman A VR and T HTR prototypes, and the U S F ort S aint V rain a nd P each B ottom prototypes. The VHTR extends the capabilities of HTGR to a chieve further improvements in thermal efficiency and future additional high-temperature applications.

The reactor core can be a prismatic block core or a pebble bed core design. Both the prismatic and pebble be $\mathrm{d}$ cores $\mathrm{h}$ ave the same key design characteristics and use the $\mathrm{s}$ ame $\mathrm{c}$ eramic or TRIstructual ISOtropic (TRISO) coated fuel particles. The TRISO coating provides a miniature containment ve ssel for e ach fuel particle, a llowing complete retention of fission fragments at high temperatures [37].

The $\mathrm{c}$ ore $\mathrm{t}$ ype ut ilized in the nuc lear e nergy system is the pr ismatic bl ock design. $T$ he prototypical prismatic VHTR produces a thermal power of $600 \mathrm{M} \mathrm{W}$ th with a low power density of a pproximately $7 \mathrm{~W} / \mathrm{cm}^{3}$ and a $\mathrm{n}$ a nnular $\mathrm{fuel} \mathrm{c}$ onfiguration. In ba sic $\mathrm{t}$ erms, the $\mathrm{c}$ ore i s composed of fuel blocks, control rod guide blocks, and reflectors blocks. The fuel blocks consist of a he xagonal graphite bl ock w ith bor ings for the $\mathrm{pl}$ acement of fuel $\mathrm{c}$ ompacts a nd h elium coolant channels. The control rod guide blocks are hexagonal graphite blocks with borings for the control rods to pass through. The reflector blocks are simply solid graphite hexagonal blocks used to limit neutron leakage. The fuel blocks, control rod guide blocks, and reflector blocks are stacked on t op of one a nother and then arranged side-to-side in a hexagonal lattice to create a cylindrically shaped core.

\section{Model Description}

The VHTR model is based on the High Temperature Test Reactor (HTTR) of the Japan Atomic Energy R esearch Institute (JAERI) [38]. The HTTR w as s elected because of the doc umented experimental test results and the opportunity it presented for performing an experiment-to-code benchmark analysis, as described later in this section. The basic design features of the smaller HTTR w ere us ed to create the scaled-up VHTR pow er reactor. T he VHTR de sign parameters are listed in Table 4.4 . 
Table 4.4. VHTR Design Parameters.

\begin{tabular}{|c|c|c|c|}
\hline Fuel & $\begin{array}{c}\mathrm{U} \\
\mathrm{O} 2\end{array}$ & Power (MWth) & 600 \\
\hline Enrichment(\%) & 8 & Power Density $\left(\mathrm{W} / \mathrm{cm}^{3}\right)$ & 6.9 \\
\hline \multirow[t]{2}{*}{ Coolant } & \multirow{2}{*}{$e^{H}$} & Pressure (MPa) & 7.0 \\
\hline & & Inlet/Outlet Temperature $\left({ }^{\circ} \mathrm{C}\right)$ & $490 / 950$ \\
\hline \multirow[t]{3}{*}{ \# of Columns } & \multirow{3}{*}{$02^{1}$} & \# of Fuel Columns & 66 \\
\hline & & \# of Control Columns & 36 \\
\hline & & \# of Blocks/Column & 13 \\
\hline Block Pitch (cm) & $6^{3}$ & \# of Fuel Pins/Fuel Block & 32 \\
\hline \multirow[t]{7}{*}{ Block Height $(\mathrm{cm})$} & \multirow{7}{*}{$8^{5}$} & \# of Burnable Poison Rods/Fuel Block & 2 \\
\hline & & Control Rods/Control Block & 2 \\
\hline & & Emergency Rods/Control Block & 1 \\
\hline & & Compact Pitch $(\mathrm{cm})$ & 5.15 \\
\hline & & Fuel Hole Radius $(\mathrm{cm})$ & 4.1 \\
\hline & & Compact Inner Radius (cm) & 0.5 \\
\hline & & Compact Outer Radius (cm) & 1.3 \\
\hline \multirow[t]{7}{*}{ Packing (\%) } & \multirow{7}{*}{$0^{3}$} & $10.41 \mathrm{~g} / \mathrm{cm}^{3}$ Kernel Radius $(\mathrm{cm})$ & 0.0300 \\
\hline & & $1.14 \mathrm{~g} / \mathrm{cm}^{3}$ Buffer Radius (cm) & 0.0359 \\
\hline & & $1.89 \mathrm{~g} / \mathrm{cm}^{3}$ PyC1 Radius $(\mathrm{cm})$ & 0.0390 \\
\hline & & $3.20 \mathrm{~g} / \mathrm{cm}^{3}$ SiC Radius $(\mathrm{cm})$ & 0.0419 \\
\hline & & $1.87 \mathrm{~g} / \mathrm{cm}^{3}$ PyC2 Radius $(\mathrm{cm})$ & 0.0465 \\
\hline & & Matrix $\left(\mathrm{g} / \mathrm{cm}^{3}\right)$ & 1.77 \\
\hline & & Block $\left(\mathrm{g} / \mathrm{cm}^{3}\right)$ & 1.69 \\
\hline
\end{tabular}

The general procedure for creating the model was to build the three types of prismatic hexagonal blocks that compose the VHTR, and then arrange these blocks in an array of rows and columns to $\mathrm{c}$ onstruct the $\mathrm{c}$ ore. The three pr ismatic bl ocks include: f uel a ssembly bl ocks, replaceable reflector bl ocks, and $\mathrm{c}$ ontrol $\mathrm{r}$ od guide bl ocks. $\mathrm{T}$ o $\mathrm{c}$ omplete the core the $\mathrm{c}$ onfiguration of prismatic blocks was then surrounded by a permanent graphite reflector.

The fuel a ssemble bl ock c onsists of 33 fuel e lements with he lium c oolant $\mathrm{c}$ hannels a nd $\mathrm{t}$ wo burnable poison rods, which are arranged in a hexagonal graphite block to create a pin-in-block type assembly. The fuel block is $36 \mathrm{~cm}$ in width across the flats and $58 \mathrm{~cm}$ in height. The block has 33 ve rtical borings with a di ameter of $4.1 \mathrm{c} \mathrm{m}$ for placement of the a nnular fuel rods. In addition, each fuel graphite block has three burnable poison insertion holes measuring $50 \mathrm{~cm}$ in height and $1.5 \mathrm{~cm}$ in diameter. Two are loaded with burnable poison rods, while the third is left empty. In the center of each block is a fuel-handling hole.

Figure $4.6 \mathrm{~s}$ hows t he a rrangement a nd dimensions of $t$ he pr ismatic $f$ uel bl ock. $T$ he measurements and material properties of the block are given in Table 4.5, with all measurements provided in units of $\mathrm{cm}$. 


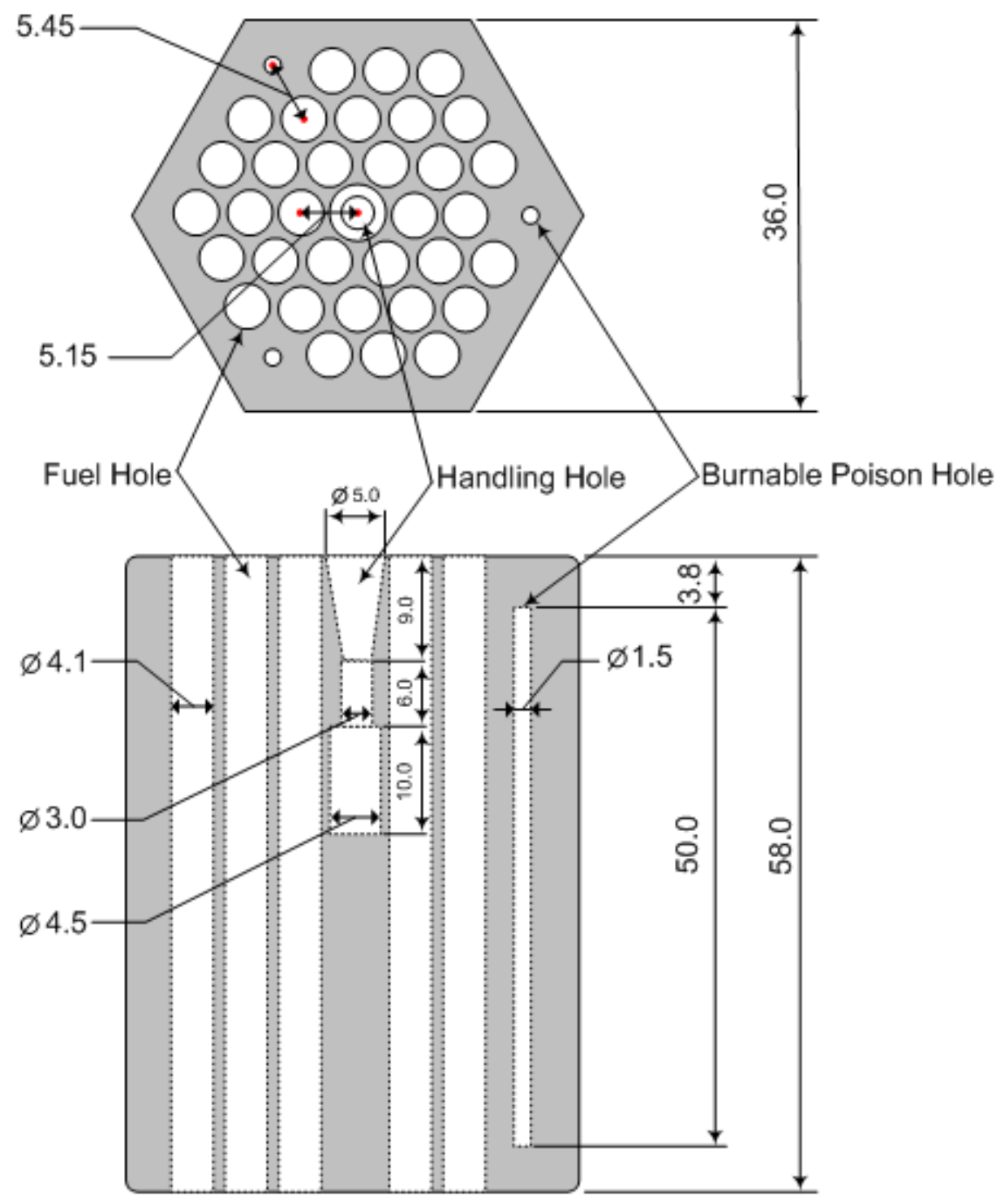

Figure 4.6. VHTR Prismatic Fuel Block (measurements in cm). 
Table 4.5. VHTR Prismatic Fuel Block Properties.

\begin{tabular}{|l|l|}
\hline Type & Pin-in-block \\
\hline Configuration & Hexagonal \\
\hline Material & IG-110 Graphite \\
\hline Density $\left(\mathrm{g} / \mathrm{cm}^{3}\right)$ & 1.77 \\
\hline Height $(\mathrm{cm})$ & 58 \\
\hline Width Across the Flats $(\mathrm{cm})$ & 36 \\
\hline \# of Fuel Holes/Block & 33 \\
\hline Fuel Hole Diameter $(\mathrm{cm})$ & 4.1 \\
\hline Fuel Hole Height $(\mathrm{cm})$ & 58 \\
\hline \# of Burnable Poison Holes/Block & 3 \\
\hline Burnable Poison Hole Diameter $(\mathrm{cm})$ & 1.5 \\
\hline Burnable Poison Hole Height $(\mathrm{cm})$ & 50 \\
\hline
\end{tabular}

The fuel element consists of TRISO fuel particles imbedded within a graphite matrix in the form of an annular rod (fuel compact), that is encapsulated by a graphite sleeve. Figure 4.7 illustrates how the T RISO $\mathrm{p}$ articles, fuel com pact, and protective s leeve are arranged to create the fuel element. E ach fuel element contains 176,515 TRISO particles within the fuel compact with a packing $\mathrm{f}$ raction of $30 \%$. $\mathrm{T}$ able $4.6 \mathrm{c}$ ontains $\mathrm{t}$ he $\mathrm{f}$ uel e lement di mensions a nd $\mathrm{m}$ aterial properties. The MCNP model uses a square lattice array for the TRISO particles contained in the graphite matrix of the fuel compact.

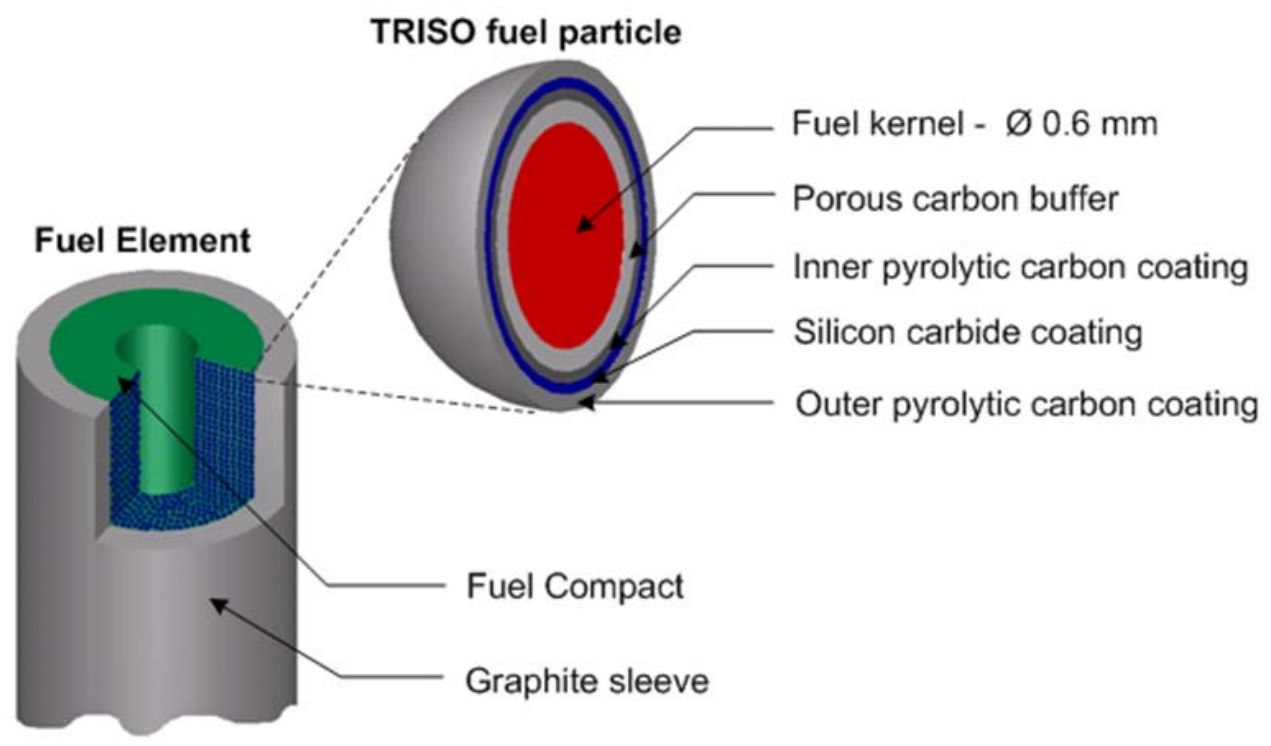

Figure 4.7. VHTR Fuel Element. 
Table 4.6. VHTR Fuel Element Properties.

\begin{tabular}{|l|c|c|c|}
\hline a) TRISO particle & Material & Density $\left(\mathrm{g} / \mathrm{cm}^{3}\right)$ & Radius $(\mathrm{cm})$ \\
\hline Fuel kernel & $\mathrm{UO}_{2}$ & 10.41 & 0.0300 \\
\hline 1st coating & $\mathrm{PyC}$ & 1.14 & 0.0359 \\
\hline 2nd coating & $\mathrm{PyC}$ & 1.89 & 0.0390 \\
\hline 3rd coating & $\mathrm{SiC}$ & 3.2 & 0.0419 \\
\hline 4th coating & $\mathrm{PyC}$ & 1.87 & 0.0465 \\
\hline
\end{tabular}

\begin{tabular}{|l|c||l|c|}
\hline \multicolumn{2}{|c|}{ b) Fuel Compact } & \multicolumn{2}{c|}{ c) Graphite Sleeve } \\
\hline Number of fuel particles & 176,515 & Material & Graphite \\
\cline { 2 - 4 } Graphite matrix density & $1.690 \mathrm{~g} / \mathrm{cm}^{2}$ & Density & $1.770 \mathrm{~g} / \mathrm{cm}^{2}$ \\
\hline Diameter-inner & $1.0 \mathrm{~cm}$ & Diameter-inner & $2.6 \mathrm{~cm}$ \\
\hline Diameter-outer & $2.6 \mathrm{~cm}$ & Diameter-outer & $3.4 \mathrm{~cm}$ \\
\hline Height & $54.6 \mathrm{~cm}$ & Height & $57.7 \mathrm{~cm}$ \\
\hline
\end{tabular}

The burnable poison rod is $1.4 \mathrm{~cm}$ in diameter and $50 \mathrm{~cm}$ in height. It is made up of two neutron absorber sections $(20 \mathrm{~cm}$ in height) separated by a graphite section $(10 \mathrm{~cm}$ in height). Table 4.7 lists the properties of the burnable poison rods.

Figure 4.8 s hows a three-dimensional representation of the prismatic fuel block and the relative locations of the a nnular fuel rods, c oolant c hannels, bur nable poi son r ods, a nd fuel-handling hole. Within the core there are 858 fuel blocks.

Table 4.7. VHTR Burnable Poison Rod Properties.

\begin{tabular}{|c|l|}
\hline Absorber Section Material & $\mathrm{B}_{4} \mathrm{C}-\mathrm{C}$ \\
\hline Density $\left(\mathrm{g} / \mathrm{cm}^{3}\right)$ & 1.82 \\
\hline Natural Boron Concentration (wt. \%) & 2.74 \\
\hline Diameter $(\mathrm{cm})$ & 1.39 \\
\hline Height $(\mathrm{cm})$ & 2.5 \\
\hline B-10 Abundance Ratio (wt. \%) & 18.7 \\
\hline Graphite Section Density $\left(\mathrm{g} / \mathrm{cm}^{3}\right)$ & 1.77 \\
\hline Diameter $(\mathrm{cm})$ & 1.4 \\
\hline Height $(\mathrm{cm})$ & 10 \\
\hline
\end{tabular}




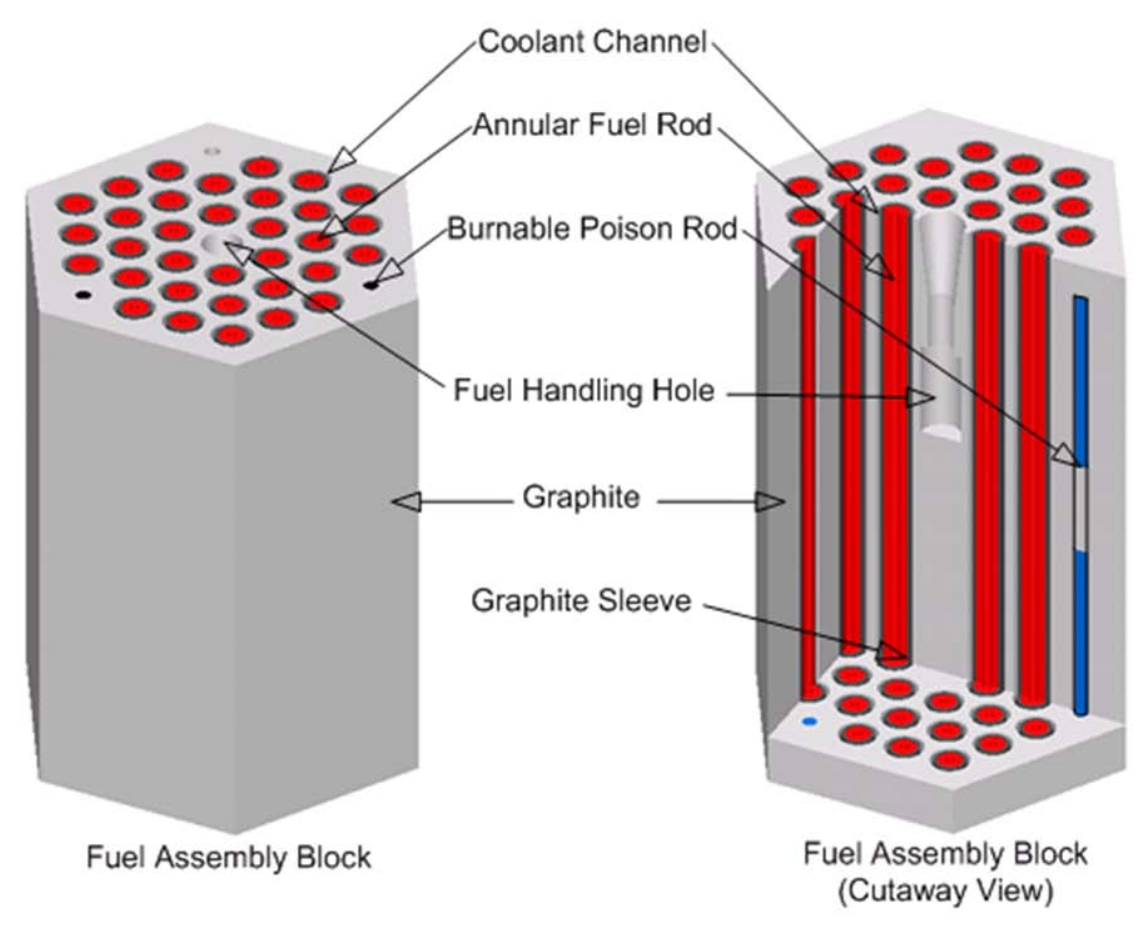

Figure 4.8. VHTR Prismatic Fuel Block.

The replaceable reflector block has the same external form as the fuel assembly block, $36 \mathrm{~cm}$ in width across the flats and $58 \mathrm{~cm}$ in height with a handling hole in the center of the block. There are two types of reflector blocks: one being a solid graphite block and the other having helium coolant channels in it. Examples of the replaceable reflector blocks are provided in Figure 4.9, with the properties listed in Table 4.8.

Table 4.8. VHTR Replaceable Reflector Block Properties.

\begin{tabular}{|l|l|}
\hline Configuration & Hexagonal \\
\hline Material & IG-110 Graphite \\
\hline Density $\left(\mathrm{g} / \mathrm{cm}^{3}\right)$ & 1.76 \\
\hline Height $(\mathrm{cm})$ & 58 \\
\hline Width across the flats $(\mathrm{cm})$ & 36 \\
\hline Coolant hole diameter $(\mathrm{cm})$ & 4.1 \\
\hline Coolant hole height $(\mathrm{cm})$ & 58 \\
\hline
\end{tabular}




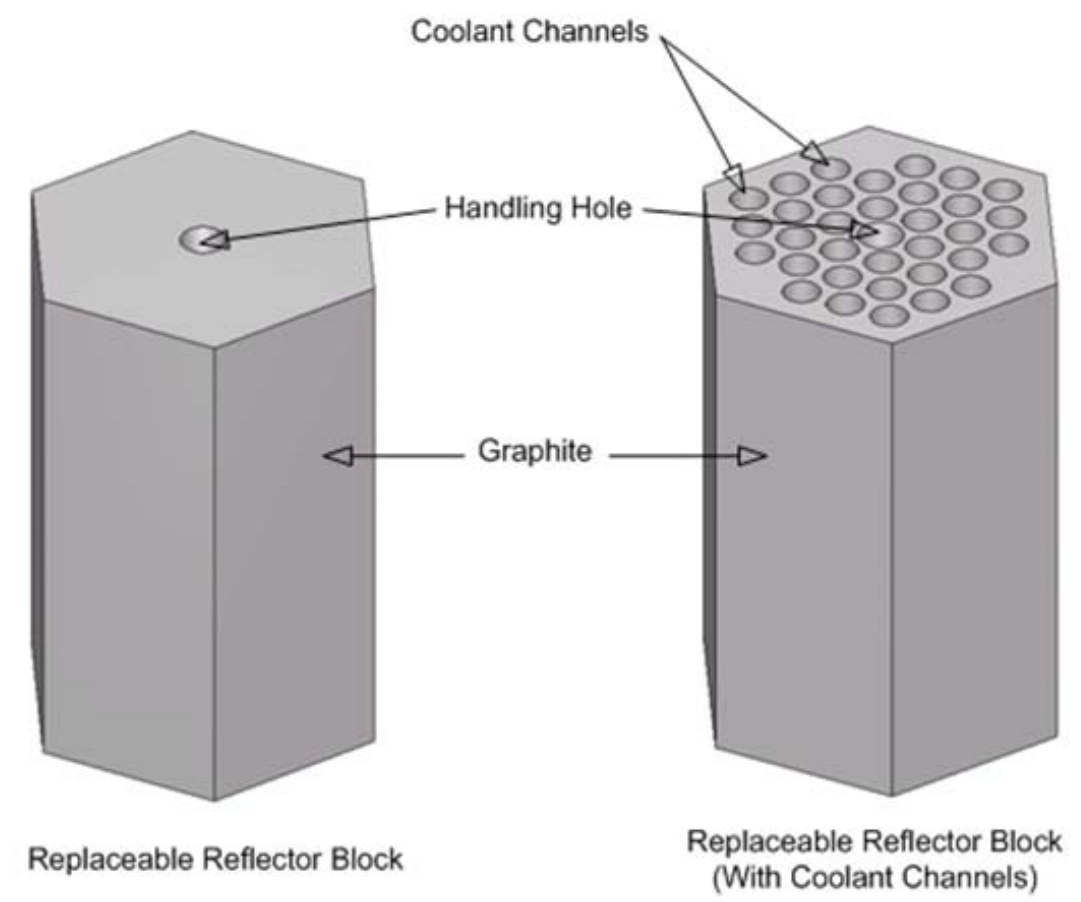

Figure 4.9. VHTR Replaceable Reflector Blocks.

The r eflector bl ocks w ith the coolant c hannels a re s tacked di rectly a bove a nd be low the fuel assembly blocks. This creates a fuel column, being composed of 2 replaceable reflector blocks on top, 13 fuel assembly blocks in the middle (active core), and 2 replaceable reflector blocks on the bottom. The replaceable reflector blocks with coolant channels have the same dimensions as the fuel $g$ raphite bl ock $w$ ithin the $s$ ame c olumn, $w$ ith the e xception of not ha ving the three burnable poi son i nsertion hol es. $\mathrm{T}$ his allows the he lium gas coolant t o flow i nto the core, through the fuel assemble blocks and around the fuel elements, and then exit the core.

The $f$ inal $t$ ype of pr ismatic bl ock i s t he $\mathrm{c}$ ontrol $\mathrm{r}$ od g uide bl ock. T he bl ock c onsists of a hexagonal graphite block with three large vertical borings. Like the fuel block, it is $58 \mathrm{c} \mathrm{m}$ in height and $36 \mathrm{~cm}$ in width a cross the flats. The hol es created by the borings have a $12.3 \mathrm{~cm}$ diameter and extend through the entire length of the block. T wo of the holes are us ed for the control r ods to pa ss through, while the third is 1 eft e mpty t o s erve a s the r eserve s hutdown system. In the center of each block is a fuel-handling hole. Figure 4.10 shows the arrangement and dimensions of the control rod guide block and Table 4.9 lists the properties of the block. 


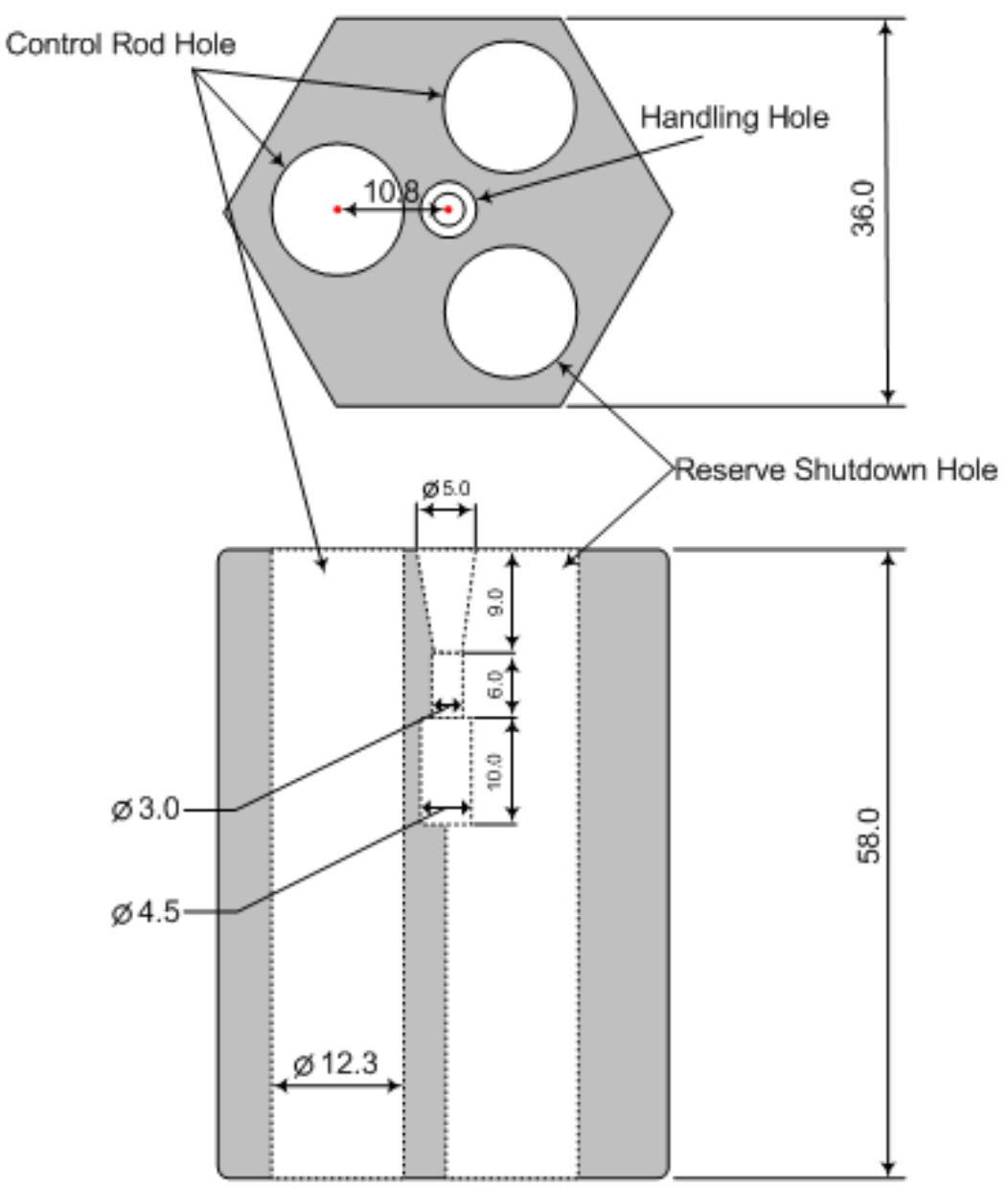

Figure 4.10. VHTR Control Rod Guide Block (measurements in cm).

Table 4.9. VHTR Control Rod Guide Block Properties.

\begin{tabular}{|l|l|}
\hline Material & IG-110 Graphite \\
\hline Density $\left(\mathrm{g} / \mathrm{cm}^{3}\right)$ & 1.77 \\
\hline Height $(\mathrm{cm})$ & 58 \\
\hline Width across the flats $(\mathrm{cm})$ & 36 \\
\hline Number of control rod holes in block & 2 \\
\hline Control rod hole diameter $(\mathrm{cm})$ & 12.3 \\
\hline Control rod hole height $(\mathrm{cm})$ & 58 \\
\hline Number of reserve shutdown holes in block & 1 \\
\hline Reserve shutdown hole diameter $(\mathrm{cm})$ & 12.3 \\
\hline Reserve shutdown hole height $(\mathrm{cm})$ & 58 \\
\hline
\end{tabular}

The model can now be described by fuel columns, control columns, the central reflector, and the outer reflector. T he fuel and control columns are arranged in an annular configuration that is three bl ocks w ide t o c reate the fueled $\mathrm{r}$ egion of the $\mathrm{c}$ ore. $\mathrm{T}$ he $\mathrm{c}$ entral $\mathrm{g}$ raphite column a nd surrounding graphite reflector make up the remainder of the core. The active core is composed 
of 66 fuel columns and 36 control columns that have 13 blocks per column. The bottom reflector is $160 \mathrm{~cm}$ thick and the top reflector is $116 \mathrm{~cm}$ thick. The active core is $754 \mathrm{~cm}$ in height and the overall core is $1030 \mathrm{~cm}$ in height. The radial distance from the center of the core to the closest fuel column is $144 \mathrm{~cm}$ and the fueled region is $108 \mathrm{~cm}$ thick (three fuel/control columns across). The outer reflector is $88 \mathrm{~cm}$ thick giving an outer cylindrical core radius of $340 \mathrm{~cm}$. Figure 4.11 shows a 3D and 2D view of the VHTR model with geometry details.

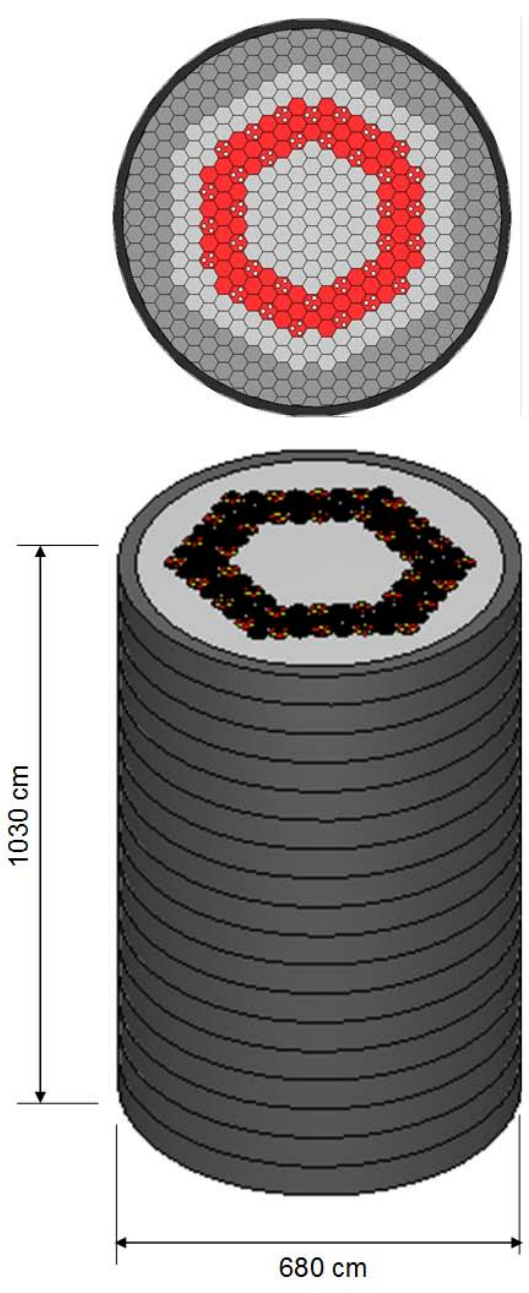

a) VHTR 3D View

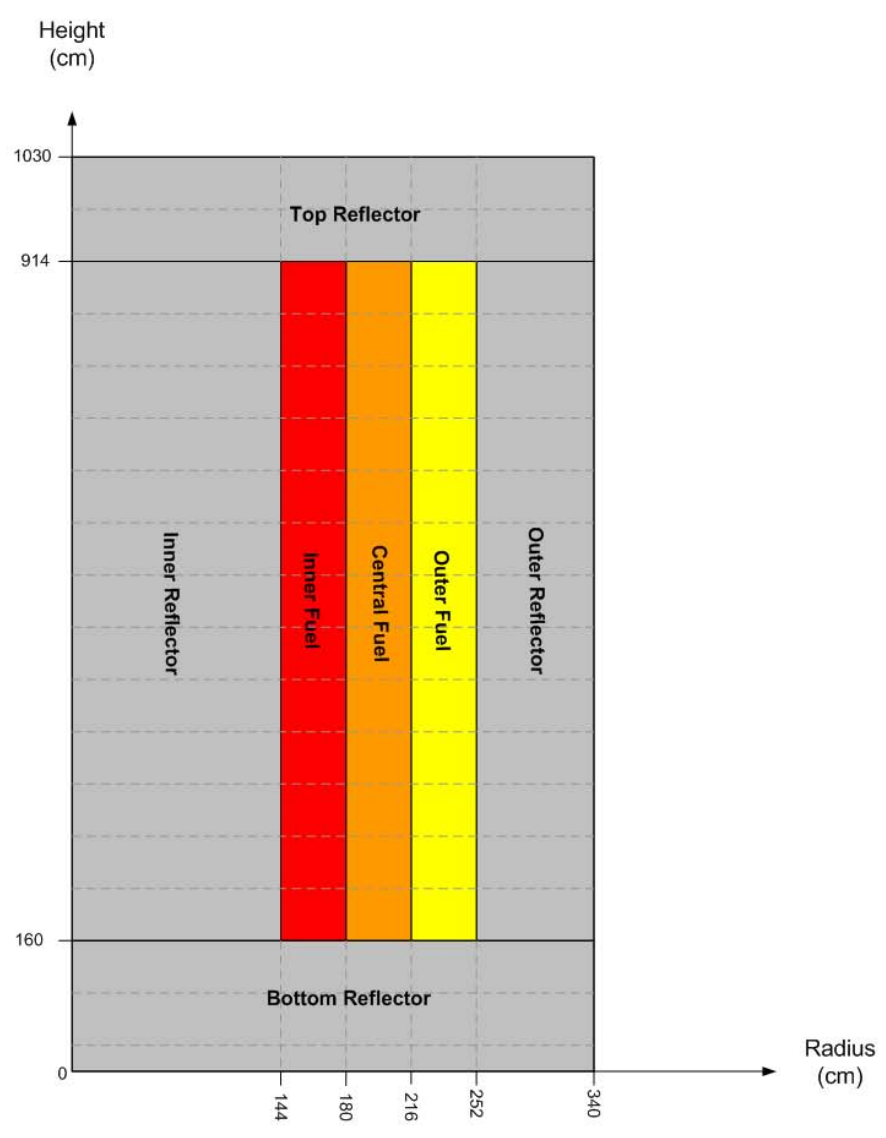

b) VHTR 2D View

Figure 4.11. VHTR Whole-core 3D Model Geometry Details. 


\section{Benchmark Analysis}

Many of the w ell-established computer cod e s ystems available for V HTR ana lysis w ere originally developed and validated for evaluating LWRs. Although VHTRs and LWRs are both thermal ne utron s pectrum $r$ eactors and s hare m uch in common, the V HTR pr esents uni que phenomena that may not be accounted for correctly by the code system and, therefore, must be addressed. $\mathrm{T}$ he $\mathrm{m}$ ain $\mathrm{c}$ oncern i s the randomness in particle di stribution and related mul tiheterogeneity effects as sociated with VHTRs. D ue t o t his conc ern, a de tailed be nchmark procedure was developed for the VHTR model.

Greater importance was placed on the ability to perform experiment-to-code benchmarking and to $\mathrm{c}$ ombine that $\mathrm{w}$ ith additional $\mathrm{c}$ ode-to-code co mparisons. The availability of ex perimental results led to the HTTR of the JAERI, from which startup core physics results are provided by the IAEA in a T echnical D ocument publ ication [38]. T he major de sign specifications for the HTTR are given in Table 4.10.

Table 4.10. HTTR Design Specifications.

\begin{tabular}{|l|l|}
\hline Thermal Power (MW) & 30 \\
\hline Outlet Coolant Temperature $\left({ }^{\circ} \mathrm{C}\right)$ & 950 \\
\hline Inlet Coolant Temperature $\left({ }^{\circ} \mathrm{C}\right)$ & 395 \\
\hline Primary Coolant Pressure $(\mathrm{MPa})$ & 4 \\
\hline Core Structure & Graphite \\
\hline Equivalent Core Diameter $(\mathrm{cm})$ & 230 \\
\hline Effective Core Height $(\mathrm{cm})$ & 290 \\
\hline Average Power Density $\left(\mathrm{W} / \mathrm{cm}^{3}\right)$ & 2.5 \\
\hline Fuel & UO2 \\
\hline Uranium Enrichment $(\mathrm{wt} . \%)$ & 3 to 10 \\
\hline Type of Fuel & Pin-in-block \\
\hline Burnup Period (days) & 660 \\
\hline Coolant Material & Helium gas \\
\hline Flow Direction in Core & Downward \\
\hline Top Reflector Thickness (cm) & 116 \\
\hline Side Reflector Thickness (cm) & 99 \\
\hline Bottom Reflector Thickness (cm) & 116 \\
\hline Number of Fuel Assemblies & 150 \\
\hline Number of Fuel Columns & 30 \\
\hline Number of Pairs of Control Rods & 16 \\
\hline In Core & 7 \\
\hline In Reflector & 9 \\
\hline
\end{tabular}

In addition to the HTTR benchmark model description provided in this section, complete details of material compositions and geometry specifications are included in Appendix A. The SCALE code system was chosen as the computational tool for modeling the HTTR due to its flexibility in geometry $\mathrm{r}$ epresentation, existing te mperature treatment opt ions, availability o f te chniques accounting for double heterogeneity effects, and computational run time for complex whole-core $3 \mathrm{D}$ models. 
An assessment was performed to determine the best pos sible method to account for the double heterogeneity effects [39]. This was accomplished by creating two HTTR models, one using the provided DOUBLEHET unit cell treatment available in SCALE 5.1, while the other bypasses the feature. Instead the Dancoff correction factor is independently determined by the code system DANCOFF-MC [40] and manually entered into the model as an external parameter. Table 4.11 provides a comparison of the results for the two different treatments of the heterogeneity effects. As s hown, a hi gher d egree of a ccuracy was accomplished $w$ ith the DOUBLEHET m odel; therefore, it was chosen to represent the HTTR model for further benchmark efforts.

Table 4.11. Results for Different Heterogeneity Treatments.

\begin{tabular}{|l|c|c|}
\hline \multicolumn{1}{|c|}{ HTTR Model } & $\mathbf{k}_{\text {eff }}$ & Error (\%) \\
\hline \hline Experimental & 1.1363 & - \\
\hline SCALE 5.0 (with DANCOFF-MC) & 1.1122 & $2.12 \%$ \\
\hline SCALE 5.1 (with DOUBLEHET) & 1.1368 & $0.04 \%$ \\
\hline
\end{tabular}

The benchmark problems are related to start-up core physics tests and include the analysis of the effective multiplication factor for the fully loaded c ore with control rods fully withdrawn and fully inserted, control rod pos ition at c riticality, and the isothermal temperature co efficient of reactivity.

Following th e e stablished international be nchmark program practices, in the present a nalysis $10 \%$ di screpancy b etween computed values and the ava ilable ex perimental va lues $\mathrm{w}$ ere considered as the model's acceptability threshold. As evident in Table 4.12, the results are well within acceptable range. Aside from the temperature coefficient, each of the benchmark cases is within $0.25 \%$ of the experimental va lues a nd fall $\mathrm{w}$ ithin the experimental er ror value. The computed value of the isothermal temperature coefficient deviates by approximately $2 \%$ from the corresponding experimental va lue. $\mathrm{H}$ owever, $\mathrm{t}$ he e xperimental va lue is $\mathrm{w}$ ithin $\mathrm{t}$ he $\mathrm{s}$ tandard deviation limits of the computational result. It is expected that increasing the sample size of the model would result in reducing the discrepancy to within the range of the other benchmark tests, but for $\mathrm{t}$ he be nchmark calculations a m aximum c omputational $\mathrm{r}$ un $\mathrm{t}$ ime $\mathrm{w}$ as $\mathrm{s}$ et and hi gher accuracy results were not obtained in the present analysis.

Table 4.12. HTTR Experiment-to-code Benchmark Results.

\begin{tabular}{|l|c|c|c|c|}
\hline \multicolumn{2}{|c|}{ Benchmark } & $\begin{array}{c}\text { HTTR } \\
\text { (experimental) }\end{array}$ & $\begin{array}{c}\text { VHTR model } \\
\text { (calculated) }\end{array}$ & $\begin{array}{c}\text { Error } \\
\text { (\%) }\end{array}$ \\
\hline \hline Control Rods Fully Withdrawn & $\mathrm{k}_{\text {eff }}$ & $1.1363 \pm 0.041$ & $1.1368 \pm 0.0023$ & 0.044 \\
\hline Control Rods Fully Inserted & $\mathrm{k}_{\text {eff }}$ & $0.685 \pm 0.010$ & $0.6858 \pm 0.0019$ & 0.117 \\
\hline Critical Insertion Depth (300K) & $\mathrm{cm}$ & $177.5 \pm 0.5$ & 177.1 & 0.225 \\
\hline Critical Insertion Depth $(418 \mathrm{~K})$ & $\mathrm{cm}$ & $190.3 \pm 0.5$ & 189.9 & 0.210 \\
\hline Temperature Coefficient & $\Delta \mathrm{k} / \mathrm{k} / \mathrm{K}$ & $-1.42 \times 10^{-4}$ & $-1.45 \times 10^{-4}$ & 2.113 \\
\hline
\end{tabular}

The H TTR configuration w ith the c ontrol rods fully withdrawn was chosen as the prototype VHTR c onfiguration. The be st a greement with experimental data $\mathrm{w}$ as o bserved for that case. 
Table 4.13 summarizes the basic reactor physics characteristics obtained for the prototype VHTR configuration.

Table 4.13. Basic Reactor Physics Results (Withdrawn Control Rods).

\begin{tabular}{|c|c|c|c|}
\hline $\mathbf{k}_{\text {eff }}$ & $\begin{array}{c}\text { Fission-Inducing } \\
\text { Energy (eV) }\end{array}$ & $\begin{array}{c}\text { System Mean Free } \\
\text { Path }(\mathbf{c m})\end{array}$ & $\begin{array}{c}\text { Fission Neutron } \\
\text { Yield }\end{array}$ \\
\hline \hline $1.1368 \pm 0.0023$ & $0.814041 \pm 0.0002014$ & $2.9445 \pm 0.00121$ & $2.43872 \pm 0.00001$ \\
\hline
\end{tabular}

The HTTR is currently the only operating VHTR prismatic core design; making it a focal point for VHTR related research. The HTTR was designed according to established objectives, which categorize it as a small-scale VHTR. The future VHTR power reactors will most likely consist of annular core designs, whereas the HTTR is a cylindrical core design. An annular core is one of $t$ he pr omising $\mathrm{c}$ ore $t$ ypes $f$ or $t$ he $f$ uture VHTRs be cause of $i$ ts hi gh i nherent s afety characteristics related to a loss of coolant accident. The decay heat removal is enhanced by the introduction of the a nnular $\mathrm{c}$ ore be cause the he at $\mathrm{t}$ ransfer pa th $\mathrm{w}$ ill be shortened due t $\mathrm{o}$ the relatively thin active core region. As a result, the fuel temperature in a loss of coolant accident can be maintained at less than the fuel temperature limit of $1600^{\circ} \mathrm{C}$ [41].

The prismatic whole-core 3D model was adjusted from the original cylindrical core of the HTTR to that of a larger annular power core $(600 \mathrm{MW}$ th), which represents the VHTR model used in the nuclear energy system within this study, as described in Table 4.4 and Figure 4.11.

To maintain the consistency of the annular VHTR model an exact model was built in MCNP to perform a cod e-to-code be nchmark $f$ or $t$ he new $c$ onfiguration. A $c$ omparison of $t$ he multiplication factor for the SCALE and MCNP models is provided in Table 4.14.

Table 4.14. VHTR Code-to-code Results.

\begin{tabular}{|l|c|c|}
\hline Code System & $\mathbf{k}_{\text {eff }}$ & \% difference \\
\hline \hline MCNP5 & 1.26737 & \multirow{2}{*}{0.124} \\
\hline SCALE (KENO-VI) & 1.26580 & \\
\hline
\end{tabular}

In a ddition to the multiplication factor, the ave rage energy-dependent $n$ eutron flux $w$ ithin the fuel com pacts $\mathrm{w}$ as al so evaluated for the models. A s shown in Figure 4.12 the flux profile is typical for that of VHTRs, but what is of more interest is the direct comparison of the spectrums produced by the two code systems, which are almost indistinguishable. 


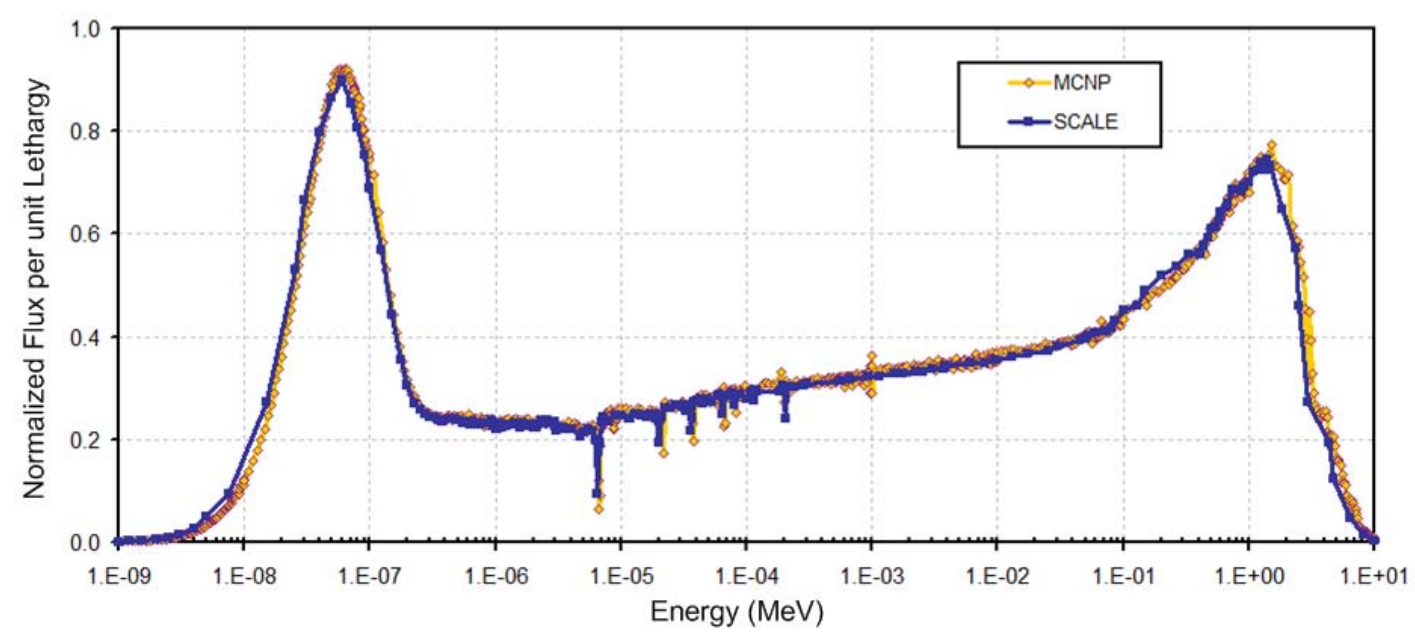

Figure 4.12. Neutron Flux Profiles in the VHTR Fuel Compacts (MCNP vs. SCALE).

\subsubsection{High-energy External Source Transmuter (HEST)}

Subcritical cores driven by an external neutron source (often referred to as hybrid nuclear reactor systems) have been the subject of many earlier research studies dating back to the early 1950s $[42,43,44]$. The foreseen advantages for fuel generation, energy production, and most recently, waste $\mathrm{m}$ inimization ha ve $\mathrm{dr}$ iven $\mathrm{s}$ uch e fforts. Even $\mathrm{s} \mathrm{o}$, h ybrid nuc lear s ystems ha ve $\mathrm{n}$ ever advanced pa st the c onceptual s tudy ph ase, making them qui te different from the A P1000 and VHTR reactor units. Both of these designs (especially the AP1000) rely on previous operating experience and on proven designs.

In recent years a great deal of interest, or a renewal of interest, has been displayed worldwide in hybrid reactors mainly due to the perceived advantages for transmuting the long-lived actinides of spent nuclear fuel into a much more manageable waste form [ 8-14, 45]. T hese advantages stem from the safety features that accompany subcritical s ystems, allowing for ex tremely high transmutation efficiencies as compared to other options.

\section{External Neutron Source Survey}

Potential ne utron sources for h ybrid s ystems mus t me et tw o important criteria: 1 ) be a hi gh intensity source and 2) produce high-energy neutrons. In addition, the size of the neutron source can play an important role, with the ultimate goal being a small compact source.

Many pos sibilities for ne utron s ources ha ve be en i dentified a nd s tudied. In r egard to h ybrid systems, the most promising and consequently the most investigated ne utron sources fall into two m ain c ategories: 1 ) a ccelerator dr iven s ystem (ADS) s pallation ne utron s ources, and 2) fusion neutron sources.

ADS ne utron s ources us e proton a ccelerators, which de liver continuous wave n eutron be ams with an energy of $1 \mathrm{GeV}$. The accelerator is either the linac or cyclotron type. The protons are 
impinged upon a heavy element spallation target to produce source neutrons. The spectrum of spallation ne utrons is s imilar to the fission ne utron s pectrum but $\mathrm{s}$ hifted to a s lightly hi gher energy. In addition, very high neutron yields are attainable. The production of extremely intense and high-energy neutrons makes ADS systems at tractive for d riving subcritical cor es for waste elimination and energy generation. High cost and reliability is sues are the main detractors for ADS systems.

A s imilar a lternative to ADS is a phot onuclear-based ne utron s ource us ing a n e lectron 1 inear accelerator [ 46]. Comparatively, electron LINAC-based neutron sources a re an attractive alternative to s pallation neutron sources due to being inherently com pact, economical, reliable, ease to handle, and less hazardous in nature. Of c ourse a tradeoff comes in the intensity and energy spectrum of the neutrons produced, and it is debatable whether the tradeoffs make it a serious contender for hybrid systems. With that in mind, and looking to the future, promise has been shown towards improving neutron yields to a level that might make electron LINAC-based neutron sources advantageous to the more expensive and complicated ADS.

The most promising fusion neutron s ources us e the neutrons produced from the de uterium and tritium fusion reaction. The nuclei of two isotopes of hydrogen, deuterium (D), and tritium (T) react to produce a helium nucleus $(\alpha)$ and a neutron (n). In each reaction 17.6 MeV of energy is liberated:

$$
D+T \rightarrow n(14.1 \mathrm{MeV})+\alpha(3.5 \mathrm{MeV})
$$

There are a number of different options for creating the conditions necessary for the D-T fusion reaction, which are classified as follows:

- Strong magnetic field c oncepts: involves s uspending a plasma in a magnetic field and increasing its temperature and pressure to immense levels.

o Tokamaks: $m$ agnetic field is us ed t o c onfine a plasma in the s hape of a $t$ orus (pulsed operation)

o Stellarators: like the Tokamak, has a toroidal magnetic field topology, but is not azimuthally symmetric (continuous operation)

o Mirror machines: "open" system that uses mirrors to reflect ions and electrons back towards the plasma (continuous operation)

- Inertial confinement de vices: pr ocess w here nu clear f usion reactions are ini tiated by using intense energy beams for heating and compressing a fuel target.

o Laser-driven inertial c onfinement: us es la ser lig ht to compress a nd heat ta rget (pulsed).

o Z-pinch: int ermediate of ma gnetic a nd inertial c onfinement. A t ype of pl asma confinement s ystem that us es an electrical cur rent in the $\mathrm{pl}$ asma to generate a magnetic field that compresses it (pulsed).

o Inertial electrostatic confinement (IEC): invol ves the creation of deep electrostatic potential wells within a plasma in order to accelerate ions up to energies sufficient for fusion reactions to occur (continuous or pulsed).

- Muon-catalyzed fusion $(\mu \mathrm{CF})$ : $\mathrm{p}$ rocess al lowing nu clear $\mathrm{f}$ usion to $\mathrm{t}$ ake $\mathrm{pl}$ ace at temperatures significantly lower than the temperatures required for thermonuclear fusion. (cold fusion). 


\section{Model Description}

The HEST a nalysis focuses $m$ ore on $t$ he pot ential for T RU t ransmutation a s oppos ed to the technological feasibility of specific concepts. A physics approach to transmutation $[47,48] \mathrm{w}$ as utilized for a full understanding of the transmutation potential of different neutron fields.

The neutron consumption/fission $\left(\mathrm{D}_{\mathrm{j}}\right)$ of isotope $\mathrm{J}$ is defined as the number of neutrons needed to transform the nuc leus a nd $i$ ts $r$ eaction products $i$ nto $f$ ission pr oducts. The e valuation of $D_{j}$ considers a cor e with an ave rage ne utron flux that is fed by actinides at a $\mathrm{r}$ ate $\mathrm{S}$ (nuclides/s). Under $i$ rradiation $t$ he transmutation of $t$ he feed nuc lides ( $J$-vectors $r$ epresenting $t$ he $i \mathrm{n}$ components) yields the out components of the J-vectors. The transmutation behavior of each the $\mathrm{J}$-vectors $\mathrm{c}$ an be considered s eparately a nd it is pos sible t o $\mathrm{c}$ alculate the num ber of ne utrons produced/consumed by each during irradiation. The branching of the J-vectors, a result from the many nuc lear $r$ eactions, 1 eads t $o$ paths that $w$ ill ha ve one of three out comes: 1) c onsume neutrons, 2) produce more neutrons, or 3) have no influence on the total neutron balance. The total number of neutrons $\mathrm{D}_{\mathrm{j}}$ is calculated by:

$$
D_{J}=\sum_{J 1_{i}} P_{J \rightarrow J 1_{i}}\left\{R_{J \rightarrow J 1_{i}}+\sum_{J 2_{i}} P_{J 1 \rightarrow J 2_{i}}\left[R_{J 1 \rightarrow J 2_{k}}+\sum_{J 3_{n}} P_{J 2_{k} \rightarrow J 3_{n}}(\ldots .)\right]\right\},
$$

where $\mathrm{P}_{\mathrm{JNr} \rightarrow \mathrm{J}(\mathrm{N}+1) \mathrm{s}}$ is the probability of transmutation of the nuclide $\mathrm{JNr}$ into the nuclide $\mathrm{J}(\mathrm{N}+1) \mathrm{s}$. $\mathrm{R}_{\mathrm{A} \rightarrow \mathrm{B}}$ is the neutron consumption factor representing the number of neutrons consumed during the transition $\mathrm{A} \rightarrow \mathrm{B}$, with each reaction type defined as:

- Neutron capture $(n, \gamma)$ with 1 neutron being captured

- Neutron c apture and s ubsequent $\mathrm{m}$ ultiplication $(n, m n) \mathrm{w}$ ith $(1-m) \mathrm{n}$ eutrons be ing produced,

- Fission with $\left(1-v_{f}\right)$ neutrons being produced,

- Natural decay with 0 neutrons being captured,

- Discharge and nuclide loss with 0 neutrons being captured.

In a ccordance $\mathrm{w}$ ith $\mathrm{t}$ he a bove de finitions, $\mathrm{T}$ able $4.15 \mathrm{~g}$ ives $\mathrm{t}$ he va lues $\mathrm{f}$ or $\mathrm{t}$ he ne utron consumption factor $\mathrm{R}_{\mathrm{A} \rightarrow \mathrm{B}}$.

Table 4.15. Neutron Consumption Factor for Different Reaction Types.

\begin{tabular}{|c|c|c|c|c|}
\hline Reaction Type & $\begin{array}{c}\text { Capture } \\
(n, \gamma)\end{array}$ & $\begin{array}{c}\text { Fission } \\
(n, f)\end{array}$ & $(n, 2 n)$ & $\begin{array}{c}\text { Radioactive } \\
\text { Decay }\end{array}$ \\
\hline $\mathrm{R}_{\mathrm{A} \rightarrow \mathrm{B}}=$ & 1 & $\left(1-v_{f}\right)$ & -1 & 0 \\
\hline
\end{tabular}

If parasitic neutron consumption (fission products, structural material, etc.) and neutron leakage is neglected, then the total number of neutrons, $\mathrm{D}_{\mathrm{j}}$, consumed by the given $\mathrm{J}$-vector is a measure of the capability of the core to achieve destruction of a given J-vector feed. Positive $\mathrm{D}_{\mathrm{j}}$ indicates neutron consumption dominates over neutron production and the core requires a supplementary neutron s ource $t$ o s upport $t$ ransmutation. Negative $D_{j}$ indicates $t$ he $c$ ore pr oduces e nough neutrons to support transmutation. 
The linearity properties of the neutron concentration equation make it simple to determine $\mathrm{D}_{\text {fuel }}$ for a mixture of isotopes using the formula below:

$$
D_{\text {fuel }}=\sum_{J} \varepsilon_{J} D_{J}
$$

where $\varepsilon_{J}$ is the fraction of the J-vector in the feed stream.

The $\mathrm{D}$-factor concept $\mathrm{h}$ elps to unde rstand if $\mathrm{t}$ ransmutation is feasible in a pa rticular $\mathrm{t}$ ype of reactor. However, to gain a complete understanding, the global neutron balance of a core needs to be considered. The general equation for the Neutron Surplus $\left(\mathrm{NS}_{\text {core }}\right)$ expressed in units of neutrons per fission then becomes:

$$
N S_{\text {core }}=S_{\text {ext }}-D_{\text {fuel }}-C_{\text {par }}-C_{F P}-L_{\text {core }}
$$

where $\mathrm{S}_{\text {ext }}$ is a potential external ne utron source, $\mathrm{C}_{\mathrm{par}}$ is parasitic capture in structural material, $\mathrm{C}_{\mathrm{FP}}$ is capture in fission products, and $\mathrm{L}_{\text {core }}$ is neutrons lost to leakage.

By equations (20) and (21) the ne utron ba lance, $D_{\text {mix }}, c$ an be de termined for a composition consisting of $i$-components by:

$$
D_{\text {mix }}=\sum_{i} \sum_{r} R_{r}^{(i)} P_{r}^{(i)} \bar{N}_{i}
$$

where $\bar{N}_{i}$ is the asymptotic solution of the nuclide production/destruction equations, $R_{r}^{(i)}$ is the neutron consumption factor for reaction $(r)$ and nuclide $(i), P_{r}^{(i)}$ is the reduced transition rate for reaction $(r)$ and nuclide (i). Table 4.16 shows $R_{r}^{(i)}$ and $P_{r}^{(i)}$ for the main reactions.

Table 4.16. $R_{r}^{(i)}$ and $P_{r}^{(i)}$ for Reaction Type.

\begin{tabular}{|l|l|l|}
\hline Reaction, $\boldsymbol{r}$ & $\boldsymbol{P}_{\boldsymbol{r}}$ & $\boldsymbol{R}_{\boldsymbol{r}}$ \\
\hline Radiative Capture & $\sigma_{\mathrm{c}} \phi$ & 1 \\
\hline Fission & $\sigma_{\mathrm{f}} \phi$ & $1-v_{\mathrm{f}}$ \\
\hline Radioactive Decay & $\lambda$ & 0 \\
\hline
\end{tabular}

Consider the nuclide production/destruction equation in the following form:

$$
\frac{d}{d t} \bar{N}=\hat{M} \cdot \bar{N} \phi-\bar{F}
$$

where $\bar{N}$ is a c olumn ve ctor of the a tomic c oncentrations, $\hat{M}$ is a $n x n$ matrix related to all nuclear interaction processes, $\phi$ is the flux, and $\bar{F}$ is the nuclei feed vector. A problem of this form ha s a $\mathrm{n}$ exponential s olution. A s $t \rightarrow \infty$, the a symptotic s olution c orresponds t o the equilibrium case, in which $d \bar{N} / d t=0$. Thus the solution can be expressed in matrix form by:

$$
\bar{N}=\hat{A}^{-1} \bar{F}
$$

where $\hat{A}=\hat{M} \times \phi$ and $\bar{F}=\left[F_{i}: i=0,1, \ldots I\right] ; I=$ num ber of nuc lides. The 1 inear ch aracter of equation (6) allows evaluation of the concentrations of each vector nuclide independently, with a "unit" source for the corresponding feed, $F_{i}=1$.

Equations (21), (23), and (25) can b e u sed to calculate the ne utron balance for the TRU fuel $\left(D_{\mathrm{eq}}{ }^{\mathrm{TRU}}\right)$ and the individual TRU nuclides $\left(\mathrm{D}_{\mathrm{eq}}{ }^{\mathrm{I}}\right)$ as a function of the core flux, assuming the TRU 
feed i sotopic concentrations a nd a 11 the nu clear i nteraction pr ocesses of the $\hat{M}$ matrix are known. T he T RU composition is pr edetermined b y the V HTR bur nup c alculations a nd the subsequent de cay time before i rradiation in the HEST. H owever, de termining the on e group microscopic cr oss-sections a nd a verage num ber of f ission ne utrons 1 iberated for e ach of the isotopes of interest is no trivial feat, since they are spatially and energy dependent.

In or der to produce the m icroscopic cross-sections $(\sigma)$ and fission ne utrons $(v)$ fo $r$ the TRU isotopes, whole-core $3 \mathrm{D}$ models were created in MCNP. T wo HEST core configurations were chosen for evaluation. The first utilizes the concept of an intense external fusion neutron source placed at the cent er of a subcritical core. The core design is the same as the VHTR, with the central graphite column removed and the surrounding graphite reflector replaced with a stainless steel type reflector and shield.

Figure $4.13 \mathrm{~s}$ hows the c ore $\mathrm{c}$ ross s ection for the HEST C oncept I. T he i sotropic $14.1 \mathrm{M} \mathrm{eV}$ neutron source has an intensity ranging from $10^{17}-10^{20} \mathrm{n} / \mathrm{s}$. The fuel assemblies are hexagonal graphite blocks with fuel compacts containing used TRISO fuel from the VHTR. The presence of graphite $\mathrm{w}$ ill m oderate a portion of the n eutrons, but the s pectrum is s till expected to be skewed towards high energy levels.

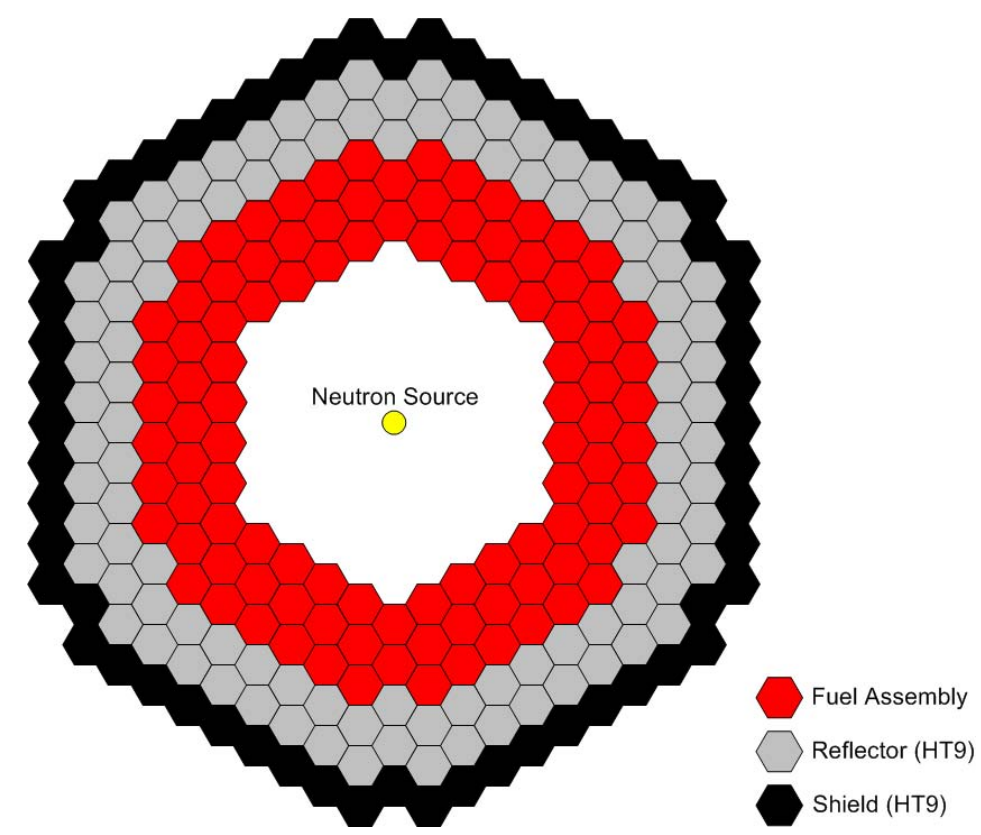

Figure 4.13. HEST Concept I.

The second concept utilizes the small compact IEC fusion neutron source. Compared to the first concept, the intensity of the IEC source is considerably lower, but its small size, portability, and low cost make it pos sible to implant the s ource very close to the fuel elements. In addition, a large num ber of s ources $\mathrm{c}$ an be us ed to provide a di stribution of s ource ne utrons, t o provide flexibility in core design, and in flux profile control.

Figure 4.14 s hows the HEST Concept II, which consist of a VHTR fuel assembly block with a cylindrical IEC neutron source placed in a boring running lengthwise through the center of the 
block. The cylindrical IEC acts as a line source emitting $14.1 \mathrm{MeV}$ neutrons at an intensity of $10^{10}-10^{14} \mathrm{n} / \mathrm{s}$.

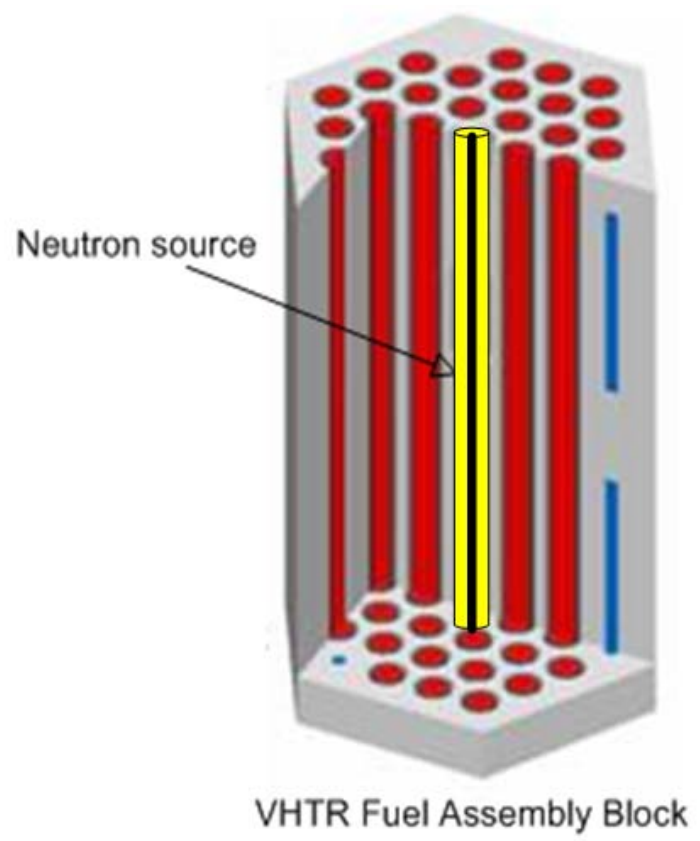

Figure 4.14. HEST Concept II.

Currently, IEC sources are commercially available from a number of companies. N SD-Fusion $\mathrm{GmbH}$ of Germany produces c ylindrical type IEC de vices that produce $10^{11} \mathrm{n} / \mathrm{s}$ at $14.1 \mathrm{MeV}$. IEC c oncepts c arried ou t on t he laboratory s cale ha ve reached ove $10^{12} \mathrm{n} / \mathrm{s}$ and de velopment plans target a $10^{14} \mathrm{n} / \mathrm{s}$ prototype in the intermediate term, followed by a full demo unit at $10^{18} \mathrm{n} / \mathrm{s}$ [49]. The IEC is driven electrically and is very compact in size. Compared to the other neutron sources i t i s pa rticularly simple, $\mathrm{m}$ uch 1 ess e xpensive, a nd $\mathrm{r}$ equires c onsiderably 1 ess $\mathrm{t}$ o implement.

The HEST Concept II model does not include a reflector, so ne utron leakage is expected to be high. T he model pe rformance w ill be extrapolated to that expected for a c ore m ade up o $\mathrm{f}$ multiple assembly blocks all embedded with IEC drivers.

The ne utron balance calculations are performed by the MATLAB code system. An algorithm was developed to use the output generated by the MCNP5 models for HEST Concept I and II (core specific on e group microscopic cross-sections and fission neutrons for the TRU nuclides) to s olve for the equilibrium concentrations as de fined by equation (6). The concentrations a re then used to solve for the neutron balance for the TRU fuel, $\mathrm{D}_{\mathrm{eq}}{ }^{\mathrm{TRU}}$, by equation (4) and then the neutron balance for the individual TRU nuclides, $\mathrm{D}_{\text {eq }}$, e quation (2) a re calculated. T he model provides the neutron balance results as a function of av erage core flux, allowing for a range of neutron source intensities to be evaluated for TRU transmutation potential. 


\subsection{Fuel Cycle Components}

\subsubsection{Front-end Components}

Accompanying the reactor units in NES are the fuel cycle components. Composing the front-end portion of the cycle are the mining, milling, conversion, enrichment, and fuel fabrication. As a result of front-end procedures, DU and mill tailings are accumulated and must be stored as LLW. The main concern for the front-end is material flow and its effect on mining and waste storage strategies.

The IAEA's simulation system NFCSS was used to model the portion of the NES that includes the front-end components and the AP1000, as shown in Figure 4.15. NFCSS is a scenario based computer model for the estimation of nuclear fuel cycle material and service requirements. It has been de signed to qui ckly estimate long-term fuel c ycle r equirements and a ctinide production. Natural ur anium, c onversion, e nrichment, a nd f uel fabrication qua ntities a re pr edicted. Additionally, the quantities and qualities (isotopic composition) of unloaded fuels are evaluated.

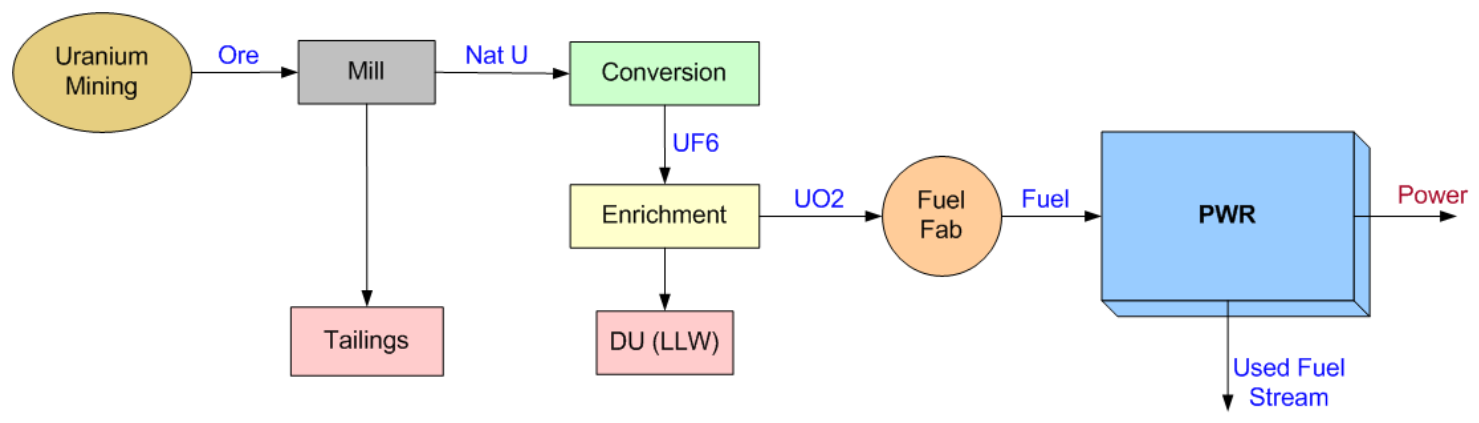

Figure 4.15. NFCSS Components.

The NFCSS model tracks the overall material flow in each of the processes described in the fuel cycle as presented in Figure 4.16. The model assumes zero losses in the conversion, enrichment, and fuel fabrication stages. The reactor model (fuel depletion model) is the most important part of the simulation since it calculates the inv entory of us ed fuel a fter ir radiation. The r eactor model is required to be an optimum combination of simplicity, accuracy, and speed. Therefore, the IAEA developed CAlculation of INventory of spent fuel (CAIN) specifically for the needs of NFCSS. C AIN solves the Bateman's Equations for a point assembly using one group neutron cross-sections. In o rder t o $\mathrm{m}$ eet $\mathrm{t}$ he a ccuracy, simplicity, and s peed $\mathrm{r}$ equirements, a $\mathrm{s}$ et of assumptions were built into the code. C AIN currently has 28 reaction and decay chains during irradiation and 14 decay chains during cooling. The main assumptions built into CAIN are listed below [27].

- The selection of the nu clides has be en performed for the importance of the nuclides in radiotoxicity of the spent fuel and their nuclear characteristics.

- Although na tural ur anium i ncludes ${ }^{234} \mathrm{U}(<0.01 \%)$, this nuc lide is ignored, be cause the transmutation from ${ }^{234} \mathrm{U}$ to ${ }^{235} \mathrm{U}$ is too small. 
- Nuclides with short half-lives (half life $<8$ days) are i gnored. T hat is, ${ }^{237} \mathrm{U}$ (7 days), ${ }^{238} \mathrm{~Np}$ ( 2 da ys $),{ }^{238} \mathrm{Pu}(5 \mathrm{hrs}),{ }^{242} \mathrm{Am}$ ( $\left.16 \mathrm{hrs}\right),{ }^{244} \mathrm{Am}(10 \mathrm{hrs})$, and ${ }^{244 \mathrm{~m}} \mathrm{Am}(26 \mathrm{~min})$ are assumed to decay and go to the next nuclide simultaneously.

- Long half-life nuc lides ( half-life $>400$ years) ar e as sumed as stable for the irradiation period. A s example, ${ }^{241} \mathrm{Am}$ ( $432 \mathrm{yr}$ ) is treated a s s table during irradiation. F or de cay (cooling) period after discharge, all nuclides are treated by their actual decay scheme.

- In the chain shown in Figure 4.16 transmutation is terminated for certain nuclides (shown as " $\mathrm{x}$ ").

- The 28 reaction chains and 14 decay ch ains ar e selected to be s uitable for fresh fuels containing a ny o $\mathrm{ft}$ he 14 nuc lides of the $\mathrm{C}$ AIN 1 ibrary. S ome $\mathrm{r}$ eaction $\mathrm{c}$ hains a re neglected due to their c ontribution to the composition of the s pent fuel. The nuc lides included in the calculations are listed in Table 4.17.

- Among 14 nuc lides, de cays of ${ }^{238} \mathrm{Pu}$ ( $\left.87.7 \mathrm{yr}\right),{ }^{241} \mathrm{Pu}$ ( $\left.14.4 \mathrm{yr}\right),{ }^{242} \mathrm{Cm}$ ( $\left.0.447 \mathrm{yr}\right)$, a nd ${ }^{244} \mathrm{Cm}$ ( $\left.18.1 \mathrm{yr}\right)$ are considered during irradiation. F igure $4.16 \mathrm{~s}$ hows the transmutation chain after specification for the CAIN code.

Table 4.17. Nuclides Included in CAIN Calculation.

\begin{tabular}{|l|c|c|c|c|c|}
\hline Uranium & ${ }^{235} \mathrm{U}$ & ${ }^{236} \mathrm{U}$ & ${ }^{238} \mathrm{U}$ & & \\
\hline Neptunium & ${ }^{237} \mathrm{~Np}$ & & & & \\
\hline Plutonium & ${ }^{238} \mathrm{Pu}$ & ${ }^{239} \mathrm{Pu}$ & ${ }^{240} \mathrm{Pu}$ & ${ }^{241} \mathrm{Pu}$ & ${ }^{242} \mathrm{Pu}$ \\
\hline Americium & ${ }^{241} \mathrm{Am}$ & ${ }^{242 \mathrm{~m}} \mathrm{Am}$ & ${ }^{243} \mathrm{Am}$ & & \\
\hline Curium & ${ }^{242} \mathrm{Cm}$ & ${ }^{244} \mathrm{Cm}$ & & & \\
\hline
\end{tabular}

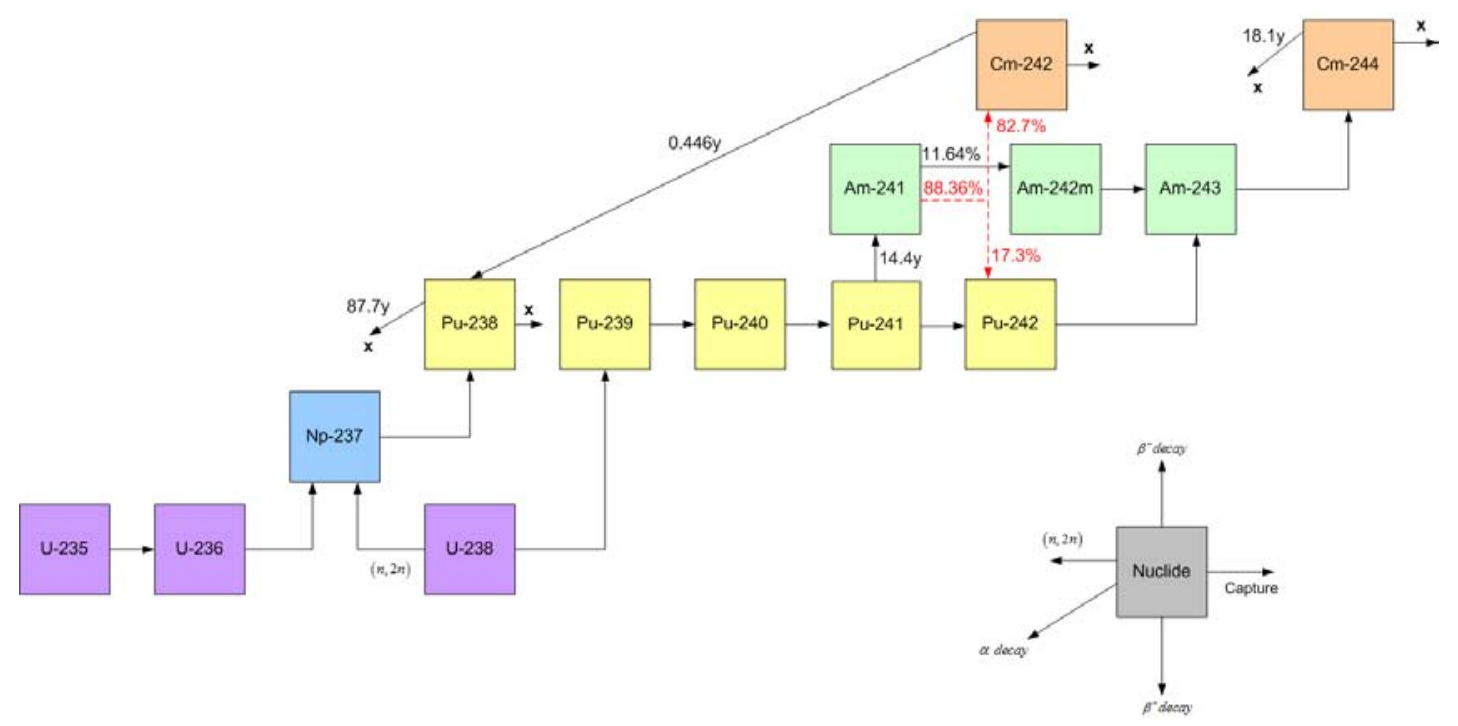

Figure 4.16. CAIN Transformation Chain.

The input parameters for the model a re m ostly dependent on the parameters for the A P1000 model, with the exception of the grade of the uranium ore and the enrichment tail assay, which are both adjusted to current typical values for each case. The mine grade is set at a value of $1 \%$ uranium containment within the ore, and the tail assay, which is defined as the percent of ${ }^{235} \mathrm{U}$ 
remaining in the depleted stream of enrichment operations is $0.30 \%$. The parameters consisting of reactor type, fuel type, power, and thermal efficiency are determined by the design parameters for $t$ he A P1000. T he $\mathrm{r}$ emaining i nput pa rameters of 1 oad $\mathrm{f}$ actor, e nrichment, a nd a verage discharge burnup are dependent on the optimum values determined for the NES. Table 4.18 lists the input parameters for the NFCSS.

The NFCSS model produces output indicating the required quantity of uranium ore, the natural uranium needed for the conversion process, the amount of $\mathrm{UF}_{6}$ needed for enrichment, the final quantity of $\mathrm{UO}_{2}$ for reactor operation, and the a mount of DU produced. T he Separative Work Unit (SWU) is also calculated for the system in addition to the isotopic composition of the used fuel.

Table 4.18. NFCSS Input Parameters.

\begin{tabular}{|l|l|}
\hline Reactor Type & $\mathrm{PWR}$ \\
\hline Fuel Type & $\mathrm{UO}_{2}$ \\
\hline Nuclear Power $\left(\mathrm{MW}_{\mathrm{e}}\right)$ & 1115 \\
\hline Load Factor & Variable \\
\hline Thermal Efficiency & 32.8 \\
\hline Average Discharge Burnup (GWd/tlHM) & Variable \\
\hline Initial ${ }^{235} \mathrm{U}$ Enrichment (wt. \%) & Variable \\
\hline Mine Grade $(\% \mathrm{U})$ & 1.0 \\
\hline Tail Assay $\left(\%{ }^{235} \mathrm{U}\right)$ & 0.3 \\
\hline
\end{tabular}

\subsubsection{Reprocessing - Partitioning/Separation}

The com putational $\mathrm{m}$ odel $\mathrm{r}$ epresenting t he $\mathrm{r}$ eprocessing pr ocess $\mathrm{w}$ as $\mathrm{d}$ esigned to track the material streams while accounting for radioactive decay and material losses accrued during the procedure. The $\mathrm{m}$ aterial $\mathrm{t}$ racks ar e m odeled according t o t he U Ranium $\mathrm{E}$ xtraction (UREX) process in which the Uranium and Technetium are separated from each other and the other FP and actinides. A suite of UREX+ processes of fer the ability to produce different product lines with varying mixtures of actinides and FPS. The process used for the NES model is UREX+1a, which has five product lines made up of: 1) Uranium, 2) Technetium, 3) Cesium/Strontium, 4) TRU, and 5) remaining FP. In addition to tracking materials, the model creates a da tabase for storing $\mathrm{m}$ aterial compositions $\mathrm{f}$ or va rying A P1000 i nput pa rameters $\mathrm{m}$ aking $\mathrm{t}$ hem easily assessable for analysis. The numerical computational environment MATLAB is utilized for the simulation procedure and material database storage.

\subsubsection{High Level Waste Storage Facility}

The computational model for the waste storage facility applies the normalized heat factors and normalized radiotoxicity factors for the TRU and the related isotopic priority rankings developed in $\mathrm{C}$ hapter III $\mathrm{t}$ o qu antify $\mathrm{r}$ epository pe rformance, w hich i $\mathrm{n} t$ urn can be us ed $\mathrm{f}$ or $\mathrm{m}$ aking comparisons to other fuel cycles. It will simulate a ge ological repository by tracking is otopic compositions ove $\mathrm{r} l$ ong $\mathrm{p}$ eriods of $\mathrm{t}$ ime a nd $\mathrm{c}$ alculating resulting he at 1 oad a nd dos $\mathrm{e}$ 
measurements in order to analyze waste management strategies. The ORIGEN-S code package is utilized for predicting radionuclide inventories after many years of decay. MATLAB is used for data processing involving dose and heat load calculations for assorted isotopic compositions.

\subsection{Integrated System Model}

The Integrated $\mathrm{S}$ ystem $\mathrm{M}$ odel ( ISM) $\mathrm{w}$ as de veloped $\mathrm{w}$ ithin the $\mathrm{M}$ ATLAB/Simulink environment. S imulink works $w$ ith M ATLAB t o of fer m odeling, s imulation, a nd a nalysis of multidomain dynamic systems under a graphical user interface environment. Simulink includes a comprehensive set of customizable block libraries for both linear and nonlinear analyses. A s Simulink is a n integral part of MATLAB, it is easy to $\mathrm{s}$ witch back and forth du ring a nalysis making it possible to take advantage of the features offered in each environment. The available options and flexibility of MATLAB/Simulink make it an ideal candidate for the ISM.

The main objective of the NES integrated model is to develop an approach to seamlessly couple the various models that compose the environmentally benign system. The goal being to devise a computational shell that effectively controls the set of reactor and fuel cycle component models with command over key us er input parameters and the ability to effectively consolidating vital output $\mathrm{r}$ esults $\mathrm{i}$ nto $\mathrm{r}$ eadily us able form, a nd $\mathrm{t}$ do $\mathrm{s}$ o $\mathrm{i} \mathrm{na} \mathrm{m}$ anner $\mathrm{t}$ hat a llows uncertainty/sensitivity a nalysis a nd opt imization procedures to be performed in a realistic and time efficient manner.

In basic terms, the ISM is a MATLAB/Simulink based computational model that uses a specially prepared da tabase to $\mathrm{p}$ redict ove rall $\mathrm{s}$ ystem pe rformance and be havior $\mathrm{b}$ ased on a num ber of different input parameters that are allowed to vary over a specified range. The input parameters are introduced into a database and the appropriate data is retrieved and prepared to construct a function that describes the behavior of the data. An interpolation or extrapolation method is then called to calculate the corresponding $d$ ata, which is then processed and manipulated into final output form, or f ed ba ck i nto the s ystem a nd the procedure i s r epeated a s m any $t$ imes a $\mathrm{s}$ necessary to obtain a set of output results as related to the input parameters. Figure 4.17 shows the basic operational procedures for the ISM.

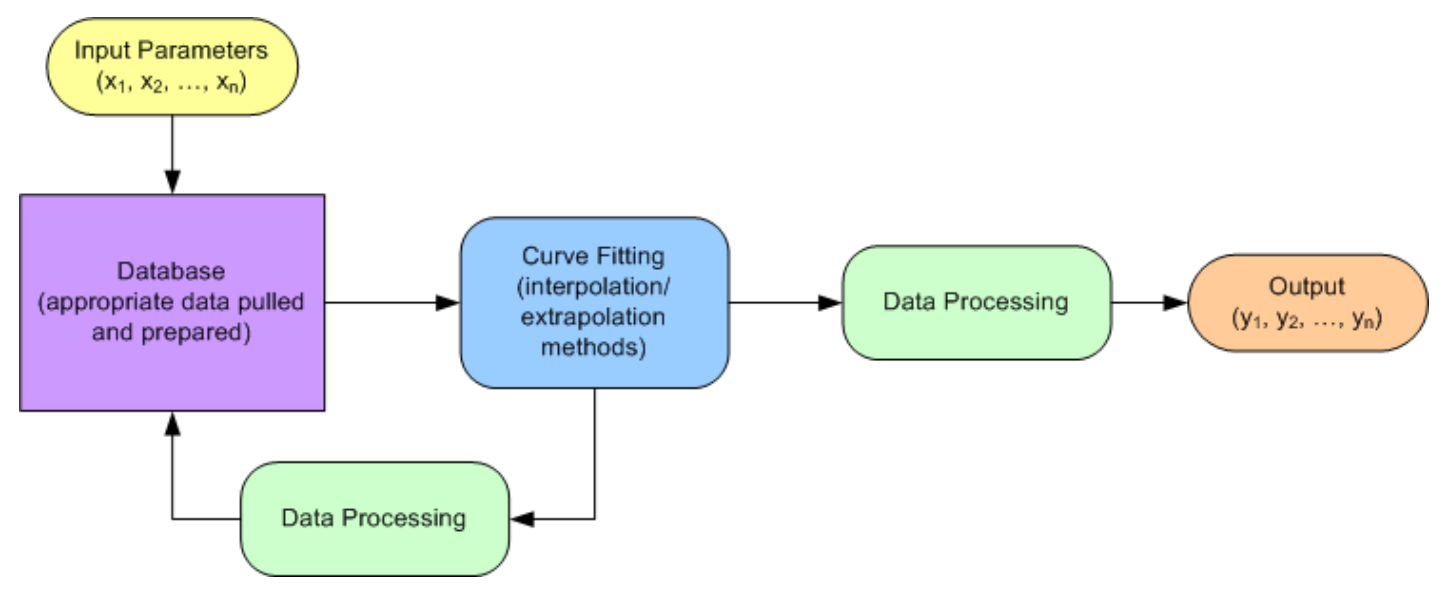

Figure 4.17. ISM Basics Flowchart. 
To de scribe the ISM in further de tail the ove rall $\mathrm{s}$ ystem is br oken dow $\mathrm{n}$ i nto $\mathrm{i}$ ts i ndividual components, w hich can be thought of as a $\mathrm{s}$ et of i nteracting or $\mathrm{i}$ nterdependent e ntities (subsystems) forming a $\mathrm{n}$ i ntegrated $\mathrm{w}$ hole. E ach of $\mathrm{t}$ he $\mathrm{s}$ ubsystems $\mathrm{c}$ an a lso $\mathrm{c}$ ontain i nput variables, which, may or may not, progressively rely on one another as additional subsystems are added to the system.

The r eactors and fuel cycle c omponents w ithin the NES, as de scribed earlier in this ch apter, represent the individual s ubsystems. B efore de tailing the procedures of the ISM as it directly relates $t o$ the $\mathrm{NES}$, the procedure will be $\mathrm{d}$ escribed in general $\mathrm{t}$ erms. T he $\mathrm{r}$ ational is that although the ISM was developed with the NES in mind, it can be modified to fit other systems that share common characteristics. For example, reactor components can be added or removed from $t$ he $\mathrm{N} E S$ a long $w$ ith $t$ heir $r$ elated i nput $v$ ariables, $t$ hus pr oducing a $n$ e ntirely di fferent advance nuclear fuel cycle. Even so, the new system's structure, behavior, and interconnectivity are ve ry $\mathrm{s}$ imilar $\mathrm{t}$ o $\mathrm{t}$ he $\mathrm{N}$ ES a nd, 1 ikewise, $\mathrm{i} t \mathrm{c}$ an be $\mathrm{m}$ odeled $\mathrm{b} \mathrm{y} t$ he ISM $\mathrm{w}$ ith $\mathrm{m}$ inor modifications. A good candidate for simulation by the ISM is any system that operates under similar c haracteristics and is composed of complicated subsystems that a re extensively time consuming to model or study experimentally.

Changes made to system dependencies or to the dataflow in the system will be reflected in the database for the ISM. The database structure and indexing is directly related to the subsystems, input variables, and their interdependence within the system.

\subsubsection{Generic System}

The features of the ISM can best be de scribed by a generic system, named SystemABC. The system is composed o $\mathrm{ft}$ hree $\mathrm{s}$ eparate but i nterdependent $\mathrm{s}$ ubsystems, $\mathrm{c}$ alled $\mathrm{s}$ ubsystem-A, subsystem-B, and subsystem-C. Each subsystem contains input variables, such that subsystem-A has input variables $\mathrm{a}_{1}$ and $\mathrm{a}_{2}$; subsystem-B has input variables $\mathrm{b}_{1}, \mathrm{~b}_{2}$, and $\mathrm{b}_{3}$; and subsystem-C has input variables $c_{1}$ and $c_{2}$. Figure 4.18 shows the arrangement of SystemABC. In general, the number of subsystems and input variables that makeup the system are arbitrary, as each system will be di fferent. T he ar rangement $\mathrm{f}$ or $\mathrm{S} y$ stem $\mathrm{ABC} w$ as chosen $t$ o i llustrate $t$ he $\mathrm{m}$ odeling procedure.

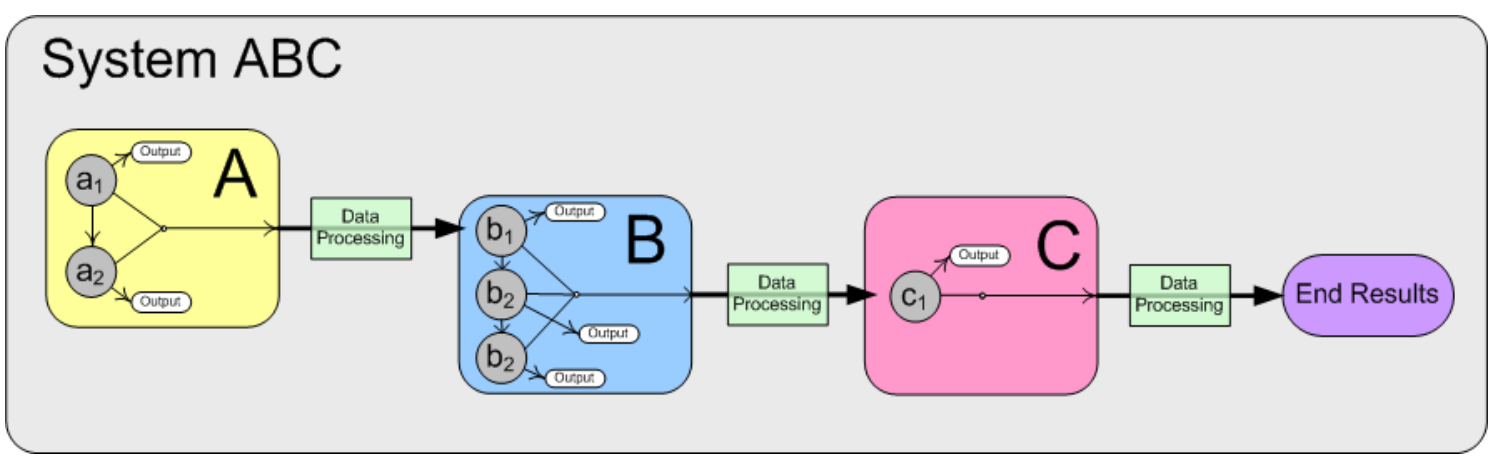

Figure 4.18. Arrangement of Generic SystemABC. 


\section{ISM Database}

The backbone of the ISM is its extensive database. The database can be viewed as a set of multidegree arrays that are arranged to allow quick computational access. The database is structured to $\mathrm{m}$ atch $\mathrm{t}$ he num ber of $\mathrm{s}$ ubsystems a nd $\mathrm{i}$ nput va riables within $\mathrm{t}$ he $\mathrm{s}$ ystem a nd the interdependence between them. W ith the database correctly populated and indexed, the system can e fficiently $\mathrm{m}$ ap i nput to a $\mathrm{s}$ et of ou tput $\mathrm{v}$ alues $\mathrm{b}$ y a ssembling a lookup $\mathrm{t}$ able a nd $\mathrm{t}$ hen constructing the appropriate mathematical functions be tween selected da ta points and applying curve fitting techniques for interpolation or extrapolation methods.

The input variables determine the degree of the array needed for the database in order to support the ISM. A s the number of input variables increases, so do the dimensions of the array. One variable needs a $1 \mathrm{D}$ data array, two variables require a $2 \mathrm{D}$ array, three input variables require a $3 \mathrm{D}$ array, and so forth. To support the SystemABC, a $6 \mathrm{D}$ array is required for the database.

Each of the input va riables is a llowed to vary within a specified range. For ex ample, within subsystem-A variable $\mathrm{a}_{1}$ has a range that is represented by:

$$
a_{1}=a_{1,1} \rightarrow a_{1, n},
$$

where $a_{1,1}$ is the smallest value for the variation in $a_{1}$, and $a_{1, n}$ is the largest value. Each of the input variables in the overall system will have its own specified range according to the desired analysis related to each.

Breakpoints within the specified $r$ ange for each of the input variables is a ssigned according to user know ledge related to the ef fect that the va riable of interest has on $t$ he subsystem. $T$ his includes experience from prior analysis and/or the difficulty involved with producing the needed data. For instance, if the input variable has a highly randomized effect on the system relative to small va riations in that parameter, then a hi gher num ber of br eakpoints $\mathrm{w}$ ould be s uggested. Whereas, if the input parameter has a minimal effect or it results in a change that is a smooth steady transition, then fewer breakpoints would be needed. Also of concern is the difficulty and time involved in producing results at each breakpoint, as it can limit the amount of a chievable breakpoints. The breakpoints assigned to $a_{1}$ are as follows:

$$
a_{1}=a_{1, b 1}, a_{1, b 2}, \ldots ., a_{1, b n},
$$

where $a_{1, b 1}$ is the first breakpoint for $a_{1}$, and each additional breakpoint increases monotonically until $\mathrm{t}$ he $\mathrm{f}$ inal br eakpoint a $\mathrm{a}_{1, \mathrm{bn}}$ is a chieved. $\mathrm{T}$ he br eakpoints a re required $\mathrm{t}$ o i ncrease monotonically in order for the lookup table to operate correctly, which creates index values for the interpolation and extrapolation procedures. Similarly, the remaining breakpoints within the system are assigned for each input parameter.

Demonstratively, the number of breakpoints for SystemABC is arbitrarily set as follows: $a_{1}=5$, $\mathrm{a}_{2}=3, \mathrm{~b}_{1}=4, \mathrm{~b}_{2}=3, \mathrm{~b}_{3}=4$, and $\mathrm{c}_{1}=6$. E ach set of breakpoints are spaced an equal distance apart in the ex ample, but this is a choi ce of the user, as ideal spacing between each breakpoint will be dependent on the input variable and its effect on the subsystem. Additionally, the index search $\mathrm{m}$ ethod $\mathrm{f}$ or $\mathrm{t}$ he ISM $\mathrm{c}$ an be $\mathrm{s}$ et $\mathrm{t} \mathrm{o}$ one of $\mathrm{t}$ hree $\mathrm{m}$ ethods $\mathrm{f}$ or i mproved pe rformance depending on the spacing of the breakpoints. If the breakpoint data is evenly spaced the greatest speed can be achieved by using the "evenly spaced points" index search method. For irregularly spaced breakpoint sets with input signals that do not vary much from one step to the next, the 
"linear s earch" method offers the be st performance. If the br eakpoints ar e i rregularly spaced with $r$ apidly va ry i nput $s$ ignals $t$ hat pr oduce $l$ arge va riations i $n t$ he $s$ ubsystem, $t$ he " binary search" method produces the best performance. The binary search method is the default setting for the ISM.

The br eakpoints de termine the num ber of the elements required $w$ ithin e ach dimension of the multi-dimensional array that comprises the database. Each breakpoint will represent an element within the array and is indexed according to the input variable it is associated with. Therefore, the overall size of the database is set by the total system input variables (array dimension) and the br eakpoints $f$ or each va riable ( elements $\mathrm{w}$ ithin $\mathrm{t}$ he $\mathrm{m}$ ulti-dimensional a rray). $\mathrm{T}$ hus, $\mathrm{t}$ he database r equired to s upport $\mathrm{S}$ ystem $\mathrm{ABC}$ is a $6 \mathrm{D}$ a rray of $\mathrm{s}$ ize $5 \times 3 \times 4 \times 3 \times 4 \times 6$, indicating that 4320 elements are needed to populate the database.

The ISM i s a rranged s o t hat out put i nformation $\mathrm{c}$ an be ga thered $\mathrm{f}$ or e ach i nput va riable signifying the a ffect that that particular va riable ha $s$ at its s pecified level in the s ystem. To accomplish this the database must include an individual data array, or lookup table, for each of the input variables. The dimension of the array is incremental with the position of the variable in the overall system. Each array is a portion of the overall system's multi-dimensional array, just of a 1 esser di mension. In any case, this f eature i ncreases $t$ he $\mathrm{s}$ ize of the da tabase, but $t$ he uniqueness of the elements making up the database remain the same.

With the da tabase popul ated and indexed a ccordingly, the s ystem m odel calls the appropriate data for curve fitting and us es interpolation or extrapolation a lgorithms for calculating output data. If the input value matches a specified breakpoint value then the corresponding elemental value in the mul ti-dimensional a rray $i \mathrm{~s}$ out put. If $\mathrm{t}$ he $\mathrm{i}$ nput doe $\mathrm{s} n$ ot $\mathrm{m}$ atch a $\mathrm{s}$ pecified breakpoint, the interpolator generates the appropriate output. If the input is beyond the range of the breakpoints, the extrapolator outputs appropriate values.

\section{Interpolation Methods}

The ISM of fers $t$ he $c$ hoice of $t$ hree $t$ ypes of $i$ nterpolation m ethods that pr esent a $t$ rade-off between c omputational $t$ ime and s moothness of the $r$ esults. The first $m$ ethod us es rounding methods and is the quickest but least smooth. The second method is linear interpolation and is slower $t$ han $r$ ounding $b$ ut $g$ enerates s moother $r$ esults, e xcept a $t$ br eakpoints $w$ here $t$ he $s$ lope changes. The third and final method is cubic spline interpolation that is the slowest but produces the smoothest results.

The rounding method simply checks if an input value falls between breakpoint values or outside the range of a breakpoint data set and then rounds the value to an adjacent breakpoint and returns the corresponding output value. Three choices are available for rounding. The first uses input nearest, which returns an output value corresponding to the nearest input value. The second uses input below, returning an output value corresponding to the breakpoint value that is immediately less than the input va lue. If no br eakpoint va lue e xists be low the input va lue, it $r$ eturns the breakpoint value nearest the input value. T he third us es input above, which returns an out put value corresponding to the breakpoint value that is immediately greater than the input value. If 
no breakpoint value exists above the input value, it returns the breakpoint value nearest the input value.

The linear interpolation method fits a curve using linear pol ynomials between breakpoints. In effect, a straight line is produced between breakpoints and the output value corresponding to the input is produced. As example, for a value $x$ in the interval $\left[x_{0}, x_{1}\right]$, the value $y$ along the straight line is given by:

$$
y=y_{0}+\left(x-x_{0}\right) \frac{y_{1}-y_{0}}{x_{1}-x_{0}} .
$$

The cubic spline interpolation method fits a cubic spline to the adjacent breakpoints, and returns the poi nt on $t$ hat s pline c orresponding t o the i nput. $T$ he $\mathrm{c}$ ubic s pline $t$ echnique is us ed $\mathrm{t} o$ generate a $\mathrm{f}$ unction $\mathrm{t}$ o $\mathrm{f}$ it $\mathrm{t}$ he $\mathrm{s}$ upplied da ta. $\mathrm{T}$ he process us es a $\mathrm{s}$ eries of uni que $\mathrm{c}$ ubic polynomials that are fitted between each of the breakpoints, with the stipulation that the curve obtained be continuous and appear s mooth. T he cubic s plines $\mathrm{c}$ an then be us ed to d etermine rates of change and cumulative change over an interval. The governing idea behind the process is to fit a piecewise function of the form:

$$
S(x)=\left\{\begin{array}{ccc}
s_{1}(x) & \text { for } & x \in\left[x_{1}, x_{2}\right] \\
s_{2}(x) & \text { for } & x \in\left[x_{2}, x_{3}\right] \\
\square & & \\
\square & & \\
s_{n-1}(x) & \text { for } & x \in\left[x_{n-1}, x_{n}\right]
\end{array}\right.
$$

where $s_{i}$ is a third degree polynomial defined by:

$$
s_{i}(x)=a_{i}+b_{i}\left(x-x_{i}\right)+c_{i}\left(x-x_{i}\right)^{2}+d_{i}\left(x-x_{i}\right)^{3}
$$

for $i=1,2, \ldots, n-1$. The function $\mathrm{S}(x)$ has $4 n-4$ unknowns, and in order to uniquely define the function, e ach unknow $\mathrm{n}$ has to be accounted for, which $\mathrm{c}$ an be a chieved by i mposing $\mathrm{c}$ ertain constraints on the system. In thi $\mathrm{s} \mathrm{c}$ ase, it is a ccomplished by $\mathrm{r}$ equiring the $\mathrm{c} u b i c \mathrm{~s}$ pline to conform to the following stipulations:

1. The piecewise function $\mathrm{S}(x)$ will interpolate all data points,

2. $\mathrm{S}(x)$ will be continuous on the interval $\left[x_{1}, x_{\mathrm{n}}\right]$,

3. $\mathrm{dS}(x) / \mathrm{dx}$ will be continuous on the interval $\left[x_{1}, x_{\mathrm{n}}\right]$,

4. $\mathrm{d}^{2} \mathrm{~S}(x) / \mathrm{dx}^{2}$ will be continuous on the interval $\left[x_{1}, x_{\mathrm{n}}\right]$,

5. "Not-A-Knot" spline: $\mathrm{d}^{3} \mathrm{~S}(x) / \mathrm{d}^{3}$ will be continuous at $x_{2}$ and $x_{\mathrm{n}-1}$.

Applying stipulation 1, the piecewise function $\mathrm{S}(x)$ will interpolate all of the data points, and can be represented by:

$$
s_{i}\left(x_{i}\right)=y_{i}=a_{i}, \text { for } i=1,2, \ldots, n-1 .
$$

Given stipulation 2, the curve $\mathrm{S}(x)$ must be continuous a cross the interval, therefore, it $\mathrm{c}$ an be concluded that each sub-function must join at the interior points (breakpoints) such that:

$$
s_{i}\left(x_{i+1}\right)=s_{i+1}\left(x_{i+1}\right)=y_{i+1} \text {, for } i=1,2, \ldots, n-2 .
$$


Additionally, at the far right value of $\mathrm{x}$, the single constraint applies as follows:

$$
s_{n-i}\left(x_{n}\right)=y_{n} .
$$

To satisfy stipulation 3 , the curve $\mathrm{S}(x)$ must be smooth across the interval, thus the derivatives must be equal at the breakpoints, giving:

$$
\frac{d}{d x} s_{i}\left(x_{i}\right)=\frac{d}{d x} s_{i-1}\left(x_{i}\right), \text { for } i=1,2, \ldots, n-2 .
$$

Similarly, $\mathrm{s}$ tipulation $4 \mathrm{i}$ nstates a $\mathrm{s}$ econd $\mathrm{s}$ moothness $\mathrm{c}$ ondition $\mathrm{b}$ y requiring $\mathrm{t}$ he $\mathrm{s}$ econd derivatives of curve $\mathrm{S}(x)$ to be equal at the breakpoints, represented by:

$$
\frac{d^{2}}{d x^{2}} s_{i}\left(x_{i}\right)=\frac{d^{2}}{d x^{2}} s_{i-1}\left(x_{i}\right), \text { for } i=1,2, \ldots, n-2 .
$$

The final stipulation is the implementation of the not-a-knot boundary conditions, which requires continuity of the third derivative of $\mathrm{S}(x)$ at the two interior breakpoints $x_{2}$ and $x_{\mathrm{n}-1}$, such that:

$$
\begin{aligned}
& \frac{d^{3}}{d x^{3}} S_{1}\left(x_{2}\right)=\frac{d^{3}}{d x^{3}} s_{2}\left(x_{2}\right), \text { and } \\
& \frac{d^{3}}{d x^{3}} S_{n-2}\left(x_{n-2}\right)=\frac{d^{3}}{d x^{3}} S_{n-1}\left(x_{n-2}\right) .
\end{aligned}
$$

Equations (30-36) impose $4_{n}-4$ constraints matching the $4_{n}-4$ unknowns for equation (27), thus the $\mathrm{c}$ ubic s pline is defined uni quely, and a ny po int on $\mathrm{t}$ he interval $\left[x_{1}, x_{\mathrm{n}}\right] \mathrm{c}$ an be $\mathrm{s}$ olved for explicitly.

The interpolation method utilized for each input va riable is not required to be the same. $T$ he three methods can be used interchangeably within any system and depends on the most suitable choice for that particular input variable.

\section{Extrapolation Methods}

When input falls out side the breakpoint data set's range, extrapolation methods can be used to determine output values. Caution must be practiced for ISM analysis of input values that are not contained within the breakpoints for that particular input variable. Large errors can be associated with input values that are well outside of the set of breakpoint's range, as the curve fit between the out ermost pa ir of breakpoints $\mathrm{c}$ annot be expected $\mathrm{t}$ o pr edict actual da ta i ndefinitely. Accordingly, the ISM will generate a warning when an input value is outside the range of its breakpoint da ta s ets. It i s r ecommended that i nput va lues for each i nput pa rameter do not precede/exceed breakpoint endpoints by a measure greater than the distance between the first/last two br eakpoints a ssociated $\mathrm{w}$ ith $\mathrm{t}$ hat $\mathrm{i}$ nput pa rameter. $\mathrm{T}$ he us er $\mathrm{m}$ ust us e caut ion when evaluating data outside breakpoints and to make note when it occurs outside the breakpoints.

The extrapolation methods are very similar to the interpolation methods. In both cases a curve fitting technique is employed to match a function between breakpoints, but with extrapolation the curve is extended be yond the end br eakpoints for de riving out put da ta corresponding to input 
values out side the br eakpoint da ta $\mathrm{r}$ ange. A s w ith interpolation, three o ptions a re a vailable, including both linear and cubic spline extrapolation. The first option is to disable extrapolation and in the event that the input value is outside the breakpoints, an output value corresponding to the end of the breakpoint data set range is returned. The second option is linear extrapolation, which operates the same as linear interpolation except that the linear polynomial is fit between the first or last pair of breakpoints, depending if the input is less than the first or greater than the last breakpoint. It then extends the line and returns the point on it that corresponds to the input. The $t$ hird opt ion i s c ubic s pline e xtrapolation, $w$ hich ope rates $t$ he $s$ ame a s c ubic s pline interpolation except that the spline is fit between the first or last pair of breakpoints, depending if the input is less than the first or greater than the last breakpoint. It then extends the curve and returns the point that corresponds to the input. The cubic spline extrapolation method is only an option if the cubic spline interpolation method is also utilized.

Optimally, the choice of breakpoints used to populate the database should minimize the need for extrapolation methods to be called for within the ISM and interpolation will be utilized to a much greater extent during analysis.

\section{Data Processing}

At a ll le vels within the system the da ta $\mathrm{c}$ an be processed and ma nipulated to fit the de sired output form. In SystemABC, data processing is performed between each subsystem in order to maintain system c ompatibility. The output from s ubsystem-A must be formatted properly for input into subsystem-B, and so forth. Also, output results from the ISM can be processed and presented in many different forms giving the user latitude of selecting from many options. F or example the data $\mathrm{c}$ an be plotted, nor malized, a rranged in table or matrix format, compared to previous results, formatted for immediate use by other software analysis tools, stored for future use, etc. The available tools for processing data include, but are not limited to, the mathematical operations existing in the MATLAB/Simulink environment.

\subsubsection{Integrated System Model for the Nuclear Energy System}

The first s tep to effectively s imulate the NES is to define the ove rall system. This inc ludes assigning and characterizing the subsystems and components that compose the system and then identifying and s howing the interdependence of e ach. Figure $4.19 \mathrm{illustrates}$ the NES a s it functions in the ISM environment. The components or subsystems of the NES are the AP1000, the reprocessing and fuel fabrication facility, the VHTR, the HEST, and the HLW repository.

The AP1000 includes fuel enrichment and lag time as input variables. The fuel enrichment can range between $3 \%$ and $6 \%$. The lag time is defined as the span of time from which the fuel is removed from irradiation in the AP1000 reactor core until it is sent to the reprocessing facility. The lag time is required to allow the used fuel to decay to an acceptable level in order to perform reprocessing. D uring th is time pe riod the us ed fuel is stored onsite at the AP1000 facility in designated cooling pools. The input variable representing lag time can vary from 0 and 20 years. The bur nup level of the fuel in relation to enrichment is provided as output and is used in the external c ode s ystem NFCSS for front-end fuel c ycle ana lysis. The energy generated by the 
AP1000 core according to fuel enrichment is supplied as output as well. The composition of the used fuel, as related to enrichment and lag time, is also presented as output.

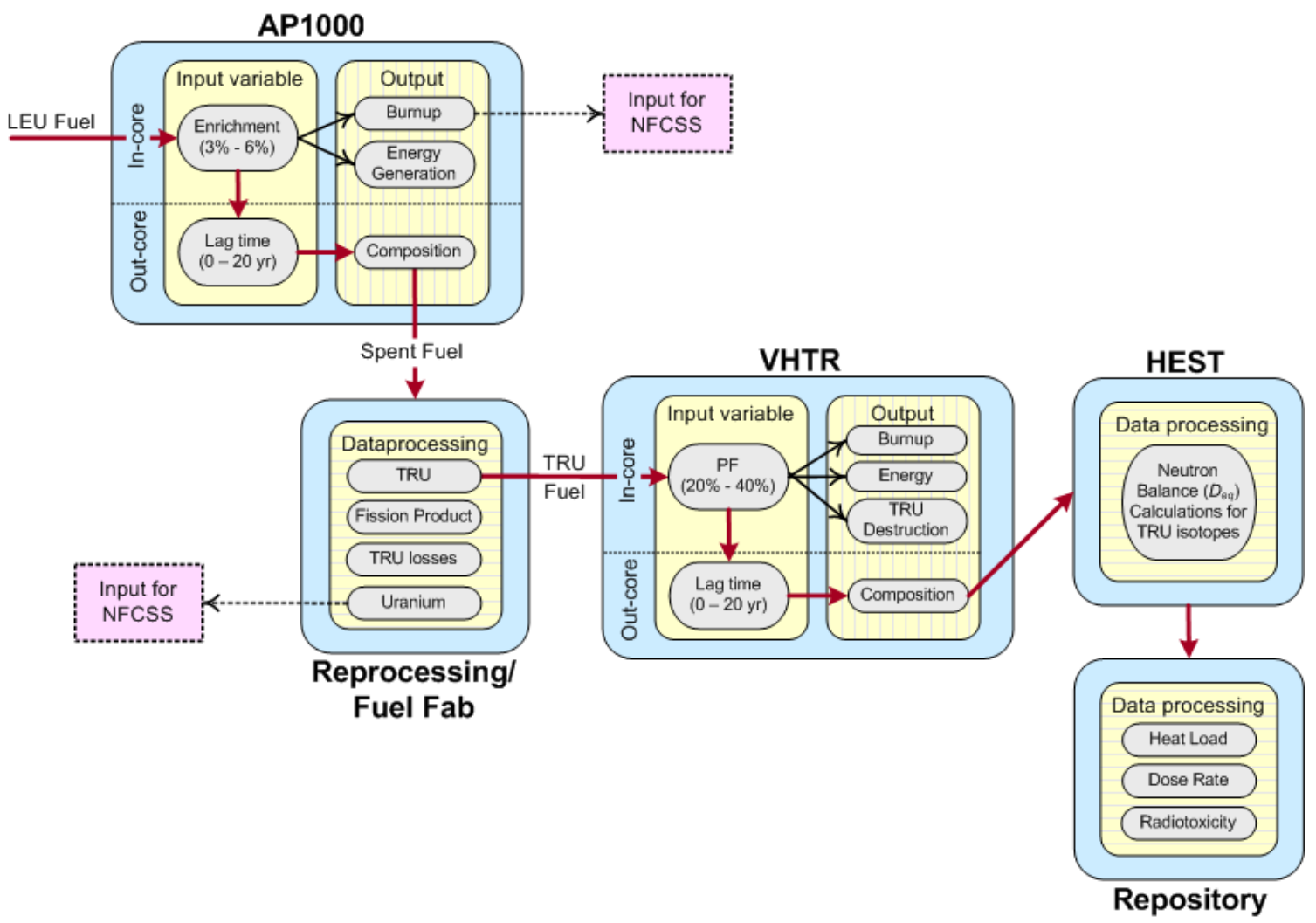

Figure 4.19. NES Interdependence Flowchart for ISM Simulation.

The composition of the used fuel from the A P1000 is then provided t o the r eprocessing/fuel fabrication subsystem. The data is processed by segregating the used fuel material into streams consisting of uranium, TRU, or FP. The mass of the uranium is calculated and used as an input parameter fo $\mathrm{r} t$ he N FCSS c ode for $\mathrm{f}$ ront-end fuel $\mathrm{c}$ ycle analysis. T he $\mathrm{m}$ ass of $\mathrm{t}$ he $\mathrm{F} \mathrm{P}$ a re calculated for waste management analysis. The FP are grouped as a whole in each case, but the uranium and TRU are broken into individual nuclide constituents, with the TRU output being in terms of $\mathrm{c}$ omposition by nuclide $\mathrm{w}$ eight pe rcentage $\mathrm{r}$ elated $\mathrm{t}$ o $\mathrm{t}$ he $\mathrm{t}$ otal a mount of $\mathrm{T}$ RU. Reprocessing losses associated with TRU separation process for a range of $0.1 \%$ to $0.0 \%$ are also calculated and stored as mass values.

The calculated TRU composition is then passed to the VHTR subsystem as the fuel component. The input variables for the VHTR are the packing fraction of the TRISO fuel particles within the fuel compact and the lag time. The packing fraction can vary from $20 \%$ to $40 \%$, and the lag time can $\mathrm{f}$ all $\mathrm{w}$ ithin the $\mathrm{t}$ ime $\mathrm{r}$ ange of $0 \mathrm{t}$ o 20 years. T he out put $\mathrm{r}$ esults for $\mathrm{t}$ he V HTR w ill be dependent of the input parameters for the AP1000, a long with the corresponding VHTR input variable. The core burnup level, energy generation, and TRU production/destruction rate output results are dependent on the TRISO packing fraction in addition to the AP1000 fuel enrichment 
and lag time. Likewise, the TRU composition will be dependent on the same input variables, but will also include the lag time associated with the VHTR subsystem.

The us ed fuel from the VHTR is then passed to the HEST s ubsystem model and the ph ysics approach method for calculating the ne utron e conomy ba lance $\left(D_{\text {eq }}{ }^{T R U}\right.$ and $D_{\text {eq }}{ }^{I}$ ) for the TRU nuclides under irradiation conditions in the HEST is applied. The output results allow a measure of the feasibility and degree of transmutation by fission achievable in the HEST as a function of the system's input variables.

The data is then evaluated in the repository subsystem model by applying the methods developed for determining normalized heat factors and normalized radiotoxicity factors for the TRU and the related isotopic priority rankings. By doing so provides a means for the final results produced by the ISM to be us ed to quantify repository performance, which in turn can be us ed for making comparisons to other fuel cycles.

As explained pr eviously, the s ize and s tructure of the multi de gree a rrays that form the ISM database are the key to successfully simulating systems within the ISM. T he NES includes 4 input va riables translating to a da tabase composed of 4 a rrays, w hich progressively i ncreases from a 1D array to a 4D array. The data entries within each of the arrays are determined by the breakpoint sets for each input variable. The input variable for the AP1000 fuel enrichment has 7 breakpoints set at: $[3.0,3.5,4.0,4.5,5.0,5.5,6.0]$ weight percent. The lag time variable for the AP1000 i ncludes 4 br eakpoints a t: $[5,10,15,20]$ years. T he $p$ acking f raction for T RISO particles in the VHTR represents the third input variable and its corresponding breakpoint set is: $[20,30,40]$ percent. The final input variable is the lag time associated with the VHTR, which has the breakpoint set of: $[5,10,15,20]$ years.

With the input variables and br eakpoint s ets a ssigned, the da tabase size and structure is fixed. The $1 \mathrm{D}$ array is simply composed of 7 elements. The $2 \mathrm{D}$ array is a $7 \mathrm{x} 4$ matrix, the $3 \mathrm{D}$ array is $4 \times 3 \times 7$, and the $4 \mathrm{D}$ array is $3 \times 4 \times 4 \times 7$. The resulting database will require 455 data entries. The system model for the NES must produce results for a number of individual isotopes and element groups for each input $\mathrm{v}$ ariable. Therefore, the database $\mathrm{m}$ ust be expanded a ccordingly. The tracking of the T RU el ements i nclude $15 \mathrm{i}$ ndividual i sotopes, ur anium i ncludes 4 di fferent isotopes, and the FP are grouped together as on e, plus the burnup values for both the AP1000 and VHTR must be accounted for. Taking this into consideration, the data entries for the ISM database is expanded from 455 to 9,121 .

The data entries are produced by the high fidelity whole-core 3D exact geometry models for the AP1000 and VHTR, as detailed in sections 4.1.1 a nd 4.1.2. W hole-core depletion calculations for each reactor are performed using MCNPX. In the case of the AP1000, the core (for each of the breakpoint values for enrichment) is depleted until it can no longer support criticality, after which it is decayed in ORIGEN for the specified breakpoints for lag time. Thus, producing the data e ntries ( fuel i sotopic c oncentrations) ne eded f or the da tabase a s r elated t o the A P1000 subsystem. S imilarly, the VHTR c ore is depleted and decayed to produce database entries for the specified breakpoints, providing the remaining entries needed to complete the ISM database. To fully populate the database, the minimum number of depletion calculations to be performed is set at 64 . However, being that the cores are required to be depleted exactly to critical $\left(\mathrm{k}_{\mathrm{eff}}=1\right)$, 
the number of calculations is doubled to 128. Considering that the average MCNPX depletion runtimes for the available computer platform (2 - Xeon E5530 2.4GHz quad core CPU, 12.0 GB memory), the tot al $\mathrm{c}$ omputational $\mathrm{c}$ ost $\mathrm{f}$ or $\mathrm{g}$ enerating input da ta $\mathrm{f}$ or $\mathrm{t}$ he ISM da tabase i s approximately 7000 hours of continual runtime. The cost can be reduced by a factor of about 7 if t he de pletion cases ar e conf igured to execute i $n$ parallel, or i f multiple cas es ar e $r$ un simultaneously.

The completed database is entered into the framework of the ISM. With the database in place, the ISM is s et to interpolate and e xtrapolate da ta us ing the $\mathrm{c}$ ubic $\mathrm{s}$ pline $\mathrm{m}$ ethod. T he i nput parameters are entered into the ISM and then the simulation is executed. U pon completion the output results are provided in the MATLAB environment for further processing and analysis if desired. Figure 4.20 shows the data path and setup for the NES simulation. T he grey blocks contain the subsystems so they can be easily identified. The green path (uranium) and the red path (TRU) both represent multiple isotopes, indicating that each has been collapsed to contain information that is applied similarly to the each of the isotopes they contain. The uranium path controls 4 isotopes, while the TRU path controls 15 isotopes.

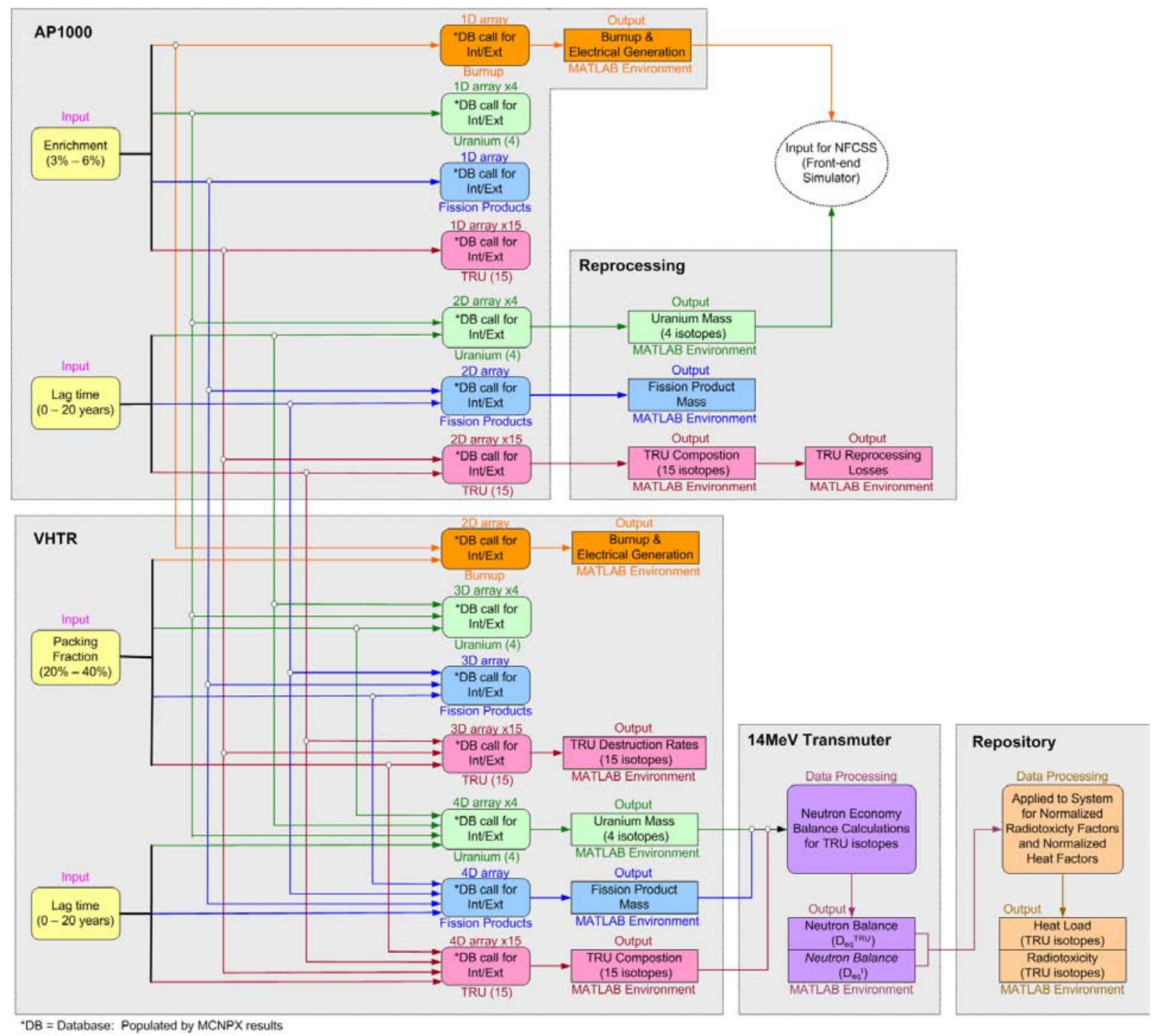


Figure 4.20. Detailed Mapping of the ISM Dataflow as Related to the NES.

The integrated model for the NES offers control and manipulation of the input parameters and the output can be modified countless different ways, since it is produced within the MATLAB environment. In addition, the computational cost of the simulation is minimal, especially when compared to MCNPX depletion calculations for the AP1000 and VHTR. On average the ISM computational cost is approximately five orders of magnitude less than that for a single MCNPX depletion calculation. 


\section{ENERGY SYSTEM NEUTRONIC AND FUEL COMPOSTION ANALYSIS}

\subsection{AP1000}

The r eference co re has an average fuel enr ichment of 4.5 wt.\% and uses a s ingle ba tch fuel management scheme. The ENDF/B-VII cross-section library was us ed for fuel temperatures at $900 \mathrm{~K}$ and moderator temperatures at $600 \mathrm{~K}$. Depletion calculations were performed by MCNPX using 50 day intervals and 700,000 neutron histories per interval.

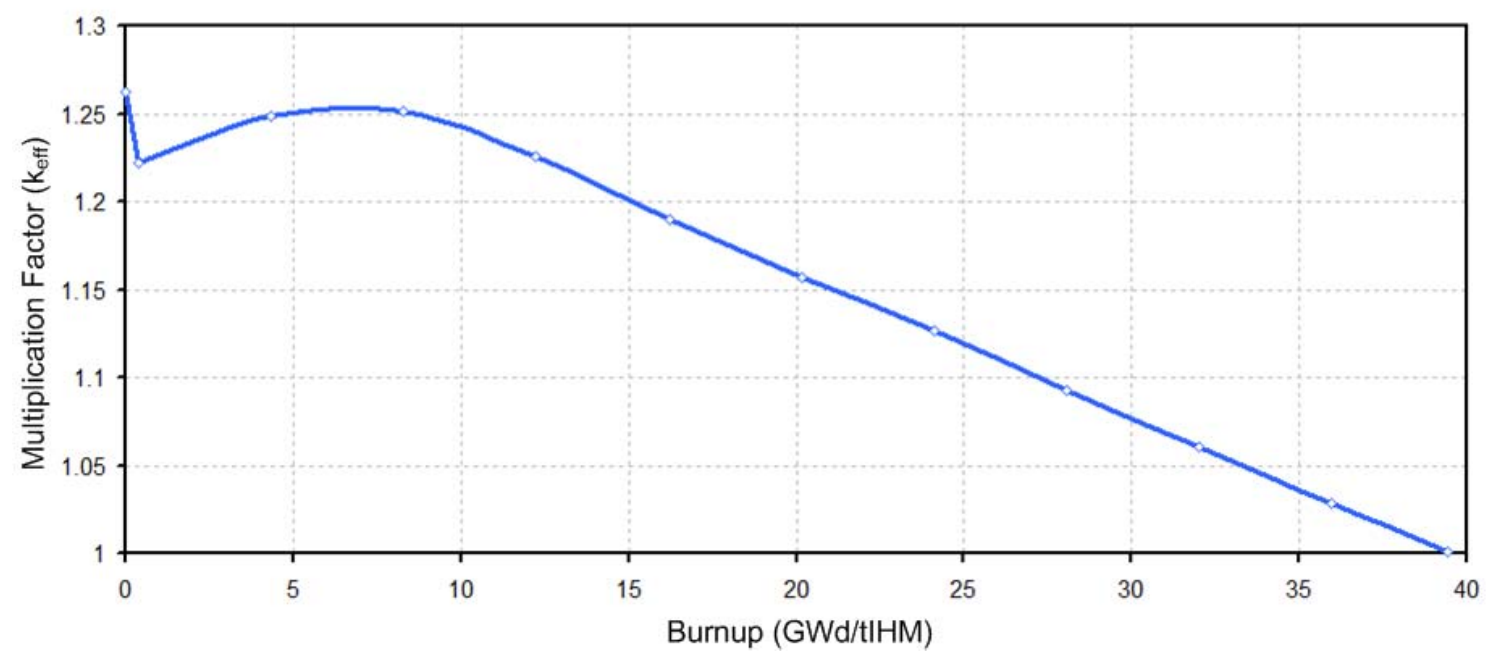

Figure 5.1. AP1000 Whole Core Depletion.

Figure 5.1 s hows the time evolution of the AP1000 core $\mathrm{k}_{\text {eff }}$ determined by MCNPX. The core has a $n$ initial $\mathrm{k}_{\text {eff }}$ value of 1.26. A short time $\mathrm{s}$ tep $\mathrm{w}$ as incorporated in the bur nup $\mathrm{s}$ cheme to show the ne utron poi son e ffect a ccompanying the introduction of F Ps into the core at r eactor startup. The reactivity level of the core then gradually increases for a s hort time period before decreasing again. The PYREX rods and IFBA rods that are present in the core cause the initial increase in $\mathrm{k}_{\text {eff. }}$ At Beginning of Cycle (BOC) the boron in the PYREX and IFBA rods acts as a strong $\mathrm{n}$ eutron poi son and $\mathrm{s}$ ignificantly $\mathrm{d}$ epresses $\mathrm{t}$ he reactivity $\mathrm{o} f \mathrm{t}$ he $\mathrm{c}$ ore, but as $\mathrm{t}$ ime progresses the bor on is depleted, which is e vident by the increase in $\mathrm{k}_{\text {eff. }}$ The cor e reaches a subcritical 1 evel at a pproximately $39.4 \mathrm{G} \mathrm{Wd}$ /tIHM, w hich is e quivalent to $997 \mathrm{E}$ ffective F ull Power Days (EFPD). 


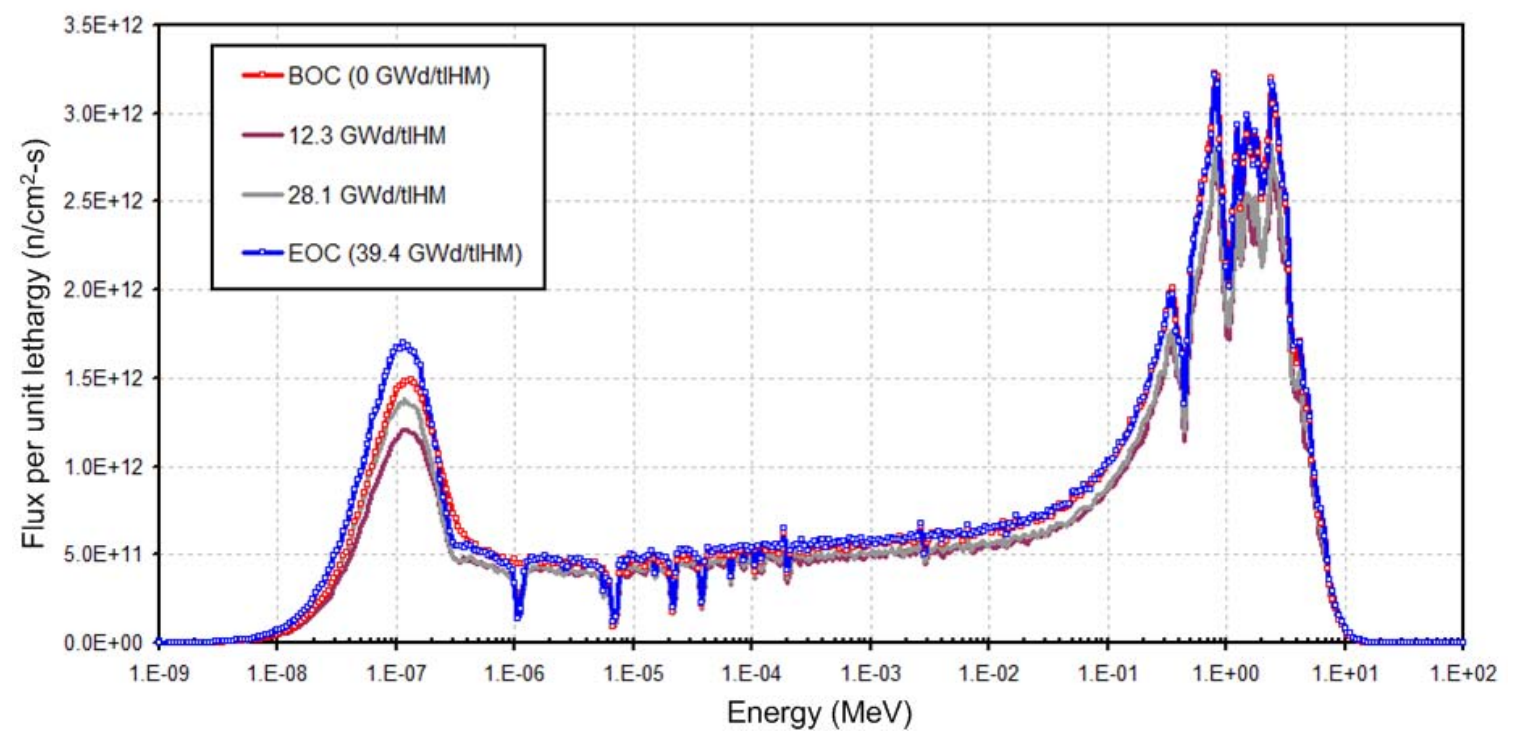

Figure 5.2. AP1000 Spectra at Different Burnup Levels.

The pr ofile of the a verage ne utron $\mathrm{f}$ lux in the $\mathrm{f}$ uel e lements a $\mathrm{t}$ di fferent bur nup 1 evels a re provided in Figure 5.2. To maintain a constant power throughout the core lifetime, the flux must constantly change to compensate for the isotopic transformations caused by neutron irradiation. The main competing factors in the process are the consumption/production of fissile nuclides, the depletion of the bur nable poi sons, and the a ccumulation of fission products in the core. The spectrum pr ofile in each case is $s$ imilar w ith the mos $t$ not able di fference be ing the the rmal energy peak. At BOC, the burnable poisons are at full strength, but as time evolves the powerful thermal energy neutron absorber ${ }^{10} \mathrm{~B}$ is depleted and consequently less thermal energy neutrons are $\mathrm{r}$ emoved from the s ystem. T he de pletion of B urnable $\mathrm{P}$ oison (BP) ha ppens e arly in the core's lifetime and only a small fraction of the ${ }^{10} \mathrm{~B}$ remains at a fuel burnup level of $15 \mathrm{G} \mathrm{Wd}$ / tIHM. The effect is evident by the decrease in the flux between BOC and $12.3 \mathrm{G} \mathrm{Wd} / \mathrm{tIHM}$. Additionally, as the burnup level increases the amount of total FP in the core continues to grow. The FP are neutron absorbers and over time have a strong negative effect on the core's neutron economy. Also, the fissionable material in the core is gradually decreased as ${ }^{235} \mathrm{U}$ is diminished throughout core lifetime and the production of ${ }^{239} \mathrm{Pu}$ and ${ }^{241} \mathrm{Pu}$ levels of $\mathrm{ft}$ owards the End of cycle (EOC). The cumulative effect translates to an increase in neutron flux, as shown by the flux plots for burnup levels between $12.3 \mathrm{GWd} / \mathrm{tIHM}$ and EOC.

The c ore is initially loaded w ith $86 \mathrm{M}$ etric t ons of U ranium (MTU), w ith a pproximately 3.9 tones be ing ${ }^{235} \mathrm{U}$. F rom the time of reactor s tartup until E OC, the fissile c omponent ${ }^{235} \mathrm{U}$ is depleted but other fissile components are produced when ${ }^{238} \mathrm{U}$ is transmuted to higher actinides, particularly ${ }^{239} \mathrm{Pu}$ and ${ }^{241} \mathrm{Pu}$. F igure 5.3 s hows the time evolution of important i sotopes within the core, from which a comparison can be made between the consumption of the fuel and the production of TRU isotopes. 


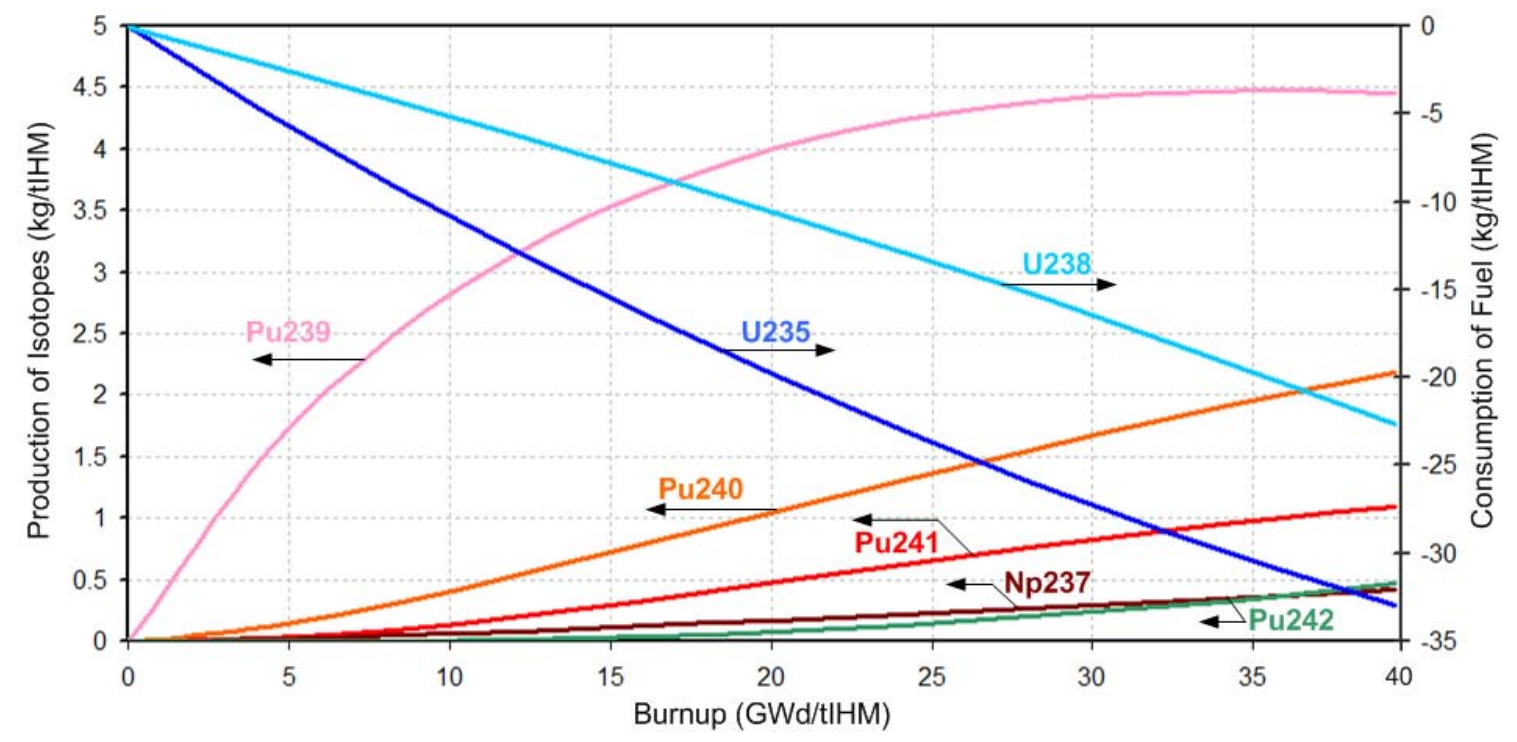

Figure 5.3. AP1000 Production and Consumption of Higher Isotopes.

The TRU produced during the lifetime of the AP1000 core is dominated by $\mathrm{Pu}$, which accounts for more than $93 \%$ of the TRU. Even so, the production of higher actinides is crucial because of the impact they can have on $\mathrm{w}$ aste management. F igure $5.4 \mathrm{~s}$ hows the production rate of the higher a ctinides that bui ldup qui ckest in the core. A s i ndicated by the trend 1 ines for T RU nuclide production, higher fuel burnup results in greater concentrations of TRU in the core. The lone exception being ${ }^{239} \mathrm{Pu}$, in which the production rate plateaus, and with high enough burnup will be gin $t \mathrm{o}$ be consumed. $\mathrm{G}$ enerally, hi gher bur nup $\mathrm{c}$ ore $\mathrm{c}$ onfigurations a re $\mathrm{t}$ argeted $\mathrm{f}$ or economic reasons, but the increased bui ldup of higher actinides and how it effects the ov erall fuel cycle must also be taken into consideration when designing for high burnup PWR cores.

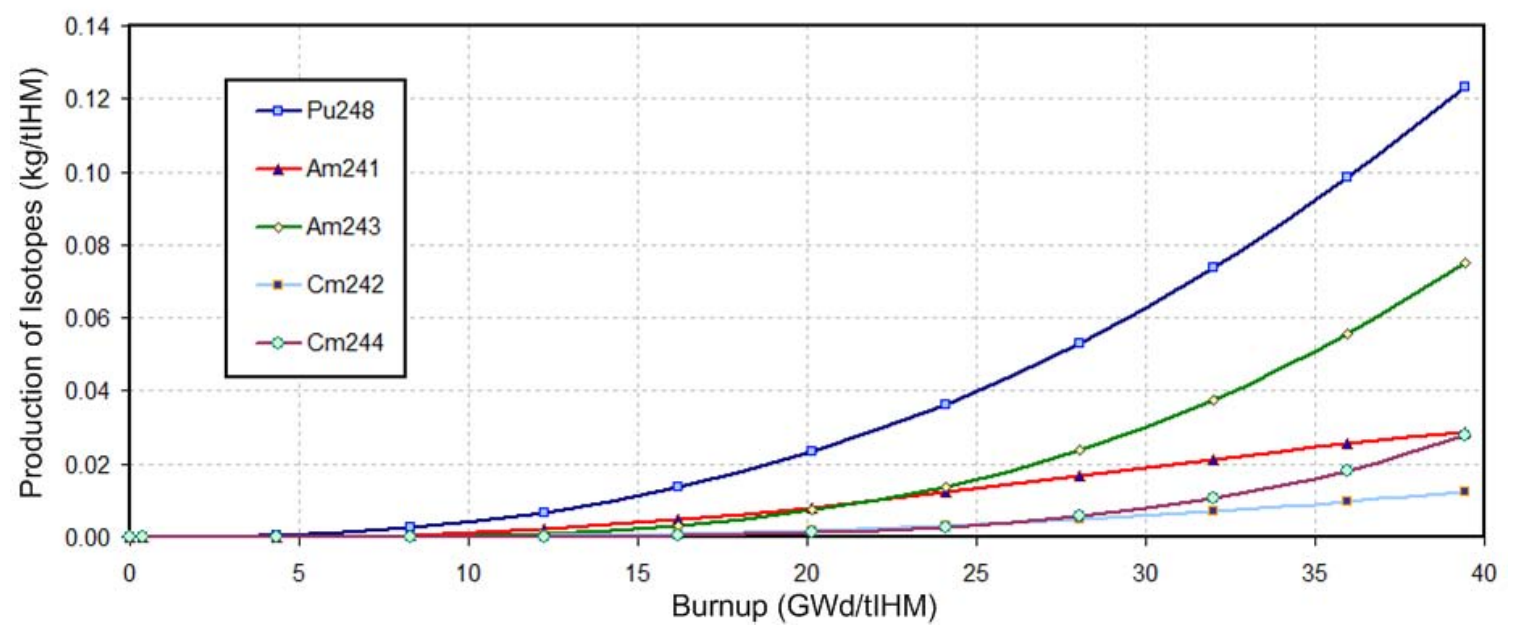

Figure 5.4. AP1000 Production of Higher Isotopes. 
A more complete tabulation of the actinide and FP transformations within the core is provided in Table 5.1. The mass is given for the actinides produced and consumed at various burnup levels, along w ith the F Ps a s a g roup. A t E OC ( $39.4 \mathrm{G} \mathrm{Wd} / \mathrm{tIHM})$, the us ed fuel is a lmost e ntirely composed of Uranium, which is $96.5 \%$ of the total by weight. The FP make up about $2.5 \%$, with the TRU only accounting for $1 \%$ of the fuel at EOC.

Of greater importance is the isotopic composition of the TRU produced during the core lifetime as it w ill become the fuel component for the VHTR. The us ed fuel is very "hot" immediately after removal and must be stored in the onsite reactor cooling pool before being transported to other $\mathrm{f}$ acilities for $\mathrm{r}$ eprocessing and fuel $\mathrm{f}$ abrication. T he $\mathrm{r}$ eprocessing and fuel $\mathrm{f}$ abrication procedures will also involve a substantial amount of time, which translates to a decay/cool-down time period between fuel removal from the AP1000 up to the time the recycled fuel is ready to be loading into the VHTR.

Table 5.1. Nuclide Masses in the AP100 at Different Burnup Levels.

\begin{tabular}{|c|c|c|c|c|c|c|c|}
\hline \multirow{2}{*}{\multicolumn{2}{|c|}{ Nuclide }} & \multicolumn{6}{|c|}{ Average Fuel Burnup (GWd/tIHM) } \\
\hline & & 0 & 8 & 16 & 24 & 32 & 39.4 \\
\hline \multirow{20}{*}{ 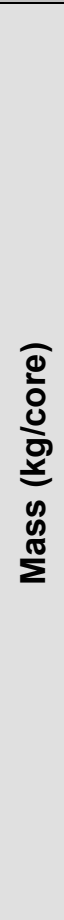 } & ${ }^{234} \mathrm{U}$ & 0.0 & 0.056 & 0.099 & 0.135 & 0.168 & 0.202 \\
\hline & ${ }^{235} \mathrm{U}$ & 3867 & 3081 & 2445 & 1887 & 1408 & 1029 \\
\hline & ${ }^{236} \mathrm{U}$ & 0.0 & 141.5 & 251.8 & 343.1 & 417.9 & 472.9 \\
\hline & ${ }^{238} \mathrm{U}$ & 82190 & 81820 & 81460 & 81080 & 80660 & 80240 \\
\hline & ${ }^{237} \mathrm{~Np}$ & 0.0 & 3.883 & 10.39 & 18.44 & 27.52 & 36.15 \\
\hline & ${ }^{238} \mathrm{Pu}$ & 0.0 & 0.225 & 1.174 & 3.12 & 6.35 & 10.59 \\
\hline & ${ }^{239} \mathrm{Pu}$ & 0.0 & 215.3 & 315.0 & 365.1 & 382.9 & 383.8 \\
\hline & ${ }^{240} \mathrm{Pu}$ & 0.0 & 26.34 & 68.51 & 112.4 & 153.8 & 188.2 \\
\hline & ${ }^{241} \mathrm{Pu}$ & 0.0 & 7.768 & 28.93 & 53.63 & 76.62 & 93.45 \\
\hline & ${ }^{242} \mathrm{Pu}$ & 0.0 & 0.471 & 3.822 & 11.38 & 23.98 & 40.39 \\
\hline & ${ }^{244} \mathrm{Pu}$ & 0.0 & 0.0 & 0.00003 & 0.00015 & 0.00050 & 0.00121 \\
\hline & ${ }^{241} \mathrm{Am}$ & 0.0 & 0.056 & 0.400 & 1.058 & 1.831 & 2.462 \\
\hline & ${ }^{242} \mathrm{Am}$ & 0.0 & 0.0 & 0.002 & 0.006 & 0.010 & 0.013 \\
\hline & ${ }^{243} \mathrm{Am}$ & 0.0 & 0.014 & 0.269 & 1.182 & 3.216 & 6.448 \\
\hline & ${ }^{242} \mathrm{Cm}$ & 0.0 & 0.004 & 0.068 & 0.259 & 0.613 & 1.062 \\
\hline & ${ }^{243} \mathrm{Cm}$ & 0.0 & 0.0 & 0.0 & 0.003 & 0.009 & 0.020 \\
\hline & ${ }^{244} \mathrm{Cm}$ & 0.0 & 0.001 & 0.032 & 0.229 & 0.898 & 2.392 \\
\hline & ${ }^{245} \mathrm{Cm}$ & 0.0 & 0.0 & 0.001 & 0.007 & 0.036 & 0.113 \\
\hline & ${ }^{246} \mathrm{Cm}$ & 0.0 & 0.0 & 0.0 & 0.0 & 0.003 & 0.012 \\
\hline & FP & 0.0 & 760 & 1470 & 2180 & 2890 & 3550 \\
\hline
\end{tabular}

Table 5.2 pr ovides the i sotopic c omposition of $\mathrm{t}$ he T RU pr oduced a $\mathrm{t}$ a bur nup 1 evel of 40 $\mathrm{GWd} / \mathrm{tIHM}$ for a range of decay times. F or thermal ne utron spectrum systems ${ }^{239} \mathrm{Pu}$ and ${ }^{241} \mathrm{Pu}$ are important because they are fissile isotopes. The decay chain and long half life for ${ }^{239} \mathrm{Pu}(2.41$ $\mathrm{x} 10^{4} \mathrm{yrs}$ ) cause it to remain at a stable rate for the time range of concern, but ${ }^{241} \mathrm{Pu}$ has a shorter half life (14.4 yrs) and decreases noticeably. ${ }^{241} \mathrm{Am}$ and ${ }^{237} \mathrm{~Np}$ demonstrate neutronic properties that classify them as burnable poisons in thermal neutron spectrum systems. The very long halflife of ${ }^{237} \mathrm{~Np}\left(2.14 \times 10^{6} \mathrm{yrs}\right) \mathrm{m}$ akes it s table dur ing the de cay t ime, but the 1 ong half-life and 
decay chain (beta-decay of ${ }^{241} \mathrm{Pu}$ ) for ${ }^{241} \mathrm{Am}$ ( $433 \mathrm{yrs}$ ) cause it to increase significantly over the 20 year period. The remaining TRU i sotopes are considered ne utron absorbers with very low fission probability in thermal neutron spectrums, and none of them change much over the given time pe riod. The com bination of the de crease in ${ }^{241} \mathrm{Pu}$ and i ncrease in ${ }^{241} \mathrm{Am}$ is impor tant because extended periods of decay time can have a negative impact on the neutronic properties (e.g. difficulty achieving and/or maintaining criticality) of the recycled TRU when considered as a fuel component for thermal neutron spectrum systems such as the VHTR.

Table 5.2. AP1000 TRU Vectors at $40 \mathrm{GWd} / \mathrm{tlHM}$.

\begin{tabular}{|c|c|c|c|c|c|c|}
\hline \multirow{2}{*}{\multicolumn{2}{|c|}{ Nuclide }} & \multicolumn{5}{|c|}{ Decay/Cool-Down Time (years) } \\
\hline & & 0 & 5 & 10 & 15 & 20 \\
\hline \multirow{15}{*}{ 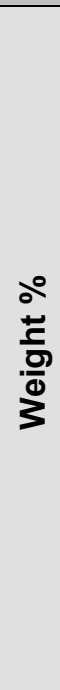 } & ${ }^{237} \mathrm{~Np}$ & 4.72 & 4.79 & 4.82 & 4.87 & 4.93 \\
\hline & ${ }^{238} \mathrm{Pu}$ & 1.38 & 1.46 & 1.40 & 1.35 & 1.30 \\
\hline & ${ }^{239} \mathrm{Pu}$ & 50.16 & 50.62 & 50.65 & 50.68 & 50.72 \\
\hline & ${ }^{240} \mathrm{Pu}$ & 24.60 & 24.35 & 24.39 & 24.44 & 24.47 \\
\hline & & 12.21 & 9.54 & 7.50 & 5.90 & 4.63 \\
\hline & ${ }^{242} \mathrm{Pu}$ & 5.28 & 5.22 & 5.23 & 5.23 & 5.23 \\
\hline & ${ }^{244} \mathrm{Pu}$ & $1.57 \times 10^{-4}$ & $1.56 \times 10^{-4}$ & $1.56 \times 10^{-4}$ & $1.57 \times 10^{-4}$ & $1.57 \times 10^{-4}$ \\
\hline & ${ }^{241} \mathrm{Am}$ & 0.32 & 2.91 & 4.93 & 6.50 & 7.71 \\
\hline & ${ }^{242} \mathrm{Am}$ & $1.75 \times 10^{-3}$ & $1.70 \times 10^{-3}$ & $1.66 \times 10^{-3}$ & $1.62 \times 10^{-3}$ & $1.58 \times 10^{-3}$ \\
\hline & ${ }^{243} \mathrm{Am}$ & 0.843 & 0.843 & 0.843 & 0.844 & 0.844 \\
\hline & ${ }^{242} \mathrm{Cm}$ & 0.1388 & $6.27 \times 10^{-5}$ & $4.36 \times 10^{-6}$ & $4.23 \times 10^{-6}$ & $4.130^{-6}$ \\
\hline & ${ }^{243} \mathrm{Cm}$ & $2.60 \times 10^{-3}$ & $2.28 \times 10^{-3}$ & $2.03 \times 10^{-3}$ & $1.80 \times 10^{-3}$ & $1.59 \times 10^{-3}$ \\
\hline & ${ }^{244} \mathrm{Cm}$ & 0.313 & 0.257 & 0.212 & 0.175 & 0.145 \\
\hline & ${ }^{245} \mathrm{Cm}$ & 0.015 & 0.015 & 0.015 & 0.015 & 0.015 \\
\hline & ${ }^{246} \mathrm{Cm}$ & $1.54 \times 10^{-3}$ & $1.53 \times 10^{-3}$ & $1.53 \times 10^{-3}$ & $1.52 \times 10^{-3}$ & $1.52 \times 10^{-3}$ \\
\hline
\end{tabular}

\subsection{VHTR}

The results for the VHTR prismatic core were produced by the MCNP code package. Depletion calculations were pe rformed b y CNPX, w ith core criticality evaluations b y M CNP5. T he MAKXSF code $\mathrm{w}$ as $\mathrm{u}$ sed to create $\mathrm{t}$ emperature de pendent ne utron cross-section libraries necessary for temperature coefficients of reactivity calculations performed by MCNP5.

\subsubsection{LEU Fuel}

The reference VHTR core has a ${ }^{235} \mathrm{U}$ fuel enrichment of $8.0 \mathrm{wt} . \%$ and uses a single batch fuel management s cheme. The E valuated N uclear Data Files - Basic V II ( ENDF/B-VII) c rosssection library was us ed for fuel temperatures at $1200 \mathrm{~K}$ and moderator temperatures at $900 \mathrm{~K}$. Depletion calculations were performed by MCNPX using 50 da y intervals and 600,000 ne utron histories per interval.

Figure 5.5 shows the change of the core $\mathrm{k}_{\text {eff }}$ as a function of fuel burnup. The core has an initial $\mathrm{k}_{\text {eff }}$ value of 1.20. A short time step was incorporated in the burnup scheme to show the neutron poison e ffect a ccompanying $t$ he i ntroduction of $F$ Ps i nto $t$ he $c$ ore a $t$ reactor $s$ tartup. $T$ he 
reactivity level of the core then increases until a burnup level of approximately $13.5 \mathrm{GWd} / \mathrm{tIHM}$ is achi eved at which time the co re r eactivity reaches a m aximum va lue of about 1.22. The burnable absorber rods present in the fuel assembly blocks cause the initial increase in $k_{\text {eff. }}$ The core r eaches a subcritical level at a pproximately $56.5 \mathrm{G} \mathrm{Wd} / \mathrm{tIHM}$, which is equivalent to 473 EFPD.

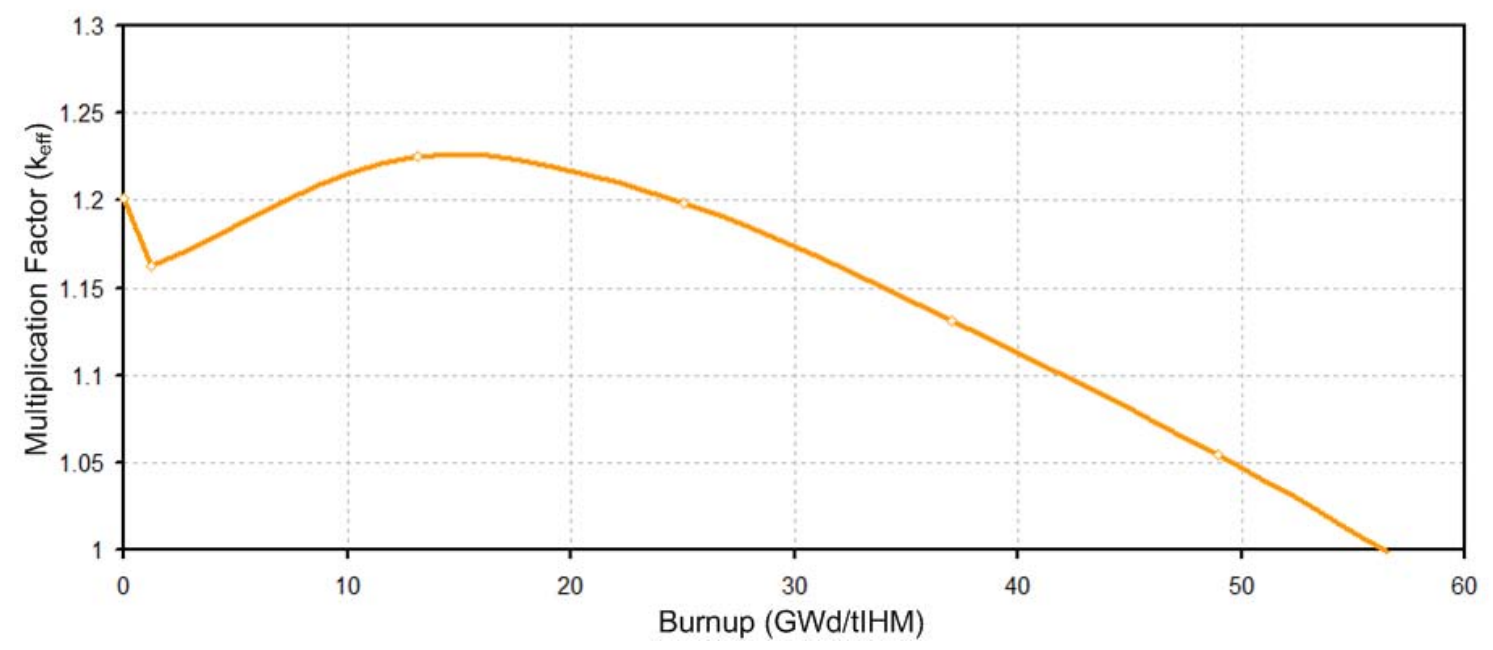

Figure 5.5. LEU-fueled VHTR Whole Core Depletion.

The ne utron flux for different core levels is provided in Figure 5.6. T he fuel particle and fuel compact produce similar profiles. T he s omewhat larger thermal ene rgy peak and smaller fast peak in the fuel block s pectrum signify the additional ne utron moderation due to the graphite prismatic fuel block. The same effect is even more pronounced as the average flux for the core is taken into consideration.

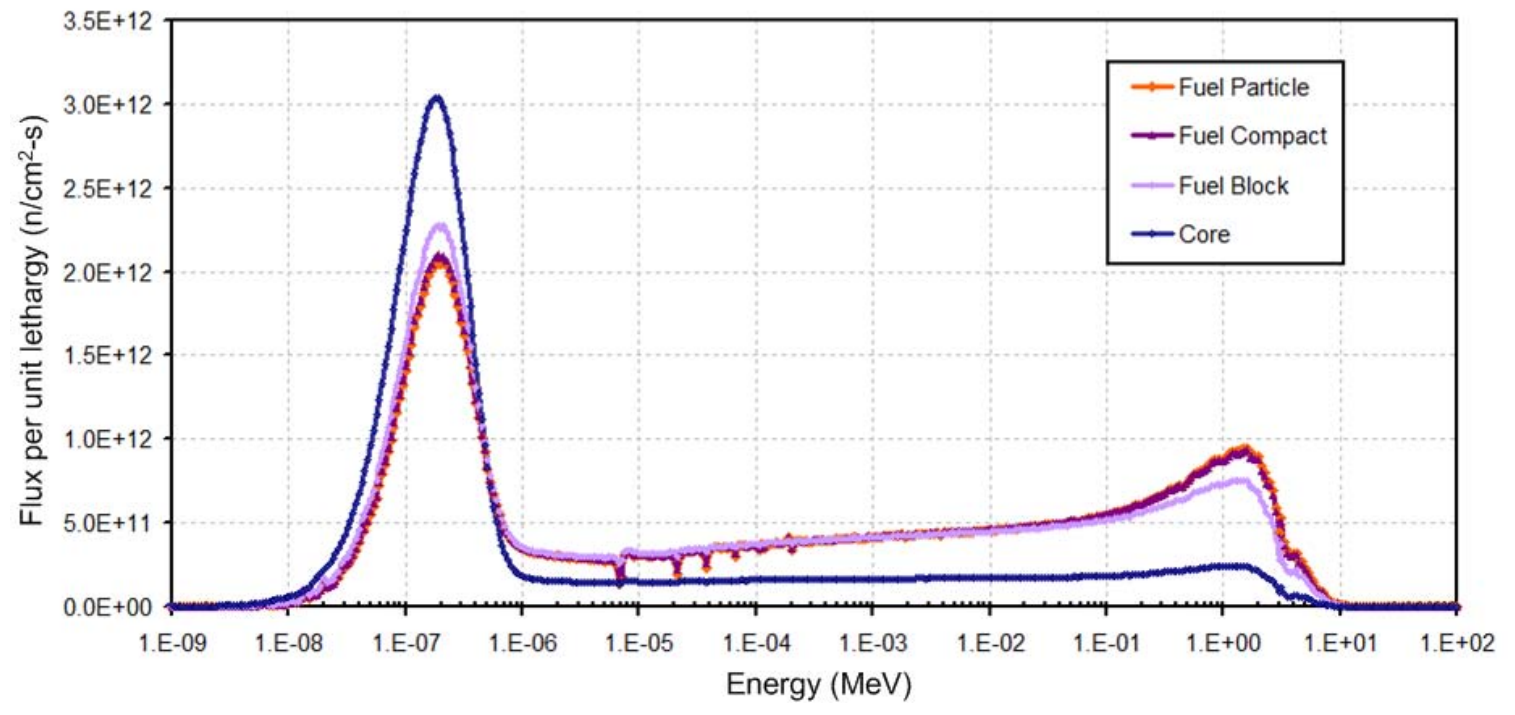

Figure 5.6. LEU-fueled VHTR Spectra for Core Regions. 
Figure 5.7 shows the time evolution of important isotopes within the core. A quick comparison between the normalized production and consumption rates for the major isotopes in the AP1000 and VHTR indi cate s imilar tr ends. T he tw o ma in differences being: 1) the faster $r$ ate of consumption of ${ }^{235} \mathrm{U}$ in the VHTR due to its hi gher enrichment c ontent, and 2) the increased production of ${ }^{239} \mathrm{Pu}$ in the A P1000. O therwise, dur ing the lifetime of each core the i sotopic compositions are very similar.

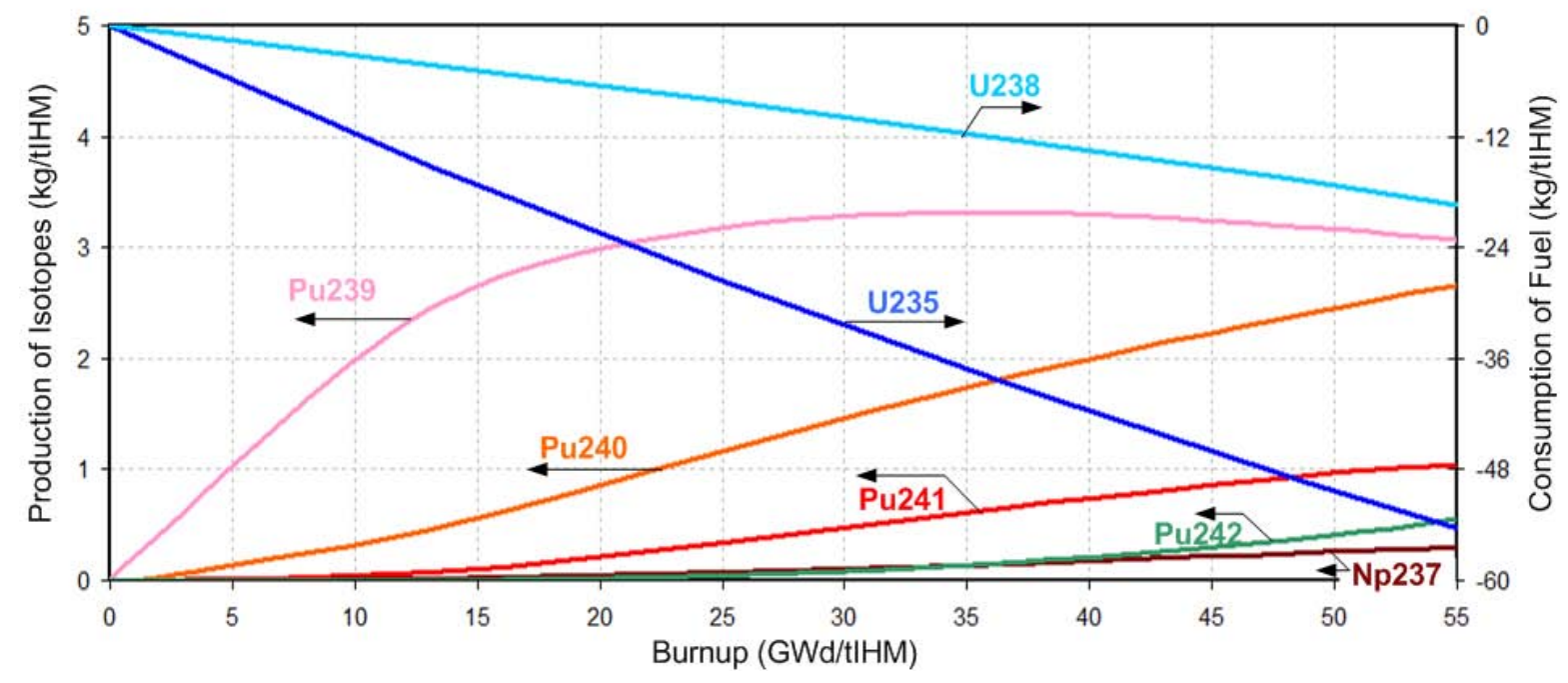

Figure 5.7. Production and Consumption of Higher Isotopes in LEU-fueled VHTR.

The A P1000 a nd V HTR s hare many s imilarities, most s ignificantly t hey are bot $\mathrm{h}$ thermal neutron spectrum systems and operate on LEU fuel. The similarities make it useful to compare the performance of both in order to gain further understanding of each. F igure $5.8 \mathrm{~s}$ hows the average flux in the fuel component for e ach reactor. The VHTR has a larger thermal ne utron spectrum pe ak and s omewhat hi gher e pithermal ne utron s pectral c omponent, due t o t he difference in moderator material, when compared to the AP1000. The graphite moderator of the VHTR ha s a m uch s maller thermal energy ne utron a bsorption c ross-section than the w ater moderator of the AP1000, thus the larger thermal energy neutron peak. However, the hydrogen in water is a very effective moderator and slows hi gh-energy ne utrons to lower energies more efficiently than graphite. Therefore, the VHTR has a much higher moderator-to-fuel ratio, which results in $m$ uch lower p ower de nsity a nd $m$ uch higher s pecific pow er. The hi gher op erating temperature of the VHTR shifts the thermal neutron spectrum peak to a higher energy compared to the A P1000, g iving t he V HTR a ha rder s pectrum a nd e ffecting t he i nitial e nrichment requirements and transmutation capabilities of each. 


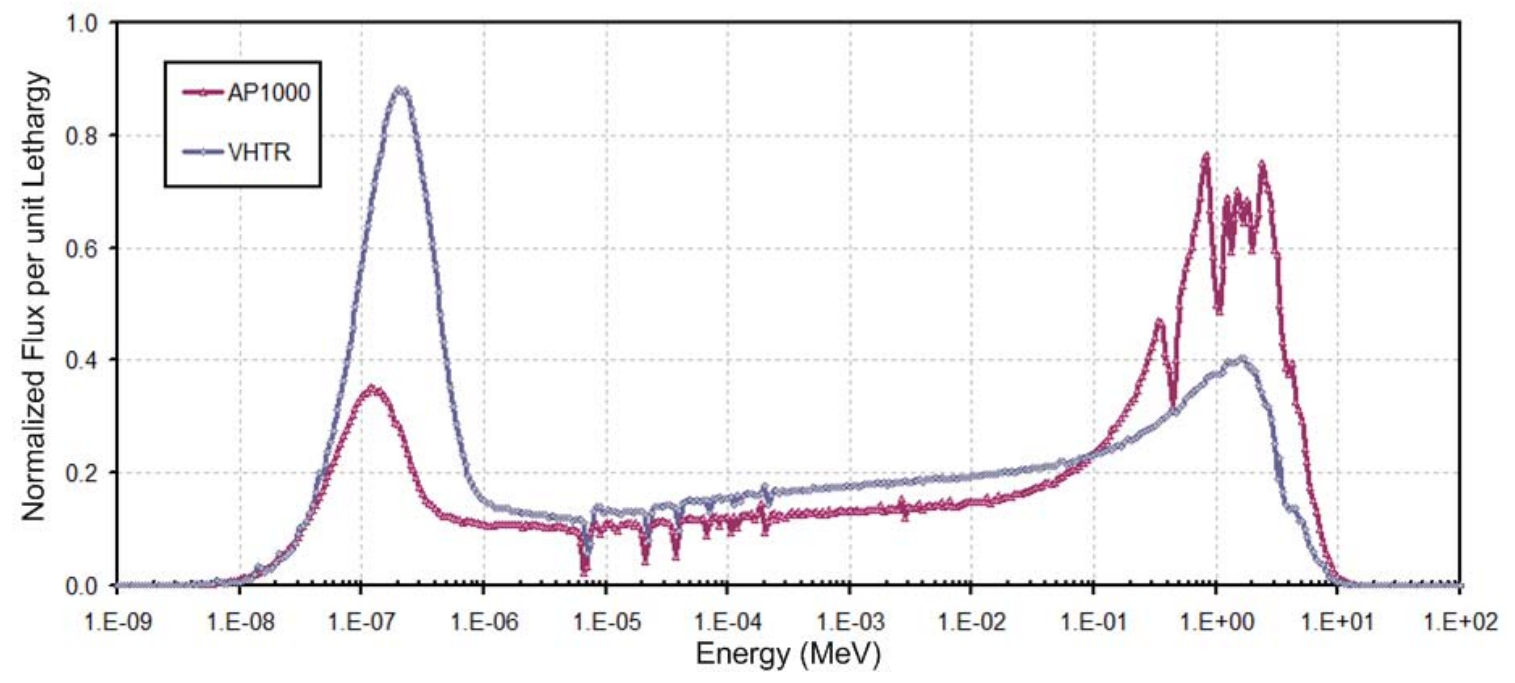

Figure 5.8. Average Neutron Flux in the Fuel Components for the AP1000 \& VHTR.

A comparison of important results between the AP1000 and the VHTR is provided in Table 5.3. The VHTR has close to twice the initial enrichment as the AP1000 and produces a higher fuel burnup, but at about half the duration (EFPD) of the AP1000. The VHTR also produces less Pu and T RU t han $t$ he A P1000, w hich i s e ven more a pparent $w$ hen $t$ he T RU production i s normalized to electricity generation.

Although the results are us eful, one must take into consideration that ne ither reactor $h$ as been optimized for performance and the comparison is for a generalized once through fuel cycle. As expected, optimized fuel shuffling schemes and higher burnup cores (particularly for the VHTR) would affect the results, but general trends can be established from the results.

Table 5.3. LEU-fueled VHTR vs. AP1000.

\begin{tabular}{|l|c|c|}
\hline \multicolumn{1}{|c|}{ Parameter } & AP1000 & VHTR \\
\hline \hline Burnup (GWd/tIHM) & 39.4 & 56.5 \\
\hline EFPD & 997 & 473 \\
\hline Enrichment (wt.\%) & 4.5 & 8.0 \\
\hline Enrichment at EOC (wt.\%) & 1.26 & 2.62 \\
\hline Pu content $(\mathrm{kg} / \mathrm{tlHM})$ & 8.32 & 7.48 \\
\hline TRU content $(\mathrm{kg} / \mathrm{tlHM})$ & 8.89 & 7.87 \\
\hline TRU production $(\mathrm{g} / \mathrm{GW}$ t $\mathrm{d})$ & 226 & 139 \\
\hline Thermal Efficiency $(\%)$ & 34 & 48 \\
\hline TRU production $\left(\mathrm{g} / \mathrm{GW}_{\mathrm{e}} \mathrm{d}\right)$ & 663 & 290 \\
\hline
\end{tabular}

\subsubsection{TRU Fuel}

The r esults presented in this s ection focus on $t$ he pe rformance of the VHTR fueled $w$ ith the recycled TRU arising from the AP1000 used fuel. Countless possibilities exist for the isotopic 
composition of the TRU, a s they are de pendent on $\mathrm{c}$ ontrol pa rameters for the A P1000. T he TRU-fueled VHTR reference case stems from the used AP1000 fuel, which had an initial fuel enrichment of $4.5 \mathrm{wt}$ t. $\%$, reached a burnup level of $40 \mathrm{G} \mathrm{Wd} / \mathrm{tIHM}$, and had a decay/cool-down time of 10 years. The resulting fuel composition for the TRU-fueled VHTR is listed in Table 5.4 .

The $r$ eference $T$ RU-fueled VHTR co re us es a single ba tch fuel $\mathrm{m}$ anagement $\mathrm{s}$ cheme. $\mathrm{T}$ he ENDF/B-VII cross $s$ ection 1 ibrary $w$ as us ed $\mathrm{f}$ or $\mathrm{f}$ uel $\mathrm{t}$ emperatures at $1200 \mathrm{~K}$ a nd m oderator temperatures at $900 \mathrm{~K}$. D epletion calculations w ere $\mathrm{p}$ erformed b y M CNPX us ing 91 da $\mathrm{y}$ intervals and 600,000 neutron histories per interval.

Table 5.4. Fuel Composition for the TRU-fueled VHTR.

\begin{tabular}{|c|r|r|}
\hline Nuclide & Mass $\mathbf{( k g )}$ & Weight \% \\
\hline \hline${ }^{237} \mathrm{~Np}$ & 243.31 & 4.8301 \\
${ }^{238} \mathrm{Pu}$ & 70.86 & 1.4067 \\
${ }^{239} \mathrm{Pu}$ & 2550.57 & 50.6321 \\
${ }^{240} \mathrm{Pu}$ & 1231.89 & 24.4547 \\
${ }^{241} \mathrm{Pu}$ & 376.29 & 7.4698 \\
${ }^{242} \mathrm{Pu}$ & 263.54 & 5.2316 \\
${ }^{241} \mathrm{Am}$ & 247.23 & 4.9078 \\
${ }^{242 \mathrm{~m}} \mathrm{Am}$ & 0.08 & 0.0017 \\
${ }^{243} \mathrm{Am}$ & 42.09 & 0.8356 \\
${ }^{243} \mathrm{Cm}$ & 0.10 & 0.0020 \\
${ }^{244} \mathrm{Cm}$ & 10.67 & 0.2119 \\
${ }^{245} \mathrm{Cm}$ & 0.73 & 0.0146 \\
${ }^{246} \mathrm{Cm}$ & 0.08 & 0.0015 \\
\hline Total & 5037.44 & 100.0000 \\
\hline
\end{tabular}

Figure 5.9 shows the reactivity as a function of burnup for the TRU-loaded VHTR. The $\mathrm{k}_{\text {eff }}$ at BOC is 1.17 and criticality is maintained up to a burnup level of $264 \mathrm{GWd} / \mathrm{tIHM}$, which equates to a cycle length of 2,220 EFPD. It is clear that the core reactivity decreases much slower and a much higher bu rnup is a chieved as compared to the LEU-fueled VHTR. The s mall reactivity swing and high fuel burnup is the result of many contributing factors, which can be reduced to just a few dominating phenomena. Throughout the core lifetime ${ }^{240} \mathrm{Pu}$ is being converted into the fissile isotope ${ }^{241} \mathrm{Pu}$ at a greater rate than ${ }^{241} \mathrm{Pu}$ is being depleted. In addition, the fissile isotope ${ }^{239} \mathrm{Pu}$ is also being produced by neutron capture in ${ }^{238} \mathrm{Pu}$, albeit at a slower rate, than it is being destroyed, but the combination of the two $\left({ }^{241} \mathrm{Pu}\right.$ and ${ }^{239} \mathrm{Pu}$ generation) counteract the depletion of the main fissile component ${ }^{239} \mathrm{Pu}$, allowing the core to stay above critical for long periods of time. Furthermore, ${ }^{240} \mathrm{Pu}$ comprises a large percentage of the TRU fuel and is also produced by neutron capture in ${ }^{239} \mathrm{Pu}$ throughout core life, which along with the large absorption cross section of ${ }^{240} \mathrm{Pu}$ make it a very effective burnable absorber; effectively limiting the reactivity swing from $\mathrm{BOC}$ to EOC. 


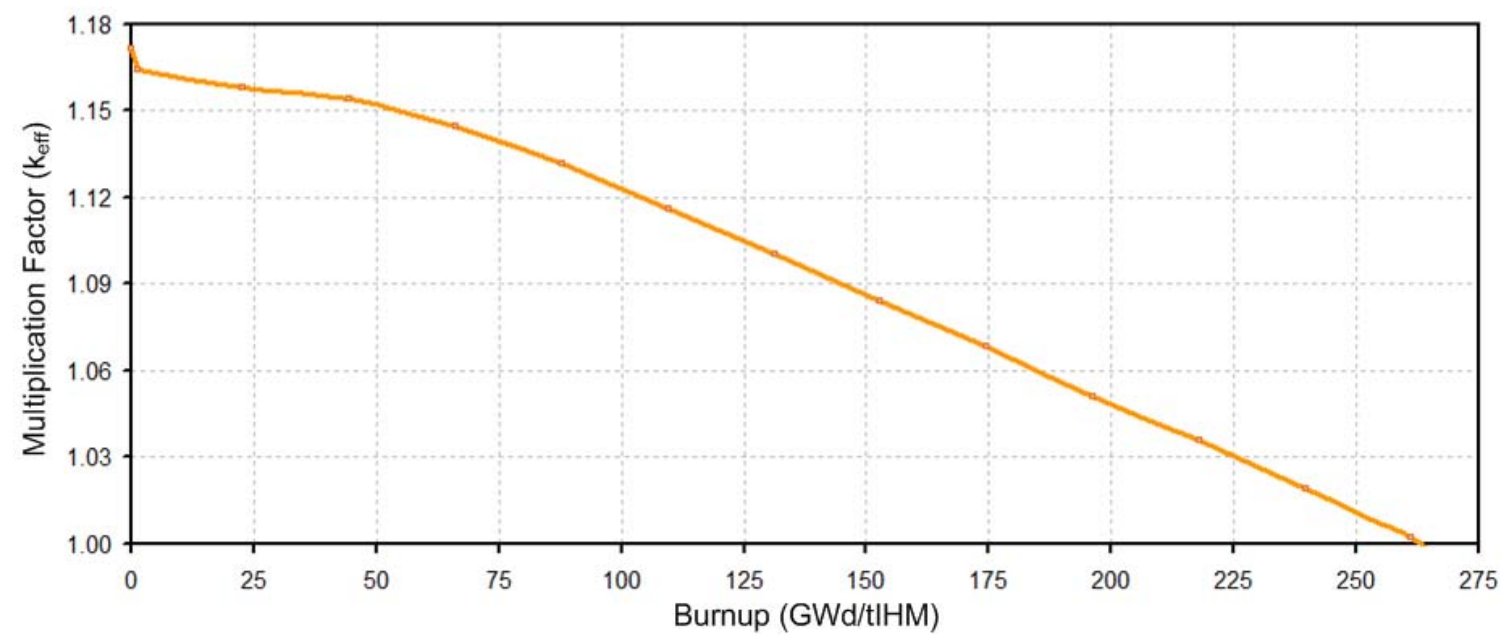

Figure 5.9. TRU-fueled VHTR Whole Core Depletion.

As the case in the previous section, the flux profile for different core levels is provided in Figure 5.10. C ompared to the LEU-fueled VHTR, there is a v ery not iceable difference in the thermal energy region of the flux profiles. The thermal energy peak is almost completely de pressed in the fuel particle and compact, but m ore di stinguishable in the fuel bl ock. $T$ he 1 arge thermal energy absorption cross-sections for ${ }^{231} \mathrm{Am}$ and ${ }^{240} \mathrm{Pu}$ in particular, and also ${ }^{237} \mathrm{~Np}$ and ${ }^{242} \mathrm{Pu}$ work together to remove a large portion (as compared to LEU fuel) of the thermal spectrum neutrons causing $t$ he de pressed peak. This ef fect $\mathrm{c}$ an have $\mathrm{s}$ afety $\mathrm{i}$ mplications as $\mathrm{t}$ he $\mathrm{f}$ uel $\mathrm{D}$ oppler reactivity co efficient is r eliant on the br oadening of low en ergy resonances c ross-sections in order to provide core stability (negative reactivity feedback for increases in fuel temperature). To a ssure $t$ he s tability of $t$ he T RU-fueled V HTR, a com plete ana lysis of t he $t$ emperature coefficients of reactivity (fuel Doppler, moderator, and isothermal) throughout core lifetime was performed and presented in the next section.

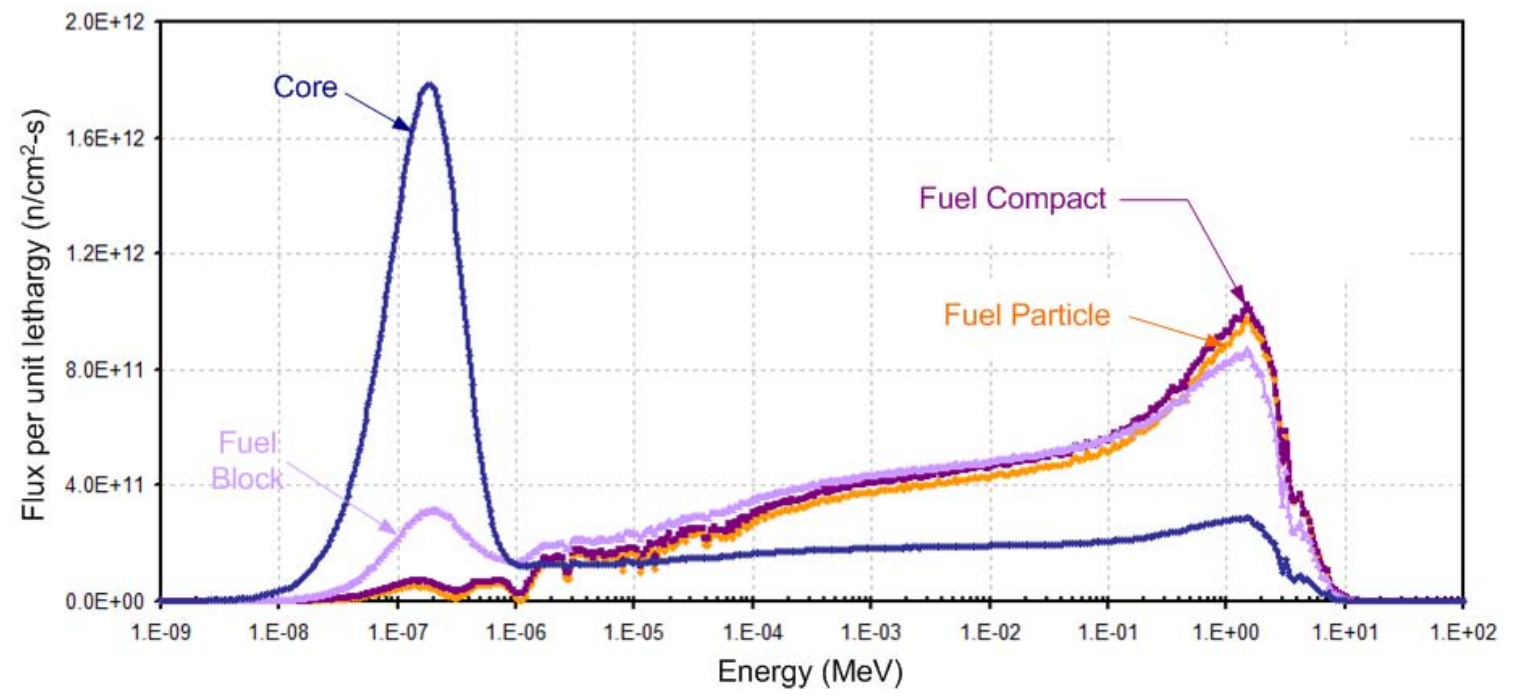

Figure 5.10. TRU-fueled VHTR Spectra for Core Regions. 
Figure 5.11 shows the time evolution of TRU consumption within the core. Plotted on the right axis is the consumption of ${ }^{239} \mathrm{Pu}$ which, by far, has the greatest consumption rate, registering an EOC c onsumption of m ore than $-300 \mathrm{~kg} / \mathrm{tIHM}$. T he three ot her nu clides $\left({ }^{237} \mathrm{~Np},{ }^{240} \mathrm{Pu}\right.$, a nd ${ }^{241} \mathrm{Am}$ ) are plotted on the right axis, showing EOC consumption of ${ }^{237} \mathrm{~Np}$ and ${ }^{241} \mathrm{Am}$ at about -20 $\mathrm{kg} / \mathrm{tIHM}$ and $-16 \mathrm{~kg} / \mathrm{tIHM}$. Although ${ }^{240} \mathrm{Pu}$ is produced during the first half of the core lifetime at EOC, its consumption rate is such that there is a lesser amount present than at BOC, with a slight overall consumption of $\quad-2.5 \mathrm{~kg} / \mathrm{tIHM}$.

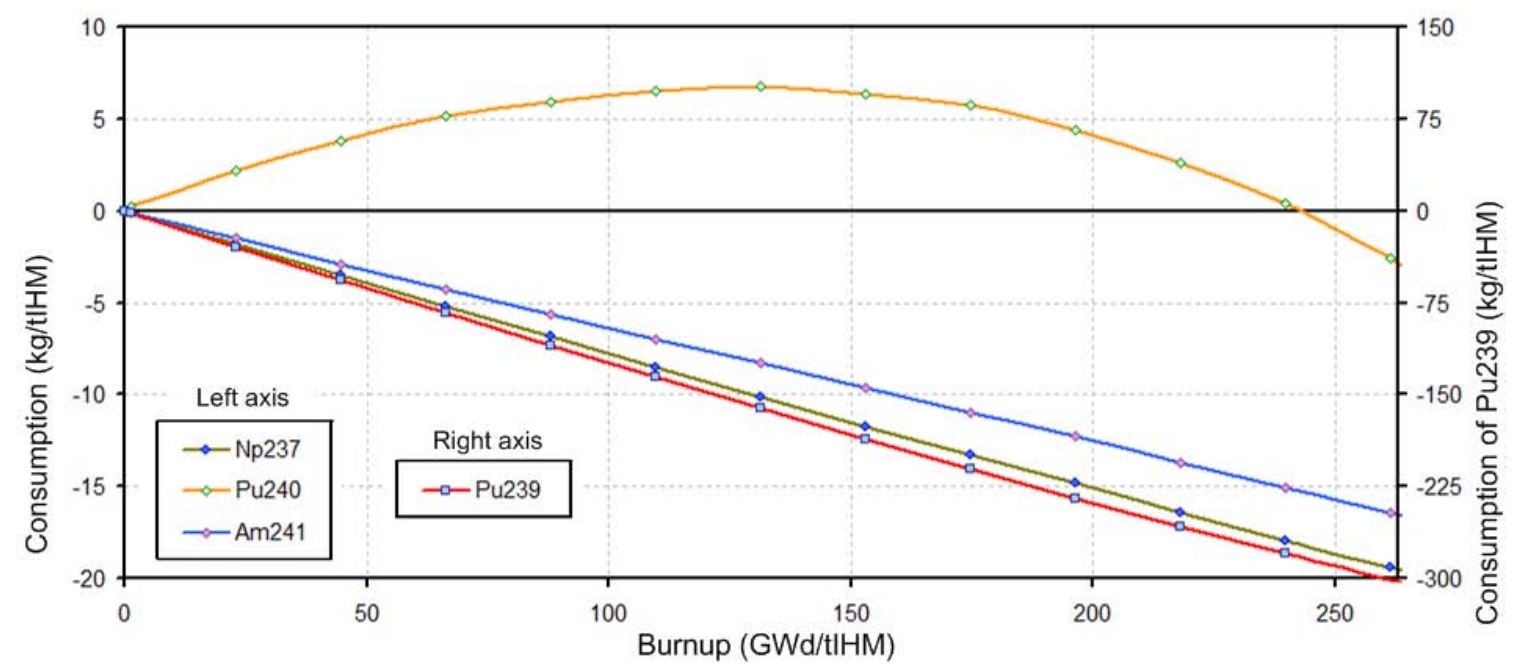

Figure 5.11. TRU-fueled VHTR Actinide Consumption.

The production of TRU isotopes is presented in Figure 5.12. The greatest production rate is that of ${ }^{238} \mathrm{Pu}$, plotted on the right axis, reaching $33 \mathrm{~kg} / \mathrm{tIHM}$ at EOC. The remaining nuclides are all plotted on the left axis and all remain under $10 \mathrm{~kg} / \mathrm{tIHM} .{ }^{244} \mathrm{Cm}$ has the highest production over the core lifetime and at EOC it is at about $9.5 \mathrm{~kg} / \mathrm{tIHM}$. T he production of ${ }^{241} \mathrm{Pu}$ is the next greatest at EOC being about $9 \mathrm{~kg} / \mathrm{tIHM}$, which is important because it is one of the two major fissile nuc lides, and as described earlier, is instrumental in a llowing hi gh bur nup levels. It is important to consider the buildup and production/consumption rate trends of the higher actinides due to their effect on core performance and future waste management.

The core is initially loaded with $5,037 \mathrm{~kg}$ of TRU, where as the amount of TRU generated by the AP1000 is approximately $770 \mathrm{~kg}$. Therefore, the ratio for AP1000-to-VHTR is roughly 6.5. At EOC the amount of TRU discharged from the VHTR is about $3,674 \mathrm{~kg}$, giving an overall TRU destruction of $27 \%$. The consumption of plutonium is over $28 \%$ including a $60 \%$ consumption of ${ }^{239} \mathrm{Pu}$. 


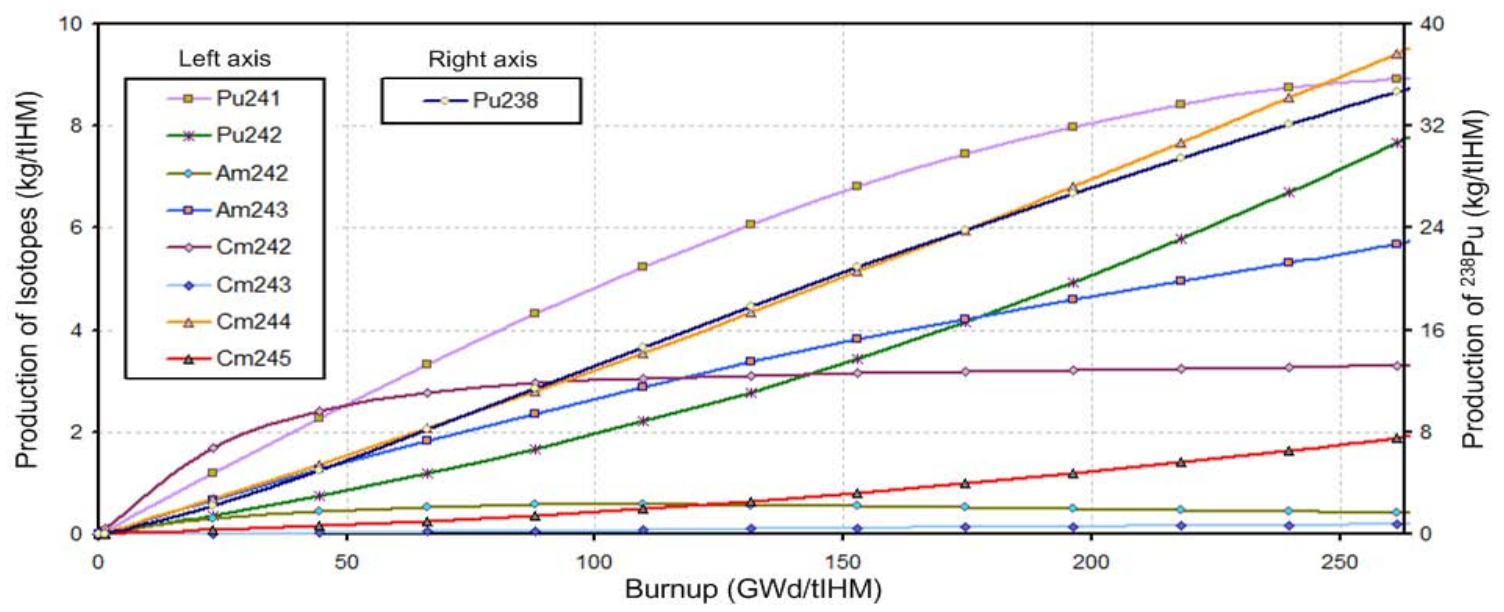

Figure 5.12. TRU-fueled VHTR Actinide Production.

Table 5.5 includes details for TRU consumption/production during the core lifetime. A negative value in the $\mathrm{P}$ ercent $\mathrm{C}$ hange $(\mathrm{BOC} \rightarrow$ EOC) c olumn represents consumption, with a pos itive value indicating production. S ome of the higher actinides have very large percent increases, but their TRU composition fractions remain very small (fractional in most cases). Of main concern is the buildup of ${ }^{244} \mathrm{Cm}$ and ${ }^{243} \mathrm{Am}$, having EOC concentrations of $58.7 \mathrm{~kg}$ and $70.9 \mathrm{~kg}$, with each contributing to over $1.5 \%$ e ach of the TRU composition. Increases in the inventory of these highly radiotoxic long-lived isotopes need to be limited, if possible. ${ }^{242} \mathrm{Cm}$ is also exceptionally radiotoxic and experiences a large buildup going from 0 to $16.7 \mathrm{~kg}$ at $\mathrm{EOC}$, but the short half-life (163 days) renders it to be of little concern in the long term. However, the very high heat load associated with the d ecay of ${ }^{242} \mathrm{Cm}$ ma kes it potentially pr oblematic in the short $\mathrm{term}$, as preparation for irradiation in the HEST is considered.

Table 5.5. BOC and EOC Fuel Composition for the TRU-fueled VHTR.

\begin{tabular}{|l|r|r|r|}
\hline \multirow{2}{*}{ Nuclide } & \multicolumn{2}{|c|}{ BOC } & \multicolumn{2}{c|}{$\begin{array}{c}\text { EOC } \\
\text { Initial Loading (kg) }\end{array}$} & $\begin{array}{c}\text { Percent Change } \\
\text { DOC } \rightarrow \text { EOC (\%) }\end{array}$ \\
\hline \hline${ }^{237} \mathrm{~Np}$ & 243.31 & 144.70 & -40.53 \\
\hline${ }^{238} \mathrm{Pu}$ & 70.86 & 246.90 & 248.43 \\
${ }^{239} \mathrm{Pu}$ & 2550.57 & 1019.00 & -60.05 \\
${ }^{240} \mathrm{Pu}$ & 1231.89 & 1217.00 & -1.21 \\
${ }^{241} \mathrm{Pu}$ & 376.29 & 421.30 & 11.96 \\
${ }^{242} \mathrm{Pu}$ & 263.54 & 302.80 & 14.90 \\
\hline${ }^{241} \mathrm{Am}$ & 247.23 & 163.50 & -33.87 \\
${ }^{242 \mathrm{~m}} \mathrm{Am}$ & 0.08 & 2.12 & 2452.73 \\
${ }^{243} \mathrm{Am}$ & 42.09 & 70.93 & 68.51 \\
\hline${ }^{242} \mathrm{Cm}$ & 0.00 & 16.65 & $\mathrm{n}$ \\
${ }^{243} \mathrm{Cm}$ & 0.10 & 0.97 & 852.12 \\
${ }^{244} \mathrm{Cm}$ & 10.67 & 58.69 & 449.81 \\
${ }^{245} \mathrm{Cm}$ & 0.73 & 9.62 & 1211.57 \\
${ }^{246} \mathrm{Cm}$ & 0.08 & 0.53 & 586.88 \\
\hline $\mathrm{Pu}$ & 4493.14 & 3207.00 & -28.62 \\
\hline $\mathrm{TRU}$ & 5037.44 & 3674.71 & -27.05 \\
\hline
\end{tabular}




\section{Temperature Coefficients of Reactivity}

The r eactivity effects d ue to core t emperature excursions w ere ana lyzed and the temperature dependent reactivity coefficients for: 1) fuel Doppler, 2) moderator, and 3) i sothermal w ere calculated. The fuel and moderator temperature distributions w ere assumed to remain uniform throughout the core. The fuel is TRU oxide discharged from the AP1000 with particle packing fraction of $30 \%$, a nd the $m$ oderator i ncludes the $g$ raphite $m$ aterial (graphite in the f uel, $f$ uel blocks, reflector blocks, and permanent reflector) within the core. In each case the ENDF/B-VII cross-section libraries w ere utilized for depletion and criticality calculations. The temperature coefficients $w$ ere eva luated using the e ffective multiplication factors a ccording the following relationship:

$$
\begin{aligned}
& \alpha\left(T_{n, n+1}\right)=\frac{d k}{d T}=\frac{k_{n+1}-k_{n}}{k_{n+1} \cdot k_{n}} \cdot \frac{1}{T_{n+1}-T_{n}} \\
& T_{n, n+1}=\frac{T_{n}+T_{n+1}}{2}
\end{aligned}
$$

where $\alpha$ is the temperature co efficient b etween $T_{n}$ and $T_{n+1}, T_{n}$ is the cor e temperature at $n^{\text {th }}$ measurement, and $\mathrm{k}_{\mathrm{n}}$ is the effective multiplication factor at $\mathrm{T}_{\mathrm{n}}$.

To accurately predict the coefficients at different burnup levels during the core lifetime, wholecore de pletion calculations at reference cor e temperature (fuel $1200 \mathrm{~K}$, moderator $900 \mathrm{~K}$ ) w ere performed by MCNPX with 3 million neutron histories per burnup step. The fuel and burnable poison material compositions were then retrieved at the burnup levels of interest $(0,66,130,200$, 260 , and $326 \mathrm{GWd} / \mathrm{tIHM}$ ) to be us ed for additional standalone MCNP5 criticality calculations, which were performed at a series of varying fuel and/or moderator temperature levels in order to provide $t$ he $\mathrm{r}$ equired $\mathrm{d}$ ata $\mathrm{f}$ or $\mathrm{c}$ alculating the $\mathrm{t}$ emperature coefficients $\mathrm{c}$ orresponding to e ach selected bur nup 1 evel. F igure $5.13 \mathrm{~s}$ hows a graphical $r$ epresentative of $t$ he procedure $f$ or calculating the reactivity temperature coefficients.

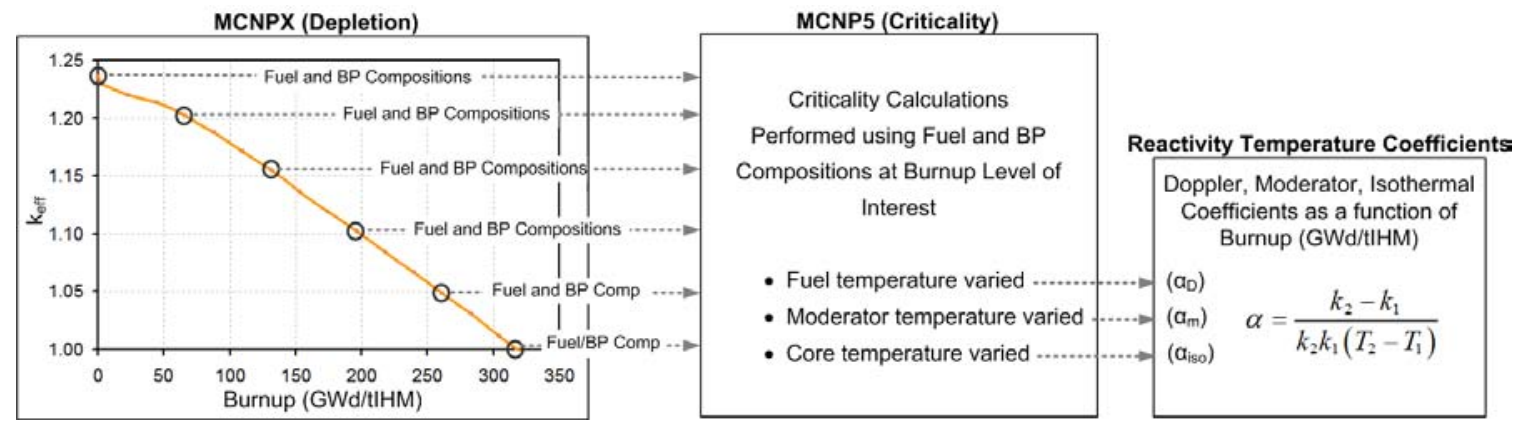

Figure 5.13. Procedure for Calculating Reactivity Temperature Coefficients.

Temperature dependent neutron cross-section libraries were created by the MAKXSF code [23], which is a utility program for manipulating cross-section library files for MCNP5. Capabilities of M AKXSF ut ilized $f$ or the $t$ emperature coefficient s tudy include: D oppler br oadening of resolved da ta to a ny hi gher t emperature, i nterpolation of unr esolved $r$ esonance da ta $b$ etween 
datasets at tw o different te mperatures, and interpolation of the rmal s cattering k ernels $(\mathrm{S}(\alpha, \beta)$ data) between datasets at two different temperatures.

Due to the high s ensitivity of the temperature c oefficients to core r eactivity changes, the $\mathrm{k}_{\text {eff }}$ value computed by MCNP5 was limited to a standard deviation of 0.00020 or less. T his high accuracy i s ne eded be cause $\mathrm{t}$ he e rror propagation i ntroduced $\mathrm{b}$ y $\mathrm{t}$ he unc ertainty $\mathrm{i} \mathrm{n} \mathrm{k}$ eff can produce a substantial er ror in the temperature coefficient calculated by Equation (1). With the criticality limit set, the coefficients are assured to have minimal associated errors in all cases. To accomplish this, the MCNP5 criticality calculations required $15 \mathrm{~m}$ illion ne utron histories to be used for $\mathrm{k}_{\mathrm{eff}}$ estimates.

\section{Fuel Doppler}

The fuel Doppler coefficient $\left(\alpha_{D}\right)$ of reactivity was estimated for six burnup conditions: BOC or 0, 66, 130, 200, 260, and 326 ( EOC) GWd/tIHM. T he calculated core $\mathrm{k}_{\text {eff }}$ assumes that the graphite moderator temperature is fixed at $900 \mathrm{~K}$ and the fuel temperature varies from 293.6 $2500 \mathrm{~K}$. Six fuel temperature steps: 1) 293.6 - $600 \mathrm{~K}$, 2) $600-900 \mathrm{~K}$, 3) $900-1200 \mathrm{~K}$, 4) 1200 - $1500 \mathrm{~K}$, 5) $1500 \mathrm{~K}-1800 \mathrm{~K}$, and 6) $1800 \mathrm{~K}-2500 \mathrm{~K}$, were us ed to produce $\alpha_{\mathrm{D}}$ estimates representing each of the burnup steps. Figure 5.14 shows the calculated $\alpha_{D}$ values for the six fuel temperature $\mathrm{r}$ anges, a long $\mathrm{w}$ ith a $\mathrm{n}$ ove rall a veraged $\mathrm{v}$ alue, a s a function of fuel bur nup. A 11 coefficients ar e ne gative and range from $-2.36 \times 10^{-6}$ to $-1.53 \times 10^{-5} \Delta \mathrm{k} / \mathrm{k} / \mathrm{K}$. The general trend indicates $t$ hat as $t$ he $t$ emperature $i$ ncreases, the $m$ agnitude of $\alpha_{D}$ decreases, and as bur nup increases, the magnitude of $\alpha_{\mathrm{D}}$ increases. This trend is e asily ide ntified by the fuel Doppler coefficient averaged over the entire temperature range $(293.6 \mathrm{~K}-2500 \mathrm{~K})$ shown in bold black.

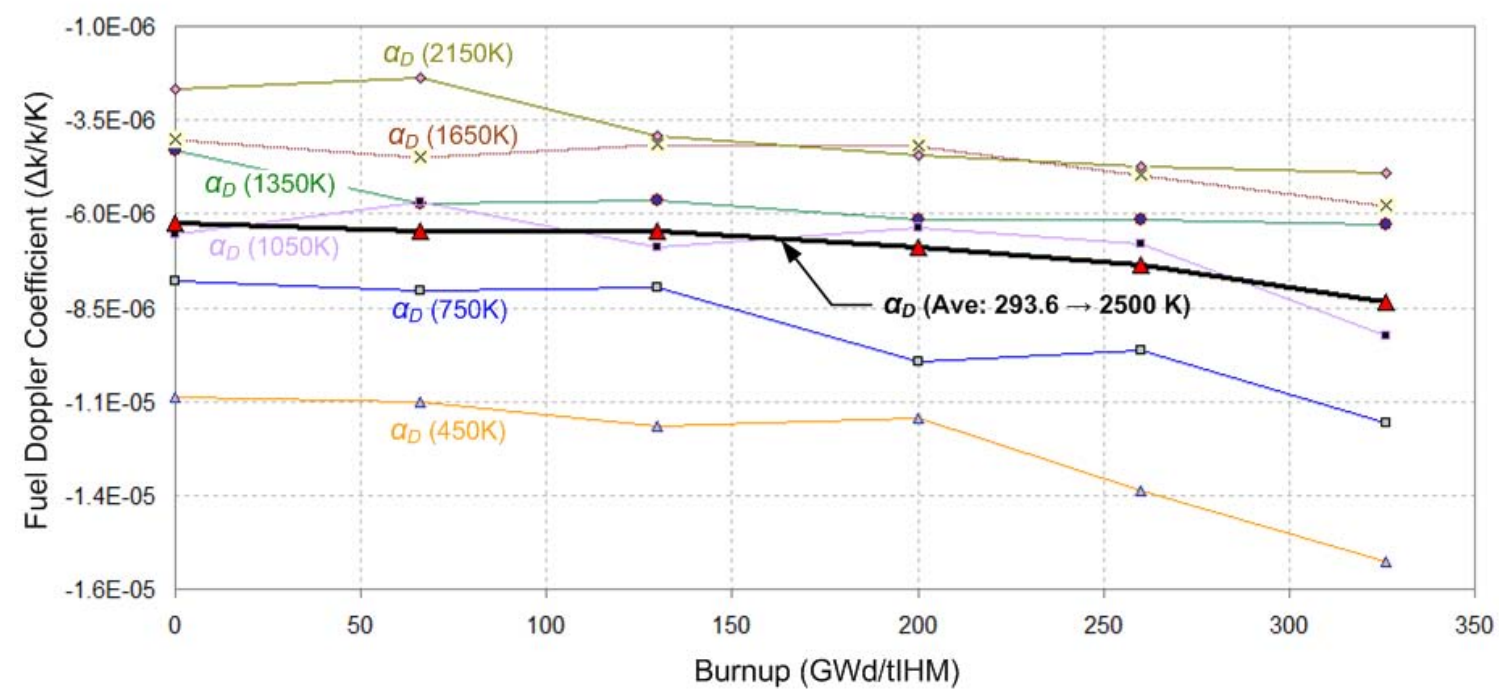

Figure 5.14. Fuel Doppler Coefficient at Specified Temperatures as Function of Burnup.

Changes in $\alpha_{D}$ are a ttributed t o e nhanced ne utron a bsorption as cross-section pe aks in $\mathrm{t}$ he resonance region are broadened due to fuel temperature increases. The large resonance integral of ${ }^{240} \mathrm{Pu}$ i s the $\mathrm{m}$ ain $\mathrm{c}$ ontributor t o ne gative $\alpha_{\mathrm{D}}$ values. T he 1 arge resonance of ${ }^{242} \mathrm{Pu}$ also 
contributes to the negative feedback but to a lesser extent due the smaller fraction present in the TRU fuel. As the TRU fuel composition is continually changing with burnup, so does $\alpha_{D}$. In general, the increase in ${ }^{240} \mathrm{Pu}$ and ${ }^{242} \mathrm{Pu}$ throughout the lifetime of the core outweighs the positive fuel temperature feedback mechanisms of the other nuclides and $\alpha_{D}$ remains fairly constant or becomes more negative as burnup increases from BOC to EOC. The effect of fuel temperature variations on reactivity is more strongly felt at lower temperatures.

\section{Moderator Temperature Coefficient}

The $\mathrm{m}$ oderator $\mathrm{t}$ emperature co efficient $\left(\alpha_{\mathrm{mod}}\right)$ of $\mathrm{r}$ eactivity was e stimated $\mathrm{f}$ or $\mathrm{s}$ ix bur nup conditions: BOC or $0,66,130,200,260$, and 326 (EOC) GWd/tIHM. The calculated core $\mathrm{k}_{\text {eff }}$ assumes that the fuel temperature is fixed at $1200 \mathrm{~K}$ and the graphite moderator temperature varies from 293.6 - $2000 \mathrm{~K}$. Five moderator temperature steps: 1) 293.6 - $600 \mathrm{~K}$, 2) 600 - 900 $\mathrm{K}$, 3) $900-1200 \mathrm{~K}$, 4) $1200-1600 \mathrm{~K}$, and 5) 1600 - $2000 \mathrm{~K}$, w ere used to produce $\alpha_{\bmod }$ estimates as a function of burnup.

Figure 5.15 shows the calculated $\alpha_{\text {mod }}$ values for the five moderator temperature specifications as related to fuel burnup. For the lowest temperature range $(293.6-600 \mathrm{~K})$ the coefficients are positive a nd i ncrease with $\mathrm{f}$ uel bur nup. $\mathrm{T}$ he $\mathrm{c}$ oefficients calculated $\mathrm{f}$ or $\mathrm{t}$ he ne $\mathrm{xt} \mathrm{l}$ owest temperature range $(600-900 \mathrm{~K})$ are negative, except at EOC where it becomes slightly positive. The remaining coefficients are all ne gative. The overall range for $\alpha_{\bmod }$ is from $7.59 \times 10^{-5}$ to $1.18 \times 10^{-4} \Delta \mathrm{k} / \mathrm{k} / \mathrm{K}$.

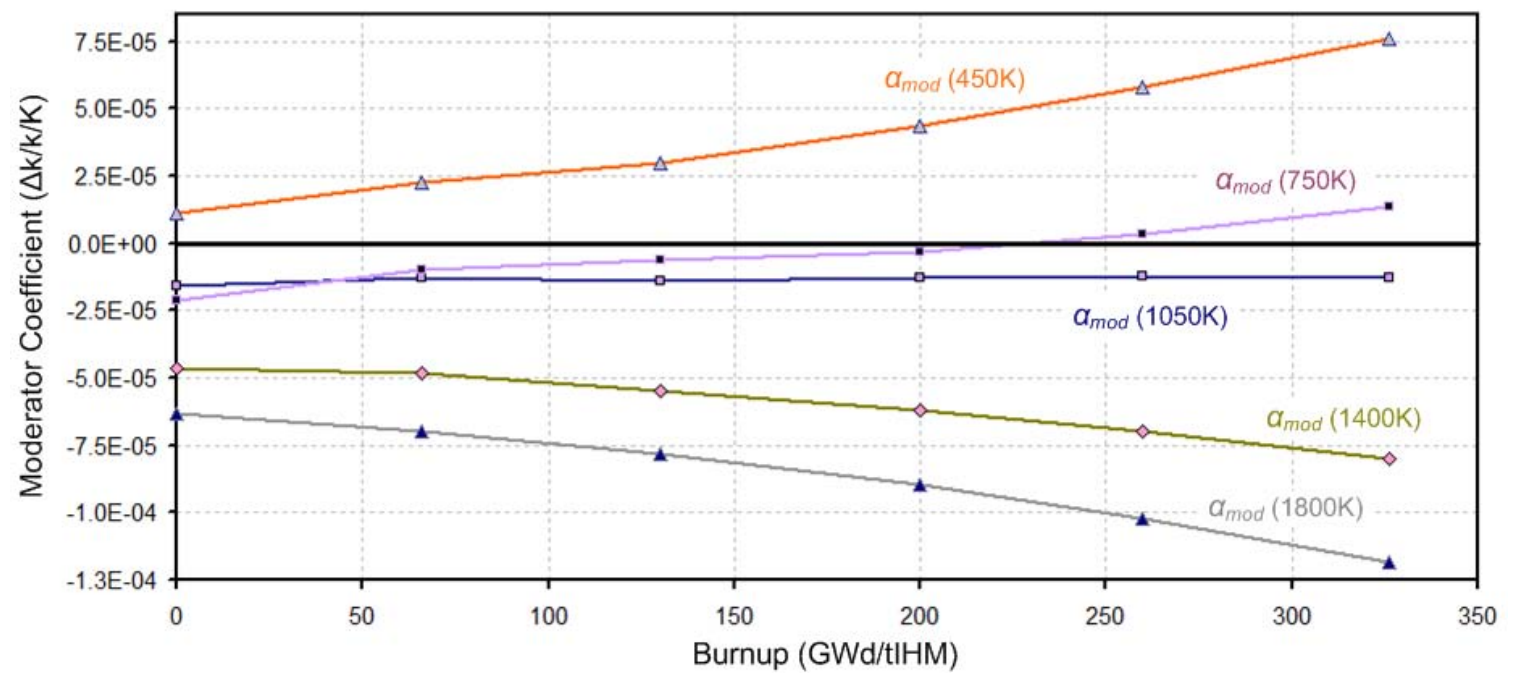

Figure 5.15. Moderator Coefficient at Specified Temperatures as Function of Burnup.

Temperature ch anges $\mathrm{i} n$ the $\mathrm{m}$ oderator will af fect $\mathrm{r}$ eactivity feedback differently $\mathrm{t}$ han temperature changes in the fuel. Instead of D oppler br oadening the r esonance cross-sections, fluctuations in moderator temperature will cause a shift in the thermal neutron flux peak. Figure 5.16 shows the average neutron flux in a VHTR fuel block for moderator temperatures of $300 \mathrm{~K}$, $1000 \mathrm{~K}$, a nd $2000 \mathrm{~K}$. T he flux is ove rlaid on c apture-to-cross $r$ atio pl ots for the four m ost 
abundant nuclides in the TRU fuel $\left({ }^{239} \mathrm{Pu},{ }^{240} \mathrm{Pu},{ }^{241} \mathrm{Pu}\right.$, and $\left.{ }^{242} \mathrm{Pu}\right)$. T he ${ }^{240} \mathrm{Pu}$ and ${ }^{242} \mathrm{Pu}$ ratios have been decreased by a factor of 4000 in order to fit them on the plot and keep the necessary resolution for relevant a nalysis of $\alpha_{\text {mod }}$ variations. The a ctual va lues for the ${ }^{240} \mathrm{Pu}$ a nd ${ }^{242} \mathrm{Pu}$ ratios ar e not as i mportant a $\mathrm{s} t$ he $\mathrm{t}$ rends $\mathrm{t}$ hey e xhibit a nd $\mathrm{t}$ he $\mathrm{f}$ act $\mathrm{t}$ hat $\mathrm{t}$ hey a re or ders of magnitude above unity. As shown, the thermal energy neutron peak shifts from 0.075 e V to 0.5 $\mathrm{eV}$ as the moderator temperature increases from $300 \mathrm{~K}$ to $2000 \mathrm{~K}$. This shift significantly affects the moderator temperature coefficient as the alignment of the thermal energy neutron peak aligns with the peaks and valleys of the capture-to-fission ratio of the fissionable isotopes ${ }^{239} \mathrm{Pu}$ and ${ }^{241} \mathrm{Pu}$. Consequently, when the thermal energy neutron flux peak shifts along an energy region in which the capture-to-fission ratio for ${ }^{241} \mathrm{Pu}$ is decreasing, the corresponding temperature increase causes r eactivity to be added to the s ystem, e vident by the pos itive $\alpha_{\text {mod }}$ values at ve ry low temperatures. As the moderator temperature continues to increase, the thermal energy neutron peak is then pushed to higher energies where within both the ${ }^{241} \mathrm{Pu}$ and ${ }^{239} \mathrm{Pu}$ capture-to-fission ratio a re $\mathrm{i}$ ncreasing, thus $\mathrm{r}$ educing the reactivity of the s ystem a nd $\mathrm{p}$ roducing $\mathrm{n}$ egative $\alpha_{\bmod }$ values. In addition, at higher temperatures $(900-2000 \mathrm{~K})$ neutron absorption by ${ }^{240} \mathrm{Pu}$ and ${ }^{242} \mathrm{Pu}$ is $i$ ncreased as the thermal e nergy $n$ eutron pe ak $s$ hifts $t o$ hi gher energies a nd c aptures $t$ his phenomenon. Of the four nuclides, only ${ }^{239} \mathrm{Pu}$ continually decreases with core lifetime, while the others buildup over time. This explains the increase in $\alpha_{\text {mod }}$ with burnup at lower temperatures, caused mainly by the production of ${ }^{241} \mathrm{Pu}$. In contrast, at hi gher temperatures the effect is the exact o pposite. T he increase in ${ }^{241} \mathrm{Pu}$ translates to a strong ne gative reactivity ins ertion, with ${ }^{240} \mathrm{Pu}$ and ${ }^{242} \mathrm{Pu}$ also contributing to additional neutron absorption as burnup increases.

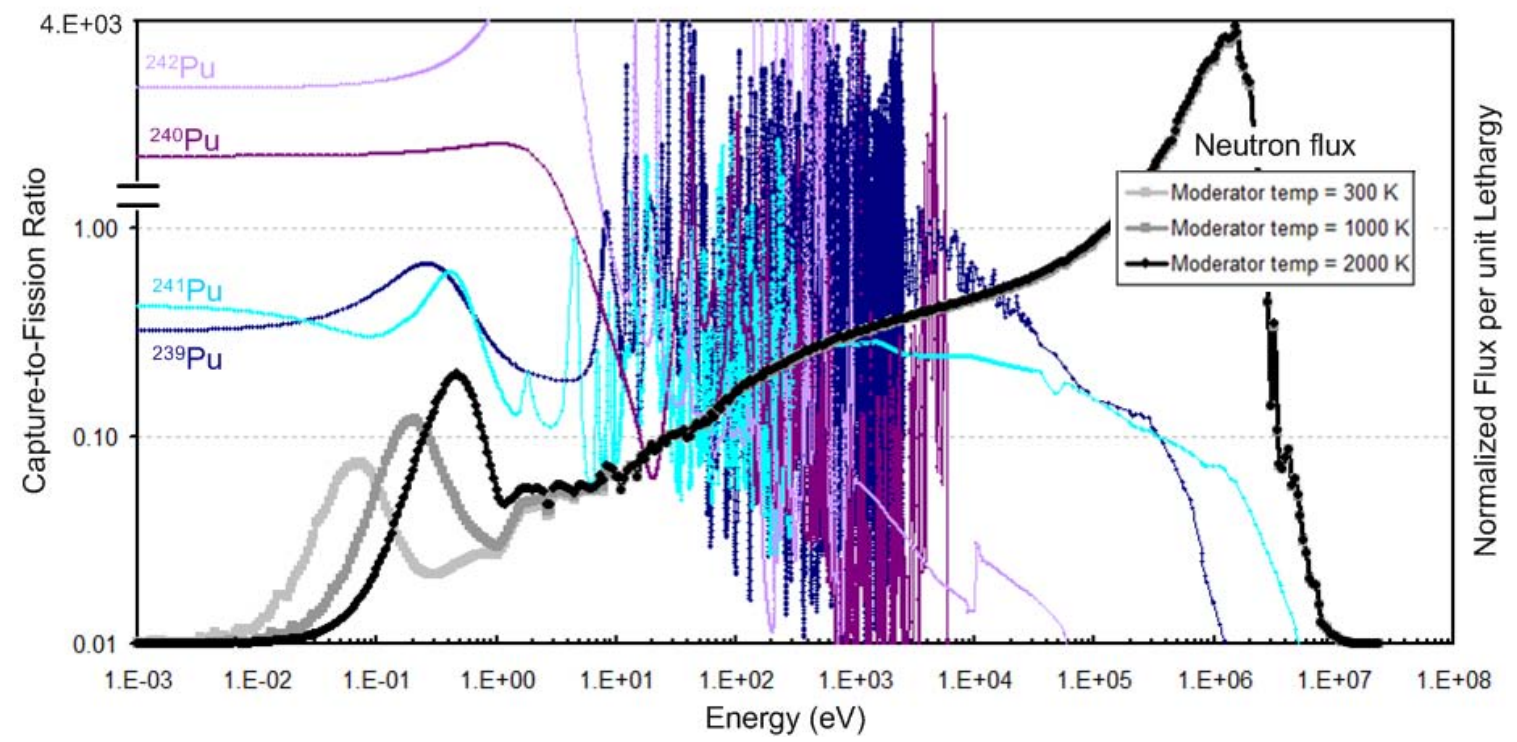

Figure 5.16. Neutron Flux and Capture-to-cross Section Ratios.

\section{Isothermal Temperature Coefficient}

The $\mathrm{i}$ sothermal $\mathrm{t}$ emperature co efficient $\left(\alpha_{\text {iso }}\right)$ of $\mathrm{r}$ eactivity $\mathrm{w}$ as e stimated $\mathrm{f}$ or $\mathrm{s}$ ix bur nup conditions: B OC or 0, 66, 130, 200, 260, and EOC or $326 \mathrm{G} \mathrm{Wd} / \mathrm{tIHM.} \mathrm{T} \mathrm{he} \mathrm{calculated} \mathrm{k}_{\text {eff }}$ assumes $t$ hat $t$ he $t$ emperature a cross $t$ he core $i$ s cons tant; $f$ uel and gr aphite $m$ oderator 
temperatures are identical. Five core temperature steps: 1) $293.6-600 \mathrm{~K}, 2) 600-900 \mathrm{~K}, 3$ ) $900-1200 \mathrm{~K}$, 4) $1200-1600 \mathrm{~K}$, and 5) $1600-2000 \mathrm{~K}$ were used to produce $\alpha_{\text {iso }}$ estimates for each of the burnup steps.

Figure 5.17 shows the calculated $\alpha_{\text {iso }}$ values for the five core temperature ranges as a function of fuel burnup. At BOC $\alpha_{\text {iso }}$ values are all negative, but positive values appear as burnup increases for the lower temperature $(293.6 \mathrm{~K}-600 \mathrm{~K})$ cases. The overall range for $\alpha_{\text {iso }}$ is from $5.89 \times 10^{-5}$ to $-1.32 \times 10^{-4} \Delta \mathrm{k} / \mathrm{k} / \mathrm{K}$. T he va lue of $\mathrm{t}$ he $\mathrm{i}$ sothermal $\mathrm{c}$ oefficient de pends on bot $\mathrm{h} \mathrm{D}$ oppler broadening f rom i ncreased $f$ uel $t$ emperatures a nd s pectrum $s$ hifting $d$ ue $t$ o $c$ hanges in $t$ he moderator temperature, which is evident by values and trends shown in Figure 5.17.

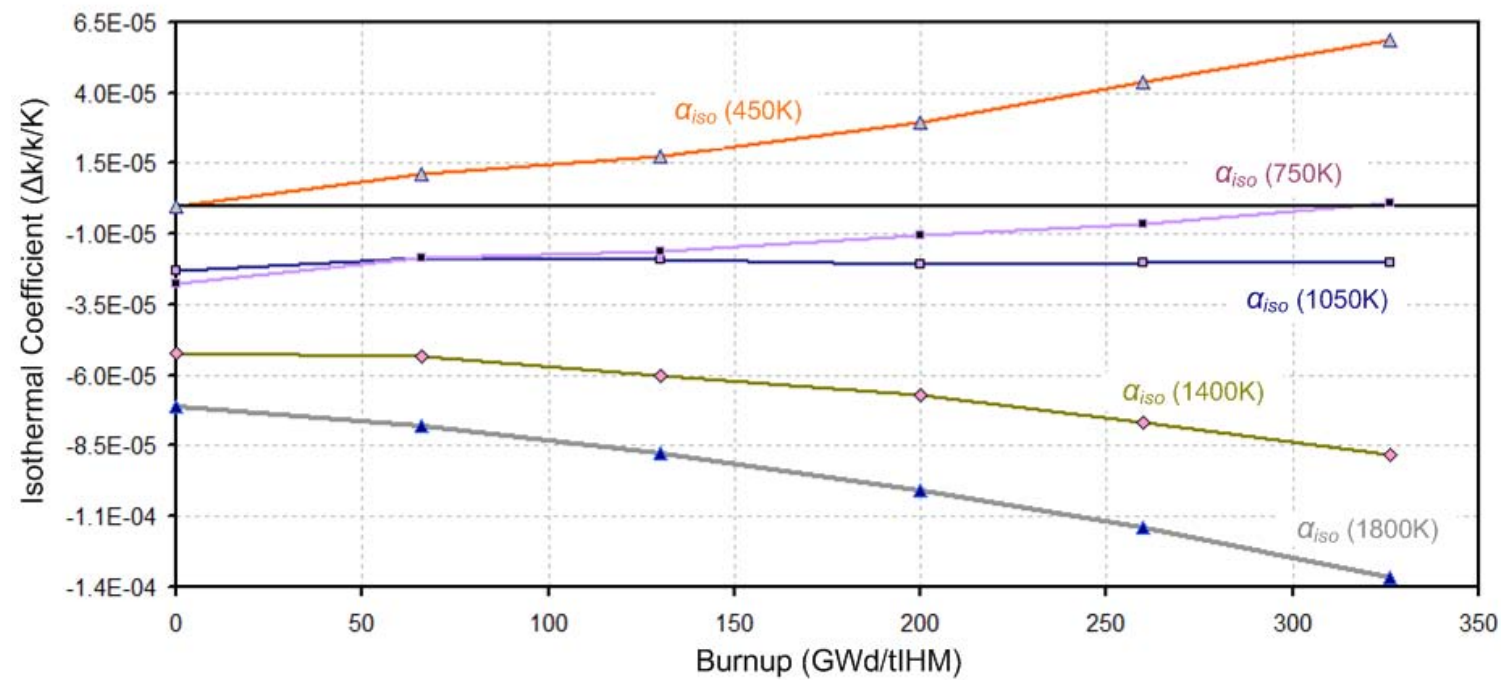

Figure 5.17. Isothermal Coefficient at Specified Temperatures as Function of Burnup.

The $t$ emperature coefficients of $r$ eactivity $f$ or $f$ uel $D$ oppler, $m$ oderator, a nd i sothermal a $t$ different burnup levels and a veraged ov er the entire temperature range are given in Table 5.6. As i ndicated, all coe fficients ar e s trongly $n$ egative and range f rom $-6.29 \times 10^{-6}$ to $-2.97 \times 10^{-5}$ $\Delta \mathrm{k} / \mathrm{k} / \mathrm{K}$.

Table 5.6. Temperature Coefficients Averaged Over Entire Temperature Range.

\begin{tabular}{|c|c|c|c|c|c|c|}
\hline \multicolumn{7}{|c|}{ Temperature Coefficient of Reactivity $(\Delta \mathbf{\Delta} / \mathbf{k} / \mathbf{K})$} \\
\hline \hline Average for T & \multicolumn{7}{|c|}{ Burnup $(\mathrm{GWd} / \mathrm{tIHM})$} \\
\cline { 2 - 7 }$(296.3-2000 \mathrm{~K})$ & 0 & 66 & 130 & 200 & 260 & 326 \\
\hline Fuel Doppler & $-6.29 \times 10^{-6}$ & $-6.53 \times 10^{-6}$ & $-6.56 \times 10^{-6}$ & $-7.09 \times 10^{-6}$ & $-7.61 \times 10^{-6}$ & $-8.84 \times 10^{-5}$ \\
\hline Moderator & $-2.13 \times 10^{-5}$ & $-1.68 \times 10^{-5}$ & $-1.67 \times 10^{-5}$ & $-1.47 \times 10^{-5}$ & $-1.26 \times 10^{-5}$ & $-9.64 \times 10^{-6}$ \\
\hline Isothermal & $-2.97 \times 10^{-5}$ & $-2.51 \times 10^{-5}$ & $-2.57 \times 10^{-5}$ & $-2.44 \times 10^{-5}$ & $-2.33 \times 10^{-5}$ & $-2.23 \times 10^{-5}$ \\
\hline
\end{tabular}

Although the averaged coefficients are all ne gative values, analysis of smaller temperature step increases in the moderator, that fall within the lower temperature range (particularly $296.3 \mathrm{~K}-$ $600 \mathrm{~K}$ ), produce pos itive r eactivity i nsertion ov er the c ore lifetime. The ex pected operating 
temperatures of the VHTR a re $\mathrm{c}$ onsiderably hi gher, but $\mathrm{s}$ tartup $\mathrm{c}$ ore $\mathrm{c}$ onditions $\mathrm{c}$ ould be of concern. T he current a nalysis did not take into a ccount graphite expansion with temperature, which reduces neutron thermalization to provide an additional negative moderator feedback and when $\mathrm{f}$ actored in c ould flip the pos itive coefficients. A dding a bu rnable poi son that has an absorption resonance in the energy range of concern $(0.03-0.1 \mathrm{eV}) \mathrm{c}$ an also provide desired coefficients, e.g., ${ }^{154} \mathrm{Eu}$.

\subsection{High-energy External Source Transmuter (HEST)}

The main pur pose of the HEST m odel is t $\mathrm{o}$ a ssess the T RU t ransmutation pot ential of $t$ wo externally d riven subcritical cor e configurations (Concept I and Concept II). In ea ch case a MATLAB a lgorithm is used t o pr oduce the $\mathrm{n}$ eutron c onsumption pe $\mathrm{r}$ fission $\left(D_{\mathrm{eq}}{ }^{\mathrm{TRU}}, D_{\mathrm{eq}}{ }^{\mathrm{I}}\right)$ values. T he s ystem de pendent nuc lear i nteraction pr ocesses (microscopic $\mathrm{c}$ ross $\mathrm{s}$ ections and fission neutrons) are provided by whole-core 3D MCNP calculations.

\subsubsection{HEST Concept I}

The a verage ne utron flux w ithin the fuel pa rticle for the T RU-fueled V HTR a nd the HEST Concept I is shown in Figure 5.18. The VHTR flux is included to provide a reference point and comparison case for the HEST Concept I. Overall, the HEST Concept I core produces a harder spectrum. $\mathrm{T}$ his i s e vident $\mathrm{b}$ y $\mathrm{t}$ he $\mathrm{n}$ early none xistent $\mathrm{t}$ hermal e nergy neutron pe ak, greater epithermal region component, and the increased portion of neutrons in the fast energy region of HEST Concept I. At $14.1 \mathrm{MeV}$ there is a large spike representing the external neutron source within the HEST, which pr ovides a considerable a mount of ne utrons b eyond e nergies of the neutron fission spectrum (above $3 \mathrm{MeV}$ ). Another distinguishing attribute that is shared by each system is a significant downward spike in the flux at an energy of $1 \mathrm{eV}$, caused by the very large absorption resonance cross-section of ${ }^{240} \mathrm{Pu}$.

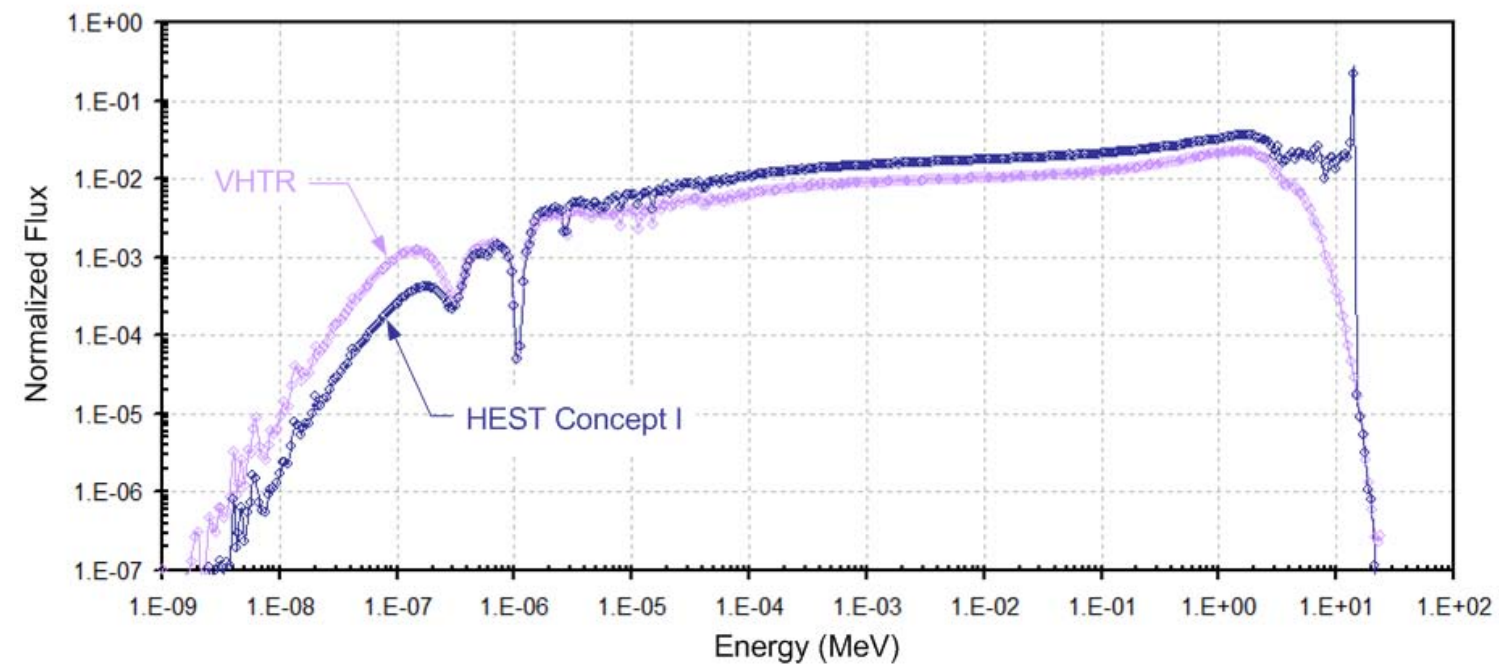

Figure 5.18. Neutron Flux Spectrum in the Fuel Particle for HEST Concept I and VHTR. 
The transmutation potential of a system can be assessed by calculating the neutron balance $\left(D_{\text {fuel }}\right)$ following the ph ysics a pproach de scribed in $\mathrm{C}$ hapter 5.1.3. $\mathrm{T}$ he $D_{\text {fuel }}$ value $\mathrm{r}$ epresents $\mathrm{t}$ he neutron c onsumption pe $\mathrm{r}$ fission of the fuel component, and is de fined a s 'production' when values ar e ne gative $\left(-D_{\text {fuel }}\right)$. T herefore, large $-D_{\text {fuel }}$ values i ndicate gr eater $t$ ransmutation feasibility for that particular system.

The e quilibrium $\mathrm{c}$ ase ( asymptotic s olution) $\mathrm{f}$ or the a tomic $\mathrm{c}$ oncentrations $\mathrm{w}$ as e mployed to calculate the $D_{e q}{ }^{T R U}$ values for the HEST Concept I and VHTR systems. Figure 5.19 shows the $D_{e q}{ }^{T R U}$ values as a function of neutron flux for the VHTR and HEST Concept I. Both systems produce positive values at low fluxes but crossover to negative values at about $7.0 \times 10^{13} \mathrm{n} / \mathrm{cm}^{2}-\mathrm{s}$ for the HEST C oncept I, and about $1.3 \times 10^{14} \mathrm{n} / \mathrm{cm}^{2}-\mathrm{s}$ for the VHTR. The HEST C oncept I system ha s s maller $D_{e q}{ }^{\text {TRU }}$ values f or t he e ntire $\mathrm{f}$ lux $\mathrm{r}$ ange, $\mathrm{w}$ ith $\mathrm{t}$ he average va lue $\mathrm{b}$ eing approximately a factor of 21 ower. $\mathrm{T}$ hus, $\mathrm{i} t$ is e xpected $\mathrm{t}$ o pr ovide s uperior $\mathrm{t}$ ransmutation potential.

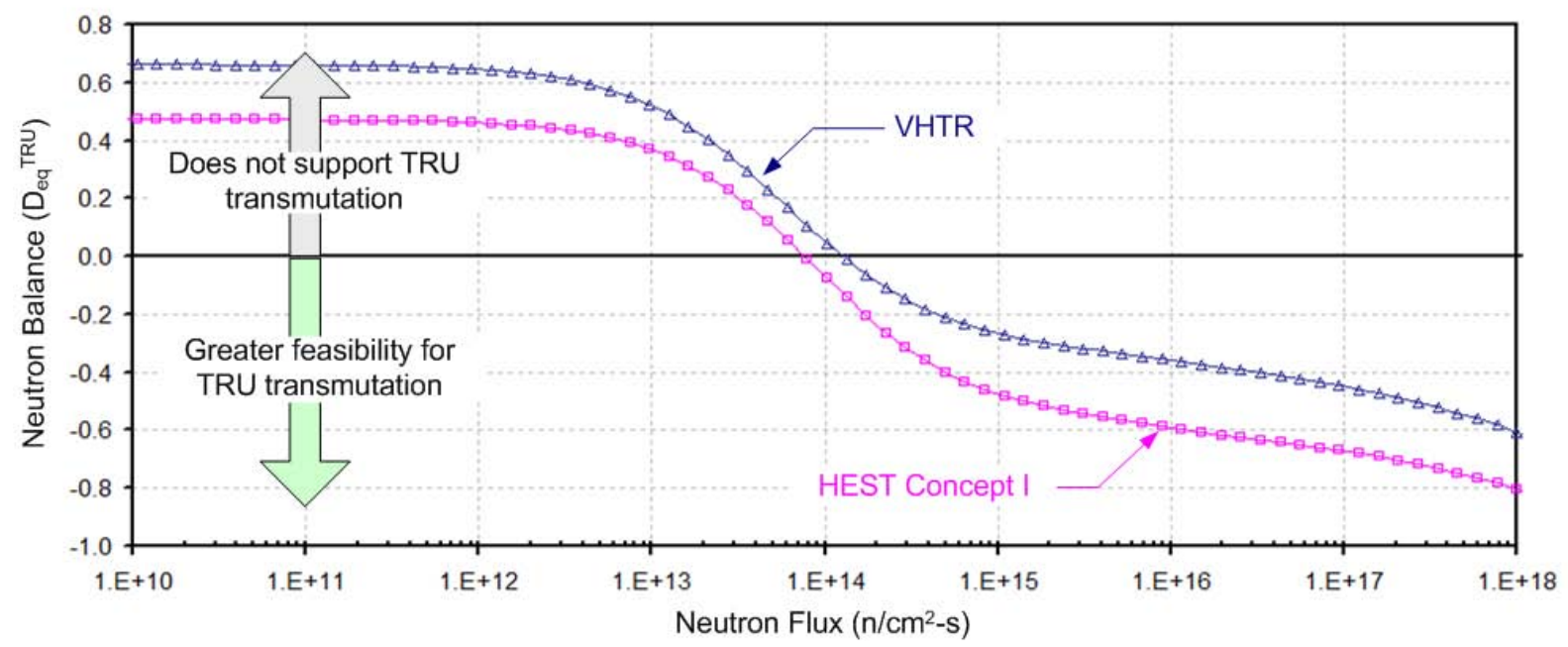

Figure 5.19. $\mathrm{D}_{\text {eq }}{ }^{\mathrm{TRU}}$ (neutron consumption/fission) for VHTR and HEST Concept I.

To gain further understanding of the system, the neutron balance values for the individual TRU nuclides $\left(D_{\text {eq }}^{\mathrm{I}}\right)$ at different flux levels are provided in Table 5.7. Also included in the table are the T RU c ompositions used for the $D_{e q}{ }^{T R U}$ calculations. C ompositions $\mathrm{m}$ atch $\mathrm{t}$ hose for $\mathrm{t}$ he reference TRU-fueled VHTR at a burnup level of $264 \mathrm{G} \mathrm{Wd} / \mathrm{tIHM}$ with a 7 year decay period. Appendix B contains individual TRU nuclide plots of the $D_{\mathrm{eq}}{ }^{\mathrm{I}}$ values as a function of ne utron flux for the HEST Concept I system.

The transmutation capabilities of the HEST Concept I s ystem are sensitive to the neutron flux levels. At a flux of $10^{12} \mathrm{n} / \mathrm{cm}^{2}-\mathrm{s}$, more than half of the TRU isotopes are neutron consumers per fission, whereas at $10^{16} \mathrm{n} / \mathrm{cm}^{2}-\mathrm{s}$ only ${ }^{237} \mathrm{~Np}$ and ${ }^{242} \mathrm{Pu}$ are neutron consumers, and at $10^{18} \mathrm{n} / \mathrm{cm}^{2}-\mathrm{s}$ only ${ }^{242} \mathrm{Pu}$ is a consumer and v ery close to unity. However, neutron flux levels of the HEST Concept I system are a function of the source strength and constrained by design limitations such as the multiplication factor and he at generation. A s previously stated, a ph ysics a pproach to 
transmutation feasibility is targeted; therefore the evaluation takes into consideration the possible flux levels attainable for the HEST Concept I as it relates to the external source strength. At the upper a chievable limits for a $14.1 \mathrm{M} \mathrm{eV}$ ne utron s ource is a generation $\mathrm{r}$ ate of about $10^{20} \mathrm{n} / \mathrm{s}$, $[14,50]$, which, when combined with the HEST Concept I subcritical core produces an average core flux of approximately $10^{16} \mathrm{n} / \mathrm{cm}^{2}$-s.

Table 5.7. $D_{\text {eq }}{ }^{\prime}$ Values for VHTR and HEST Concept I.

\begin{tabular}{|c|c|c|c|c|c|c|c|c|c|}
\hline \multirow[b]{3}{*}{$\begin{array}{c}\text { TRU } \\
\text { (I) }\end{array}$} & \multirow[b]{3}{*}{$\begin{array}{l}\text { TRU } \\
\text { (\%) }\end{array}$} & \multicolumn{4}{|c|}{ VHTR } & \multicolumn{4}{|c|}{ HEST Concept I } \\
\hline & & \multicolumn{8}{|c|}{ Neutron Flux, $\varphi\left(\mathrm{n} / \mathrm{cm}^{2}-\mathrm{s}\right)$} \\
\hline & & $10^{12}$ & $10^{14}$ & $10^{16}$ & $10^{18}$ & $10^{12}$ & $10^{14}$ & $10^{16}$ & $10^{18}$ \\
\hline${ }^{237} \mathrm{~Np}$ & 4.071 & 1.069 & 0.791 & 0.533 & -0.492 & 0.623 & 0.409 & 0.175 & -0.618 \\
\hline${ }^{238} \mathrm{Pu}$ & 6.670 & 0.137 & -0.147 & -0.313 & -0.349 & -0.263 & -0.486 & -0.686 & -0.711 \\
\hline${ }^{239} \mathrm{Pu}$ & 27.900 & -0.372 & -0.722 & -0.926 & -0.971 & -0.517 & -0.829 & -1.107 & -1.143 \\
\hline${ }^{240} \mathrm{Pu}$ & 33.786 & 1.356 & 0.405 & -0.150 & -0.273 & 1.150 & 0.319 & -0.421 & -0.516 \\
\hline${ }^{241} \mathrm{Pu}$ & 7.119 & 0.450 & -0.529 & -1.100 & -1.226 & 0.366 & -0.520 & -1.310 & -1.412 \\
\hline${ }^{242} \mathrm{Pu}$ & 8.293 & 1.850 & 1.217 & 0.687 & 0.189 & 1.680 & 1.305 & 0.439 & 0.039 \\
\hline${ }^{241} \mathrm{Am}$ & 8.786 & 0.478 & 0.469 & -0.049 & -1.780 & 0.385 & 0.373 & -0.175 & -1.265 \\
\hline${ }^{242 m} \mathrm{Am}$ & 0.055 & -2.351 & -2.351 & -2.351 & -2.351 & -2.500 & -2.500 & -2.500 & -2.500 \\
\hline${ }^{243} \mathrm{Am}$ & 1.940 & 0.948 & 0.298 & -0.238 & -0.248 & 0.912 & 0.219 & -0.407 & -0.419 \\
\hline${ }^{243} \mathrm{Cm}$ & 0.021 & -2.031 & -2.120 & -2.193 & -2.195 & -2.145 & -2.241 & -2.329 & -2.331 \\
\hline${ }^{244} \mathrm{Cm}$ & 1.096 & -0.015 & -0.672 & -1.215 & -1.225 & -0.015 & -0.714 & -1.356 & -1.368 \\
\hline${ }^{245} \mathrm{Cm}$ & 0.263 & -2.170 & -2.170 & -2.170 & -2.170 & -2.285 & -2.285 & -2.285 & -2.285 \\
\hline
\end{tabular}

Considering ne utron f lux levels g reater than $10^{14} \mathrm{n} / \mathrm{cm}^{2}-\mathrm{s}$, e specially in the vi cinity o f $10^{16}$ $\mathrm{n} / \mathrm{cm}^{2}$-s, the HEST Concept I possesses the capability of transmuting most of the TRU nuclides as a neutron production process. In the case of the $\mathrm{Pu}$ isotopes, only the ${ }^{242} \mathrm{Pu}$ transmutation is a neutron consuming process for all flux levels considered. W hereas, the transmutation of ${ }^{240} \mathrm{Pu}$ becomes a neutron production process at $\varphi=2.3 \times 10^{14} \mathrm{n} / \mathrm{cm}^{2}-\mathrm{s}$. The transmutation of ${ }^{241} \mathrm{Am}$ and ${ }^{243}$ Am become neutron production processes at $\varphi=5.3 \times 10^{15} \mathrm{n} / \mathrm{cm}^{2}-\mathrm{s}$ and $2.0 \times 10^{14} \mathrm{n} / \mathrm{cm}^{2}-\mathrm{s}$. The remaining TRU nuclides are all neutron producers for flux levels between $10^{14}$ and $10^{16} \mathrm{n} / \mathrm{cm}^{2}-\mathrm{s}$.

The HEST Concept I spectrum is not a true fast neutron spectrum as there is still a considerable epithermal and thermal energy component due to the g raphite in the core. A s hift to hi gher energies would $\mathrm{r}$ esult i $\mathrm{n}$ m ore favorable $-D_{\text {fuel }}$ values $\mathrm{f}$ or $\mathrm{t}$ ransmutation, but $\mathrm{t}$ here a re s ome transmutation advantages that accompany the HEST Concept I spectrum. The main advantage being the greater reaction rates due to the much higher cross section values at thermal energies. Thus, the de struction $r$ ate of the T RU nuc lides is $m$ ore rapid than it $w$ ould be for a ha rder spectrum system.

\subsubsection{HEST Concept II}

The average neutron flux within the fuel particle for the HEST Concept I and the HEST Concept II is shown in Figure 5.20. O verall, the HEST Concept II core produces a significantly harder 
spectrum. The difference between the flux level in the thermal energy range and the fast region for Concept II is more than 4 orders of magnitude, whereas it is only about 2 orders of magnitude for $\mathrm{C}$ oncept I. A lso noticeable for Concept II is the flux s pike at $14.1 \mathrm{MeV}$ representing the external ne utron $\mathrm{s}$ ource. A nother distinguishing a ttribute $\mathrm{s}$ hared $\mathrm{b}$ ye ach a re $\mathrm{s}$ ignificant downward s pikes in the fluxes a $t$ a $n$ e nergy of 1.0 a nd $0.3 \mathrm{eV}$, caused b y the ve ry 1 arge absorption resonance cross sections of ${ }^{240} \mathrm{Pu}$ and ${ }^{239} \mathrm{Pu}$ respectively.

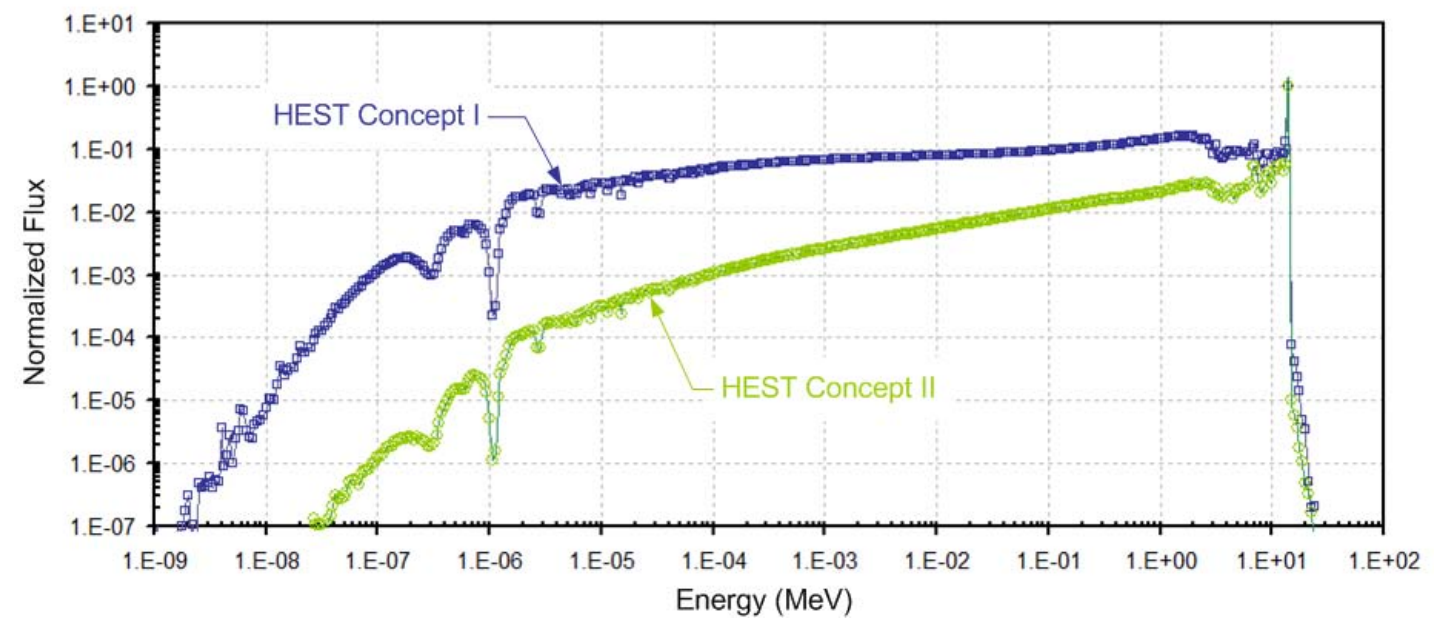

Figure 5.20. Neutron Flux Spectrum in the Fuel Particle for HEST Concept I and II.

The calculated $D_{e q}{ }^{T R U}$ values as a function of neutron flux for the VHTR, HEST Concept I, and HEST Concept II are shown in Figure 5.21. The $D_{e q}{ }^{T R U}$ values are not as sensitive to flux level changes as they are for the VHTR and Concept I. At flux measurements below $10^{13} \mathrm{n} / \mathrm{cm}^{2}$-s the $D_{e q}{ }^{T R U}$ values are es sentially non -changing a s they are no 1 onger de pendent on $\mathrm{flux}$. A $\mathrm{t}$ flux measurements greater than $10^{17} \mathrm{n} / \mathrm{cm}^{2}$-s, the s ame is true as the $D_{e q}{ }^{T R U}$ values $\mathrm{r}$ emain fairly constant. T herefore, the $D_{e q}{ }^{T R U}$ values for C oncept I a re onl y flux de pendent be tween $10^{13}$ $\mathrm{n} / \mathrm{cm}^{2}$-s and $10^{17} \mathrm{n} / \mathrm{cm}^{2}-\mathrm{s}$, and within this range do not change a great deal. A dditionally, no matter what the flux level, the $D_{e q}{ }^{T R U}$ value is strongly negative.

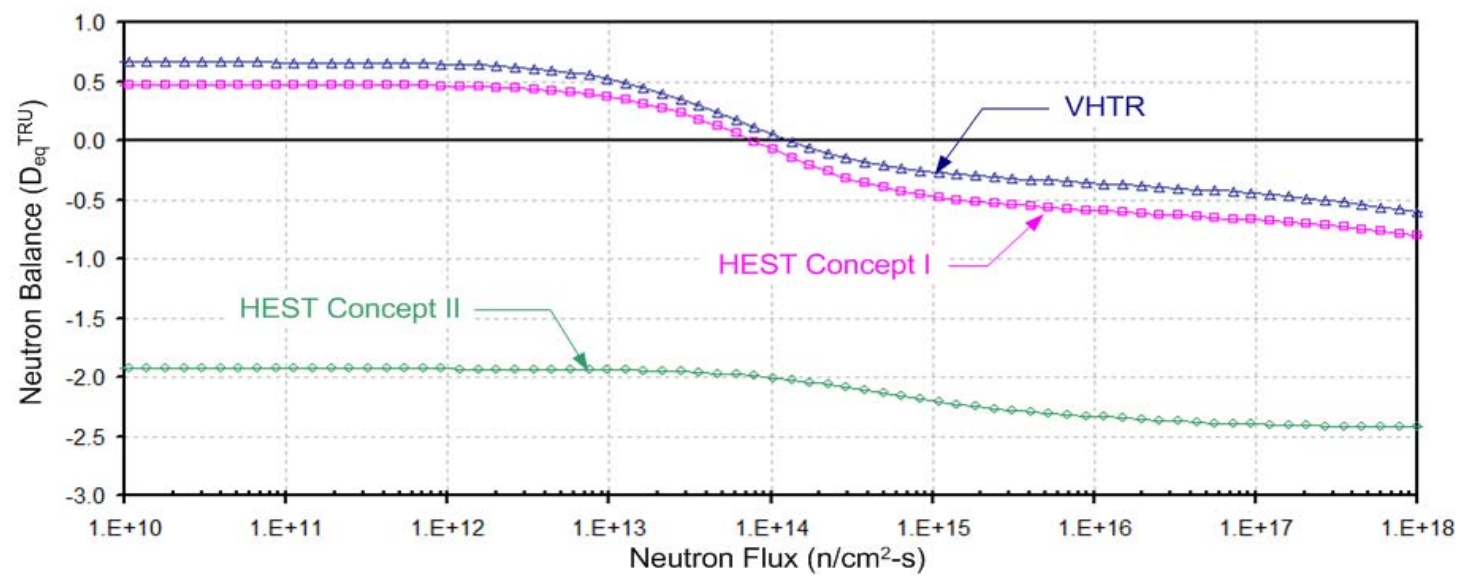

Figure 5.21. $\mathrm{D}_{\mathrm{eq}}{ }^{\mathrm{TRU}}$ (neutron consumption/fission) for HEST Concept II. 
To gain further understanding of the system, the neutron balance values for the individual TRU nuclides $\left(D_{\text {eq }}{ }^{\mathrm{I}}\right)$ at different flux levels are provided in Table 5.8. Also included in the table are the TRU compositions used for the $D_{e q}{ }^{T R U}$ calculations. TRU Compositions match those for the reference TRU-fueled VHTR at a burnup level of $264 \mathrm{G} \mathrm{Wd} / \mathrm{tIHM}$ with a 7 year decay period. Appendix B contains individual TRU nuclide plots of the $D_{\text {eq }}{ }^{\mathrm{I}}$ values as a function of neutron flux for the HEST Concept II system.

Table 5.8. $D_{\mathrm{eq}}{ }^{\prime}$ (neutron consumption/fission) for VHTR, HEST Concept I and II.

\begin{tabular}{|c|c|c|c|c|c|c|c|}
\hline \multirow[b]{3}{*}{$\begin{array}{c}\text { TRU } \\
\text { (I) }\end{array}$} & \multirow{3}{*}{$\begin{array}{l}\text { TRU } \\
(\%)\end{array}$} & \multicolumn{2}{|c|}{ VHTR } & \multicolumn{2}{|c|}{ HEST Concept I } & \multicolumn{2}{|c|}{ HEST Concept II } \\
\hline & & \multicolumn{6}{|c|}{ Neutron Flux, $\varphi\left(\mathrm{n} / \mathrm{cm}^{2}-\mathrm{s}\right)$} \\
\hline & & $10^{12}$ & $10^{14}$ & $10^{14}$ & $10^{16}$ & $\leq 10^{13}$ & $10^{14}$ \\
\hline${ }^{237} \mathrm{~Np}$ & 4.071 & 1.069 & 0.791 & 0.409 & 0.175 & -1.965 & -1.967 \\
\hline${ }^{238} \mathrm{Pu}$ & 6.670 & 0.137 & -0.147 & -0.486 & -0.686 & -2.464 & -2.468 \\
\hline${ }^{239} \mathrm{Pu}$ & 27.900 & -0.372 & -0.722 & -0.829 & -1.107 & -2.420 & -2.437 \\
\hline${ }^{240} \mathrm{Pu}$ & 33.786 & 1.356 & 0.405 & 0.319 & -0.421 & -1.902 & -1.990 \\
\hline${ }^{241} \mathrm{Pu}$ & 7.119 & 0.450 & -0.529 & -0.520 & -1.310 & -1.312 & -1.567 \\
\hline${ }^{242} \mathrm{Pu}$ & 8.293 & 1.850 & 1.217 & 1.305 & 0.439 & -1.662 & -1.777 \\
\hline${ }^{241} \mathrm{Am}$ & 8.786 & 0.478 & 0.469 & 0.373 & -0.175 & -1.312 & -1.317 \\
\hline${ }^{242 m} \mathrm{Am}$ & 0.055 & -2.351 & -2.351 & -2.500 & -2.500 & -2.990 & -2.990 \\
\hline${ }^{243} \mathrm{Am}$ & 1.940 & 0.948 & 0.298 & 0.219 & -0.407 & -0.650 & -0.975 \\
\hline${ }^{243} \mathrm{Cm}$ & 0.021 & -2.031 & -2.120 & -2.241 & -2.329 & -2.745 & -2.804 \\
\hline${ }^{244} \mathrm{Cm}$ & 1.096 & -0.015 & -0.672 & -0.714 & -1.356 & -0.012 & -0.544 \\
\hline${ }^{245} \mathrm{Cm}$ & 0.263 & -2.170 & -2.170 & -2.285 & -2.285 & -2.886 & -2.886 \\
\hline
\end{tabular}

The flux levels attainable for the HEST Concept II are considerably lower than for Concept I. Mainly because the model does not include a reflector and the source intensity is much smaller. Estimates for the flux are in the range of $10^{9} \mathrm{n} / \mathrm{cm}^{2}$-s when considering an external source strength of $10^{13} \mathrm{n} / \mathrm{s}$. Although the design of the HEST Concept II is not the focus, a variant of the model that includes multiple fuel blocks, each with its own IEC external neutron source configured in a cylindrical core shape surrounded by a reflector is envisioned. Such a design could be optimized to produce a significantly higher neutron flux, create conditions necessary for manageable criticality levels, effectively destroy TRU, and enable energy generation.

Considering that the $D_{\text {eq }}{ }^{\mathrm{I}}$ values are unaffected by neutron flux levels less than $10^{13} \mathrm{n} / \mathrm{cm}^{2}$-s, the lower $\mathrm{f}$ lux $\mathrm{f}$ or $\mathrm{C}$ oncept II i s not of $\mathrm{c}$ oncern, at 1 east $\mathrm{w}$ hen $\mathrm{c}$ onsidering $\mathrm{t}$ he $\mathrm{t}$ ransmutation feasibility as related to $D_{\text {eq }}{ }^{\mathrm{I}}$ values. All TRU nuclides show strongly negative $D_{\text {eq }}{ }^{\mathrm{I}}$ values except for ${ }^{244} \mathrm{Cm}$, which is only slightly negative.

The HEST Concept II spectrum provides favorable conditions for transmuting the TRU nuclides. The s trongly $-D_{\text {fuel }}$ values $\mathrm{m}$ ake it a $\mathrm{n}$ i deal $\mathrm{c}$ andidate for i ncinerating the T RU c omponent remaining after i rradiation in the VHTR. C oupled with the AP1000 and VHTR, a NES that greatly limits actinide waste and efficiently utilizes fuel resources is complete. 


\subsection{Integrated System Model}

The pur pose of the ISM is for a nalysis of s ystems that a re composed of a $\mathrm{s}$ et of interacting subsystems. In the $\mathrm{c}$ ase of the NES, the ISM couples the individual r eactor models and fuel cycle component models together for an effective and time efficient system analysis tool that is capable of accounting for different subsystem input parameters that vary over a range of interest. The computational timesaving of the ISM are directly related to the treatment of the whole-core $3 \mathrm{D}$ depletion models representing the AP100 and VHTR systems.

The output of the ISM includes the following NES features:

1) TRU mass and composition at AP1000 EOC

2) TRU mass and composition after reprocessing and at VHTR BOC

3) TRU mass and composition at VHTR EOC

4) TRU composition for $D_{\text {eq }}{ }^{\text {TRU }}$ (neutron consumption/fission) calculations specific to HEST Concepts I and II.

5) EFPD for AP1000

6) EFPD for VHTR

7) Fuel burnup levels (GWd/tIHM) for AP1000

8) Fuel burnup levels (GWd/tIHM) for VHTR

9) Electricity generation for AP1000 (GWd)

10) Electricity generation for VHTR (GWd)

11) Total FP mass separated during reprocessing

12) Total FP mass generated during VHTR operation

13) Uranium mass and composition at AP1000 EOC

14) Uranium mass and composition at VHTR EOC

15) TRU production rates for AP1000

16) TRU production/destruction rates for VHTR

17) Uranium ore requirements

18) Quantity of $\mathrm{UO}_{2}$ for NES operation

19) DU generated during frontend enrichment procedures

To illustrate the capabilities of the ISM, a reference case was created for NES simulation. The reference case includes the following input parameters:

- mine grade $1 \% \mathrm{U}$,

- tail assay $0.3 \%{ }^{235} \mathrm{U}$,

- AP1000 LEU fuel enriched to $3.8 \%$,

- AP1000 thermal efficiency of $32.8 \%$,

- 12 years decay time between AP1000 EOC and VHTR BOC,

- $100 \%$ separation procedures during reprocessing,

- Reprocessed TRU becomes fuel component for VHTR,

- TRISO packing fraction of $27 \%$,

- VHTR thermal efficiency of $48 \%$,

- 7 year lag time before HEST $D$-factor calculations.

A set of selected results for the reference ISM case are listed in Table 5.9 (a-d). 
Table 5.9. ISM Reference Case Results.

(a) Front-End.

\begin{tabular}{|l|c|}
\hline Uranium Ore (mine grade 1\% U) & $73,343 \mathrm{MT}$ \\
\hline Natural Uranium & $735.3 \mathrm{MT}$ \\
\hline DU stock from enrichment process $\left(0.3 \%{ }^{235} \mathrm{U}\right)$ & $647.3 \mathrm{MT}$ \\
\hline DU recovered from reprocessing $\left(1.5 \%{ }^{235} \mathrm{U}\right)$ & $82.42 \mathrm{MT}$ \\
\hline AP1000-to-VHTR support ratio & 4.6 \\
\hline
\end{tabular}

(b) AP1000 and VHTR.

\begin{tabular}{|c|c|c|c|c|}
\hline & \multicolumn{2}{|c|}{ AP1000 EOC } & \multicolumn{2}{|c|}{ VHTR EOC } \\
\hline & Mass $(\mathrm{kg})$ & TRU (w/o) & Mass (kg) & TRU (w/o) \\
\hline FP & 1760 & & 818.1 & \\
\hline${ }^{234} \mathrm{U}$ & 0.14 & & 4.78 & \\
\hline${ }^{235} U$ & 950 & & 1.23 & \\
\hline${ }^{236} \mathrm{U}$ & 383.3 & & 0.68 & \\
\hline${ }^{238} \mathrm{U}$ & 81090 & & 0.0023 & \\
\hline${ }^{237} \mathrm{~Np}$ & 28.02 & 4.000 & 108.88 & 3.375 \\
\hline${ }^{238} \mathrm{Pu}$ & 7.25 & 1.035 & 210.69 & 6.530 \\
\hline${ }^{239} \mathrm{Pu}$ & 368.43 & 52.59 & 893.28 & 27.69 \\
\hline${ }^{240} \mathrm{Pu}$ & 172.97 & 24.69 & 1094.90 & 33.94 \\
\hline${ }^{241} \mathrm{Pu}$ & 82.67 & 11.80 & 387.12 & 12.00 \\
\hline${ }^{242} \mathrm{Pu}$ & 32.42 & 4.628 & 250.56 & 7.766 \\
\hline${ }^{244} \mathrm{Pu}$ & 0.001 & 0.00012 & 0.009 & 0.00027 \\
\hline${ }^{241} \mathrm{Am}$ & 1.898 & 0.271 & 143.04 & 4.434 \\
\hline${ }^{242 m} \mathrm{Am}$ & 0.010 & 0.0014 & 1.795 & 0.056 \\
\hline${ }^{243} \mathrm{Am}$ & 4.610 & 0.658 & 60.81 & 1.885 \\
\hline${ }^{242} \mathrm{Cm}$ & 0.774 & 0.110 & 16.60 & 0.515 \\
\hline${ }^{243} \mathrm{Cm}$ & 0.013 & 0.0018 & 0.981 & 0.030 \\
\hline${ }^{244} \mathrm{Cm}$ & 1.436 & 0.205 & 49.29 & 1.528 \\
\hline${ }^{245} \mathrm{Cm}$ & 0.060 & 0.0085 & 7.894 & 0.245 \\
\hline${ }^{246} \mathrm{Cm}$ & 0.006 & 0.00080 & 0.443 & 0.014 \\
\hline TRU & 700.58 & 100 & 3226.3 & 100 \\
\hline Burnup & \multicolumn{2}{|c|}{$32.63 \mathrm{GWd} / \mathrm{iTHM}$} & \multicolumn{2}{|c|}{$284.9 \mathrm{GWd} / \mathrm{iTHM}$} \\
\hline EFPD & \multicolumn{2}{|c|}{826} & \multicolumn{2}{|c|}{2160} \\
\hline Elec. Gen. & \multicolumn{2}{|c|}{$921.1 \mathrm{GWd}$} & \multicolumn{2}{|c|}{$441.2 \mathrm{GWd}$} \\
\hline
\end{tabular}


(c) TRU Production/Destruction in VHTR.

\begin{tabular}{|c|c|c|c|}
\hline Nuclide & $\begin{array}{l}\text { BOC } \\
(\mathrm{kg})\end{array}$ & $\begin{array}{l}\mathrm{EOC} \\
(\mathrm{kg})\end{array}$ & $\begin{array}{l}\text { TRU Production/Destruction (\%) } \\
\text { (- values indicate destruction) }\end{array}$ \\
\hline${ }^{237} \mathrm{~Np}$ & 188.61 & 108.88 & -42.27 \\
\hline${ }^{238} \mathrm{Pu}$ & 47.71 & 210.69 & 341.58 \\
\hline${ }^{239} \mathrm{Pu}$ & 2431.45 & 893.28 & -63.26 \\
\hline${ }^{240} \mathrm{Pu}$ & 1120.48 & 1094.90 & -2.28 \\
\hline${ }^{241} \mathrm{Pu}$ & 301.34 & 387.12 & 28.46 \\
\hline${ }^{242} \mathrm{Pu}$ & 209.81 & 250.56 & 19.42 \\
\hline${ }^{244} \mathrm{Pu}$ & 0.0054 & 0.0086 & 59.77 \\
\hline${ }^{241} \mathrm{Am}$ & 245.25 & 143.04 & -41.68 \\
\hline${ }^{242 m} \mathrm{Am}$ & 0.06 & 1.80 & 2839.02 \\
\hline${ }^{243} \mathrm{Am}$ & 29.85 & 60.81 & 103.75 \\
\hline${ }^{242} \mathrm{Cm}$ & 0 & 16.60 & na \\
\hline${ }^{243} \mathrm{Cm}$ & 0.07 & 0.98 & 1370.98 \\
\hline${ }^{244} \mathrm{Cm}$ & 5.92 & 49.29 & 733.21 \\
\hline${ }^{245} \mathrm{Cm}$ & 0.39 & 7.89 & 1946.49 \\
\hline${ }^{246} \mathrm{Cm}$ & 0.04 & 0.44 & 1126.57 \\
\hline TRU & 4580.97 & 3226.30 & -29.57 \\
\hline $\mathrm{Pu}$ & 4110.80 & 2836.57 & -31.00 \\
\hline
\end{tabular}

(d) $D_{\text {eq }}{ }^{T R U}$ (neutron consumption/fission) Results for HEST.

\begin{tabular}{|l|c|c|c|c|c|}
\hline HEST & $\begin{array}{c}\varphi=10^{10} \\
\left(\mathrm{n} / \mathrm{cm}^{2}-\mathrm{s}\right)\end{array}$ & $\begin{array}{c}\varphi=10^{12} \\
\left(\mathrm{n} / \mathrm{cm}^{2}-\mathrm{s}\right)\end{array}$ & $\begin{array}{c}\varphi=10^{14} \\
\left(\mathrm{n} / \mathrm{cm}^{2}-\mathrm{s}\right)\end{array}$ & $\begin{array}{c}\varphi=10^{16} \\
\left(\mathrm{n} / \mathrm{cm}^{2}-\mathrm{s}\right)\end{array}$ & $\begin{array}{c}\varphi=10^{18} \\
\left(\mathrm{n} / \mathrm{cm}^{2}-\mathrm{s}\right)\end{array}$ \\
\hline Concept I & 0.46 & 0.45 & -0.12 & -0.65 & -0.82 \\
\hline Concept II & -1.91 & -1.91 & -1.99 & -2.37 & -2.41 \\
\hline
\end{tabular}

The ISM is very us eful because it can quickly produce results for the NES while also allowing user c ontrol over i nput parameters. To exemplify this point the ISM is compared to results obtained by executing e ach of the models individually and m anually linking them together to produce the same system as with the ISM.

The pa th of e xecution $\mathrm{f}$ or $\mathrm{t}$ he $\mathrm{i}$ ndividual $\mathrm{m}$ odels $\mathrm{s}$ tarts $\mathrm{w}$ ith A P1000 $\mathrm{w}$ hole-core $3 \mathrm{D}$ depletion/decay calculations i n M CNPX f ollowed b y out put da ta processing i $\mathrm{n}$ or der $\mathrm{t} o$ manipulate the data into the form required as input for the VHTR model. A s with the AP1000, the V HTR $\mathrm{m}$ odel ut ilizes M CNPX $\mathrm{f}$ or de pletion/decay $\mathrm{c}$ alculations $\mathrm{f}$ ollowed $\mathrm{b}$ y out put processing for ex tracting the data needed for calculating $D_{e q}{ }^{T R U}$ values for the HEST Concept I and II systems. In addition, the MCNP5 models representing the HEST Concept I and II have to be integrated with post processing for producing the remaining data needed for completing the $D_{e q}{ }^{T R U}$ value c alculations in M ATLAB. By $\mathrm{f}$ ar $\mathrm{t}$ he $\mathrm{m}$ ost $\mathrm{t}$ ime i ntensive pr ocedure $\mathrm{f}$ or $\mathrm{t}$ he individual models is the MCNPX depletion calculations for the AP1000 and VHTR, and that is why the ISM us es $\mathrm{p}$ redictive $\mathrm{m}$ ethods $\mathrm{f}$ or $\mathrm{s}$ imulating de pletion $\mathrm{i} \mathrm{n}$ o rder $\mathrm{t} o$ greatly reduce computational run time. 
Since the AP1000 and VHTR must $\mathrm{m}$ eet the depletion c riteria of the E OC be ing coincidence with $\mathrm{k}_{\text {eff }}=1.00$, it requires the MCNPX depletion calculation to be run twice for each reactor. Once to de termine the $\mathrm{b}$ urnup level at which $\mathrm{k}_{\text {eff }}=1.00 \mathrm{a}$ nd then a gain to $\mathrm{s}$ top the de pletion sequence at that pre-determined burnup level and follow it with decay time calculations. Since a single depletion sequence for the AP1000 has a computational time of 30 hours and the VHTR a time of 42 hour s, the total c omputational time is 144 hour s. T his doe s not include the time necessary for pre and post data processing and additional calculations, which can be significant, but in comparison to the MCNPX depletion sequences, are minimal.

The main capability of the ISM is to quickly predict fuel cycle pa rameters related to material depletion within the A P1000 and VHTR, and then us e the information to de termine ke y fuel cycle characteristics. Table 5.10 list the differences of the ISM results with the results obtained by performing the calculations with MCNPX. The input parameters for each were set to:

- AP1000 enrichment $=3.8 \%$

- Lag time between AP1000 EOC and VHTR BOC $=12$ years

- VHTR TRISO packing fraction $=27 \%$

- Decay period after VHTR irradiation $=7$ years

The savings in computational time for the ISM is over -5 orders of magnitude when compared to MCNPX and the difference between the results are minimal. For the AP1000, the TRU nuclides with very small masses produce larger differences, particularly the $\mathrm{Cm}$ isotopes. The same is true for the VHTR, most notably ${ }^{242} \mathrm{Cm}$ at 7 years decay, which due to its short half-life onl y remains at very s mall quantities. O verall, the di fferences be tween the ISM and MCNPX calculations are minimal, and the computational time efficiency of the ISM provides much more flexibility for NES evaluation. 
Table 5.10. Percent Difference MCNPX to ISM.

\begin{tabular}{|c|c|c|c|c|}
\hline \multirow[b]{2}{*}{ Parameter } & \multicolumn{2}{|c|}{ AP1000 } & \multicolumn{2}{|c|}{ VHTR } \\
\hline & EOC (\%) & Lag, 12 yr (\%) & EOC (\%) & Decay, 7 yr (\%) \\
\hline${ }^{234} U$ & 0.82 & 1.65 & -1.29 & -1.29 \\
\hline${ }^{235} \mathrm{U}$ & -0.80 & -0.80 & -2.50 & -2.18 \\
\hline${ }^{236} U$ & 0.23 & 0.23 & -1.60 & -0.82 \\
\hline${ }^{238} \mathrm{U}$ & -0.02 & -0.02 & 0.18 & 0.18 \\
\hline${ }^{237} \mathrm{~Np}$ & 0.31 & 0.28 & 0.02 & -0.01 \\
\hline${ }^{238} \mathrm{Pu}$ & 1.35 & 1.41 & 0.01 & -0.10 \\
\hline${ }^{239} \mathrm{Pu}$ & -0.53 & -0.53 & 0.46 & 0.79 \\
\hline${ }^{240} \mathrm{Pu}$ & 0.07 & 0.13 & -0.45 & -0.57 \\
\hline${ }^{241} \mathrm{Pu}$ & 0.77 & 0.23 & -0.47 & -1.60 \\
\hline${ }^{242} \mathrm{Pu}$ & 2.25 & 2.24 & 0.45 & 0.47 \\
\hline${ }^{244} \mathrm{Pu}$ & 2.34 & 2.39 & -0.42 & -1.21 \\
\hline${ }^{241} \mathrm{Am}$ & 0.53 & 0.57 & 0.73 & 0.58 \\
\hline${ }^{242 \mathrm{~m}} \mathrm{Am}$ & 0.58 & 0.51 & 2.37 & 1.93 \\
\hline${ }^{243} \mathrm{Am}$ & 2.83 & 2.83 & 0.03 & 0.05 \\
\hline${ }^{242} \mathrm{Cm}$ & 1.82 & -4.91 & -0.59 & -5.60 \\
\hline${ }^{243} \mathrm{Cm}$ & 4.39 & 4.56 & -0.36 & 0.10 \\
\hline${ }^{244} \mathrm{Cm}$ & 4.51 & 4.02 & 0.26 & -0.14 \\
\hline${ }^{245} \mathrm{Cm}$ & 6.00 & 6.25 & 0.43 & 0.45 \\
\hline${ }^{246} \mathrm{Cm}$ & 6.99 & 7.15 & -1.37 & -1.11 \\
\hline $\mathrm{FP}$ & 1.24 & na & 0.15 & na \\
\hline Burnup & 0.85 & na & -1.21 & na \\
\hline \multicolumn{5}{|c|}{ Computational Time } \\
\hline MCNPX & \multicolumn{4}{|c|}{$144+$ hours } \\
\hline ISM & \multicolumn{4}{|c|}{$<1$ second } \\
\hline
\end{tabular}

The options for NES analysis are expanded significantly by the ISM, as the input variables can take on any value between the defined ranges specified for each. Additionally, when considering the cross-matching between each of the va riables, the pos sible combinations are limitless. As one example, the ISM is adjusted so that a ramp function produces input for the AP1000 fuel enrichment. Thus, ISM results for the NES as a function of AP1000 fuel enrichment alone are produced. Figure 5.22 shows how the quantities of ${ }^{239} \mathrm{Pu}$ and ${ }^{240} \mathrm{Pu}$ at the EOC for the VHTR are affected by fuel enrichment changes in the AP1000. 


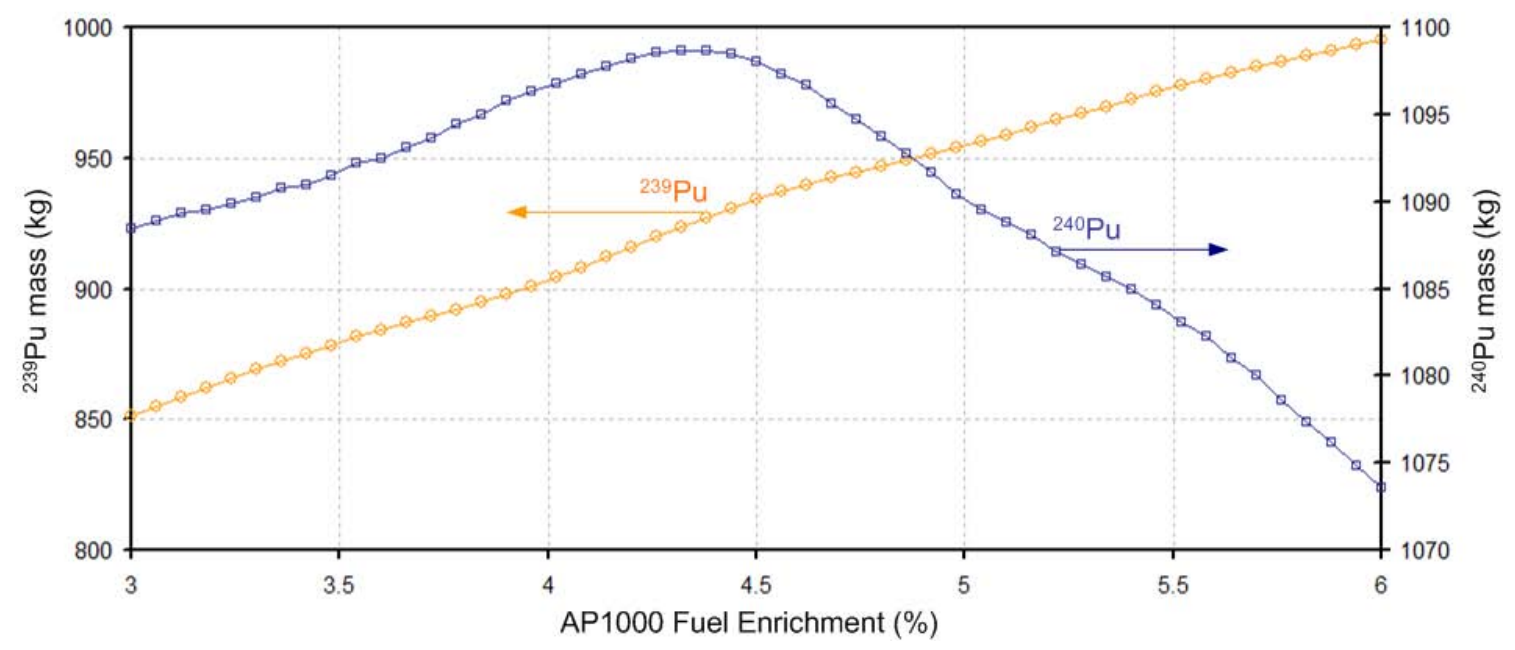

Figure 5.22. VHTR EOC Mass as a Function of AP1000 Fuel Enrichment.

Figure $5.23 \mathrm{~s}$ hows the effect that the fuel e nrichment of the A P1000 has on the e lectricity generated by both the AP1000 and VHTR. A s expected, a n increase in enrichment leads to greater e lectricity production for the A P1000 over the core lifetime, but at the same time the opposite effect is true for the electricity generated by the VHTR, which produces less electricity as enrichment increases. However, it is evident that the total electricity generation (AP1000 + VHTR) increases as enrichment increases.

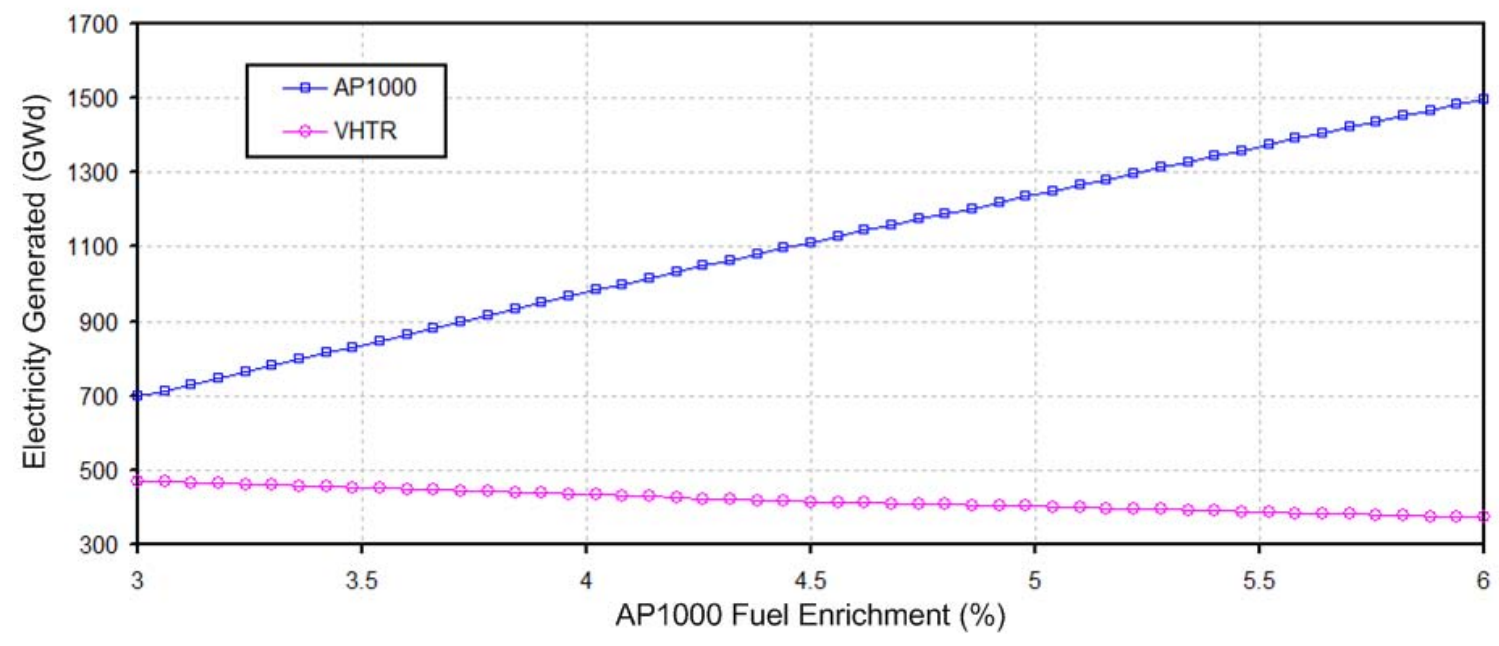

Figure 5.23. Electricity Generation as a Function of AP1000 Fuel Enrichment.

Figure 5.24 shows the overall percentage of TRU destruction in the VHTR as it relates to the fuel enrichment of the A P1000, w hich c learly i ndicates a 1 ower d estruction rate $\mathrm{f}$ or hi gher enrichments. By evaluating the change in enrichment alone, it appears that reducing TRU waste and fuel utilization are competing factors, indicating that additional analysis is required, which is addressed in the next chapter (Chapter VI: Sensitivity/Uncertainty Analysis) . 


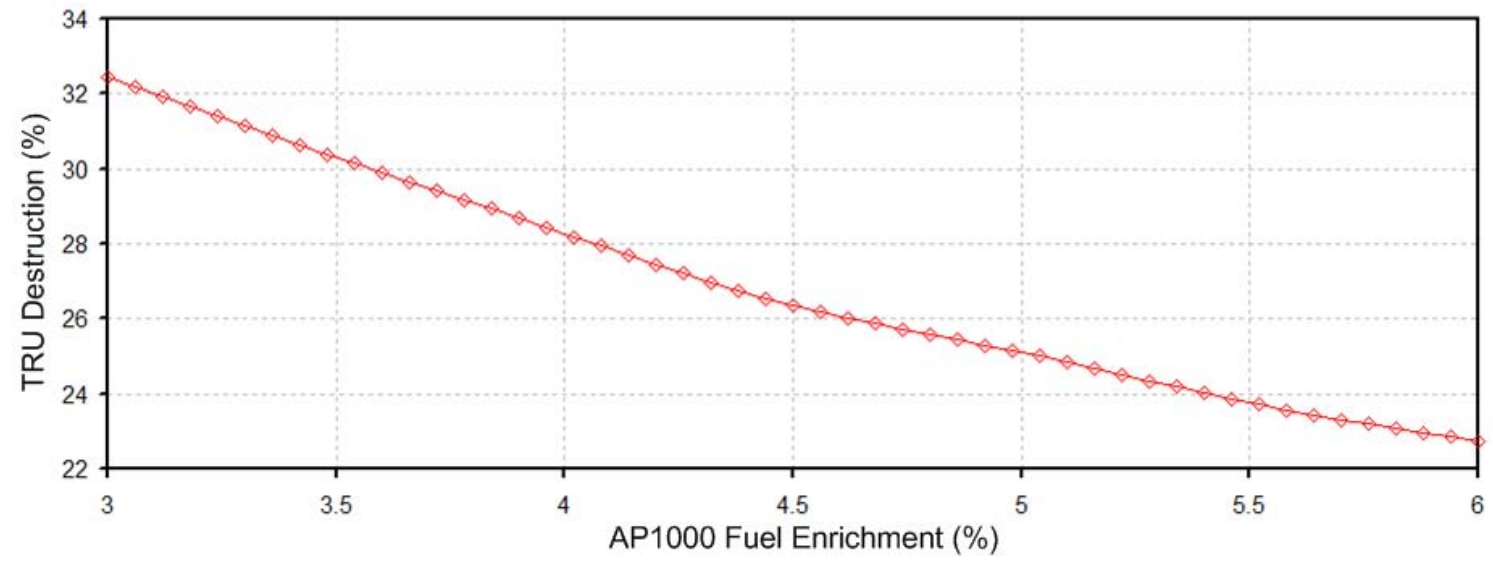

Figure 5.24. TRU Destruction in VHTR as a Function of AP1000 Fuel Enrichment.

The ISM p resents m any opt ions for e valuating the NES, especially in regard to the research objectives out lined in C hapter 1 . T he ne xt c hapter di scusses ISM a pproaches for s imulating scenarios that minimize the problematic TRU nuclides generated by the NES while at the same time a iming to fully utilizing fuel r esources. B y doing s o, it not only reduces the bur den on nuclear $\mathrm{w}$ aste m anagement and ensures a s ustainable en ergy s ource, bu $\mathrm{t}$ al so diminishes the environmental impact of front-end fuel cycle procedures, such a s ur anium mining and tailings disposal. 


\section{SENSITIVITY/UNCERTAINTY ANALYSIS}

The capabilities of the ISM make it possible to assess how variations in input will affect the NES on $\mathrm{m}$ ultiple levels. F or i nstance, a c hange i n A P1000 f uel e nrichment not onl y ge nerates enrichment dependent results for the AP1000 system, but it will also affect the results related to other NES components such as: decay calculations during lag time, irradiation related results for the VHTR, neutron balance calculations for the HEST, long-term TRU radiotoxicity calculations for waste management, and fuel resource needs for front-end procedures. Being able to perform such applications and effectively $t$ rack the $r$ esults i $n$ a $t$ ime ef ficient $m$ anner al lows $m$ any possibilities for sensitivity/uncertainty analysis.

\subsection{Sensitivity/Uncertainty Analysis}

Systematic changes were made to parameters in the NES to determine the effects of the changes on the system. The ISM was adjusted to accomplish the study by setting input parameters to linearly increase by us ing a ramp function, which allowed for the generation of s ystem wide results as a function of increasing input. Separate cases were performed for each input variable, with the pa rameter of int erest a llowed to change $\mathrm{w}$ hile th e $\mathrm{r}$ emaining variables $\mathrm{w}$ ere $\mathrm{h}$ eld constant. The ramp function performed system calculations at equally spaced intervals for each input variable of interest according to:

$$
f(t)=\left(\frac{v_{u}-v_{l}}{n}\right) t+v_{l}, \quad \text { for } t=[0,1, \ldots, n]
$$

where $v_{l}$ is the lower bound for input variable $v, v_{u}$ is the upper bound for the input variable $v, n$ is the total number of intervals, and the input variables evaluated for the system include:

1) AP1000 enrichment $(3 \% \rightarrow 6 \%)$

2) Lag time between AP1000 and VHTR (5yr $\rightarrow 20 \mathrm{yr})$

3) TRISO packing fraction in VHTR fuel compact $(20 \% \rightarrow 40 \%)$

4) Lag time between VHTR and HEST (0yr $\rightarrow$ 20yr)

System wide results were collected and processed for conducting the sensitivity analysis. Figure 6.1 provides a diagram of how the sensitivity calculations w ere performed by the ISM. The diagram indicates the inclusion of a ramp function for generating input values for the AP1000 enrichment, w ith $t$ he $r$ emaining i nput $r$ amp f unctions $t$ urned of $f$. $T$ he g enerated out put i s, therefore, a function of a 1 inear i ncreasing enrichment va lue. A dditional cal culations w ere performed as the ramp function for each input variable was alternated between on and off. 


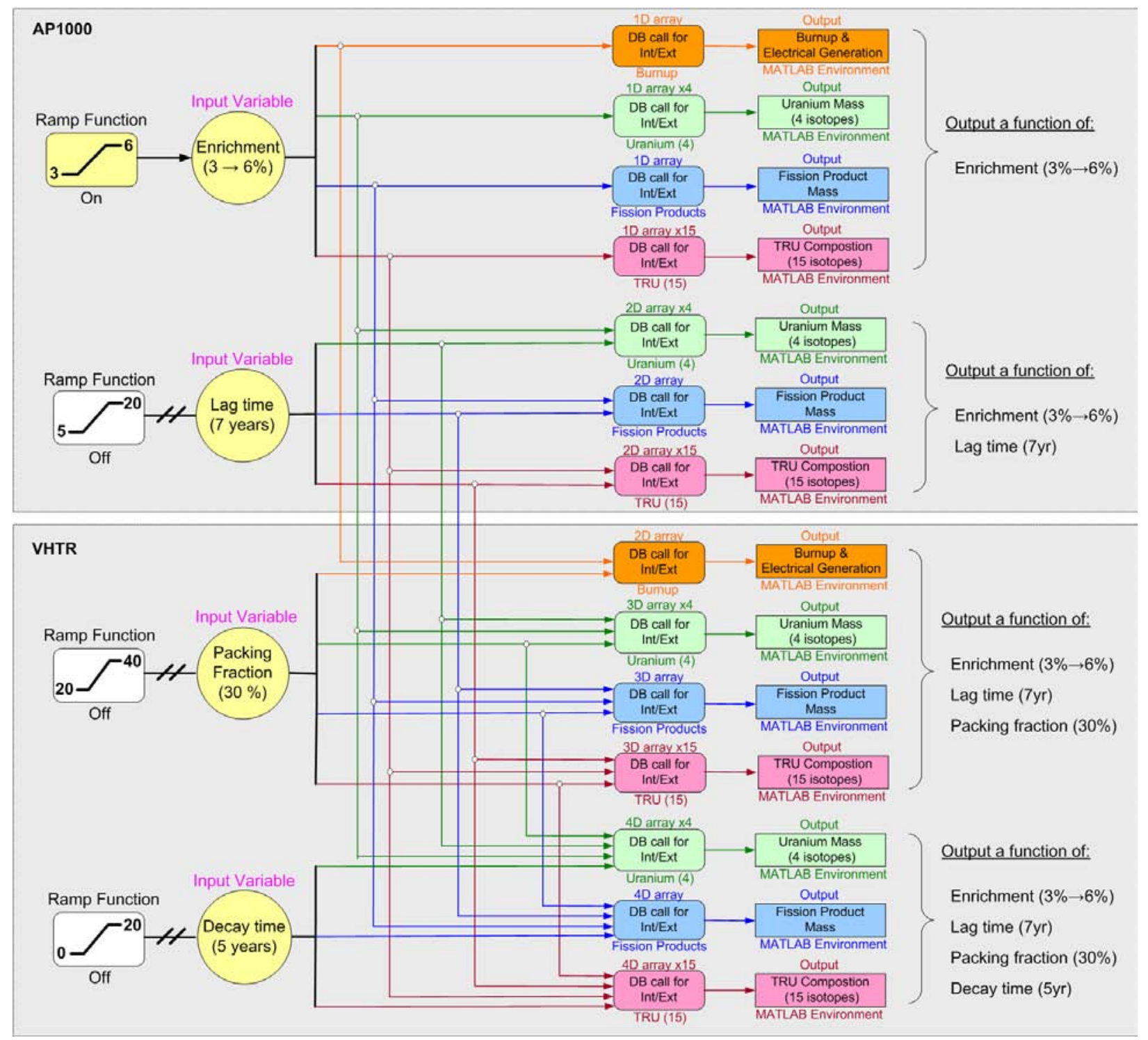

Figure 6.1. Example of Sensitivity Calculations Performed within the ISM Structure.

Considering that the input variables have different dimensions and different ranges of values, a non-dimensional sensitivity coefficient was introduced to characterize sensitivity as follows:

$$
S_{V_{i}, X_{j}} \cong \frac{\partial X_{j}}{\partial V_{i}} \cdot \frac{V_{i}}{X_{j}} \cong \frac{\delta X_{j}}{\delta V_{i}} \cdot \frac{V_{i}}{X_{j}}
$$

where $S_{V i, X j}$ is the non-dimensional sensitivity coefficient, $V_{i}$ is the $i$ th variable, and $X_{j}$ is the $j$ th output va riable. A positive/negative s ensitivity coefficient $S_{V i, X j}$ indicates that out put $X_{j}$ will increase/decrease as the variable $V_{i}$ increases. The larger the sensitivity coefficient, the larger effect the variable has on the output. The closer the value is to zero, the less impact the variable has on the output.

Table 6.1 list s ensitivity c oefficients representing the affect di fferent i nput va riables ha ve on selected out put va lues. A 1 arge num ber of $\mathrm{c}$ oefficients $\mathrm{w}$ ere de termined, $\mathrm{t}$ aking $\mathrm{i}$ nto 
consideration small increments over the range of interest for each input variable, but the reported sensitivity coefficients in the table signify the change associated with the full span of the input variable under investigation.

Table 6.1. Non-dimensional Sensitivity Coefficients for Overall System.

\begin{tabular}{|c|c|c|c|c|c|c|c|}
\hline \multicolumn{2}{|c|}{ Input variation } & $\begin{array}{l}\text { 1. AP1000 } \\
\text { Enr(3 } \rightarrow 6 \%)\end{array}$ & $\begin{array}{l}\text { 2. AP1000 } \\
\text { Enr(3 } \rightarrow 6 \%)\end{array}$ & $\begin{array}{l}\text { 3. AP1000 } \\
\text { Enr(3 } \rightarrow 6 \%)\end{array}$ & $\begin{array}{l}\text { 4. Lag Time } \\
(5 \rightarrow 20 \mathrm{yr})\end{array}$ & $\begin{array}{l}\text { 5. VHTR PF } \\
(20 \rightarrow 40 \%) \\
\end{array}$ & $\begin{array}{l}\text { 6. VHTR PF } \\
(20 \rightarrow 40 \%)\end{array}$ \\
\hline \multicolumn{2}{|c|}{ NES component } & AP EOC & VHTR EOC & VHTR EOC & VHTR BOC & VHTR EOC & VHTR EOC \\
\hline \multicolumn{2}{|c|}{ Output } & mass & mass & P/D rate & mass & mass & $\mathrm{P} / \mathrm{D}$ rate \\
\hline \multirow{19}{*}{ 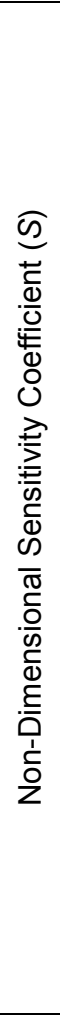 } & $\begin{array}{l}{ }^{234} U \\
{ }^{235} U \\
{ }^{236} U \\
{ }^{238} U \\
\end{array}$ & $\begin{array}{c}2.928 \\
0.408 \\
1.367 \\
-0.044 \\
\end{array}$ & $\begin{array}{c}0.149 \\
-0.103 \\
-0.309 \\
0.057 \\
\end{array}$ & & & & \\
\hline & ${ }^{237} \mathrm{~Np}$ & 1.873 & 1.299 & $-0.225^{(1)}$ & 0.010 & 0.851 & $0.082^{(1)}$ \\
\hline & ${ }^{238} \mathrm{Pu}$ & 2.599 & 0.348 & -0.671 & -0.036 & 1.052 & 0.072 \\
\hline & ${ }^{239} \mathrm{Pu}$ & 0.247 & 0.169 & $-0.177^{(1)}$ & 0.001 & 1.189 & $-0.070^{(1)}$ \\
\hline & ${ }^{240} \mathrm{Pu}$ & 0.422 & -0.014 & $-0.942^{(1)}$ & 0.002 & 1.056 & $-1.256^{(3)}$ \\
\hline & ${ }^{241} \mathrm{Pu}$ & 0.713 & -0.037 & -0.777 & -0.169 & 0.574 & -0.978 \\
\hline & ${ }^{242} \mathrm{Pu}$ & 1.429 & 0.370 & -0.675 & 0.001 & 0.880 & -0.243 \\
\hline & ${ }^{244} \mathrm{Pu}$ & 3.079 & 0.013 & $-1.072^{(2)}$ & 0 & 0.694 & -0.569 \\
\hline & ${ }^{241} \mathrm{Am}$ & 2.025 & 0.302 & $-0.071^{(1)}$ & 0.542 & 1.458 & $-0.350^{(1)}$ \\
\hline & ${ }^{242 m} \mathrm{Am}$ & 2.560 & 0.360 & -0.463 & -0.020 & 1.898 & 0.509 \\
\hline & ${ }^{243} \mathrm{Am}$ & 2.779 & 0.324 & -0.769 & 0 & 0.734 & -0.252 \\
\hline & ${ }^{242} \mathrm{Cm}$ & 2.533 & 0.198 & -1.375 & -0.312 & 0.246 & -0.362 \\
\hline & ${ }^{243} \mathrm{Cm}$ & 5.082 & 0.001 & -0.699 & -0.100 & 0.557 & -0.223 \\
\hline & ${ }^{244} \mathrm{Cm}$ & 6.361 & 0.271 & -0.794 & -0.142 & 0.768 & -0.123 \\
\hline & ${ }^{245} \mathrm{Cm}$ & 11.774 & 0.157 & -0.879 & -0.002 & 0.995 & 0.013 \\
\hline & ${ }^{246} \mathrm{Cm}$ & 17.789 & -0.035 & -0.949 & -0.003 & 1.115 & 0.081 \\
\hline & TRU & 0.483 & 0.144 & $-0.299^{(1)}$ & 0 & 1.003 & $-0.063^{(1)}$ \\
\hline & $\mathrm{FP}$ & 1.208 & -0.304 & - & - & 0.827 & - \\
\hline & Elec.(GWd) & 1.150 & -0.206 & -0.206 & -0.055 & 0.866 & 0.866 \\
\hline
\end{tabular}

The Table's first three columns of sensitivity measurements are representative of changes made to the AP1000 fuel enrichment starting at 3\% and increasing to $6 \%$. C olumns 1 a nd 2 signify how increased enrichment affects output masses for the TRU isotopes, total FP, U isotopes, total TRU, a nd t he e lectricity generated b y t he A P1000. C olumn $1 \mathrm{c}$ onsiders the $\mathrm{m}$ ass $\mathrm{r}$ esults tabulated for the AP1000 at EOC, with column 2 for the VHTR at EOC. Column 3 considers the TRU production/destruction $(\mathrm{P} / \mathrm{D})$ rates during irradiation in the VHTR.

The forth column of coefficients takes into account the amount of lag time between the AP1000 EOC and VHTR BOC and how it affects the amount of TRU by nuclide dur ing that pe riod. Additionally, the bottom row of column 4 represents the sensitivity of lag time to the electricity generated by the VHTR. 
The last two columns ( 5 and 6) list sensitivity coefficients that account for changes in the input variable representing the TRISO particle packing fraction (PF) within the fuel el ement of the VHTR. Column 5 c ontains coefficients for the output parameter of mass for TRU, U, and total FP. Coefficients for the output variables representing TRU production/destruction rates and the electricity generation for the core lifetime of the VHTR are listed in column 6.

Sensitivity coefficients listed in column 1 indicate that as enrichment increases all output masses for the nuclides calculated at AP1000 EOC al so increase, except for ${ }^{238} \mathrm{U}$. T he r eason being, higher enrichment leads to an increase in fuel burnup, which translates to a greater accumulation of actinides. The results most sensitive to changes in enrichment are the masses for the higher actinides, especially ${ }^{245} \mathrm{Cm}$ and ${ }^{246} \mathrm{Cm}$. The TRU nuclide that shows the least sensitivity is ${ }^{239} \mathrm{Pu}$.

The s ensitivity coefficients lis ted in column 2 indicate s imilar tr ends, as mos t of the T RU nuclides at E OC for the V HTR al so increase in m ass as the fuel en richment for the A P1000 increases. The ex ception being ${ }^{240} \mathrm{Pu}{ }^{241} \mathrm{Pu}$, a nd ${ }^{246} \mathrm{Cm}$, which all s how a s lightly ne gative sensitivity coefficient. Of the TRU nuclides, ${ }^{237} \mathrm{~Np}$ shows the highest sensitivity to enrichment changes. A lso of not ice is the ne gative c oefficient f or e lectricity generation, $w$ hich is the opposite of the affect for the AP1000.

The third c olumn of s ensitivity coefficients s hows that as AP1000 e nrichment i ncreases, the production and destruction rates for all the TRU nuclides decreases. ${ }^{239} \mathrm{Pu}$, which constitutes the majority of the TRU composition, shows weak sensitivity to enrichment, while ${ }^{240} \mathrm{Pu}$, the second largest $\mathrm{c}$ onstituent, $\mathrm{s}$ hows $\mathrm{m}$ uch s tronger s ensitivity. $\mathrm{T}$ aken a s a whole, a s t he A P1000 enrichment increases the overall TRU destruction rate in the VHTR is slightly reduced.

The sensitivity coefficients lis ted in column 4 are a ssociated with TRU compositions and the nuclide de cay c onstants. $M$ ost of $t$ he nuc lides a re 1 ong-lived a nd on ly s mall $\mathrm{c}$ omposition changes are experienced during the lag time between AP1000 and the VHTR. O f note, is the relatively s trong s ensitivity for the fissile is otope ${ }^{241} \mathrm{Pu}$ indicating a de crease in mass and the even s tronger s ensitivity for ${ }^{241} \mathrm{Am}$ indi cating an increase i n mass. A lso, VHTR el ectricity generation is weakly affected by lag time, as i ncreased lag time c auses a s light de crease in generated energy.

Sensitivity coefficients listed in column 5 indicate that as the TRISO particle packing fraction is increased, the TRU masses, total FP mass, and electricity generated also increase. The response is a s e xpected, c onsidering that the a mount of TRU in the s ystem is be ing i ncreased a $\mathrm{s}$ the packing fraction increases, resulting in hi gher fuel bur nup and, thus, g reater P acking Fraction (FP) bui ldup a nd hi gher e lectricity output. A lthough a ll the out put v ariables i ncrease w ith packing fraction, the rate at which they increase is not as easily discernable and the coefficients provide information in this regard.

The s ensitivity co efficients i n column 6 indicate $t$ hat as $t$ he $\mathrm{p}$ acking $\mathrm{f}$ raction increases $\mathrm{t}$ he production and destruction rates for most of the TRU nuclides decreases. The exceptions being: ${ }^{237} \mathrm{~Np},{ }^{239} \mathrm{Pu},{ }^{242 \mathrm{~m}} \mathrm{Am},{ }^{245} \mathrm{Cm}$, and ${ }^{246} \mathrm{Cm}$. A s a group, the TRU nuclides show low sensitivity to the packing fraction, with ${ }^{240} \mathrm{Pu}$ and ${ }^{241} \mathrm{Pu}$ showing the highest sensitivity levels. 
The sensitivity coefficients are a useful tool for quickly assessing system behavior, but additional information $\mathrm{m}$ ay $\mathrm{b}$ e ne eded to $\mathrm{g}$ ive a complete picture of how the i nput va riables a ffect $t$ he output for the system. The coefficients listed in Table $6.1 \mathrm{~g}$ ive information relevant to the end points of the input va riables. T herefore, i nterior be havior $m$ ight be ov erlooked, e specially if sensitivity is strongly non-linear within the variable range. To account for this possibility a set of plots showing normalized output results as a function of the corresponding input variable were generated. The slope of the curve indicates the degree of sensitivity, such that the steeper the slope, the greater the sensitivity. A positive slope signifies an increase in the corresponding output variable and a negative slope signifies a decreasing value.

Figure $6.2 \mathrm{~s}$ hows the normalized isotopic production/destruction rates in the VHTR for the Pu isotopes as they relate to TRISO packing fraction in the VHTR fuel element. The plot provides a useful means of easily comparing the sensitivity of many parameters at once. A lso, it provides the ability to pinpoint import information such as the change from destruction to production rates as seen with ${ }^{240} \mathrm{Pu}$ at a packing fraction greater than $35.2 \%$.

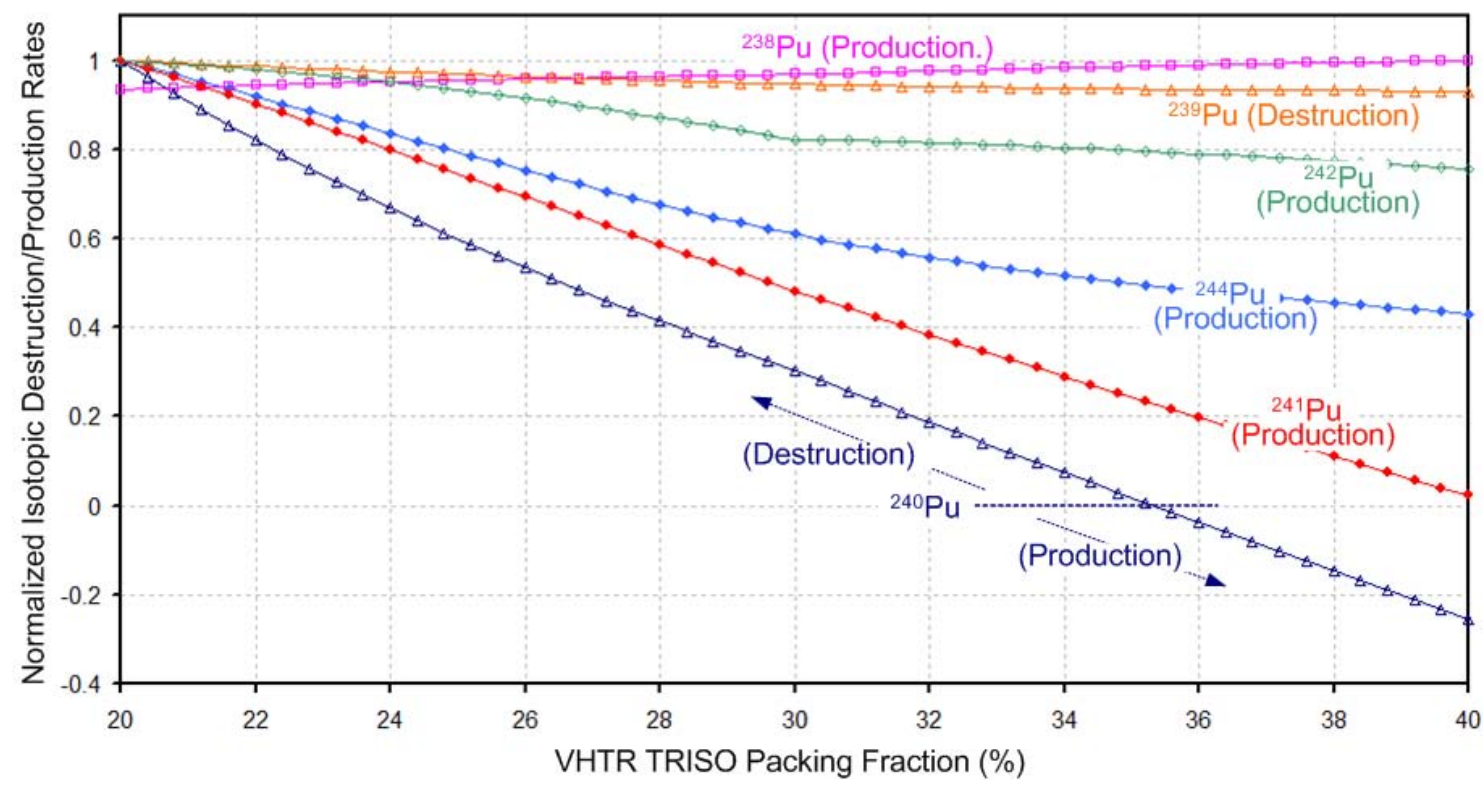

Figure 6.2. Pu Production /Destruction Rates in the VHTR vs. TRISO Packing Fraction.

The normalized production/destruction rates in the VHTR for relevant Am isotopes and ${ }^{237} \mathrm{~Np}$, as a function of the TRISO packing fraction, are shown in Figure 6.3. The plot indicates that ${ }^{241} \mathrm{Am}$ is most sensitive to changes in packing fraction and experiences a reduction in destruction rate as the pa cking fraction increases. ${ }^{237} \mathrm{~Np}$ a lso unde rgoes d estruction, but shows 1 ess s ensitivity. ${ }^{242 \mathrm{~m}} \mathrm{Am}$ and ${ }^{243} \mathrm{Am}$ a re pr oduced dur ing i rradiation in the V HTR, but the former increases in production rate, while the later decreases in production rate as the packing fraction increases. 


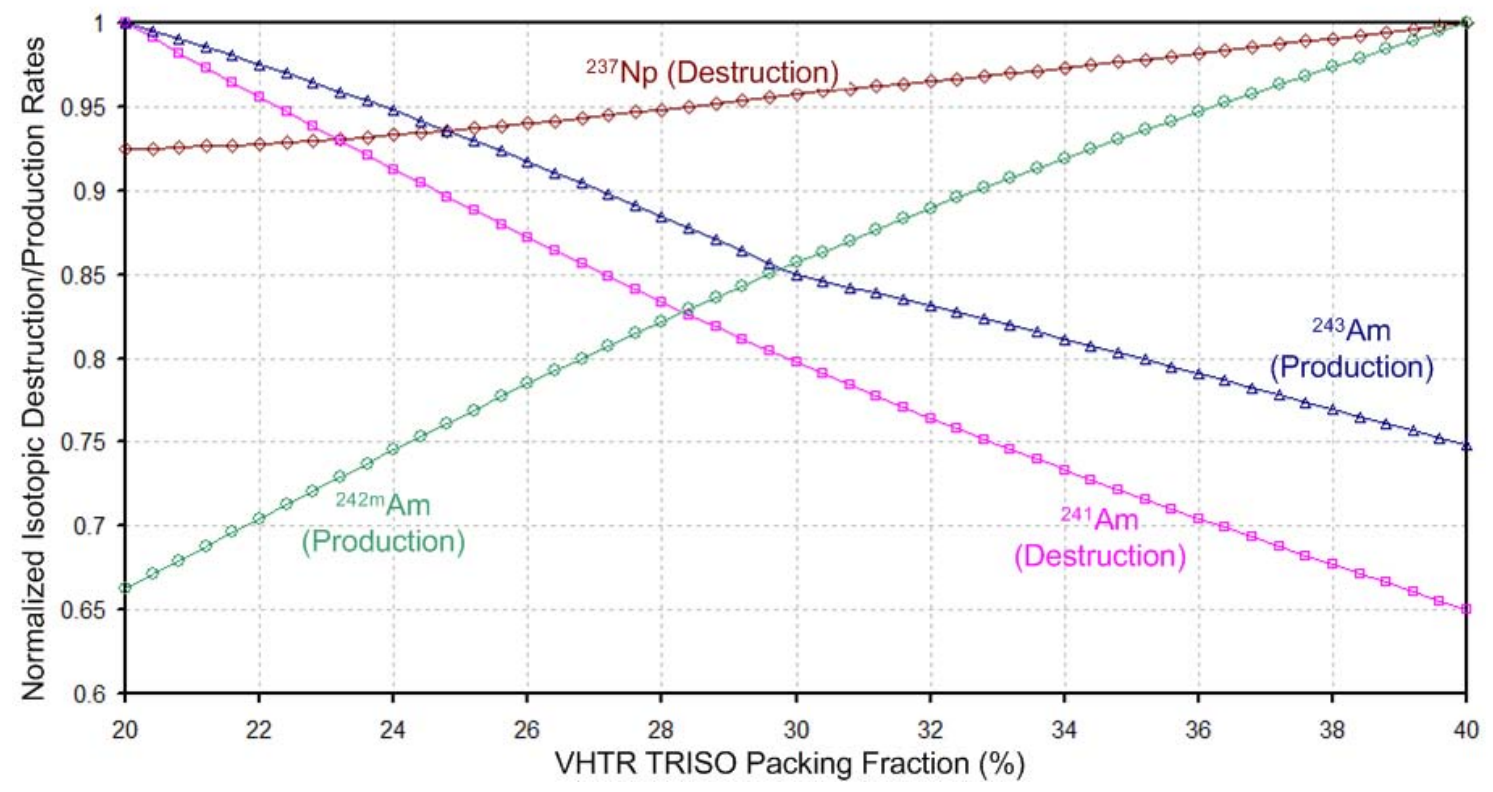

Figure 6.3. Am and ${ }^{237} \mathrm{~Np}$ Production/Destruction Rates in the VHTR vs. TRISO PF.

Figure 6.4 is an example of two results that are not linear over the input variable range. Shown are the nor malized production $r$ ates for ${ }^{240} \mathrm{Pu}$ and ${ }^{242} \mathrm{Cm}$ dur ing i rradiation in the VHTR a s a function of the fuel enrichment in the AP1000. The ${ }^{242} \mathrm{Cm}$ does not even register a production rate until enrichment levels above $3.54 \%$ a re a chieved, due to $\mathrm{i}$ ts short half-life, causing it to decay away dur ing the lag $\mathrm{t}$ ime for 1 ower enrichment 1 evels. $\mathrm{T}$ hen when it is present, i ts production rate drops rapidly at first, and then levels off for enrichment levels above $4 \%$. ${ }^{240} \mathrm{Pu}$ also show erratic behavior over the enrichment range. In both cases the behavior would not be discernable by the sensitivity coefficient alone.

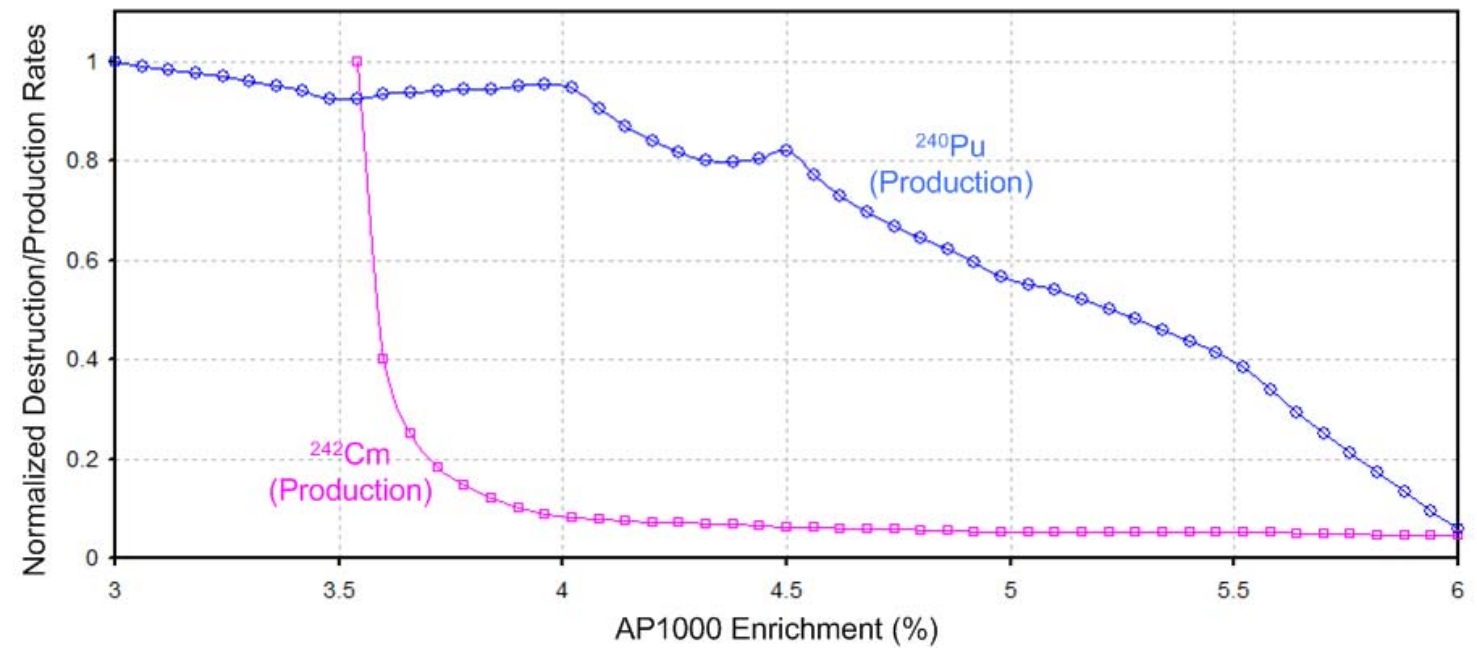

Figure 6.4. ${ }^{240} \mathrm{Pu}$ and ${ }^{242} \mathrm{Cm}$ Production Rates in the VHTR vs. AP1000 Enrichment. 


\section{DOMAIN IDENTIFICATION VIA MIN/MAX SEARCH FOR OPTIMIZATION STUDIES}

The capabilities of the ISM make it possible to assess how variations in input will affect the NES on $\mathrm{m}$ ultiple levels. F or i nstance, a c hange i n A P1000 f uel e nrichment not onl y ge nerates enrichment dependent results for the AP1000 system, but it will also affect the results related to other NES components such as: decay calculations during lag time, irradiation related results for the VHTR, neutron balance calculations for the HEST, long-term TRU radiotoxicity calculations for waste management, and fuel resource needs for front-end procedures. Being able to perform such applications and effectively $t$ rack the $r$ esults i $n$ a t ime ef ficient $m$ anner al lows $m$ any possibilities for implementing optimization techniques.

\subsection{Domain Identification}

In this $\mathrm{r}$ eport, the conceptual a pproach for opt imization procedures is br oken dow $\mathrm{n}$ i nto the following s teps: 1 ) c reate a popul ation of random solutions, 2) search for a set of opt imum solutions, and 3) select best solution based on criteria preferences.

The population size of random solutions must be large enough to assure that the sampling space accounts for the i nfinite $\mathrm{c}$ ombinations possible for the i nput va riables. To a ccomplish this, random number generators are applied to the ISM to produce input values within the specified range of each input variable. The random number generator as signed to each input variable is unique i $\mathrm{n}$ its $\mathrm{s}$ pecified interval a nd $\mathrm{s}$ tarting $\mathrm{s}$ eed. One $\mathrm{m}$ illion $\mathrm{i}$ nput va lues are $\mathrm{r}$ andomly generated for ea ch variable, thus as suring that $t$ he $\mathrm{s}$ ampling $\mathrm{s}$ pace provides e nough $\mathrm{r}$ andom solutions for complete analysis.

The randomly s elected input va lues $\left(10^{6}\right.$ for e ach input) and subsequently generated solutions $\left(10^{6}\right.$ for each output parameter) are stored within the MATLAB environment, where a subroutine is called to search and retrieve minimum and maximum output values along with their matching input values. Table 7.1 list the minimum and maximum output results for a selection of output parameters along with the input values used to produce the results for each case.

The $\mathrm{P} / \mathrm{D}$ pa rameter 1 isted in $\mathrm{T}$ able $7.1 \mathrm{~s}$ ignifies $\mathrm{w}$ hether a nuc lide is $\mathrm{p}$ roduced or de stroyed during irradiation in the VHTR. The output units for P/D are in fractional form and determined by the following relation:

$$
(P / D)_{i}=\left(\frac{m_{\text {out }}-m_{\text {in }}}{m_{\text {in }}}\right)_{i}
$$

where $m_{\text {out }}$ is the mass measurement at VHTR EOC, $m_{\text {in }}$ is the mass measurement at VHTR $\mathrm{BOC}, i$ is the TRU isotope of interest, and $\mathrm{P} / \mathrm{D}$ is either the production or destruction rate for the $i^{\text {th }}$ nuclide. As defined, $\mathrm{P} / \mathrm{D}$ represents the production rate $(\mathrm{P})$ if the outcome is a positive value and the destruction rate (D) if the value is negative. In some cases the nuclide is listed as P/D, meaning that the minimum output value is production and the maximum is destruction. 
Table 7.1. NES Minimum and Maximum Output Data.

\begin{tabular}{|c|c|c|c|c|c|c|c|c|}
\hline \multirow[b]{3}{*}{$\begin{array}{l}\text { Output } \\
\text { Parameter }\end{array}$} & \multicolumn{4}{|c|}{ Minimum } & \multicolumn{4}{|c|}{ Maximum } \\
\hline & \multirow[b]{2}{*}{ Output } & \multicolumn{3}{|c|}{ Input } & \multirow[b]{2}{*}{ Output } & \multicolumn{3}{|c|}{ Input } \\
\hline & & $\begin{array}{c}\text { Enrich } \\
(\%)\end{array}$ & $\begin{array}{l}\text { Lag } \\
\text { time (yr) }\end{array}$ & $\begin{array}{l}\text { PF } \\
(\%)\end{array}$ & & $\begin{array}{c}\text { Enrich } \\
(\%)\end{array}$ & $\begin{array}{l}\text { Lag } \\
\text { time }(y r)\end{array}$ & $\begin{array}{l}\text { PF } \\
(\%)\end{array}$ \\
\hline${ }^{237} \mathrm{~Np}(\mathrm{D})$ & -0.295 & 6.0 & 19.8 & 29.3 & -0.492 & 3 & 5 & 30 \\
\hline${ }^{238} \mathrm{Pu}(\mathrm{P})$ & 1.723 & 5 & 5 & 20 & 4.233 & 3.4 & 11 & 40 \\
\hline${ }^{239} \mathrm{Pu}(\mathrm{D})$ & -0.458 & 6 & 20 & 30 & -0.735 & 3 & 5 & 20 \\
\hline${ }^{240} \mathrm{Pu}(\mathrm{P} / \mathrm{D})$ & 0.032 & 6 & 20 & 40 & -0.068 & 3 & 5 & 20 \\
\hline${ }^{241} \mathrm{Pu}(\mathrm{P} / \mathrm{D})$ & 0.692 & 3.8 & 17 & 20 & -0.096 & 5.2 & 8 & 40 \\
\hline${ }^{242} \mathrm{Pu}(\mathrm{P})$ & 0.051 & 6 & 20 & 40 & 0.442 & 3 & 5 & 20 \\
\hline${ }^{244} \mathrm{Pu}(\mathrm{P} / \mathrm{D})$ & 1.664 & 3 & 5 & 20 & -0.446 & 6 & 20 & 40 \\
\hline${ }^{241} \mathrm{Am}(\mathrm{D})$ & -0.040 & 3 & 5 & 30 & -0.497 & 3.8 & 17 & 20 \\
\hline${ }^{242 m} \mathrm{Am}(\mathrm{P})$ & 12.37 & 5 & 5 & 20 & 43.75 & 4 & 20 & 40 \\
\hline${ }^{243} \mathrm{Am}(\mathrm{P})$ & 0.335 & 6 & 20 & 40 & 1.965 & 3 & 5 & 20 \\
\hline${ }^{242} \mathrm{Cm}(\mathrm{P})$ & 3958 & 5 & 5 & 30 & na & na & na & na \\
\hline${ }^{243} \mathrm{Cm}(\mathrm{P})$ & 4.541 & 5 & 5 & 30 & 22.25 & 3.8 & 17 & 20 \\
\hline${ }^{244} \mathrm{Cm}(\mathrm{P})$ & 2.890 & 5.4 & 11 & 40 & 11.83 & 3 & 5 & 20 \\
\hline${ }^{245} \mathrm{Cm}(\mathrm{P})$ & 3.401 & 6 & 20 & 30 & 45.67 & 3 & 5 & 30 \\
\hline${ }^{246} \mathrm{Cm}(\mathrm{P})$ & 0.413 & 6 & 20 & 30 & 40.05 & 3 & 5 & 30 \\
\hline TRU (P/D) & 0.183 & 6 & 20 & 30 & -0.373 & 3 & 5 & 20 \\
\hline VHTR: EFPD (d) & 1136 & 5.8 & 17 & 20 & 3478 & 3.2 & 8 & 40 \\
\hline $\mathrm{BU}(\mathrm{GWd} / \mathrm{tIHM})$ & 200.0 & 5.8 & 17 & 20 & 313.7 & 3.2 & 8 & 40 \\
\hline Elec. (GWd) & 257.8 & 5.8 & 17 & 20 & 679.6 & 3.2 & 8 & 40 \\
\hline AP1000: EFPD (d) & 624.9 & 3 & - & - & 1343 & 6 & - & - \\
\hline $\mathrm{BU}(\mathrm{GWd} / \mathrm{tl} H \mathrm{H})$ & 24.69 & 3 & - & - & 53.07 & 6 & - & - \\
\hline Elec. (GWd) & 696.9 & 3 & - & - & 1498.0 & 6 & - & - \\
\hline
\end{tabular}

The da ta s et provided by Table $7.1 \mathrm{o}$ ffers the ability t o $\mathrm{s}$ elect $\mathrm{s}$ ingle output pa rameters for optimization, but to select a best solution among all the options, further analysis is required. To complete the pr ocedure requires ut ilizing the N ES ba se of know ledge obtained thus far. In particular, the information collected in Chapter 3 (TRU Characterization), the ne utron balance $\left(D_{e q}{ }^{T R U}\right)$ va lues $\mathrm{c}$ alculated $\mathrm{f}$ or $\mathrm{t}$ he H EST s ystem, $\mathrm{t}$ he i nformation gather $\mathrm{f}$ or $\mathrm{t}$ he $\mathrm{s}$ ensitivity analysis, and the data in Table 7.1, are all us ed collectively to set up a criteria preference for reducing long-term HLW w aste ma nagement c oncerns, while be st ut ilizing fuel resources for energy generation. 


\subsection{Criteria Preference Method}

The cr iteria pr eference method considers m any NES pa rameters for $\mathrm{i}$ dentifying a $\mathrm{s}$ ingle be st solution set. The procedure uses a system to weight parameters according to importance relative to final overall NES performance goals.

Given that the AP1000 is considered primarily as a means to supply clean, abundant, economic, and safe base load electricity; the enrichment is weighted heavily for this means. The VHTR is an energy provider, but not on the same scale as the AP1000. The AP1000 generates more than twice the electricity output of the VHTR. Additionally, the support ratio of AP1000 to VHTR is anywhere from 4:1 to 11:1, depending on the input variables used. Therefore, the total electricity generation by the AP1000 is between 8.8 and 24.2 times greater than that for the VHTR.

Increasing the enrichment variable for the AP1000 causes an increase in TRU inventory and a decrease in isotopic production/destruction $r$ ates in the VHTR. C onsidering the goal of T RU destruction, lower enr ichment cas es ar e i deal, but the s ensitivity to enrichment is qui te lo w nonetheless. Also, P/D rates for the individual isotopes can be evaluated separately and adjusted accordingly.

The lag t ime be tween A P1000 and V HTR has low s ensitivity on t he P/D rates. O verall, the shorter the lag time, the better, for both VHTR electricity generation and TRU destruction.

An increase in TRISO packing fraction results in greater quantities of TRU at the EOC for the VHTR with the sensitivity of the individual isotopes varying differently for each. In addition, increases in packing fraction will result in higher fuel burnup, which in turn, translates to more electrical energy being generated by the VHTR core.

The $\mathrm{f}$ ast fluence 1 evels $\mathrm{f}$ or $\mathrm{t}$ he TRISO pa rticles act as a constraint on the o ptimizations parameters. The guideline for fast fluence limita tions is a pproximately $10^{26} \mathrm{n} / \mathrm{m}^{2}[51,52,53]$. The cal culated fast fluence levels for the VHTR (neutron energies greater than $0.1 \mathrm{MeV}$ ) are between $5.2 \times 10^{21}$ and $1.6 \times 10^{22} \mathrm{n} / \mathrm{cm}^{2}$. Therefore, the input parameters that produce maximum EFPD me asurements in the V HTR a pproach the tr aditional T RISO f ast fluences limita tions. Considering that the used VHTR fuel is not reprocessed before irradiation in the HEST system, it is recommended that fast fluence levels in the VHTR be minimized.

The HEST Concept II was selected for the criteria preference method. Primarily because it is foreseen t o ope rate a $t$ much 1 ower $\mathrm{flux} 1$ evels t han $\mathrm{t}$ he H EST C oncept I, pr oviding greater flexibility for fast fluence limitations. Additionally, HEST Concept II produces a harder energy spectrum, which translates to a more favorable environment for TRU transmutation. 
The ne utron b alance ( $D_{e q}{ }^{T R U}$ ) va lues c alculated $\mathrm{f}$ or $\mathrm{t}$ he H EST C oncept II s ystem pr ovide additional g uidance for the opt imal T RU compositions e ntering the HEST and ultimately the final TRU composition and quantity to be stored as HLW.

Table 7.2. NES Optimum Input Values by Criteria Preference Method.

\begin{tabular}{|l|c|c|c|}
\hline \multirow{2}{*}{ Parameter } & \multicolumn{3}{|c|}{ Optimum Input Variable } \\
\cline { 2 - 4 } & Enrichment (\%) & Lag Time (yr) & PF (\%) \\
\hline Electricity Gen. AP1000 & 6 & - & - \\
\hline TRU Inventory AP1000 & 3 & - & - \\
\hline (P/D) rate VHTR & 3 & 5 & 20 \\
\hline TRU Inventory VHTR & 3 & 5 & 20 \\
\hline Electricity Gen. VHTR & 3.2 & 8 & 40 \\
\hline EFPD VHTR & 5.8 & 17 & 20 \\
\hline
\end{tabular}

Table 7.2 provides the optimum input values according to the criteria preference method. The preferences c onsist of maximizing e lectricity generation for the A P1000 a nd V HTR s ystems, minimizing the TRU inventory, maximizing TRU destruction $r$ ates, and minimizing EFPD for the VHTR.

Considering preferential destruction rates for the TRU and minimization of the TRU inventory the input values of 3\% enrichment, 5 years lag time, and $20 \% \mathrm{PF}$ are us ed for the ISM, with results listed in Table 7.3. As shown, over $73 \%$ of ${ }^{239} \mathrm{Pu}$ and $37 \%$ of the total TRU is destroyed in the VHTR. The fast fluence at EOC for the VHTR is $8 \times 10^{21} \mathrm{n} / \mathrm{cm}^{2}$. Considering additional irradiation in the HEST Concept II, the residence time will be limited by the fast fluence. A neutron flux level of $10^{12} \mathrm{n} / \mathrm{cm}^{2}$-s for the HEST Concept II restricts the irradiation time to 30,000 days. Even so, the expected final transmutation rate for the TRU within the NES is expected to approach $95 \%$ de struction, ba sed on the "physics a pproach t o t ransmutation" a s described in Chapter 5.

Table 7.3. Criteria Preference Method Results.

(a) NES.

\begin{tabular}{|l|r|}
\hline AP1000 Electricity $(\mathrm{kW} \cdot \mathrm{hr})$ & $2.31 \times 10^{10}$ \\
\hline AP1000 BU $(\mathrm{GWd} / \mathrm{tIHM})$ & 25.12 \\
\hline AP1000 EFPD & 696.9 \\
\hline VHTR Electricity $(\mathrm{kW} \cdot \mathrm{hr})$ & $8.12 \times 10^{9}$ \\
\hline VHTR BU (GWd/tlHM) & 365.7 \\
\hline VHTR EFPD & 2077 \\
\hline VHTR fast fluence $\left(\mathrm{n} / \mathrm{cm}^{2}\right)$ & $8 \times 10^{21}$ \\
\hline AP1000:VHTR ratio & 5 \\
\hline Total Electricity $(\mathrm{kW} \cdot \mathrm{hr})$ & $1.24 \times 10^{11}$ \\
\hline Uranium recycled $(\mathrm{MT})$ & 411.5 \\
\hline
\end{tabular}


(b) Isotopic Results.

\begin{tabular}{|l|c|c|}
\hline Nuclide & $\begin{array}{c}\text { VHTR EOC Mass } \\
(\mathrm{kg})\end{array}$ & $\begin{array}{c}\text { VHTR P/D rate } \\
(\%)\end{array}$ \\
\hline${ }^{237} \mathrm{~Np}$ & 56.77 & -47.81 \\
\hline${ }^{238} \mathrm{Pu}$ & 116.6 & 380.7 \\
${ }^{239} \mathrm{Pu}$ & 510.3 & -73.48 \\
${ }^{240} \mathrm{Pu}$ & 773.1 & -6.808 \\
${ }^{241} \mathrm{Pu}$ & 331.1 & 13.86 \\
${ }^{242} \mathrm{Pu}$ & 180.3 & 44.20 \\
${ }^{244} \mathrm{Pu}$ & 0.007 & 166.4 \\
\hline${ }^{241} \mathrm{Am}$ & 66.71 & -22.30 \\
${ }^{242 \mathrm{~m}} \mathrm{Am}$ & 0.731 & 2044 \\
${ }^{243} \mathrm{Am}$ & 44.34 & 196.5 \\
\hline${ }^{242} \mathrm{Cm}$ & 10.81 & na \\
${ }^{243} \mathrm{Cm}$ & 0.555 & 1711 \\
${ }^{244} \mathrm{Cm}$ & 38.04 & 1183 \\
${ }^{245} \mathrm{Cm}$ & 6.194 & 4445 \\
${ }^{246} \mathrm{Cm}$ & 0.408 & 729.6 \\
\hline TRU & 2617.8 & -37.3 \\
\hline
\end{tabular}




\section{ENVIRONMENTAL IMPACT ANALYSIS}

Federal and state laws strictly regulate nuc lear power plants to insure the protection of human health a nd t he e nvironment. $E$ ven $\mathrm{s}, \mathrm{t}$ here $\mathrm{i} \mathrm{s}$ a $\mathrm{w}$ ide va riation of e nvironmental a ffects associated $\mathrm{w}$ ith nuc lear pow er generation. In order $\mathrm{t} o$ a ssess $t$ he e nvironmental impa cts of nuclear energy the various operations involved in the nuclear power industry must be considered. These ope rations a re the mining and $m$ illing of uranium, e nrichment, fuel fabrication, r eactor operation, reprocessing (only in the case of the recycle option), transport of radioactive materials, management of radioactive waste, and decommissioning of nuclear facilities.

Considering these ope rations, the e nvironmental i mpact of nuc lear energy i s categorized a $s$ follows:

1. Air e missions: $\mathrm{E}$ nergy generated $\mathrm{b}$ y nuc lear pow er $\mathrm{pl}$ ants doe s not pr oduce greenhouse gases; ho wever, fossil $\mathrm{f}$ uel e missions a re a ssociated $\mathrm{w}$ ith the $\mathrm{m}$ ining, enrichment, and transportation of the fuel.

2. Water resource use: The amount of water usage is a concern as populations increase and possible droughts are considered.

3. Waste heat: Discharge of waste heat to rivers, lakes, seawater and its affect on water quality and aquatic life.

4. Radioactive $\mathrm{w}$ aste: $\mathrm{T}$ he pr otection of $\mathrm{t}$ he bi osphere $\mathrm{f}$ rom al $1 \mathrm{r}$ adioactive $\mathrm{w}$ aste produced during the nuclear fuel cycle.

5. Radioactive emissions: E missions oc curring during normal ope ration as well as the possibility of the release of radioactive material due to abnormal operation or accident scenarios.

6. Reserves: Usage of natural resources and the sustainability of the energy source.

7. Land resource use: The area of land needed to support energy production, including: mining, enrichment, power plant, and waste storage.

The effect that nuclear power and other energy producing systems have on the environment has been studied in great detail in the past. The NES will share many of the environmental aspects associated with current nuclear power plants and the once-through fuel cycle. The purpose of the NES environmental impact a nalysis is to identify and evaluate the similarities and differences that oc cur b etween the NES a nd ot her energy s ources, $w$ ith focus pl aced on c urrent nuc lear power plants utilizing the once-through fuel cycle.

\subsection{Air Emissions}

Since energy generated by nuclear fission produces no greenhouse gases, the advanced reactors of the N ES a nd the r eactors c urrently us ed in the onc e-through f uel c ycle do not e mit a ny greenhouse gases to the atmosphere. H owever, when front-end procedures are included, there will be some subtle variations. The NES utilizes recycling, which provides an additional source of uranium feed. The uranium separated during the reprocessing stage is available for reuse in the AP1000, which is not the case for the once-through LEU fuel cycle. The additional uranium feed effectively reduces the amount uranium ore needed, therefore, reducing the mining related greenhouse gas emissions. 
When evaluating the sources of electricity generation in the United States, fossil fuels are by far the 1 argest $s$ ource, a ccounting for $m$ ore $t$ han $68 \%$ of $t$ he $t$ otal [48]. Considering $t$ hat $t$ he electricity generated by the N ES w ould most 1 ikely $\mathrm{r}$ eplace fossil $\mathrm{f}$ uel s ources, a us eful evaluation is the greenhouse gas emissions, particularly $\mathrm{CO}_{2}$, savings provided by the NES when compared to fossil fuels.

Table 8.1 shows the average amount of $\mathrm{CO}_{2}$ emissions that would be eliminated if the NES were to replace fossil fuel sources, using 2009 e missions data [54]. T o put the emission reductions into perspective, it would be equivalent to taking roughly 10.5 million cars of the road.

Table 8.1. $\mathrm{CO}_{2}$ Emissions Reductions per Year.

\begin{tabular}{|l|c|}
\hline $\begin{array}{c}\text { Source (\% of total fossil fuel } \\
\text { generation in U.S.) }\end{array}$ & $\begin{array}{c}\mathrm{NES} \mathrm{CO}_{2} \text { Reductions } \\
\text { (MT/year) }\end{array}$ \\
\hline Coal $(65 \%)$ & $4.78 \mathrm{E}+07$ \\
\hline Natural Gas $(33 \%)$ & $1.91 \mathrm{E}+07$ \\
\hline Petroleum $(2 \%)$ & $4.02 \mathrm{E}+07$ \\
\hline
\end{tabular}

\subsection{Water Resource Use}

Water requirements for nuclear power plants are higher than for other major energy generation sources [55]. The NES includes the VHTR and HEST systems, which operate without the need for large amounts of cooling $\mathrm{w}$ ater, thus water needs compared to the LEU onc e-through fuel cycle are lessened. H owever, since multiple AP1000 reactors are required to support the TRU fuel ne eds for a single VHTR, a nd the fact that e ach A P1000 out puts much gr eater energy $\left(3400 \mathrm{MW}_{\text {th }}\right.$ vs. $\left.600 \mathrm{MW}_{\text {th }}\right)$, indicates that the w ater savings for the NES are not very large, but nonetheless water needs are reduced.

Other strategies can be implemented to significantly reduce the amount of water taken from the water table. Such would be the case for dry cooling systems, but advancements would be needed to improve the economic aspects related to dry cooling. One possibility is to use sewage cooling as is done at the Palo Verde Nuclear Generating Station. Using seawater is another option, but it constricts the location of the energy system.

\subsection{Waste Heat}

The waste heat from energy generation is often dissipated into the surrounding environment. In some $\mathrm{c}$ ases this i nvolves $\mathrm{c}$ ooling $\mathrm{w}$ ith na tural bodi es of $\mathrm{w}$ ater, $\mathrm{w}$ hich $\mathrm{c}$ an a ffect $\mathrm{t}$ he aquatic ecosystem. C omparing the NES to the onc e-through cycle, consider that both systems reject waste heat to bodies of water containing aquatic life. The impact for each is evaluated the same way as it is for water resource use. The NES will have a slightly smaller environmental impact due to the VHTR and HEST systems not requiring cooling by large water sources. 
The best course for reducing the environmental impact due to waste heat is to use other sources for cooling, such as: dry cooling, dedicated cooling ponds, cooling towers, sewage water, etc.

\subsection{Radioactive Waste}

Radioactive waste comes from a num ber of sources and is classified according to the physical, chemical, and radiological pr operties. The $\mathrm{m}$ ost $\mathrm{w}$ idely us ed classification system $\mathrm{s}$ eparates waste into three classes: Low Level Waste (LLW), Intermediate Level Waste (ILW), and high level waste (HLW). These classes address activity content, radiotoxicity, and thermal power.

As s tated in the research obj ectives, one of the $m$ ain g oals for the NES is to a lleviate HLW management is sues by targeting the transmutation of TRU. Significant reductions to the TRU remaining after irradiation can have an important impact on the timescale involved with isolating HLW from the environment and greatly reducing the burden on long-term HLW management.

Therefore, a useful measure is the difference in timescale necessary for isolating the HLW from the biosphere for the NES and the LEU once-through fuel cycle. S ince long-term (greater than 1,000 years) effects are targeted, only the radiotoxicity behavior of the TRU is evaluated, as the fission products decay away to insignificant levels after about 300 years.

Figure 8.1 s how radiotoxicity levels resulting from the irradiated fuel that is removed from the reactor systems in the NES for a time period extending out to 1 million years. The ORIGEN-S code system was used to compute time-dependent concentrations and radiation source terms of the $i$ sotopes of interest, while unde rgoing r adioactive de cay. T he i sotopic act ivity levels and effective dos e coefficients $\mathrm{f}$ or i ngestion $e_{\text {ing }}(50)$ [34] a re us ed t o p roduce radiotoxicity measurements. The results in the pl ot a re nor malized to the a mount of na tural ur anium from which the HLW o riginated. T he radiotoxicity for the A P1000 is representative of that for a typical PWR and is used as the reference case for the LEU once-through fuel cycle.

The results in Figure 8.1 show that the TRU produced by the LEU-fueled AP1000 will remain above the radiotoxicity level of the original uranium ore for at least 100,000 years. The VHTR, which is fueled b y the TRU r esulting from the A P1000, is e ffective in de stroying a de cent fraction of the TRU (particularly the Pu). As a result, the TRU removed from the VHTR reaches uranium ore radiotoxicity levels at 50,000 years. Considering another $95 \%$ reduction takes place in the HEST system and the TRU radiotoxicity now drops below uranium ore levels in less than 2,000 years. 


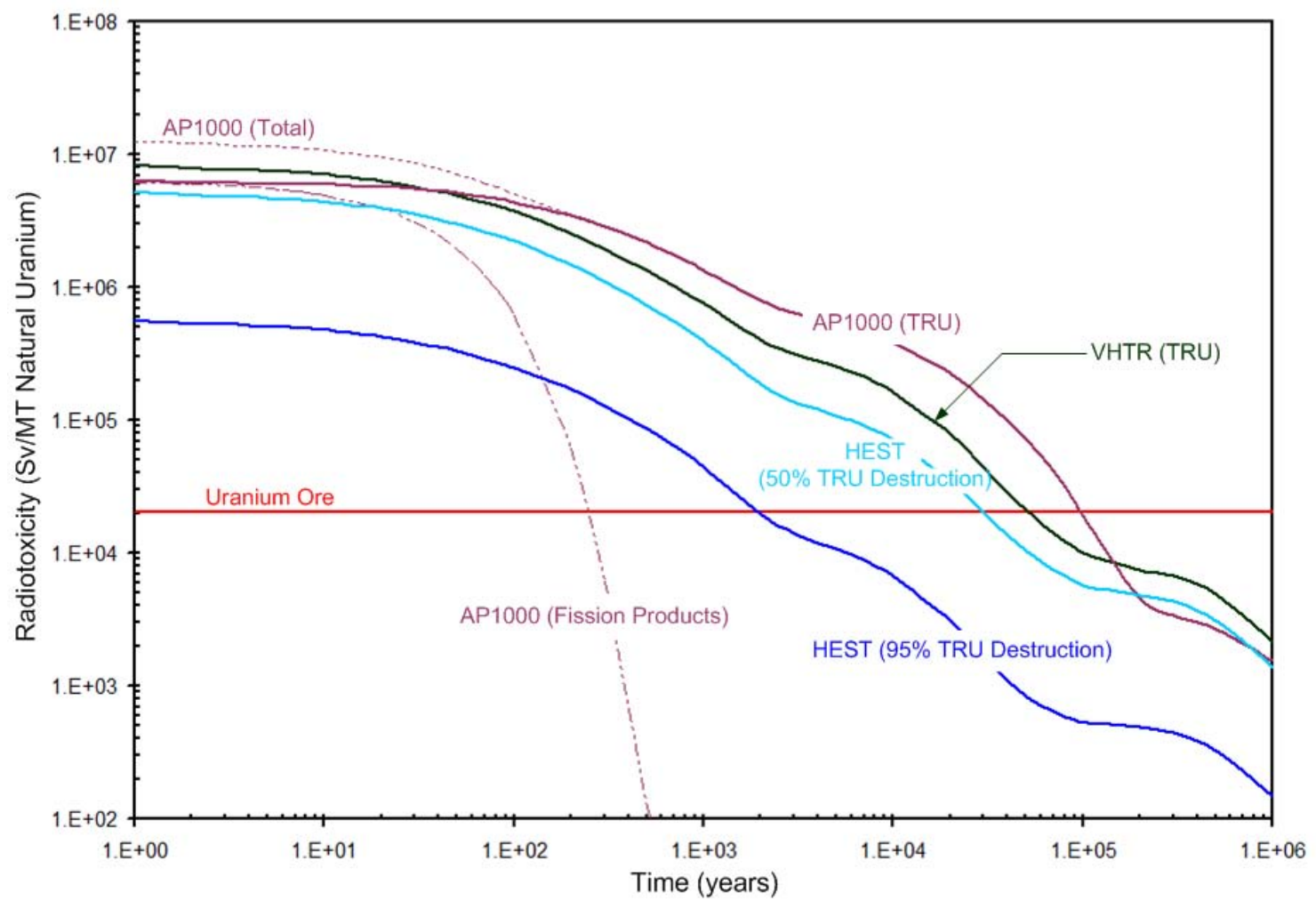

Figure 8.1. TRU Radiotoxicity Measure as a Function of Time.

For even greater time reductions, individual radionuclides $\mathrm{c}$ an be targeted for destruction in the HEST. Figure 8.2 shows how the major TRU isotopes contribute to the overall radiotoxicity of the TRU produced in the AP1000. C oncentrating on s trategies to preferentially de stroy ${ }^{239} \mathrm{Pu}$, ${ }^{240} \mathrm{Pu},{ }^{241} \mathrm{Am}$, and ${ }^{241} \mathrm{Pu}\left({ }^{241} \mathrm{Pu}\right.$ because it beta-decays to $\left.{ }^{241} \mathrm{Am}\right)$ in the HEST can produce even better results, eventually approaching the 300 year limit imposed by the fission products. 


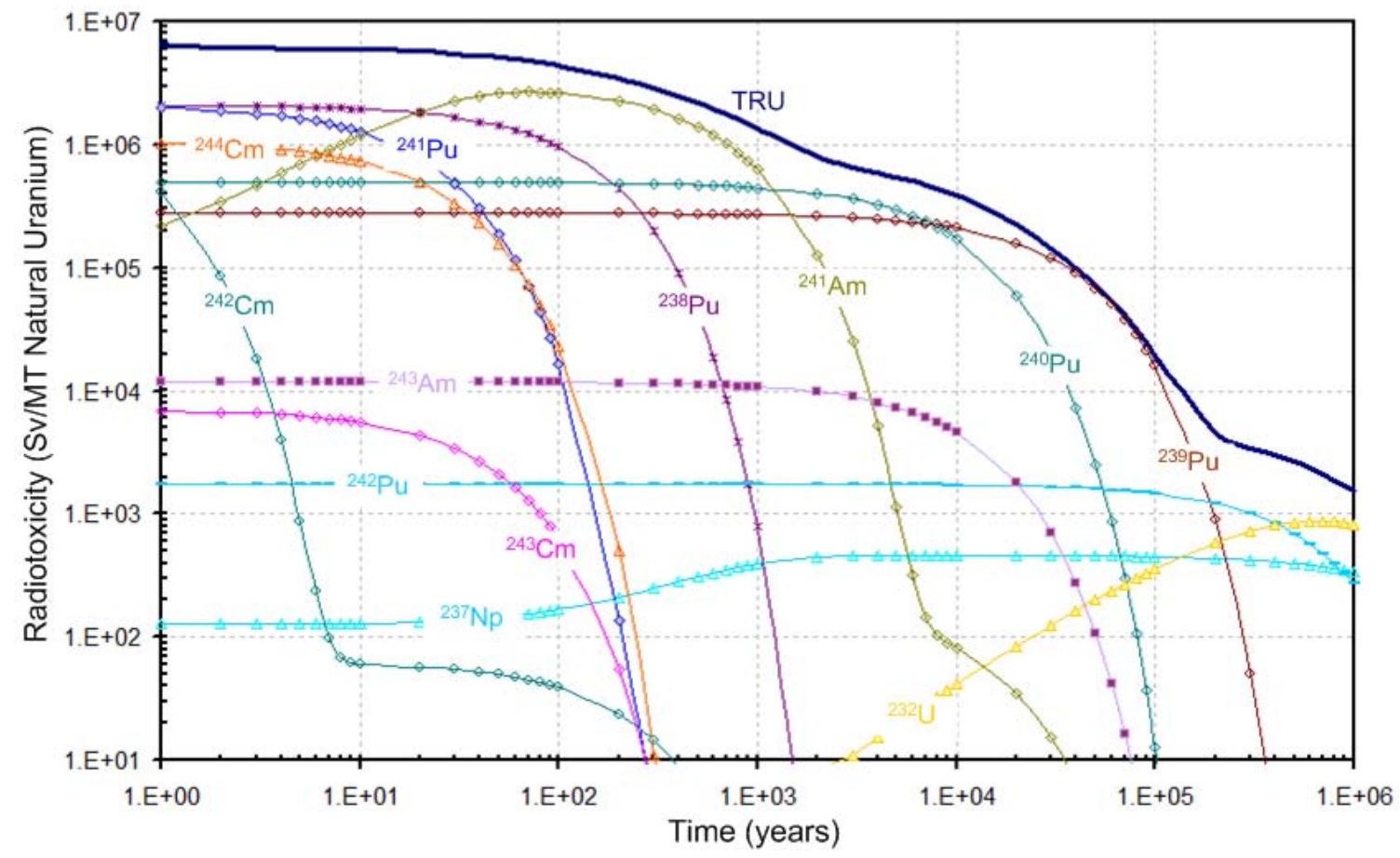

Figure 8.2. Isotopic Radiotoxicity Measure as a Function of Time.

All ene rgy sources produce waste materials that are hazardous and have adverse affects on the environment. The NES is no exception, as radioactive waste must be properly treated to protect humans and the environment. R adioactive waste differs from waste produced by other energy sources in two respects. First, the risk associated with radioactive waste decreases with time, as shown in Figure 8.2. S econd, the volume of waste (per unit energy) is much smaller than most other sources. Table 8.2 provides a comparison of HLW nuclear waste produced by the NES and the waste product associated with a typical coal fired power plant [56]. The results in the table are normalized to qua ntities of waste products produced a nnually from the generation of 1000 $\mathrm{MW}_{\mathrm{e}}$. T he values for HLW correspond to the NES w ith $90 \%$ TRU d estruction in the HEST system. 
Table 8.2. Annual Waste Production from $1000 \mathrm{MW}$.

\begin{tabular}{|l|c|l|c|}
\hline \multicolumn{1}{|c|}{ Coal } & $\begin{array}{c}\text { Mass } \\
(\mathrm{MT})\end{array}$ & \multicolumn{1}{c|}{ NES } & $\begin{array}{c}\text { Mass } \\
\text { (MT) }\end{array}$ \\
\hline Fuel Consumption / year & $2,300,000$ & Fuel Consumption / year & 2.5 \\
\hline Waste Produced / year & 50,000 & $\begin{array}{l}\text { Waste (HLW) Produced / year } \\
\text { TRU }\end{array}$ & \\
Bottom Ash & 248,000 & Fission Products & 0.06 \\
Fly Ash Retained & 46,000 & & 2.5 \\
Sulphur Retained & 344,000 & Total & 2.56 \\
Total & & Direct Air Emissions / year & \\
\hline Direct Air Emissions / Year & $6,000,000$ & $\mathrm{CO}_{2}$ & 0 \\
$\mathrm{CO}_{2}$ & 27,000 & $\mathrm{NO}_{\mathrm{x}}$ & 0 \\
$\mathrm{NO}_{\mathrm{x}}$ & 24,000 & $\mathrm{SO}_{2}$ & 0 \\
$\mathrm{SO}_{2}$ & 1,000 & Fly Ash & 0 \\
Fly Ash & 1,000 & CO & 0 \\
$\mathrm{CO}_{\text {Mercury }}^{\text {Trsenic }}$ & 5 & Mercury & 0 \\
Nickel & 5 & Arsenic & 0 \\
\hline
\end{tabular}

\subsection{Radioactive Emissions}

Radioactive emissions occur during normal operation of nuclear pow er plants. Strict limits on the a mount of $r$ adioactive e missions a llowed $t o$ be $r$ eleased $t o t$ he e nvironment ha ve be en established by the U.S. NRC. The U.S. Environmental Protection Agency and the NRC monitor radioactive effluents from nuc lear facilities to insure appliance. A $n$ example of the e mission levels are provided by the A merican Nuclear Society, stating that individuals living within 50 miles of a nuclear power plant typically receive about $0.01 \mathrm{mrem}$ dose per year. For comparison, a person living within 50 miles from a coal power plant receives about 0.03 mrem per year. The average dose per person from all sources is about 360 mrem per year and International Standards allow e xposure t o a s much a s $5,000 \mathrm{~m}$ rem p er year $\mathrm{f}$ or nuc lear i ndustry workers. Thus, emissions for both the NES and once-through fuel cycle are negligible, but the NES would most likely $\mathrm{p}$ roduce $\mathrm{m}$ ore $\mathrm{r}$ adioactive $\mathrm{e}$ ffluents unde $\mathrm{r}$ nor mal ope rating $\mathrm{c}$ onditions be cause of the addition of $\mathrm{r}$ eprocessing $\mathrm{f}$ acilities. The reprocessing facilities $\mathrm{w}$ ould be unde $\mathrm{r}$ th e $\mathrm{s}$ ame emissions monitoring as power plants.

Another environmental concern is the potential radiation exposure during an accident that may result in the release of radionuclides to the environment. The evaluation of the risk a ssociated with $\mathrm{s}$ uch oc currences i s pe rformed $\mathrm{b}$ y pr obabilistic $r$ isk a ssessment $t$ echniques. $T$ he risk associated with the cur rent $\mathrm{f}$ leet of LWR $\mathrm{r}$ eactors i s de termined to be ex tremely 1 ow and accidents resulting i $\mathrm{n}$ significant $\mathrm{r}$ adiation release $\mathrm{t}$ o t he environment ar ex traordinarily unlikely. The reactor systems within the NES are passively safe systems, thus the NES will have even lower associated risk levels for such unlikely events.

\subsection{Reserves}


The a mount of effort and e xpenditure t hat $\mathrm{h}$ as be en put $\mathrm{i}$ nto $\mathrm{u}$ ranium e xploration a nd development pales in comparison to that for gas and oil. It is widely believed that with greater uranium exploration and development, the conventional resources w ould increase significantly. Credence is given t o this prediction by the oc currence of c ontinually i ncreasing reserves as demand grows and more effort is put into exploration. A dditionally, the history of oil and gas shows, as investments are made into exploration, technology development, and extraction, more and more reserves are found.

Nevertheless, uranium resources are sufficient to sustain projected nuclear energy requirements long into the future [6]. Table 8.3 indicates this trend. The duration time assumes unchanged usage rates and un changed technology (LEU once-through cycle). The identified resources are those t hat ar e al ready "in hand." $\mathrm{T}$ he pr ognosticated resources ar e ba sed on geological investigation ut ilizing de tailed exploration m ethods, w hich a re nor mally pe rformed at $\mathrm{c}$ urrent mining sites. Considering the i dentified a nd prognosticated r esources, c urrent nuclear energy demands can be met for about 260 years. In addition, uranium can be extracted from phosphates and seawater if demand required. These resources add significantly to the amount of available uranium and extend the sustainability of nuclear energy for many more hundreds of years into the future.

Table 8.3. Uranium Resources.

\begin{tabular}{|l|c|c|}
\hline \multicolumn{1}{|c|}{ Reported Resources } & Mass (MT) & Duration (yr) \\
\hline Indentified & 5.5 & 90 \\
\hline Prognosticated & 10.5 & 170 \\
\hline Phosphate deposits & 22 & 356 \\
\hline Seawater & 4000 & 65,000 \\
\hline
\end{tabular}

Considering the strong possibility of an increase in worldwide nuclear capacity the duration time results in Table 8.3 can be somewhat misleading. As the work in this research project has clearly pointed out there are many advantages and great potential for utilizing nuclear as a future energy source. T herefore, it is s trongly recommended that nuc lear e nergy play a leading role in the world's future energy portfolio, which would result in worldwide usage rates increasing greatly. This would considerably shorten the duration time for the identified uranium resources and it is unclear if c ost i ncreases for e xtracting ur anium from phos phate de posits a nd/or s eawater a re reasonable assumptions for future resources. However, other possibilities exist within advanced fuel cycles for making nuclear power a truly sustainable energy source no matter what increases in us age are experienced i $\mathrm{t}$ he future. $\mathrm{T}$ his primarily i nvolves $\mathrm{i}$ ncluding $\mathrm{b}$ reeder reactor technology, which would improve the utilization of uranium by 50 -fold or more. Additionally, thorium can be utilized as a nuc lear fuel source and extend fuel reserves greatly. In both cases the ISM can be modified for an alysis of adva nced fuel cycles that include breeder reactors or thorium fuels.

In the NES, the u ranium is recovered and reused, extending uranium resources even m ore by recycling the used fuel. The TRU is also recovered and used to generate additional energy that would ot herwise be lost. H owever, the largest boost to nuc lear s ustainability comes from the 
recycling of the uranium present in legacy HLW waste that would now be considered as a large stockpile of uranium reserves, rather than waste that requires isolation from the environment.

\subsection{Land Resource Use}

Nuclear en ergy takes up a very small amount of land area per electricity unit generated relative to other ene rgy s ources. T his is es pecially the cas e $\mathrm{w}$ hen compared to the 1 and resources required for renewable sources such as wind, solar, and hydro.

As mentioned in the previous section, the NES recycles the uranium and TRU contained by the used fuel, thus effectively reducing the need for uranium resources produced by the mining and processing of ur anium ore. $\mathrm{T}$ herefore, i $\mathrm{n} t$ his $\mathrm{w}$ ay $\mathrm{t}$ he $\mathrm{N}$ ES $\mathrm{r}$ educes $\mathrm{t}$ he ove rall $\mathrm{f}$ ootprint associated with the LEU once-through fuel cycle.

However, recycling of the uranium means that reprocessing facilities are required, which is not the case for the once-through fuel cycle. Still it is expected that the land savings from reduced mining will outweigh the gain required by the addition of reprocessing. 


\section{CONCLUSIONS}

New high-fidelity integrated system method (ISM) and analysis approach have been developed and implemented for consistent and comprehensive evaluations of advanced fuel cycles leading to minimized TRU inventories. The method has been implemented in a developed code system integrating capabilities of MCNPX for high-fidelity fuel cycle component simulations.

Using the de veloped c omputational $t$ ool, a nuc lear e nergy s ystem (NES) c onfiguration $w$ as developed $t o t$ ake a dvantage of us ed $\mathrm{f}$ uel recycling and $t$ ransmutation $\mathrm{c}$ apabilities in w aste management scenarios leading to minimized TRU inventories. The analysis takes into account fuel cycle performance characteristics as well as potential impact of used fuel handling on the environment and resource utilization.

The r eactor systems and fuel cycle com ponents that make up the NES were selected for their ability to perform in tandem to produce clean, safe, and dependable energy in an environmentally conscious manner. The reactor systems include the AP1000, VHTR, and HEST. The diversity in performance and spectral characteristics for each was used to enhance TRU waste elimination while efficiently utilizing uranium resources and providing an abundant energy source.

The H LW s tream pr oduced by t ypical nuc lear s ystems $w$ as characterized according to the radionuclides $t$ hat are key contributors $t \mathrm{o} l$ ong-term $\mathrm{w}$ aste ma nagement is sues. It $\mathrm{w}$ as determined that the TRU com ponent be comes the main radiological co ncern for time pe riods greater than 300 years. A TRU isotopic assessment was performed to produce a priority ranking system $\mathrm{f}$ or the $\mathrm{TRU}$ nu clides a $\mathrm{s} r$ elated to long-term $\mathrm{w}$ aste $\mathrm{m}$ anagement and their expected characteristics under ir radiation in the di fferent reactor s ystems. Highest priority is otopes for destruction are: ${ }^{239} \mathrm{Pu},{ }^{240} \mathrm{Pu},{ }^{241} \mathrm{Pu}$, a nd ${ }^{241} \mathrm{Am}$. T he m edium hi gh pr iority i sotopes i nclude: ${ }^{238} \mathrm{Pu},{ }^{242} \mathrm{Pu},{ }^{243} \mathrm{Am}$, and ${ }^{244} \mathrm{Cm}$. The medium low priority isotopes are: ${ }^{242 \mathrm{~m}} \mathrm{Am},{ }^{242} \mathrm{Cm},{ }^{243} \mathrm{Cm}$, and ${ }^{245} \mathrm{Cm}$. The low priority isotopes are: ${ }^{237} \mathrm{~Np},{ }^{244} \mathrm{Pu}$, and ${ }^{246} \mathrm{Cm}$.

Detailed 3D whole-core models were developed for analysis of the individual reactor systems of the N ES. A $\mathrm{s}$ a $\mathrm{n}$ i nherent pa rt of $\mathrm{t}$ he process, $\mathrm{t}$ he $\mathrm{m}$ odels $\mathrm{w}$ ere va lidated a nd $\mathrm{v}$ erified $\mathrm{b} \mathrm{y}$ performing ex periment-to-code and/or code-to-code benchmarking procedures, which provided substantiation $\mathrm{f}$ or obt ained da ta a nd results. $\mathrm{R}$ eactor $\mathrm{c}$ ore $\mathrm{ph}$ ysics a nd $\mathrm{m}$ aterial de pletion calculations were performed and analyzed. Although the reactor models are independent, in the NES they are coupled by the fuel cycle components and material flows between them.

The ma terial $\mathrm{f}$ low in the $\mathrm{N}$ ES s tarts $\mathrm{w}$ ith the $\mathrm{f}$ ront-end $\mathrm{p}$ rocedures of ur anium $\mathrm{m}$ ining, enrichment, and fuel fabrication. N ext the LEU fuel is loaded in the AP1000, which is the primary ene rgy producing $r$ eactor s ystem in the NES. T he T RU ar e g enerated via ne utron capture by ${ }^{238} \mathrm{U}$ and subsequent decay. Upon removal from the AP1000 the used fuel decays for an a llotted a mount of time be fore it is reprocessed. D uring reprocessing the ur anium, fission products, a nd T RU a re separated. T he fission products a re $\mathrm{p}$ repared for $\mathrm{w}$ aste $\mathrm{s}$ torage, the uranium is available for reuse in the AP1000, and the TRU is fabricated into fuel for use in the VHTR. T he VHTR operates on the TRU fuel produced by the AP1000, generating electricity while also effectively destroying a fraction of the overall TRU by fission. When the VHTR can 
no longer maintain criticality the fuel blocks are prepared for further transmutation in the HEST. The last process is the removal of the fuel blocks from the HEST for long-term waste storage.

A computational modeling approach (ISM) was developed for integrating the individual models of the NES. A general approach was utilized allowing for the ISM to be modified in order to provide simulation for other systems with similar attributes. By utilizing this approach, the ISM is c apable of $\mathrm{p}$ erforming $\mathrm{s}$ ystem evaluations un der m any di fferent de sign $\mathrm{p}$ arameter opt ions. Envisioned pos sible f uture a nalysis i ncludes: a pplying AP1000 f uel s huffling schemes, including V HTR d eepburn s trategies, a nalysis of $\mathrm{m}$ oderator-to-fuel ratio a ffects, pr oviding HEST full-core depletion calculations, and implementing multiple recycles. The robustness of the ISM makes it pos sible to us e the same procedure for e valuating advanced fuel cycles that include completely different reactor systems as well.

The ISM performance was assessed by comparing it to stand alone results acquired by manually linking the individual 3D whole-core models. The predictive capabilities of the ISM proved to be more than adequate with computational savings greater than -5 orders of magnitude. Given the $\mathrm{s}$ ame NES e valuation, $\mathrm{w}$ hen $\mathrm{p}$ erformed using $\mathrm{t}$ he $3 \mathrm{D} \mathrm{w}$ hole-core $\mathrm{m}$ odels, $\mathrm{t}$ he $\mathrm{t}$ otal computational $t$ ime $w$ as 144 hour s, w hile the ISM produced ne arly id entical $r$ esults $w$ ith a computational time of less than 1 second.

A m ethod for assessing how va riations in ke y s ystem pa rameters a ffect the NES on $\mathrm{m}$ ultiple levels $\mathrm{w}$ as impl emented. T he $\mathrm{r}$ esults pr ovided valuable inf ormation pe rtaining to system performance t hat i s i mperative t o gain i nsight on how $\mathrm{s}$ ubsystem $\mathrm{c}$ hanges $\mathrm{c}$ an $\mathrm{pr}$ oduce unforeseen a ffects on $\mathrm{t}$ he ove rall $\mathrm{s}$ ystem. $\mathrm{P}$ rovided $\mathrm{i}$ nformation $\mathrm{c}$ an be us ed $\mathrm{t}$ o a ssist $\mathrm{i} \mathrm{n}$ implementing de sign changes $\mathrm{f}$ or pr oducing $\mathrm{s}$ ystem pe rformance a imed a $\mathrm{t}$ obt aining predetermined global s ystem g oals. $M$ oreover, t he $r$ esults $\mathrm{c}$ an be us ed for pr eparing f uture evaluations, as mentioned previously (shuffling schemes, deepburn strategies, etc.), making their implementation into the ISM more efficient and effective.

The potential for implementing multi-objective optimization techniques within the ISM structure have al so been demonstrated. P arameter $\mathrm{m}$ inimum/maximum searches were pe rformed and a method for w eighting s ystem va riables w as a pplied. O verall, TRU de struction $\mathrm{r}$ ates approach $40 \%$ in the VHTR, including upwards of $70 \%$ destruction of ${ }^{239} \mathrm{Pu}$. TRU Destruction rates in the HEST are estimated to be greater than $90 \%$. Overall s ystem el ectricity generation is over $10^{11}$ $\mathrm{kW} \cdot \mathrm{hr}$, with approximately 550 tons of uranium available for reuse in the next cycle.

The NES has demonstrated great potential for providing safe, clean, and secure energy and doing so with foreseen advantages over the LEU once-through fuel cycle option. The main advantages exist due to better ut ilization of na tural $r$ esources b y r ecycling the us ed nuc lear fuel, a nd by reducing the final amount and time span for which the resulting HLW must be isolated from the public and the environment due to radiological hazard. Calculations for NES scenarios estimate that the HLW waste will decay to radiotoxicity levels matching the originating uranium ore in about 2,000 years. T his is oppos ed to the 100,000 years e stimated for the onc e-through fuel cycle, a r eduction of 98,000 years, or $98 \%$. In a ddition, s trategies h ave be en i dentified for optimizing the NES to achieve even greater reductions that approach the limitations imposed by 
the radiotoxicity of the fission products, which would require the HLW waste to be isolated for only $300-500$ years.

Considering if the ubiquitous fossil fuel energy sources of today were replaced by the NES, the reduction in $\mathrm{CO}_{2}$ emissions would be immense, which would have a very positive affect on the environment. The yearly savings in emissions for the replacement of coal would be 47.8 million metric tons of $\mathrm{C} \mathrm{O}_{2}$. F or na tural gas it w ould be $19.1 \mathrm{~m}$ illion $\mathrm{m}$ etric $\mathrm{t}$ ons of $\mathrm{C} \mathrm{O}_{2}$ and $\mathrm{f}$ or petroleum it would register at 40.2 million metric tons of $\mathrm{CO}_{2}$. In more relative terms, the NES $\mathrm{CO}_{2}$ emissions savings would be equivalent to taking 10.5 million cars of the road.

The completion of this project has provided the ba sis for future research that a ims to a id in solving the energy crisis that faces future generations, with a dditional emphasis on addressing environmental concerns. The main advantages of the developed NES are the ability to recover and reuse material that is otherwise considered difficult to manage waste, substantial reduction of the radiotoxic term of spent fuel per unit of produced energy, and generation of safe, reliant, and clean energy that is sustainable for many generations into the future. If deployed, the NES can substantially reduce the long-term radiological hazard posed by current HLW, extend uranium resources, and approach the characteristics of an environmentally benign energy system. 


\section{REFERENCES}

1. F.M. VANEK, L.D. ALBRIGHT, Energy Systems Engineering: Evaluation and Implementation, McGraw-Hill Professional, New York (2008).

2. "Human D evelopment R eport 2009: O vercoming Barriers: H uman M obility a nd Development" P algrave M acmillan, United Nations D evelopment P rogram, New Y ork (2009).

3. A.D. PASTERNAK, "Global Energy Futures and Human Development: A Framework for Analysis,” Lawrence Livermore National Laboratory, UCRL-ID-140773 (October 2000).

4. "Kyoto P rotocol t o t he U nited $\mathrm{N}$ ations F ramework $\mathrm{C}$ onvention on $\mathrm{C}$ limate $\mathrm{C}$ hange," Adopted Kyoto, 11 December 1997, Crown Copyright, United Kingdom, Treaty Series No. $6(2005)$.

5. P.P. PORTNEY, R.N. STAVINS, Public Policy for Environmental Protection, $2^{\text {nd }}$ Edition, RFF Press, Washington DC (2000).

6. NEA/IAEA, "Uranium 2007: R esources, P roduction and D emand," OECD, P aris, F rance (2008).

7. J.R. LAMARSH, A.J. BARRATTA, Introduction to Nuclear Engineering, $3^{\text {rd }}$ Edition, Prentice Hall, Upper Saddle River, New Jersey (2001).

8. K. NOACK, A. ROGOV, A.A. IVANOV, E.P. KRUGLYAKOV, Yu.A. TSIDULKO, “The GDT-Based Fusion Neutron Source as Driver of a Minor Actinides Burner," Annals of Nuclear Energy 35, pp. 1216-1222 (2008).

9. A. TAYLOR, M . D UNNE, S . B ENNINGTON, S . A NSELL, e t a 1., "A R oute t o t he Brightest Possible Neutron Source?” Science 315, pp1092 (2007).

10. T.A. MEHLHORN, B.B. CIPITI, C.L. OLSON, G.E. ROCHAU, "Fusion-Fission Hybrids for Nuclear Waste Transmutation: A Synergistic Step Between Gen-IV Fission and Fusion Reactors," Fusion Engineering and Design 83, pp 948-953 (2008).

11. A.H. MARTINEZ, Y. KADI, G. PARKS, M. DAHLFORS, “Transmutation of N uclear Waste in Accelerator-Driven Systems: Fast S pectrum," Annals of Nuclear Energy 34, pp. 564-578 (2007).

12. Y. GOHAR, T.A. TAIWO, J.E. CAHALAN, P.J. FINCK, “Assessment of the General Atomics Accelerator Transmutation of Waste Concept Based on the Gas-Turbine Modular Helium R eactor T echnology," T echnology D evelopment D ivision, Argonne N ational Laboratory (2001). 
13. W.M. STACEY, V.L. BEAVERS, W.A. CASINO, J.R. CHEATHAM, Z.W. FRIIS, et al., "A Subcritical, Gas-Cooled Fast Transmutation Reactor w ith a Fusion Neutron Source," Nuclear Technology 150, pp. 162-188 (May 2005).

14. M. KOTSCHENREUTHER, P.M. VALANJU, S.M. MAHAJAN, and E.A. SCHNEIDER, "Fusion-Fission T ransmutation S cheme-Efficient D estruction of N uclear W aste," Fusion Engineering and Design 84, pp. 83-82 (2009).

15. R. B ROGLI, R . K RAKOWSKI, "Degree of S ustainability of V arious N uclear Fuel Cycles," L AUR-01-6939, ISSN 1019 -0643, Nuclear E nergy and Safety R esearch Department, Paul Scherrer Institute (2002).

16. P. F INCK, N . E DELSTIEN, Y . A LLEN, C . B URNS, e t a 1., " The P ath t o S ustainable Nuclear Energy: Basic and Applied Research Opportunities for A dvanced F uel C ycles," Technical Report, Office of Science, U.S. Department of Energy (2005).

17. E.E. BENDE, A.H. HOGENBIRK, J.L. KLOOSTERMAN and H. VAN DAM, "Analytical Calculation of the A verage D ancoff Factor for a Fuel K ernel i n a P ebble-Bed HighTemperature Reactor," Nuc. Sci. Eng. 133, 147-162 (1999).

18. J. WRIGHT, I. PAZSIT, "Neutron Kinetics in Subcritical Cores with Application to the Source Modulation Method," Annals of Nuclear Energy, 33, pp. 149-158 (2006).

19. P. COLELLA, T.H. DUNNING, W.D. GROPP, and D.E. KEYES, "A Science-Based Case for Large-Scale Simulation, Vol. 2," Technical Report, Office of Science, U.S. Department of Energy (September 2004).

20. MCNP User Manual, Version 5, LA-UR-03-1987, Vol. I, Los Alamos National Laboratory, Revised (2008).

21. MCNP User Manual, V ersion 5, LA-UR-03-1987, Vol. I I, L os A lamos National Laboratory, Revised (2008).

22. D.B. P ELOWITZ, E d., MCNPX User's Manual, LA-CP-07-1473, V ersion 2.6.0, Los Alamos National Laboratory (April 2008).

23. F.B. BROWN, "The M AKXSF C ode w ith D oppler B roadening," Los A lamos $\mathrm{N}$ ational Laboratory Report LA-UR-06-7002, Los Alamos, New Mexico, USA (2006).

24. "SCALE: A Modular Code System for Performing Standardized Computer Analyses for Licensing Evaluation, Version 6," ORNL/TM-2005/39, 3 Volumes (January 2009).

25. D.F. HOLLENBACH, L .M. PETRIE, S. GOLUOGLU, N.F. LANDERS, M.E. DUNN, "KENO-VI: A General Q uadratic V ersion of the KENO P rogram," V ol. II, S ect. F 17 of SCALE: A Modular Code System for Performing Standardized Computer Analysis for Licensing Evaluation, Version 6, ORNL/TM-2005/39, 3 Volumes (January 2009). 
26. I.C. GAULD, O.W. HERMANN a nd R.M. WESTFALL, "ORIGEN-S: SCALE S ystem Module to Calculate Fuel Depletion, Actinide Transmutation, Fission Product Buildup and Decay, and Associated Radiation Source Terms," Vol. II, Sect. F7 of SCALE: A Modular Code System for Performing Standardized Computer Analyses for Licensing Evaluation, Version 6, ORNL/TM-2005/39, 3 Volumes (January 2009).

27. "Nuclear F uel C ycle S imulation System (VISTA)," IAEA-TECDOC-1535, I nternational Atomic Energy Agency, Vienna, Austria (February 2007).

28. MATLAB ve rsion 7.9 (R2009b), $\mathrm{T}$ he $\mathrm{M}$ athWorks Inc., $\mathrm{N}$ atick, $\mathrm{M}$ assachusetts, $\mathrm{U}$ SA (2009).

29. G.F. VANDEGRIFT, M.C. REGALBUTO, S. AASE, A. B AKEL, T.J. BATTISTI, et al., "Design a nd D emonstration of t he U REX+ $\mathrm{P}$ rocess Using $\mathrm{S}$ pent $\mathrm{N}$ uclear Fuel," ATALANTE 2004: A dvances for Future $\mathrm{N}$ uclear F uel $\mathrm{C}$ ycles International $\mathrm{C}$ onference, Nimes, France, (June 2004).

30. T. KIM, T. TAIWO, R. HILL, W. YANG, F. VENNERI, “A Feasibility Study of ReactorBased Deep-Burn Concepts," ANL-AFCI-155, Argonne National Laboratory (2005).

31. D. WESTLEN, "Why Faster is Better - On Minor Actinide Transmutation in Hard Neutron Spectra," Ph.D. Thesis, January 2007, S chool of Engineering S ciences, KTH Engineering Sciences, Stockhom, Sweden (2007).

32. J. ALONSO, P. DE PRETER, A. HOOPER, H. UMEKI, et al., "Post-closure Safety Case for $\mathrm{G}$ eological R epositories: $\mathrm{N}$ ature a nd P urpose," NEA R eport, O ECD, P aris, F rance (2004).

33. R.A. WIGELAND, E.E. M ORRIS, and T.H. BAUER, "Criteria D erived for G eological Disposal C oncepts", O ECD/NEA $9^{\text {th }}$ Information E xchange M eeting on A ctinide a nd Fission Product Partitioning and Transmutation, Nimes, France (September 2006).

34. "Dose $\mathrm{C}$ oefficients for Intakes of R adionuclides b y W orkers," ICRP P ublication 68 i n: Annals of the ICRP, Vol. 24, \#4, Elsevier Science Inc., Tarrytown, New York (1995).

35. C.R. HAMMOND, "The Elements," in D. R. LIDE, Ed., CRC Handbook of Chemistry and Physics, 90th Ed., CRC Press, Boca Raton, Florida (2009).

36. "Westinghouse A P1000 D esign C ontrol D ocumentation R ev. 16 ," Tier 2, Chapter 4 , Reactor Section 4.3, Nuclear Design. ML071580897 (2007).

37. "Generation IV N uclear E nergy S ystems T en Year P rogram P lan Volume I," O ffice of Advanced Nuclear R esearch, DOE O ffice of N uclear Energy, S cience, and Technology, USDOE (March 2005). 
38. "Evaluation of High Temperature G as-cooled Reactor P erformance: B enchmark Analysis Related to Initial Testing of the HTTR and HTR-10", IAEA-TECDOC-1382, International Atomic Energy Agency, Vienna, Austria (2003).

39. D.E. AMES II, P.V. TSVETKOV, “Benchmark Efforts to S upport Studies of A dvanced VHTRs", Proc. $4^{\text {th }}$ Intern. Conf. on HTR Technology (HTR2008), Sept. 28 - Oct. 1, 2008, Washington D.C., USA, paper HTR2008-58206, pp. 1 - 8, ASME (2008).

40. S. FEHER and P.F.A. DE L EEGE, "DANCOFF-MC: A C omputer P rogram for M onte Carlo Calculation of Dancoff F actors i n Irregular G eometries," Delft U niversity o f Technology, IRI-131-95-003, Delft, Netherlands (June 1997).

41. T.A. T AIWO, T .K. K IM, W. S. YANG, and H.S. KHALIL, "Evaluation of H igh Temperature G as-Cooled R eactor P hysics Experiments as V HTR Benchmark Problems", ANL-GenIV-059, Argonne National Laboratory, USA (September 2005).

42. "AEC R esearch and Development R eport, Facilities for Electronuclear (MTA) Program," Report LWS-24736, Livermore, California, USA (1953).

43. W.B. LEWIS, “Accelerators for Intense Neutron Sources," Atomic Energy of Canada Ltd., report DL-90, Canada (1968).

44. G.A. BARTHOLOMEW and P.R. TUNNICLIFFE, " The A ECL $\mathrm{S}$ tudy $\mathrm{f}$ or a $\mathrm{n}$ Intense Neutron-Generator: Technical Details," A tomic Energy of C anada Limited Report AECL 2600, Canada (1966).

45. C.D. BOWMAN, E.D. ARTHUR, P.W. LISOWSKI, G.P. LAWRENCE, et al., "Nuclear Energy Generation and Waste Transmutation Using an Accelerator-Driven Intense Thermal Neutron Source," Nucl. Istrum. Meth. Res. A320, p. 366; (1992).

46. M.A. REDA, J.F. HARMON, and S.B. SADINENI, "A P hoto-Neutron S ource for a SubCritical N uclear R eactor P rogram,” AIP Conf. Proc., V olume 680, pp. 800 -803, (August 2003).

47. M. SALVATORES, I. SLESSAREV, and M. UEMATSU, "A Global Physics Approach to Transmutation of R adioactive N uclei," Nuclear Science and Engineering 116, pp. 1 -18 (1994).

48. M. SALVATORES, R . H ILL, I S LESSAREV, G. YOUINOU, "The Physics of T RU Transmutation - A Systematic Approach to the Intercomparison of Systems," Proceedings of P HYSOR 2004, T he Physics of Fuel C ycles and Advanced N uclear Systems: Global Developments, Chicago, IL, USA (April 2004).

49. G. H. MILEY, R. THOMAS, Y. TAKEYAMA, et al., "Driven Subcritical Fission Systems Using A Cylindrical Inertial Electrostatic Confinement (IEC) Neutron Source," DOE Office 
of F usion E nergy S ciences, R eNeW, G aithersburg, M aryland, U SA (Sept. 30 - Oct. 2, 2009).

50. W.M. STACEY, “Tokamak D - T Fusion N eutron S ource R equirements for C losing the Nuclear Fuel Cycle,” Institute of Physics Publishing, Nucl. Fusion 47, pp 217-221 (2007).

51. C. RODRIGUEZ, A. BAXTER, D. MCEACHERN, M. FIKANI, and F. VENNERI, 2003, "Deep-Burn: Making Nuclear W aste Transmutation Practical," Nucl. Eng. Des., 2805, pp. $1-19$.

52. "Critical E xperiments a nd Reactor P hysics $\mathrm{C}$ alculations $\mathrm{f}$ or Low- Enriched HTGRs," IAEA-TECDOC-1249, International Atomic Energy Agency, Vienna, Austria (2001).

53. K. MINATO, K. S AWA, T. KOYA, T. TOMITA, and A. ISHIKAWA, 2000, “ Fission Product Release Behavior of Individual Coated Fuel Particles for High Temperature GasCooled Reactors," Nucl. Technol., 131, pp. 36-46.

54. " $\mathrm{CO}_{2}$ Emissions From Fuel Combustion," International Energy Agency, OECD/IEA, Paris, France (2009).

55. "Thirsty Energy: $\mathrm{W}$ ater a nd E nergy i $\mathrm{n}$ the $21^{\text {st }}$ Century," World E conomic F orum, Cambridge Energy Research Associates, US DOE et al., (2009).

56. R.G. COCHRAN and N. TSOULFANIDIS, "The $\mathrm{N}$ uclear $\mathrm{f}$ uel $\mathrm{C}$ ycle: A nalysis and Management $2^{\text {nd }}$ ed.," American Nuclear Society, La Grange Park, Illinois, USA (1999). 


\section{APPENDIX A}

HTTR code-to-experiment benchmark supplemental data.

Fuel particle level:

TRISO particle

\begin{tabular}{|c|c|c|c|}
\hline & material & density $\mathbf{( g / \mathbf { c m } ^ { 3 } )}$ & radius (cm) \\
\hline Fuel kernel & $\mathrm{UO}_{2}$ & 10.41 & 0.02985 \\
\hline 1st coating & $\mathrm{PyC}$ & 1.14 & 0.03588 \\
\hline 2nd coating & $\mathrm{PyC}$ & 1.89 & 0.03895 \\
\hline 3rd coating & $\mathrm{SiC}$ & 3.20 & 0.04184 \\
\hline 4th coating & $\mathrm{PyC}$ & 1.87 & 0.04645 \\
\hline
\end{tabular}

Graphite matrix

\begin{tabular}{|c|c|c|}
\hline Material & Density & Impurity \\
\hline graphite & $1.69 \mathrm{~g} / \mathrm{cm}^{3}$ & $0.82 \mathrm{ppm} \mathrm{Bnat}$ \\
\hline
\end{tabular}

Unit cell measurements

\begin{tabular}{|c|c|c|}
\hline $\begin{array}{c}\text { Volume fraction } \\
\text { of grains }\end{array}$ & $\begin{array}{c}\text { Array } \\
\text { Pitch }\end{array}$ & $\begin{array}{c}\text { Number of particles } \\
\text { per fuel element }\end{array}$ \\
\hline 0.3 & $0.1377 \mathrm{~cm}$ & 176,515 \\
\hline
\end{tabular}

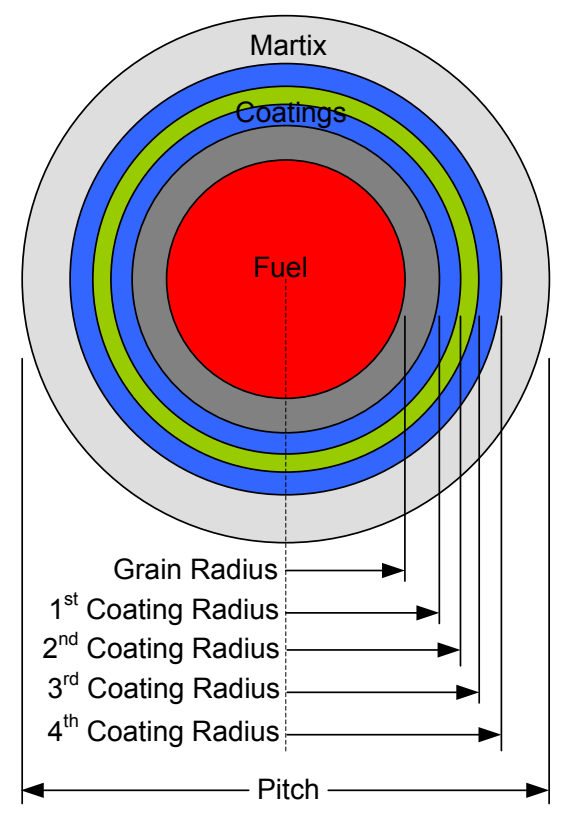

TRISO particle 


\section{Fuel element level:}

Fuel element properties

\begin{tabular}{|c|c|}
\hline \multicolumn{2}{|c|}{ Fuel Compact } \\
\hline Number of fuel particles & 176,515 \\
\hline Graphite matrix density & $1.690 \mathrm{~g} / \mathrm{cm}^{3}$ \\
\hline Graphite matrix Impurity & $0.82 \mathrm{ppm} \mathrm{Bnat}$ \\
\hline Diameter-inner & $1.0 \mathrm{~cm}$ \\
\hline Diameter-outer & $2.6 \mathrm{~cm}$ \\
\hline Effective height of fuel rod & $54.6 \mathrm{~cm}$ \\
\hline
\end{tabular}

\begin{tabular}{|c|c|}
\hline \multicolumn{2}{|c|}{ Graphite Sleeve } \\
\hline Material & Graphite \\
\hline Density & $1.770 \mathrm{~g} / \mathrm{cm}^{3}$ \\
\hline Impurity & $0.37 \mathrm{ppm} \mathrm{Bnat}$ \\
\hline Diameter-inner & $2.6 \mathrm{~cm}$ \\
\hline Diameter-outer & $3.4 \mathrm{~cm}$ \\
\hline Height & $57.7 \mathrm{~cm}$ \\
\hline
\end{tabular}
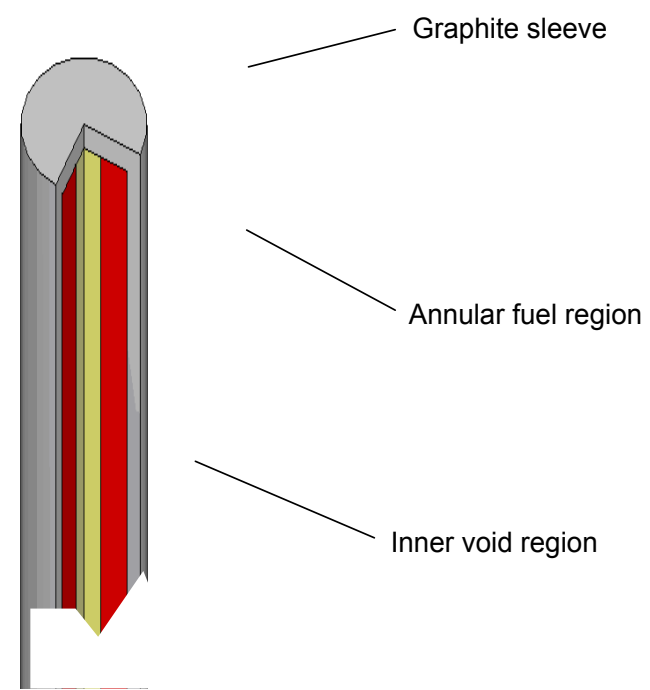

Annular fuel rod

Burnable Poison Rod Properties

\begin{tabular}{|l|c|c|}
\hline Type & H-I & H-II \\
\hline Absorber section material (2 per rod) & $\mathrm{B}_{4} \mathrm{C}-\mathrm{C}$ & $\mathrm{B}_{4} \mathrm{C}-\mathrm{C}$ \\
\hline Density & $1.79 \mathrm{~g} / \mathrm{cm}^{3}$ & $1.82 \mathrm{~g} / \mathrm{cm}^{3}$ \\
\hline Natural boron concentration & $2.22 \mathrm{wt} . \%$ & $2.74 \mathrm{wt} . \%$ \\
\hline Diameter & $1.39 \mathrm{~cm}$ & $1.39 \mathrm{~cm}$ \\
\hline Height & $20 \mathrm{~cm}$ & $20 \mathrm{~cm}$ \\
\hline B-10 abundance ratio & $18.7 \mathrm{wt} \%$ & $18.7 \mathrm{wt} . \%$ \\
\hline Graphite section density & $1.77 \mathrm{~g} / \mathrm{cc}$ & $1.77 \mathrm{~g} / \mathrm{cc}$ \\
\hline Diameter & $1.40 \mathrm{~cm}$ & $1.40 \mathrm{~cm}$ \\
\hline Height & $10 \mathrm{~cm}$ & $10 \mathrm{~cm}$ \\
\hline
\end{tabular}

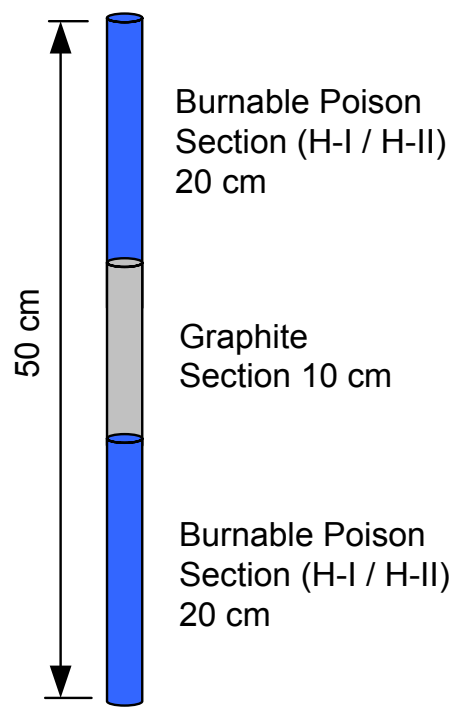

Fuel Assembly Block 


\begin{tabular}{|l|c|}
\hline Type & Pin-in-block \\
\hline Configuration & Hexagonal \\
\hline Material & IG-110 Graphite \\
\hline Density & $1.770 \mathrm{~g} / \mathrm{cm}^{3}$ \\
\hline Impurity & $0.40 \mathrm{ppm} \mathrm{Bnat}$ \\
\hline Height & $58.0 \mathrm{~cm}$ \\
\hline Width across the flats & $36.0 \mathrm{~cm}$ \\
\hline Number of fuel holes in block & $33 \mathrm{or} 31$ \\
\hline Fuel hole diameter & $4.1 \mathrm{~cm}$ \\
\hline Fuel hole height & $58.0 \mathrm{~cm}$ \\
\hline Burnable poison holes & 3 \\
\hline Burnable poison hole diameter & $1.5 \mathrm{~cm}$ \\
\hline Burnable poison hole height & $50.0 \mathrm{~cm}$ \\
\hline
\end{tabular}

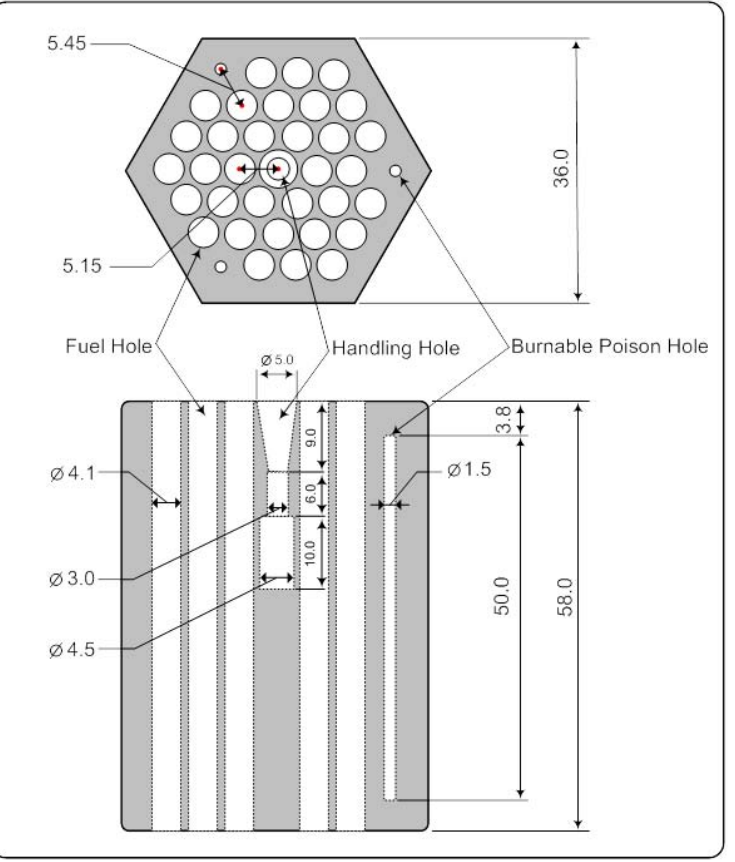

Unit cell measurements

\begin{tabular}{|c|c|c|c|c|c|c|}
\hline $\begin{array}{c}\text { Lattice } \\
\text { type }\end{array}$ & $\begin{array}{c}\text { Array Pitch } \\
(\mathrm{cm})\end{array}$ & $\begin{array}{c}\text { Fuel inner } \\
\text { radius }(\mathrm{cm})\end{array}$ & $\begin{array}{c}\text { Fuel outer } \\
\text { radius }(\mathrm{cm})\end{array}$ & $\begin{array}{c}\text { Sleeve inner } \\
\text { radius }(\mathrm{cm})\end{array}$ & $\begin{array}{c}\text { Sleeve outer } \\
\text { radius }(\mathrm{cm})\end{array}$ & $\begin{array}{c}\text { Fuel element } \\
\text { height }(\mathrm{cm})\end{array}$ \\
\hline Triangular & 5.15 & 0.5 & 1.3 & 1.3 & 1.7 & 54.6 \\
\hline
\end{tabular}

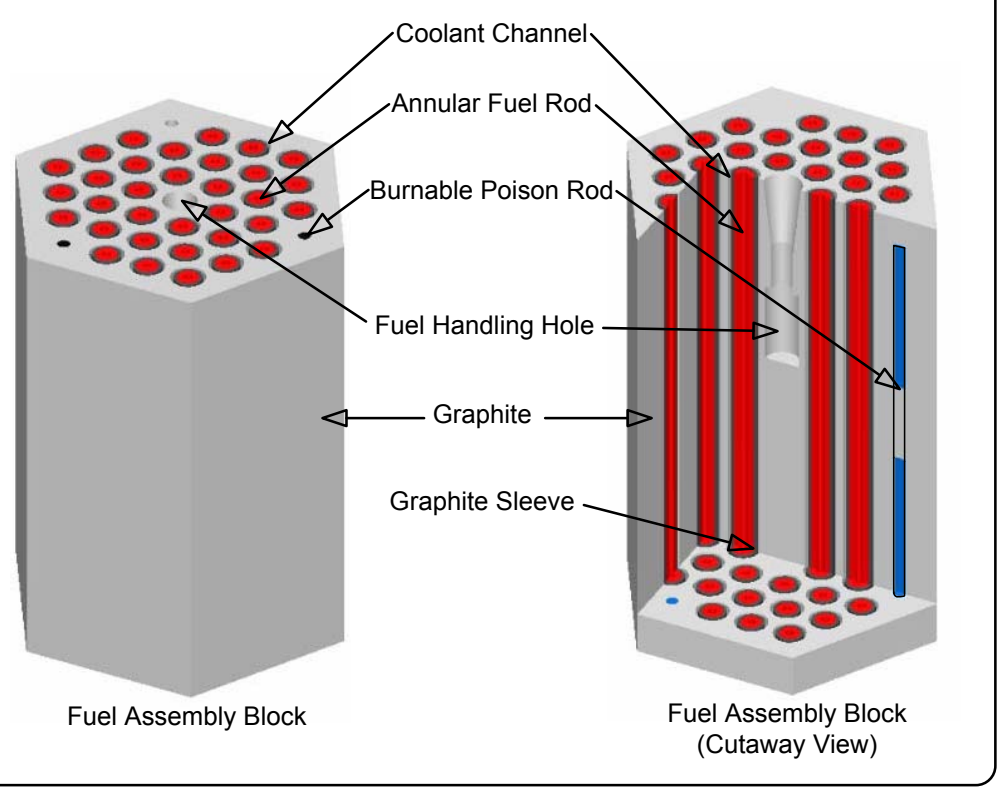

Fuel assembly block with top and quarter section removed to show fuel rods and BP rods. 
Control Rod Block and Irradiation Block (irradiation block is identical to control rod block except the holes are used for nuclear instrumentation instead of control rods)

\begin{tabular}{|l|c|}
\hline Material & IG-110 Graphite \\
\hline Density & $1.770 \mathrm{~g} / \mathrm{cm}^{3}$ \\
\hline Impurity & $5.40 \mathrm{ppm} \mathrm{Bnat}$ \\
\hline Height & $36.0 \mathrm{~cm}$ \\
\hline Width across the flats & 2 \\
\hline Number control rod holes in block & $58.0 \mathrm{~cm}$ \\
\hline Control rod hole diameter & $12.3 \mathrm{~cm}$ \\
\hline Control rod hole height & $58.0 \mathrm{~cm}$ \\
\hline Reserve shutdown holes in block & \\
\hline Reserve shutdown hole diameter & \\
\hline Reserve shutdown hole height & \\
\hline
\end{tabular}

\section{Control Rod Properties}

\begin{tabular}{|l|c|}
\hline \multicolumn{2}{|c|}{ Neutron Absorber Sections (annular) } \\
\hline Number of neutron absorber sections in each control rod & 10 \\
\hline Material & $\mathrm{B}_{4} \mathrm{C}$ and C \\
\hline Density & $1.9 \mathrm{~g} / \mathrm{cm}^{3}$ \\
\hline Diameter-inner & $7.5 \mathrm{~cm}$ \\
\hline Diameter-outer & $10.5 \mathrm{~cm}$ \\
\hline Height & $29.0 \mathrm{~cm}$ \\
\hline Effective height & $290 \mathrm{~cm}(10$ neutron absorber sections) \\
\hline Spacing between neutron absorber sections & $2.2 \mathrm{~cm}$ \\
\hline \multicolumn{2}{|c|}{ Control Rod Sleeve } \\
\hline Material & Alloy $800 \mathrm{H}$ \\
\hline Thickness & $0.35 \mathrm{~cm}$ \\
\hline \multicolumn{2}{|c|}{ Control Rod } \\
\hline Number of control rods & $32(16 \mathrm{pairs})$ \\
\hline Number of control rods in active core & $14(7 \mathrm{pairs})$ \\
\hline Number of control rods in replaceable reflector region & $18(9 \mathrm{pairs})$ \\
\hline Diameter-inner & $6.5 \mathrm{~cm}$ \\
\hline Diameter-outer & $11.3 \mathrm{~cm}$ \\
\hline Height & $310 \mathrm{~cm}$ \\
\hline
\end{tabular}




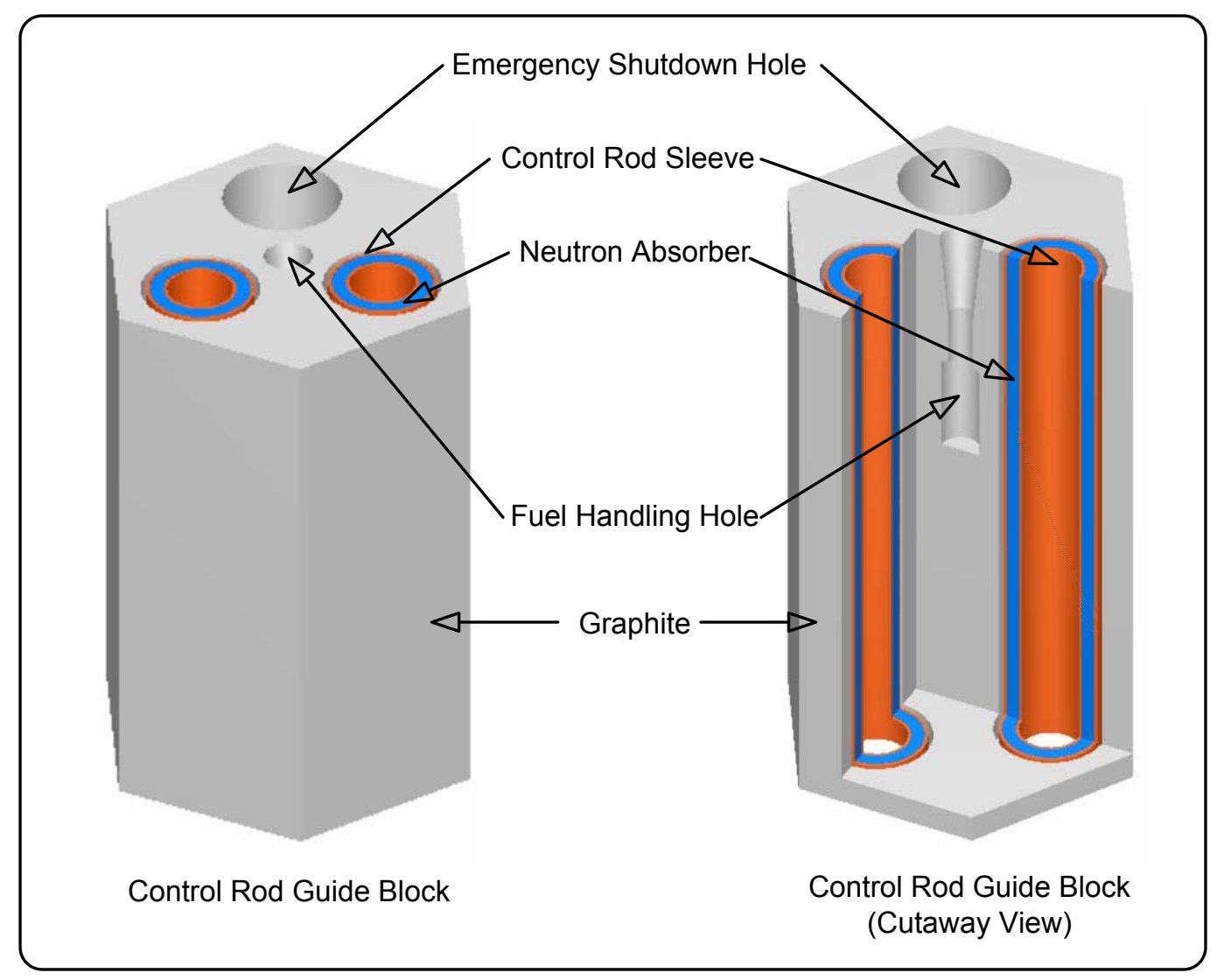

Control rod block with cutaway view

Replaceable Reflector Block (can be solid graphite block or have coolant channels to match the fuel assembly block that it would be associated with)

\begin{tabular}{|l|c|}
\hline Configuration & Hexagonal \\
\hline Material & IG-110 Graphite \\
\hline Density & $1.760 \mathrm{~g} / \mathrm{cm}^{3}$ \\
\hline Impurity & $0.37 \mathrm{ppm} \mathrm{Bnat}$ \\
\hline Height & $58.0 \mathrm{~cm}$ \\
\hline Width across the flats & $36.0 \mathrm{~cm}$ \\
\hline Coolant channels (if applicable) & $33 / 31$ \\
\hline Coolant hole diameter & $4.1 \mathrm{~cm}$ \\
\hline Coolant hole height & $58.0 \mathrm{~cm}$ \\
\hline
\end{tabular}

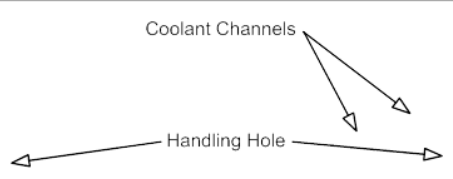

$\triangleleft$ Graphite $\longrightarrow$

\section{Core Level:}


Core Columns

\begin{tabular}{|l|l|c|}
\hline \multicolumn{1}{|c|}{ Column } & \multicolumn{1}{c|}{ Blocks } \\
\hline Fuel assembly & $\begin{array}{l}\text { 5 Fuel assembly blocks } \\
\text { 4 Reflector blocks (channels) }\end{array}$ \\
\hline Reflector & 9 Reflector Blocks \\
\hline $\begin{array}{l}\text { Control Rod / } \\
\text { Irradiation }\end{array}$ & 9 Control rod blocks
\end{tabular}

Permanent Reflector Properties

\begin{tabular}{|l|c|}
\hline Material & IG-110 Graphite \\
\hline Density & $1.732 \mathrm{~g} / \mathrm{cm}^{3}$ \\
\hline Impurity & $2 \mathrm{ppm} \mathrm{Bnat}$ \\
\hline Height & $522 \mathrm{~cm}$ \\
\hline Radius & $215 \mathrm{~cm}$ \\
\hline
\end{tabular}

Overall Core Geometry

\begin{tabular}{|l|c|c|}
\cline { 2 - 3 } \multicolumn{1}{c|}{} & Active core & Whole core \\
\hline Height & $290 \mathrm{~cm}$ & $522 \mathrm{~cm}$ \\
\hline Radius & $115 \mathrm{~cm}($ effective $)$ & $215 \mathrm{~cm}$ \\
\hline
\end{tabular}

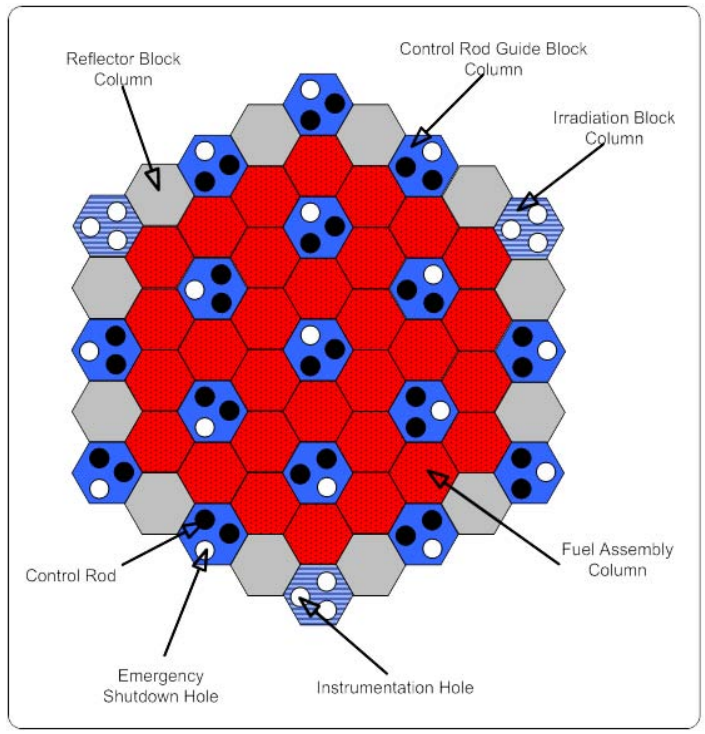

Cross-section core view

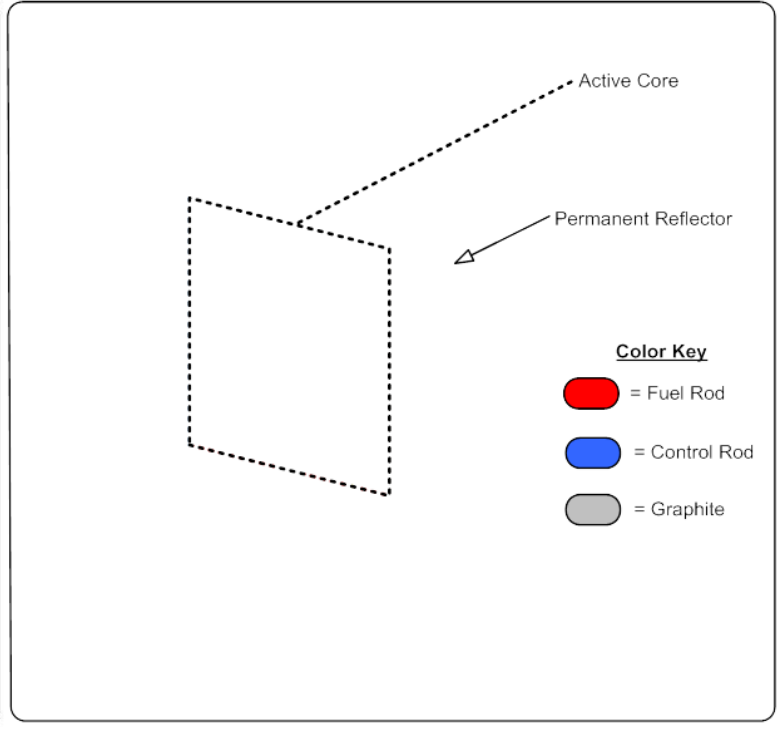

Whole core $3 \mathrm{D}$ view

Uranium Enrichments 


\begin{tabular}{|c|c|c|c|c|c|c|c|c|c|c|c|c|}
\hline number & $\mathbf{1}$ & $\mathbf{2}$ & $\mathbf{3}$ & $\mathbf{4}$ & $\mathbf{5}$ & $\mathbf{6}$ & $\mathbf{7}$ & $\mathbf{8}$ & $\mathbf{9}$ & $\mathbf{1 0}$ & $\mathbf{1 1}$ & $\mathbf{1 2}$ \\
\hline wt. \% & 3.301 & 3.864 & 4.290 & 4.794 & 5.162 & 5.914 & 6.254 & 6.681 & 7.189 & 7.820 & 9.358 & 9.810 \\
\hline
\end{tabular}

Core Arrangement

\begin{tabular}{|c|c|c|c|c|c|}
\hline \multirow{2}{*}{$\begin{array}{l}\text { Layer number } \\
\text { from top fuel } \\
\text { block }\end{array}$} & \multirow[b]{2}{*}{ Items } & \multicolumn{4}{|c|}{ Fuel zone number } \\
\hline & & 1 & 2 & 3 & 4 \\
\hline 1 & $\begin{array}{l}\text { Uranium enrichment (wt. \%) } \\
\text { Number of fuel rods in graphite block } \\
\text { Type of burnable poisons }\end{array}$ & $\begin{array}{c}6.681 \\
33 \\
\mathrm{H}-\mathrm{I} \\
\end{array}$ & $\begin{array}{c}7.820 \\
33 \\
\mathrm{H}-\mathrm{I} \\
\end{array}$ & $\begin{array}{c}9.358 \\
31 \\
\mathrm{H}-\mathrm{I} \\
\end{array}$ & $\begin{array}{l}9.810 \\
31 \\
\mathrm{H}-\mathrm{I} \\
\end{array}$ \\
\hline 2 & $\begin{array}{l}\text { Uranium enrichment (wt. \%) } \\
\text { Number of fuel rods in graphite block } \\
\text { Type of burnable poisons }\end{array}$ & $\begin{array}{c}5.162 \\
33 \\
\mathrm{H}-\mathrm{II} \\
\end{array}$ & $\begin{array}{c}6.254 \\
33 \\
\mathrm{H}-\mathrm{II} \\
\end{array}$ & $\begin{array}{c}7.189 \\
31 \\
\mathrm{H}-\mathrm{II} \\
\end{array}$ & $\begin{array}{c}7.820 \\
31 \\
\mathrm{H}-\mathrm{II} \\
\end{array}$ \\
\hline 3 & $\begin{array}{l}\text { Uranium enrichment (wt. \%) } \\
\text { Number of fuel rods in graphite block } \\
\text { Type of burnable poisons }\end{array}$ & $\begin{array}{c}4.290 \\
33 \\
\mathrm{H}-\mathrm{II} \\
\end{array}$ & $\begin{array}{c}5.162 \\
33 \\
\mathrm{H}-\mathrm{II} \\
\end{array}$ & $\begin{array}{c}5.914 \\
31 \\
\mathrm{H}-\mathrm{II} \\
\end{array}$ & $\begin{array}{c}6.254 \\
31 \\
\mathrm{H}-\mathrm{II} \\
\end{array}$ \\
\hline 4 & $\begin{array}{l}\text { Uranium enrichment (wt. \%) } \\
\text { Number of fuel rods in graphite block } \\
\text { Type of burnable poisons }\end{array}$ & $\begin{array}{c}3.301 \\
33 \\
\mathrm{H}-\mathrm{I} \\
\end{array}$ & $\begin{array}{c}3.864 \\
33 \\
\mathrm{H}-\mathrm{I} \\
\end{array}$ & $\begin{array}{c}4.290 \\
31 \\
\mathrm{H}-\mathrm{I} \\
\end{array}$ & $\begin{array}{c}4.794 \\
31 \\
\mathrm{H}-\mathrm{I} \\
\end{array}$ \\
\hline 5 & $\begin{array}{l}\text { Uranium enrichment (wt. \%) } \\
\text { Number of fuel rods in graphite block } \\
\text { Type of burnable poisons }\end{array}$ & $\begin{array}{c}3.301 \\
33 \\
\mathrm{H}-\mathrm{I}\end{array}$ & $\begin{array}{c}3.864 \\
33 \\
\mathrm{H}-\mathrm{I}\end{array}$ & $\begin{array}{c}4.290 \\
31 \\
\mathrm{H}-\mathrm{I}\end{array}$ & $\begin{array}{c}4.794 \\
31 \\
\mathrm{H}-\mathrm{I}\end{array}$ \\
\hline
\end{tabular}

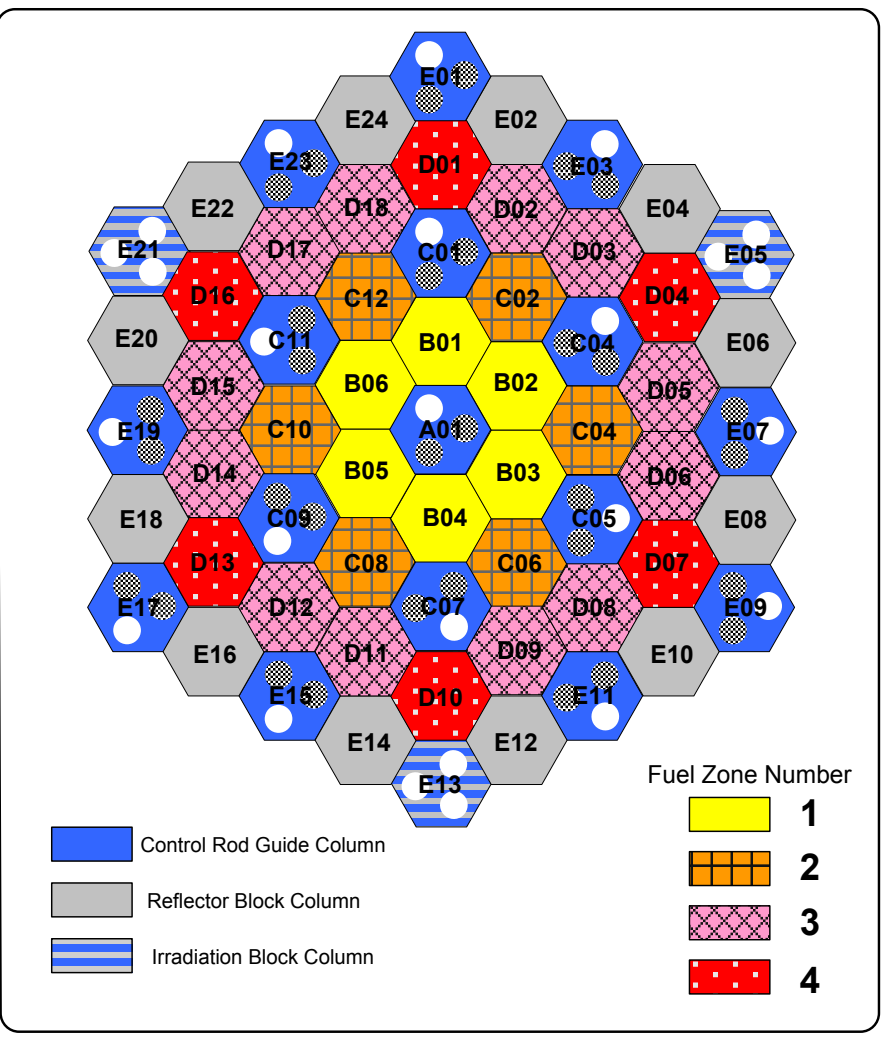

Core Map

Benchmark Results: 


\begin{tabular}{|l|c|c|c|c|}
\hline \multicolumn{2}{|c|}{ Benchumark } & $\begin{array}{c}\text { VHTR model } \\
\text { (calculated) }\end{array}$ & $\begin{array}{c}\text { HTTR } \\
\text { (experimental) }\end{array}$ & $\begin{array}{c}\text { Error } \\
\text { (\%) }\end{array}$ \\
\hline Control Rods Fully Withdrawn & k-eff & $1.1368 \pm 0.0023$ & $1.1363 \pm 0.041$ & 0.044 \\
\hline Control Rods Fully Inserted & k-eff & $0.6858 \pm 0.0019$ & $0.685 \pm 0.010$ & 0.117 \\
\hline $\begin{array}{l}\text { Critical Insertion Depth } \\
\text { (core temperature 300K) }\end{array}$ & $\mathrm{cm}$ & 177.1 & $177.5 \pm 0.5$ & 0.225 \\
\hline $\begin{array}{l}\text { Critical Insertion Depth } \\
\text { (core temperature 418K) }\end{array}$ & $\mathrm{cm}$ & 189.9 & $190.3 \pm 0.5$ & 0.210 \\
\hline Temperature Coefficient & $\mathrm{dk} / \mathrm{k} / \mathrm{K}$ & $-1.45 \mathrm{E}-04$ & $-1.42 \mathrm{E}-04$ & 2.113 \\
\hline
\end{tabular}




\section{APPENDIX B}

HEST Concept I: Individual TRU Nuclides Neutron Balance $\left(\mathrm{D}_{\mathrm{eq}}{ }^{\mathrm{TRU}}\right)$ as a Function of Flux.
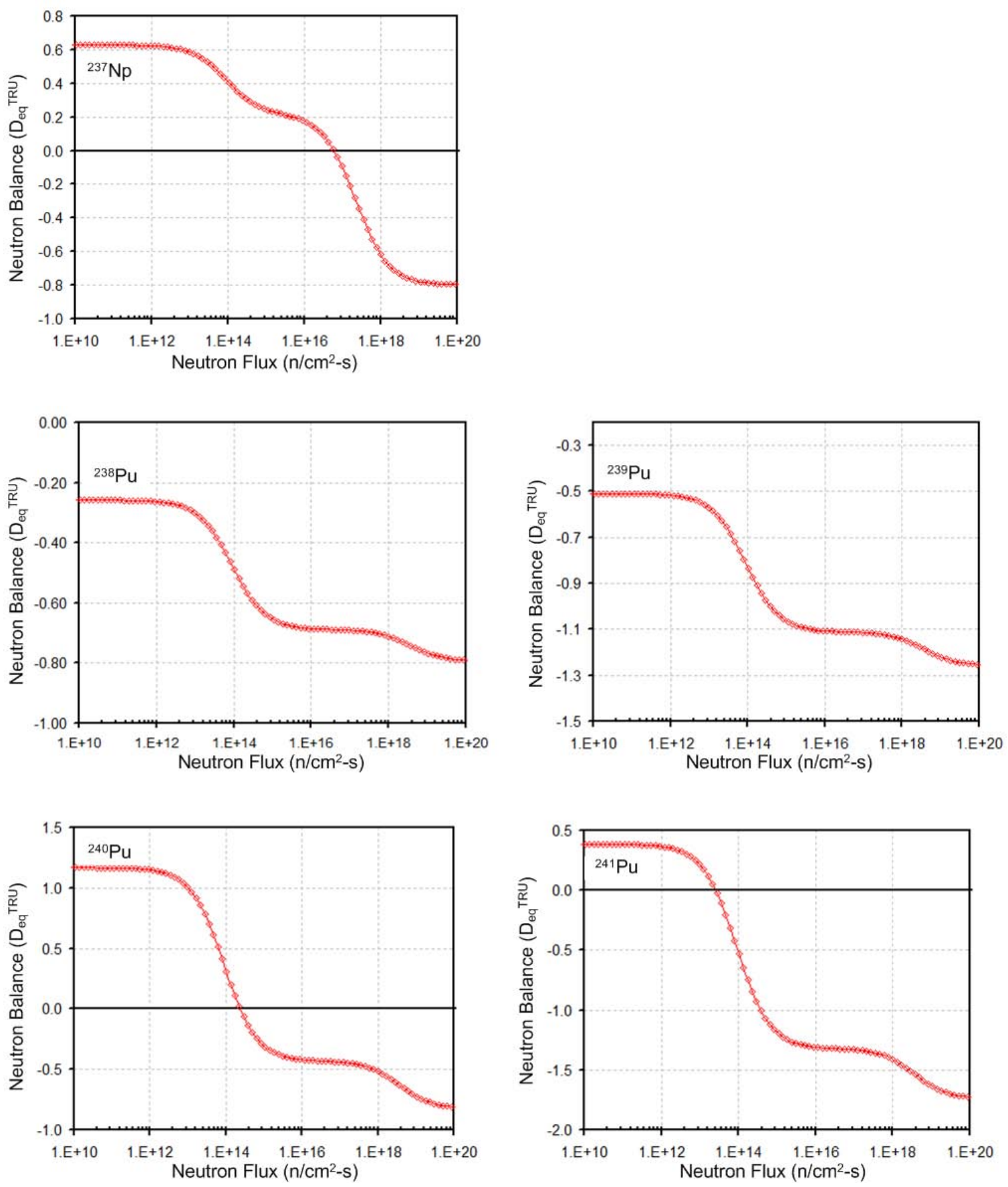

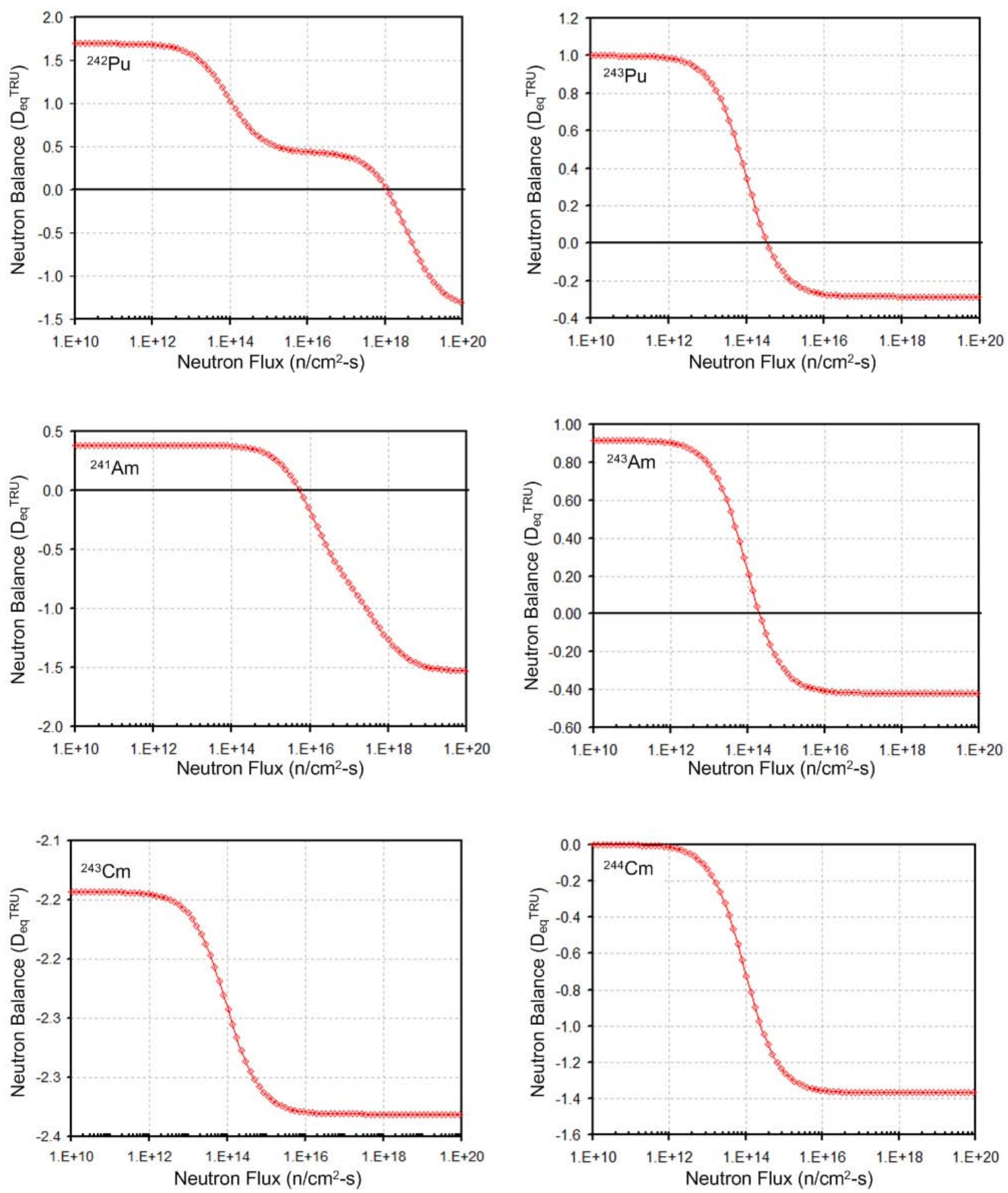
HEST Concept II: Individual TRU Nuclides Neutron Balance $\left(\mathrm{D}_{\mathrm{eq}}{ }^{\mathrm{TRU}}\right)$ as a Function of Flux.
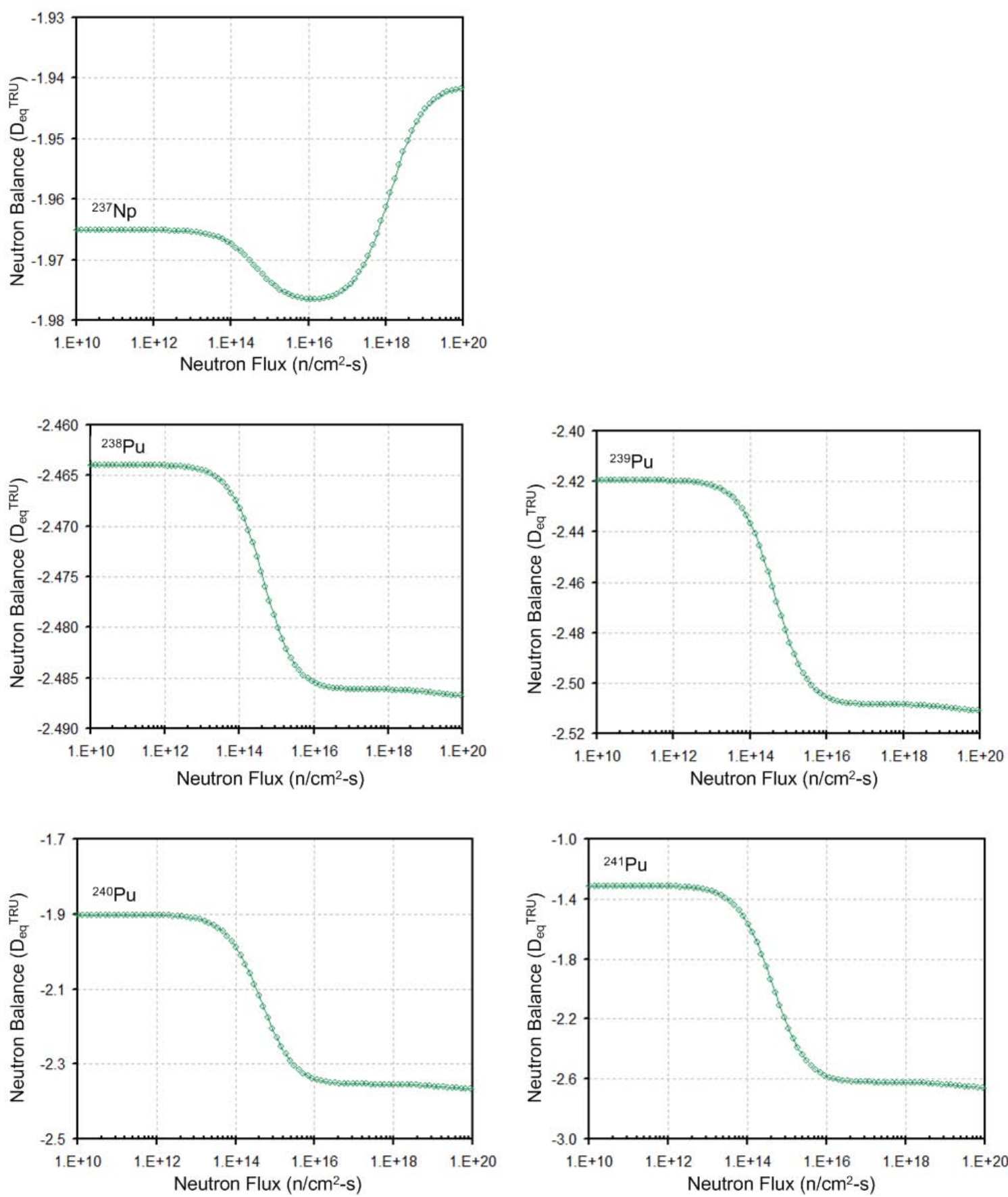

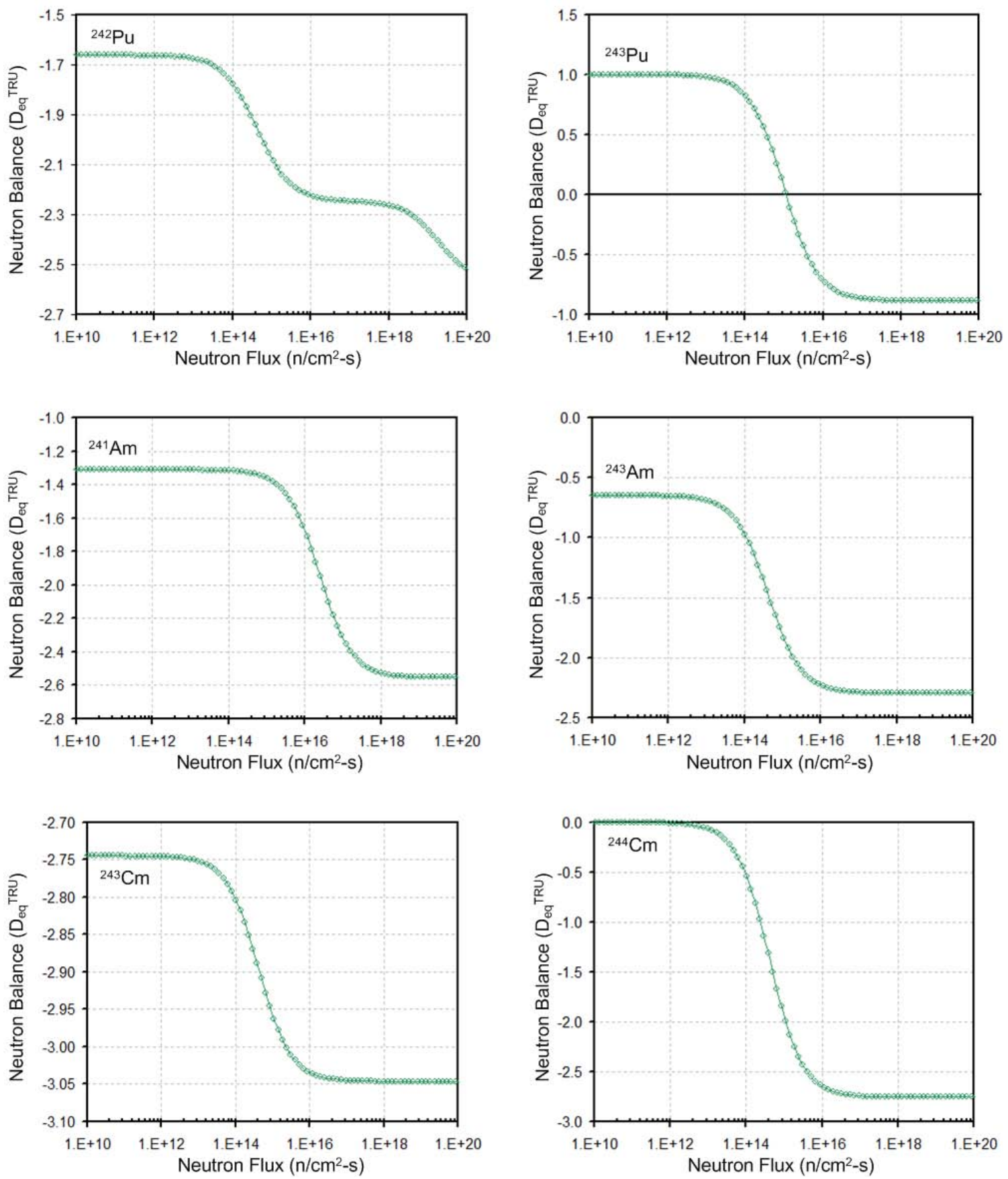


\section{PUBLICATIONS LIST}

1. D. E. Ames II, P. V. Tsvetkov, G. E. Rochau, S. Rodriguez, "High Fidelity Nuclear Energy System Optimization towards a n Environmentally B enign, S ustainable, and S ecure Energy Source", Sandia National Laboratory, October 2009, SAND2009-6831 (2009).

2. D. E . A mes II, P . V . Tsvetkov, G. E . R ochau, S . R odriguez, "Nuclear E nergy S ystem Providing a n E nvironmentally Benign, S ustainable, a nd S ecure E nergy Source", Trans. Amer. Nucl. Soc., 101, pp. 177 - 178, USA (2009).

3. D. E. Ames II, “ High Fidelity Nuclear $E$ nergy $S$ ystem $O$ ptimization towards a $n$ Environmentally Benign, S ustainable, a nd S ecure E nergy S ource", P h.D. D issertation, August 2010, Texas A\&M University, Chair - P. V. Tsvetkov (2010).

4. D. E . A mes II, P . V . Tsvetkov, "High-Fidelity System M odeling of Advanced N uclear Energy S ystems A pproaching a Zero-Nuclear-Waste L imit", Progress in Nuclear Energy, Invited, Under Review, PNUCENE-S-10-00169, American Nuclear Society (2010).

5. D. E . A mes II, P . V . Tsvetkov, G. E . R ochau, S . R odriguez, "High-Fidelity I ntegrated System M odeling f or S ustainability A nalysis of N uclear E nergy S ystems", ANS W inter Meeting, 2010, accepted, USA (2010). 


\section{DISTRIBUTION LIST}

Texas A\&M University

David Ames II, deames 99@yahoo.com

Ayodeji Alajo, dejialajo@neo.tamu.edu

Raymond Juzaitis, rjuzaitis@tamu.edu

Tom Lewis III, $\quad$ tglewis3@gmail.com

Pavel Tsvetkov, $\quad \underline{\text { Tsvetkov@tamu.edu }}$

\section{Argonne National Laboratory}

Mohamed Gohar, gohar@anl.gov

Robert Hill, $\quad$ bobhill@anl.gov

Temitope Taiwo $\quad \underline{\text { Taiwo@anl.gov }}$

\section{U.S. Department of Energy}

Madeline Feltus, $\quad$ MADELINE.FELTUS@nuclear.energy.gov

Alex Larzelere, $\quad$ alex.larzelere@nuclear.energy.gov

Rob Versluis, $\quad$ ROB.VERSLUIS@,nuclear.energy.gov

\section{General Atomics}

Timothy Bertch, $\quad$ Timothy.Bertch@ga.com

Donald McEachern, Donald.McEachern@ga.com

Arkal Shenoy, $\quad$ Arkal.Shenoy@ga.com

\section{General Electric}

Eric Loewen, $\quad$ eric.loewen@ge.com

Russell Stachowski, Russell.Stachowski@gnf.com

Electric Power Research Institute

John H. Kessler, JKESSLER@epri.com 


\section{Idaho National Laboratory}

Samuel E Bays, $\quad$ Samuel.Bays@inl.gov

Mark DeHart, $\quad$ Mark.DeHart@,inl.gov

Hans Gougar, Hans.Gougar@inl.gov

D Scott Lucas, $\quad$ D.Lucas@inl.gov

Kathryn McCarthy, Kathryn.Mccarthy@inl.gov

David Nigg, $\quad$ David.Nigg@inl.gov

Abderrafi Ougouag, Abderrafi.Ougouag@inl.gov

Michael A Pope, $\quad$ Michael.Pope@inl.gov

Hongbin Zhang, $\quad$ Hongbin.Zhang@inl.gov

Laurence Livermore National Laboratory

Jeff Latkowski, $\quad$ latkowski@1lnl.gov

Ralph Moir, $\quad$ RMoir@Pacbell.net

\section{Logos Technologies}

Francesco Venneri, $\quad$ fvenneri@mac.com

\section{Oak Ridge National Laboratory}

Ian C. Gauld, gauldi@ornl.gov

Jess Gehin, gehinjc@ornl.gov

Matthew A. Jessee, jesseema@ornl.gov

Bernadette L. Kirk, kirkbl@ornl.gov

\section{Sandia National Laboratories}

Benjamin Cipiti, MS0747 (Org 6774) ㅎbcipit@sandia.gov

Evaristo J. Bonano, MS1370 (Org 6770) ejbonan@sandia.gov

Yolanda V. Moreno, MS0359 (Org 1912) ymoreno@sandia.gov

Gary E. Rochau, MS1136 (Org 6772) gerocha@sandia.gov

Salvador B. Rodriguez, MS0821 (Org 1532) sbrodri@sandia.gov

Stephen J. Rottler, MS0351 (Org 1000)ｊsrottl@sandia.gov

Donna L. Chavez, MS0359 (Org 1911)_ dchavez@,sandia.gov

Technical Library, MS0899 (Org 9536) libref@sandia.gov 


\section{Sandia National Laboratories}

